\title{
Gliding Mammals Taxonomy of Living and Extinct Species
}

Stephen M. Jackson and
Richard W. Thorington Jr. 


\section{SERIES PUBLICATIONS OF THE SMITHSONIAN INSTITUTION}

Emphasis upon publication as a means of "diffusing knowledge" was expressed by the first Secretary of the Smithsonian. In his formal plan for the Institution, Joseph Henry outlined a program that included the following statement: "It is proposed to publish a series of reports, giving an account of the new discoveries in science, and of the changes made from year to year in all branches of knowledge." This theme of basic research has been adhered to through the years by thousands of titles issued in series publications under the Smithsonian imprint, commencing with Smithsonian Contributions to Knowledge in 1848 and continuing with the following active series:

Smithsonian Contributions to Anthropology

Smithsonian Contributions to Botany

Smithsonian Contributions to History and Technology

Smithsonian Contributions to the Marine Sciences

Smithsonian Contributions to Museum Conservation

Smithsonian Contributions to Paleobiology

Smithsonian Contributions to Zoology

In these series, the Institution publishes small papers and full-scale monographs that report on the research and collections of its various museums and bureaus. The Smithsonian Contributions Series are distributed via mailing lists to libraries, universities, and similar institutions throughout the world.

Manuscripts submitted for series publication are received by the Smithsonian Institution Scholarly Press from authors with direct affiliation with the various Smithsonian museums or bureaus and are subject to peer review and review for compliance with manuscript preparation guidelines. General requirements for manuscript preparation are on the inside back cover of printed volumes. For detailed submissions requirements and to review the "Manuscript Preparation and Style Guide for Authors," visit the Submissions page at www.scholarlypress.si.edu. 


\title{
Gliding Mammals Taxonomy of Living and Extinct Species
}

\author{
Stephen M. Jackson and \\ Richard W. Thorington Jr.
}

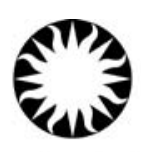

Smithsonian Institution

Scholarly Press

WASHINGTON D.C.

$$
2012
$$




\section{ABSTRACT}

Jackson, Stephen M., and Richard W. Thorington Jr. Gliding Mammals: Taxonomy of Living and Extinct Species. Smithsonian Contributions to Zoology, number 638, vi + 117 pages, 2012.There are 64 species of extant gliding mammals that are currently recognized, which are divided into six different families. These comprise eight species of gliding marsupials that live within Australasia and include six species of lesser gliding possums of Petaurus (family Petauridae), one species of greater glider of Petauroides (family Pseudocheiridae), and one species of feathertail glider of Acrobates (family Acrobatidae). The flying squirrels of the tribe Pteromyini within the rodent family Sciuridae represent the greatest diversity of gliding mammals, with a total of 48 species in 15 genera currently recognized, and occur throughout Asia, Europe, and North America. A second group of gliding rodents, known as the scaly-tailed flying squirrels, comprises six species from the family Anomaluridae that live in central and western Africa. The most specialized and unique of the extant gliding mammals are the enigmatic colugos, or flying lemurs, of the order Dermoptera that comprise two species and occur throughout Southeast Asia and the Philippines. In addition to the extant species there are various fossils of extinct species that are thought to have had an ability to glide, although there has been a lot of debate over most of these taxa. These fossil taxa include 3 marsupials, 18 dermopterans, 51 flying squirrels, 7 species of scaly-tailed flying squirrels, and 1 extinct species in each of the families Myoxidae, Eomyidae, and Volaticotheriidae. The taxonomic status of many living and extinct gliding mammals is still in a state of flux, and significant further revision of the taxonomic status of many groups still needs to be resolved.

Published by SMITHSONIAN INSTITUTION SCHOLARLY PRESS

P.O. Box 37012, MRC 957

Washington, D.C. 20013-7012

www.scholarlypress.si.edu

Text and images in this publication may be protected by copyright and other restrictions or owned by individuals and entities other than, and in addition to, the Smithsonian Institution. Fair use of copyrighted material includes the use of protected materials for personal, educational, or noncommercial purposes. Users must cite author and source of content, must not alter or modify content, and must comply with all other terms or restrictions that may be applicable. Users are responsible for securing permission from a rights holder for any other use.

\section{Library of Congress Cataloging-in-Publication Data}

Jackson, Stephen M. (Stephen Matthew), 1968-

Gliding mammals : taxonomy of living and extinct species / Stephen M. Jackson and Richard W.

Thorington, Jr.

p. cm. - (Smithsonian contributions to zoology ; no. 638)

Includes bibliographical references and index.

1. Flying squirrels-Classification. 2. Diprotodontia-Classification. 3. Flying lemurs-Classification.

4. Mammals-Flight. I. Thorington, Richard W. II. Title.

QL737.R68J32 2012

599.36 '9-dc23

2011045686

ISSN: 0081-0282 (print); 1943-6696 (online)

(6) The paper used in this publication meets the minimum requirements of the American National Standard for Permanence of Paper for Printed Library Materials Z39.48-1992. 


\section{Contents}

INTRODUCTION

Background 1

Major Groups of Gliding Mammals 2

Marsupials 2

Colugos $\quad 2$

Flying Squirrels $\quad 4$

Scaly-Tailed Flying Squirrels $\quad 5$

Enigmatic Gliders $\quad 5$

METHODS AND FORMAT $\quad 6$

Acknowledgments $\quad \mathbf{6}$

TAXONOMY OF GLIDING MAMMALS $\quad 7$

Class Mammalia Linnaeus, $1758 \quad 7$

Subclass Marsupialia Illiger, $1811 \quad 8$

Cohort Australidelphia Szalay, $1982 \quad \mathbf{8}$

Order Diprotodontia Owen, 1877

Suborder Phalangerida Aplin and Archer, 1987

Superfamily Petauroidea Bonaparte, $1832 \quad 10$

Family Petauridae Bonaparte, $1832 \quad 10$

Subfamily Petaurinae Bonaparte, $1832 \quad 10$

Petaurus Shaw, $1791 \quad 10$

Family Pseudocheiridae Winge, $1893 \quad 15$

Subfamily Hemibelideinae Kirsch et al., $1997 \quad 15$

Petauroides Thomas, $1888 \quad 15$

Superfamily Tarsipedoidea Gervais and Verreaux, $1842 \quad 18$

Family Acrobatidae Aplin, $1987 \quad 19$

Acrobates Desmarest, 1818

Subclass Placentalia Owen, $1837 \quad 20$

Order Dermoptera Illiger, $1811 \quad 20$

†Family Indeterminate $\quad 21$

†Subfamily Thylacaelurinae Van Valen, 1967

†Thylacaelurus Russell, 1954 
Family Cynocephalidae Simpson, 1945

Cynocephalus Boddaert, $1768 \quad 22$

Galeopterus Thomas, 1908

†Dermotherium Ducrocq et al., $1992 \quad 26$

†Family Plagiomenidae Matthew, 1918

†Elpidophorus Simpson, 1927

†Eudaemonema Simpson, 1935

†Subfamily Plagiomeninae Matthew, 1918

†Tribe Worlandiini Bown and Rose, 1979

†Planetetherium Simpson, 1928

†Worlandia Bown and Rose, 1979

†Tribe Plagiomenini Matthew, $1918 \quad 28$

†Plagiomene Matthew, $1918 \quad 28$

†Ellesmene Dawson et al., $1993 \quad 28$

†Subfamily Ekgmowechashalinae Szalay, $1976 \quad 28$

†Tribe Tarkadectini Szalay and Lucas, $1996 \quad 28$

†Tarkadectes McKenna, $1990 \quad 28$

†Tarka McKenna, $1990 \quad \mathbf{2 8}$

†Tribe Ekgmowechashalini Szalay, 1976

†Ekgmowechashala Macdonald, 1963

†Family Mixodectidae Cope, 1883

†Mixodectes Cope, 1883

†Dracontolestes Gazin, $1941 \quad 30$

Superorder Glires Linnaeus, $1758 \quad 30$

Order Rodentia Bowdich, 1821

Suborder Sciuromorpha Brandt, 1855 30

Family Sciuridae Fischer de Waldheim, $1817 \quad 30$

Subfamily Sciurinae Fischer de Waldheim, 1817

Tribe Indeterminate 32

†Sciurion Skwara, 1986

Tribe Pteromyini Brandt, 1855

Aeretes G. Allen, 1940

Aeromys Robinson and Kloss, 1915

†Albanensia Daxner-Höck and Mein, 1975

†Aliveria de Bruijn et al., 1980

Belomys Thomas, 1908

Biswamoyopterus Saha, 1981

†Blackia Mein, 1970

Eoglaucomys Howell, 1915

Eupetaurus Thomas, 1888

†Forsythia Mein, 1970

Glaucomys Thomas, 1908

Hylopetes Thomas, 1908

Iomys Thomas, 1908

†Meinia Qiu, 1981

†Miopetaurista Kretzoi, 1962

†Neopetes Daxner-Höck, 2004

†Oligopetes Heissig, 1979

†Parapetaurista Qiu and Liu, 1986

Petaurillus Thomas, 1908 
Petaurista Link, 1795

52

†Petauristodon Engesser, 1979

Petinomys Thomas, 1908

†Pliopetaurista Kretzoi, 1962

†Pliopetes Kretzoi, 1959

Pteromys G. Cuvier, 1800

Pteromyscus Thomas, 1908

†Shuanggouia Qiu and Liu, 1986

Trogopterus Heude, 1898

Suborder Anomaluromorpha Bugge, 1974

Superfamily Anomaluroidea Gervais, 1849

†Family Indeterminate

†Downsimys Flynn et al., 1986

Family Anomaluridae Gervais, 1849

Subfamily Anomalurinae Gervais, 1849

Anomalurops Matschie, 1914

Anomalurus Waterhouse, 1843

†Paranomalurus Lavocat, 1973

Subfamily Zenkerellinae Matschie, 1898

Idiurus Matschie, 1894

Superfamily Anomaluroidea incertae sedis

Marivaux et al., 2005

†Family Nementchamyidae Jackson and Thorington, new family

†Nementchamys Jaeger et al., 1985

†Pondaungimys Dawson et al., 2003

Infraorder Glirimorpha Thaler, 1966

Family Gliridae Muirhead, 1819

Subfamily Glirinae Muirhead, 1819

Glirulus Thomas, 1905

Infraorder Geomorpha Thaler, 1966

†Superfamily Eomyoidea Winge, 1887

†Family Eomyidae Winge, 1887

†Eomys Schlosser, 1884

†Order Volaticotheria Meng et al., 2006

†Family Volaticotheriidae Meng et al., 2006

†Volaticotherium Meng et al., 2006

\section{REFERENCES}

INDEX OF COMMON AND SCIENTIFIC NAMES

† Denotes extinct taxa. 



\section{Gliding Mammals: Taxonomy of Living and Extinct Species}

\section{INTRODUCTION}

\section{BACKGROUND}

The world's extant gliding mammals are a diverse group that includes 64 currently recognized species that are divided into six families that are united not by their phylogeny but by an ability to glide. Species that glide descend through the air, after launching, at an angle less than $45^{\circ}$ to the horizontal, whereas those that parachute descend at an angle greater than $45^{\circ}$ (Rayner, 1981). There are three families of gliding marsupials that live in Australia, New Guinea, and the surrounding islands, including six species of lesser gliding possums of the family Petauridae, one species of greater glider of the family Pseudocheiridae, and one species of feathertail glider of the family Acrobatidae. The greatest diversity of gliding mammals occurs in the rodents of the order Rodentia, in which they are represented by the flying squirrels of the rodent family Sciuridae, comprising some 51 genera and 278 species in total (Wilson and Reeder, 2005). Of these, the flying squirrels comprise 15 genera and 48 species that live throughout Asia, Europe, and North America. A second group of gliding rodents is the unrelated scaly-tailed flying squirrels of the family Anomaluridae that live in central and western Africa and include seven species (although one species does not glide).

Stephen M. Jackson, Department of Primary Industries, Locked Bag 21, Orange, New South Wales 2800, Australia. Richard W. Thorington Jr., Division of Mammals, Smithsonian Institution, MRC 108, P.O. Box 37012, Washington, D.C., 20013-7012, USA. Correspondence: S.Jackson, stephen.jackson@industry.nsw.gov .au. Manuscript received 15 June 2010; accepted 19 July 2011.
Gliding reaches its most spectacular and efficient expression in the two species of colugos, also known as flying lemurs, of the order Dermoptera that occur throughout Southeast Asia.

The fossil record for the extinct taxa that have been recognized as gliders is remarkably diverse but has not been united previously in any other taxonomic review. This study tentatively recognizes 3 species of Petauroides of the family Pseudocheiridae, 18 species from 13 genera and 4 families in the order Dermoptera, 48 species from 20 genera in the family Sciuridae, and 7 species 
from 5 genera within the superfamily Anomaluroidea. The appearance of gliding mammals in the fossil record varies greatly between the different groups and extends a maximum of 20-30 million years ago (MYA) for the marsupial gliders (although this could be as little as 5 MYA), 40 MYA for the flying squirrels, and approximately 50 MYA for the scaly-tailed flying squirrels and colugos. In addition to families of mammals that have living representatives there are three species from unrelated families that that have no living gliding descendants, with one of these dating back an estimated 125 MYA.

There are various theories as to why gliding has evolved independently in these different groups, including predator avoidance, optimizing foraging efficiency, and minimizing the cost of traversing a home range. In addition, the forests in which gliders typically live appear to have attributes that contribute to the evolution of gliding, including an open middle to lower canopy and a limited development of lianas (see Jackson and Schouten, 2012).

There is still considerable taxonomic uncertainty over many taxa of gliding mammals and even whether most extinct species were able to glide, so it is hoped that this work will help to spark further research on this unusual and diverse group of mammals. Therefore, the aims of this work are (1) to develop for the first time a complete integrated taxonomy of every taxon of gliding mammal both living and extinct, (2) to include the ranks above genus to reflect the phylogenetic diversity of each group of gliding mammal, (3) to update taxonomic changes that have occurred since the work of McKenna and Bell (1997) and Wilson and Reeder (2005), and (4) to include the full citation of every taxon to facilitate future research.

\section{Major Groups of Gliding Mammals}

\section{Marsupials}

The first gliding marsupial to be described was the yellow-bellied glider Petaurus australis by Shaw (1791). Shortly after, other junior generic names for Petaurus were used, including Sciurus (Meyer, 1793), Didelphis (Shaw, 1800), Volucella (Bechstein, 1800), Ptilotus (Fischer de Waldheim, 1814), Xenochirus (Gloger, 1841), Belideus (Waterhouse, 1839a), Petaurula (Matschie, 1916), and Petaurella (Matschie, 1916). Despite the presence of earlier terms the name Belideus, which was proposed in describing the sugar glider Petaurus breviceps, became commonly used for all the lesser marsupial gliders (e.g., Gould, 1845-1863; De Vis, 1883) until Petaurus was confirmed as the senior name by Thomas (1888a).
The greater glider Petauroides volans was described by Kerr (1792) as Didelphis volans. It was subsequently placed, via synonyms, in the genera Volucella (Bechstein, 1800), Schoinobates (Lesson, 1842), Petaurista (Desmarest, 1820), and finally, Petauroides by Thomas (1888a). Likewise, the feathertail glider Acrobates pygmaeus (Shaw, 1794) was initially allocated to Didelphis and was not placed in Acrobates until 1818 by Desmarest (1818a). This placement was frequently not recognized, however, as the single species was often placed in Petaurus (sometimes in the subgenus Acrobata) until the generic rank was fixed by Thomas (1888a).

Few marsupial fossil gliders have been described. Within the Petauridae they provisionally include fossil remains of species most similar to modern Petaurus species and three extinct species that have been placed with varying degrees of confidence within Petauroides in the family Pseudocheiridae, including one most allied to the living species Petauroides volans. Only a few remains have been obtained of fossil acrobatids, which have been tentatively identified as Acrobates pygmaeus from the Pleistocene. An undescribed species of marsupial from Paleocene deposits in Brazil in South America has tentatively been proposed to be a glider (Szalay and Sargis, 2001). This conclusion was derived from their exceptionally long and slender humeri and femora compared to their articular areas, which were suggested to have habitual tensile loading similar to living gliding mammals.

\section{Colugos}

Linnaeus (1758) described the Philippine colugo as Lemur volans, after the lemurs of Madagascar, and the Malayan colugo was described 41 years later by Audebert (1799). Boddaert (1768) created the name Cynocephalus, with other genera subsequently proposed, including $G a$ leopithecus (Pallas, 1780), Galeopus (Rafinesque, 1815), Dermopterus (Burnett, 1829), Pleuropterus (Burnett, 1829), Colugo (Gray, 1871), and Galeopterus (Thomas, 1908a). The phylogenetic position of the two currently recognized species of highly specialized gliders has remained controversial ever since their first discovery. Gregory (1910) placed the colugos into a superordinal group called the Archonta, a group that included bats, primates, tree shrews, elephant shrews, and the colugos. Although various reviews support this conclusion (see Sargis, 2004), some studies do not (e.g., Pumo et al., 1998). In particular, the question of whether colugos share a closer relationship with bats, primates, or tree shrews has remained contentious. 
The relationship between living dermopterans and fossils attributed to extant dermopterans has been highly uncertain. As suggested by Linnaeus' original name, the idea that dermopterans are most closely related to primates has been supported by various studies. Beard (1991, 1993a) considered primates and dermopterans to form the mirorder Primatomorpha. The phylogenetic arrangement that placed Primates near to the Dermoptera was followed, with modification, in the most recent comprehensive classification of living and extinct mammals by McKenna and Bell (1997) and was further supported by Janečka et al. (2007). The studies by Beard and Janečka et al. differed from each other in that Beard (1991, 1993a) included plesiadapiforms in Dermoptera, whereas Janečka et al. (2007) found plesiadapiforms closer to primates (like Bloch et al., 2007). Another study investigating mitochondrial sequences supports an alternative tree topology in which the Dermoptera are placed with the Anthropoidea, Prosimii, and Tarsioidea in the clade Dermosimii (Arnason et al., 2002).

More recent molecular studies proposed a refined clade known as the Euarchonta that suggested the morphology-based Archonta be trimmed down to exclude Chiroptera (Waddell et al., 1999). This group was envisaged by Adkins and Honeycutt (1991) using mtDNA, with subsequent support given by various studies including DNA sequence analyses (Murphy et al., 2001a), retroposon presence and absence data (Kriegs et al., 2007), and morphological data (Bloch et al., 2007).

In contrast to the alignment of Dermoptera with Primates, other studies have concluded that the Dermoptera and Chiroptera are sister taxa in a group called the Volitantia (e.g., Szalay and Drawhorn, 1980; Novacek and Wyss, 1986; Thewissen and Babcock, 1991, 1993; Simmons, 1993, 1995; Szalay and Lucas, 1993, 1996; Wible and Martin, 1993; Stafford and Thorington, 1998; Stafford and Szalay, 2000; Bloch and Silcox, 2001; Sargis, 2002a; Silcox et al., 2005). The plausibility of Volitantia was initially augmented by the traditional consideration of tree shrews as the sister taxon to primates starting with Le Gros Clark (1927). However, the Scandentia-Primate relationship began to fall out of vogue as scientists realized that many of the originally marshalled synapomorphies were likely convergent (e.g., Cartmill and MacPhee, 1980; Martin, 1990). Still, some more recent studies have found the colugos to be the out-group of a pairing of tree shrews and primates (Bininda-Emonds et al., 2007). Yet other studies using mitochondrial DNA linked the modern colugos to primates as a sister group of Anthropoidea, and they were therefore placed more closely to the higher primates than the prosimians (Murphy et al., 2001a; Arnason et al., 2002; Schmitz et al., 2002). Some evolutionary morphologists also still consider the Scandentia-Primate clade a more likely scenario (Godinot, 2007).

Another hypothesis suggested that Dermoptera and Scandentia form a natural group that is a sister to Primates that has been coined Sundatheria (Olson et al., 2005). This hypothesis is supported by both molecular (Liu and Miyamoto, 1999; Liu et al., 2001; Madsen et al., 2001; Murphy et al., 2001a, 2001b; Springer et al., 2003; Van Den Bussche and Hoofer, 2004; Olson et al., 2005) and morphological (Sargis, 2002b; Bloch et al., 2007) evidence.

The relationship of the modern dermopterans to the fossil forms has also created a great deal of debate with two studies proposing that species of two different plesiadapiform families, Paromomyidae and Micromomyidae, share a number of morphological characters with living dermopterans (Beard, 1989, 1990, 1993a, 1993b; Kay et al., 1990). It was proposed that some of the shared morphological features are evidence that the micromomyids and paromomyids were "mitten gliders" similar to the modern day colugos in having webbing between the fingers (i.e., interdigital patagia). More specifically, it was argued by Beard and Kay and their colleagues that fossils representing the paromomyid genera Phenacolemur and Ignacius show that these animals are not primates and share functionally important postcranial derived features that originated in their last common ancestor with extant colugos, suggesting that paromomyids possessed a gliding membrane. As a result of these conclusions it was proposed that the taxon Euprimates is unnecessary and should be disregarded (Kay et al., 1990). The great uncertainty of the relationship of the living Dermopterans to the fossil record has resulted in very different classifications being proposed by authors such as Simpson (1945), Beard (1993a), and McKenna and Bell (1997).

New paromomyid fossils and more detailed studies of postcranial material provide strong evidence against the hypotheses that paromomyids are related to and glided like dermopterans (Krause, 1991; Runestad and Ruff, 1995; Bloch et al., 2007; Boyer and Bloch, 2008). In contrast, these subsequent studies have suggested that paromomyids did not glide like the living colugos but were committed arborealists adapted for locomotion on large vertical supports, similar to the one of two modern primate groups with clawed hands and feet, the marmosets and tamarins of South America (Boyer et al., 2001; Boyer and Bloch, 2008). It thus appears that all plesiadapiform fossils so far attributed to Dermoptera are not related to the Dermoptera. It also appears that the paromomyids are 
more closely related to primates than colugos (Bloch et al., 2007; Janečka et al., 2007).

Recent new finds of adapisoriculid insectivoran (Eutheria, Adapisoriculidae, ?Lipotyphla) (Gheerbrant and Russell, 1989, 1991) postcrania from the Paleocene in Germany (Storch, 2008) and Hainin (Belgium) (Smith et al., 2009) suggest a relationship to Deccanolestes (Boyer et al., 2010) from the Cretaceous of India and support a euarchontan relationship for these taxa. Smith et al. (2009) argued specifically for a special relationship between adapisoriculids and dermopterans on the basis of dental features.

As can be seen from the above discussion, the attribution of nearly all fossil taxa to Dermoptera is highly contentious and probably wrong. The only fossils most likely to be dermopterans appear to be those associated with the dentitions of Dermotherium from the Eocene of Thailand (Ducrocq et al., 1992; Marivaux et al., 2006), although even these were disputed by Stafford and Szalay (2000).

\section{Flying Squirrels}

The taxonomy and phylogeny of the flying squirrels has been complicated at the lower ranks. A review of the major taxonomic changes that have occurred within the flying squirrels was described by Thorington et al. (2002), on which the following is based. The first two species to be described were by Linnaeus (1758) when he described the European flying squirrel as Sciurus volans (=Pteromys volans) and the North American flying squirrel as Mus volans (=Glaucomys volans), which created confusion due to homonymy of the species name. A further four flying squirrels were described during the remainder of the eighteenth century, three of which were placed in Sciurus. The fourth species was placed in the new genus Petaurista by Link (1795), but this generic name was not used again for more than a century. Georges Cuvier (1800) introduced the name Pteromys for flying squirrels to separate them from the nongliding squirrels of Sciurus. Cuvier placed two species in Pteromys, the European flying squirrel and one of the giant flying squirrels from southern Asia. This resulted in confusion, and disagreements occurred throughout the literature for 150 years about which group should bear the name Pteromys. To add to the confusion, Frederic Cuvier (1825a) introduced a second generic name, Sciuropterus. These two generic names were used for all but one of the 77 species named during the nineteenth century. During this period Pteromys was used for the large flying squirrels of southern Asia, and Sciuropterus was used for the small- to medium-size squirrels. During most of the nineteenth century, Sciuropterus volucella (Pallas, 1778) was the name of the southern flying squirrel of North America, and Sciuropterus volans (Linnaeus, 1758) was the accepted name of the European flying squirrel.

The one species that was not included in these two genera was the distinctive woolly flying squirrel, Eupetaurus cinereus, which was described by Thomas (1888b). Thus, in Major's (1893) classification of squirrels, only three genera were listed (Pteromys, Sciuropterus, and Eupetaurus). Subsequently, Thomas (1897) resurrected the name Petaurista for these large flying squirrels, and Sciuropterus included all the other, mostly smaller, flying squirrels.

The diversity of genera of the flying squirrels was increased by Heude (1898), who placed the complex-toothed flying squirrel Pteromys xanthipes in a new genus, Trogopterus. Subsequently, Thomas (1908b) reexamined "the Sciuropterus group" and divided it into six genera that included Trogopterus, Belomys, Pteromyscus, Sciuropterus, Petaurillus, and Lomys, on the basis of features of teeth and crania. Thomas also divided Sciuropterus into four subgenera, which were the Sciuropterus (the small north Eurasian flying squirrels), Glaucomys (both the Himalayan and the North American flying squirrels), and Hylopetes and Petinomys (small- to medium-size flying squirrels of southern Asia).

The four subgenera proposed by Thomas (1908b) were subsequently raised to full generic rank. Howell (1915) named the Himalayan flying squirrel, Eoglaucomys, and separated it from Glaucomys, the North American flying squirrels, which were both recognized as full genera. In doing this, he also separated the north Eurasian and North American flying squirrels at the generic level, which caused the name of the North American squirrel to change from Sciuropterus volucella (Pallas, 1778) to Glaucomys volans (Linnaeus, 1758). The names Hylopetes and Petinomys were elevated to full genera by Pocock (1923), who based this separation on differences between their bacula and the baculum of Glaucomys volans. Subsequently, Ellerman (1947) combined Eoglaucomys within Hylopetes, but anatomical evidence observed by Thorington et al. (1996) demonstrated this was inappropriate.

When the name Petaurista (Link, 1795) was resurrected by Thomas (1897) for the large Asian flying squirrels, he considered the name Pteromys (G. Cuvier, 1800) to be a junior synonym. It was subsequently noted by Miller (1914) that Pteromys should be used for the small Eurasian flying squirrel, with Sciuropterus (F. Cuvier, 1825a) as a junior synonym. These changes led to a variety of ways in which generic names were used in the first half of the twentieth century, which was exacerbated when an additional 131 species and subspecies of flying squirrels 
were described. The name Sciuropterus was still used by Simpson (1945), but Ellerman and Morrison-Scott (1951) agreed with Miller's (1914) conclusion that the name Pteromys should be used for the north Eurasian flying squirrel on the basis of Cuvier's (1800) original description and a subsequent clarification by Fleming (1822). With the addition of three additional genera, Aeromys (Robinson and Kloss, 1915), Aeretes (Allen, 1940), and Biswamoyopterus (Saha, 1981), and the generic recognition of Eoglaucomys the taxonomic arrangement reached approximately 40 species of flying squirrels allocated to 15 genera in the early 1990s, which has expanded to 48 species in the last 15 years as a result of taxonomic rearrangement.

The close relationship of the flying squirrels to other squirrels is reflected in the taxonomic name of the group at the family level. The flying squirrels were separated from other squirrels by Brandt (1855), who placed them in the Pteromyini, but he kept them with the squirrels. Subsequently, Major (1893) suggested that flying squirrels were not closely related to other squirrels, but he did not officially recognize this idea as he included both in the subfamily Sciurinae. Miller (1912) considered Pteromys to be a junior synonym of Petaurista and gave the flying squirrels the new name Petauristidae, a family separate from the Sciuridae. When the name Pteromys was accepted as a senior synonym for Sciuropterus, the name Pteromyinae became the valid subfamily-level name again, but the family versus subfamily question remained open (Corbet and Hill, 1992; Hoffmann et al., 1993). More recently, the closeness of the flying squirrels to other squirrels has been reflected in them being placed in the tribe Pteromyini within the subfamily Sciurinae (Steppan et al., 2004; Thorington and Hoffman, 2005), an arrangement that is followed here.

There is great uncertainty of the relationship between the 15 genera of living flying squirrels and the 21 genera of fossil squirrels that are thought to have been able to glide. To make things more complicated, there is uncertainty as to whether the currently recognized fossil gliding genera should be recognized as flying squirrels because none of these can categorically be allocated as gliders since most features used to describe them are also found in at least some tree squirrels (Thorington et al., 2005). This uncertainty arose from a thorough survey of the fossil species described as gliders that found few convincing arguments for these animals to clearly belong to the flying squirrel tribe and none to support unequivocally the hypothesis that they were gliding mammals. Therefore, it seems that all extinct fossil species currently recognized as flying squirrels (and typically the other groups as well) must be viewed with caution until further, more complete, specimens with postcranial material can be found to confirm or reject their ability to glide.

\section{Scaly-Tailed Flying Squirrels}

The first scaly-tailed flying squirrel to be described was Lord Derby's scaly-tailed flying squirrel, which was described as Pteromys derbianus (now Anomalurus derbianus) by Gray (1842). The following year, Waterhouse (1843a) introduced Anomalurus. Pel's scaly-tailed flying squirrel $(A$. pelii) was then described by Schlegel and Müller (1845), with Beecroft's scaly-tailed flying squirrel, Anomalurops beecrofti, described by Fraser (1853). The dwarf scaly-tailed flying squirrel, Anomalurus pusillus, was subsequently described by Thomas (1887). A second genus of scaly-tailed flying squirrel was described by Matschie (1894), who described Idiurus and the pygmy scaly-tailed flying squirrel Idiurus zenkeri. A second species was described several years later when the long-eared scaly-tailed flying squirrel $I$. macrotis was described by Miller (1898).

The fossil record of the superfamily Anomaluroidea is limited, being restricted to only a handful of species, including one species of Anomalurus and three species of Paranomalurus. In the related family Nementchamyidae (nova) there is one species in Nementchamys and one species in Pondaungimys.

\section{Enigmatic Gliders}

Three relatively recent species have also been discovered in addition to the groups listed above, with each having no close relatives. The first was described from Neogene fossils as a nongliding species named Glirulus lissiensis in the family Myoxidae by Hugueney and Mein (1965), but this was recognized as a glider 26 years later when Mein and Romaggi (1991) discovered further fossil evidence. The second species of glider was discovered in late Oligocene deposits and was described in 1987 as Eomys quer$c y i$ in the family Eomyidae by Compte and Vianey-Liaud (1987). Likewise, this species was not considered to be a gliding mammal until a well-preserved specimen was discovered and described by Storch et al. (1996). The third and possibly the most enigmatic of all the extinct gliders is Volaticotherium antiquus, described by Meng et al. (2006) from Middle to Late Jurassic deposits. This highly unusual animal was placed in a new family, the Volaticotheriidae, within a new order, the Volaticotheria. 


\section{METHODS AND FORMAT}

Taxonomy for genera and lower ranks generally follows Wilson and Reeder (2005) except where otherwise stated. The taxonomy of the Marsupialia above genus follows Van Dyck and Strahan (2008), with synonyms of taxa typically following those outlined by McKenna and Bell (1997). All taxa, both extant and extinct, are integrated together to reflect their phylogeny, with extinct taxa marked with a cross ( $\dagger$ ) to make them readily identifiable.

Although McKenna and Bell (1997) is an excellent overview of the different groups of living and extinct mammals, it does not include the individual citations for any rank, but rather includes only the author, year, and often (though not always) page number. The ranks above genera, including synonyms, are included here (1) because publications such as McKenna and Bell (1997) do not include the citations, (2) because of the instability of many of these ranks, (3) to reflect current phylogenetic research, and (4) to highlight errors in currently accepted names (e.g., see the discussion under the order Diprotodontia). Wilson and Reeder (2005) is recognized as the standard reference for all living mammals and includes the citations for all currently accepted families, genera, and species (in abbreviated form) but does not include citations for subspecies, synonyms, or ranks above the family level. Therefore, to facilitate future research, the full citation for all ranks has been included because of the obscurity of many of them and the resulting difficulty in accurately determining their full title (as was experienced during this review).

Because of the continued debate over the ability of most fossil species to be able to glide, a broad approach has been taken to include all proposed taxa within each group of gliding mammals, especially the flying squirrels of the tribe Pteromyini and the taxa within the order Dermoptera. It is recognized that many of these taxa may ultimately not be recognized as gliding mammals in time as postcranial specimens are found in the future that confirm or refute the ability to glide. Features that help to determine whether the fossil remains of a species are those of a glider include the presence of postcranial material, including limb structure, the styliform cartilage in flying squirrels, unciform cartilage in scaly-tailed flying squirrels, and, potentially, impressions of gliding membranes.

Currently accepted names are placed in bold, whereas junior synonyms are listed in nonbold font below. The synonymies of species cover the original name combinations and the currently accepted name combination for senior synonyms but not all subsequent name combinations, although some of these are traceable through the relevant comments section. In order to reduce the length of this review, abbreviated references are included next to each taxon's name in the text, with the full citation being included in the reference list.

\section{ACKNOWLEDGMENTS}

We sincerely thank the following people and institutions for providing invaluable assistance with this work. Kris Helgen, Don Wilson, and Maressa Takahashi from the Smithsonian Institution provided various references and valuable advice. Hein van Grouw and Lars van den Hoek Ostende from the Nationaal Natuurhistorisch $\mathrm{Mu}-$ seum (Naturalis Museum) in Leiden, Max Barclay from the Natural History Museum, and Svetlana Nikolaeva of the International Commission on Zoological Nomenclature (ICZN) Secretariat provided valuable references and advice. Paul Andrew, Douglas Boyer, Mary Dawson, Alfred Gardner, Gudrun Höck, and Eric Sargis read sections of the manuscript and made numerous valuable suggestions. Ken Aplin provided important information on the taxonomy of the marsupial genera Acrobates and Petauroides. Two anonymous referees provided numerous comments that greatly helped shape this work. Several libraries and their associated staff were very helpful in finding and providing many references for this project. These include Paul Cooper, Nicola Gamba, Samantha Gare, Carol Gokce, Kirsten Marshall, Nadja Noel, Kamila Reekie, John Rose, Emma Solway, Angela Thresher, Lisa Di Tommaso, and Eliza Walsh from the Natural History Museum in London, who provided many of the references. Therese Nouaille-Degorce and Evelyne Bremond-Hoslet from the Bibliothèque Centrale du Museum National d'Histoire Naturelle in Paris provided a number of valuable references. Staff at the National Museum of Natural History (Smithsonian Institution) libraries in Washington, D.C., including Martha Rosen, Richard Greene, Ron Lindsey, David Steere, Leslie Overstreet, Daria Wingreen-Mason, and Kirstin van der Veen, helped us enormously in finding and copying references for this project. We also extend many thanks to the Australian Museum Library staff, including Fiona Simpson, Anina Hainsworth, Fran Smith, and Leone Lemmer, and staff of the Nationaal Natuurhistorisch Museum in Leiden, including Tom Gilissen, Marianne van der Wal, and Agnes Bavelaar, for all their help. 


\section{Taxonomy of Gliding Mammals}

\section{Class Mammalia Linnaeus, 1758}

Mammalia Linnaeus, 1758:12.

Comments. McKenna and Bell (1997:35) identified several preLinnean synonyms, including Vivipera (Ray, 1693:53). Recognized as a cohort by Gardiner (1982:229) but at class rank by most recent authors, including Iredale and Troughton (1934:1), Simpson (1945:39), and McKenna and Bell (1997:35). The name of the class Mammalia was reviewed by Rowe and Gauthier (1992:372). See also Paclt (1960:47). Synonyms follow McKenna and Bell (1997:35).

Class Mastodia Rafinesque, 1814a:47.

Comments. Also referred to by Rafinesque (1814b:12), who gives the spelling as Mastodologie (p. 9). Reviewed by Paclt (1960:47). Synonymized within the class Mammalia by McKenna and Bell (1997:35).

Thricozoa Oken, 1847:xi.

Comments. Synonymized within the class Mammalia by McKenna and Bell (1997:35).

Aistheseozoa Oken, 1847:563.

Comments. Synonymized within the class Mammalia by McKenna and Bell (1997:35).

Pilifera Bonnet, 1892:236.

Comments. Synonymized within the class Mammalia by McKenna and Bell (1997:35).

Mammaliaformes Rowe, 1988:250.

Comments. Name was reviewed by McKenna and Bell (1997:507).

Class Mammalea Kinman, 1994:37.

Comments. Synonymized within the class Mammalia by McKenna and Bell (1997:35). 


\section{Subclass Marsupialia llliger, 1811}

Family Marsupialia Illiger, 1811a:75.

Comments. Ordinal rank recognized by G. Cuvier (1817:169, 1829:172), Bonaparte (1838:113, 1841:257), Gill (1871:533, 1872:vi, 25), Cope (1889:874), Gregory (1910:105, 197, 1947:46) and Simpson (1945:41) and class recognized by Newman (1843:120). Superorder rank recognized by Ride (1964:99) and Kirsch (1968:420, 1977a:111) and supercohort recognized by McKenna (1975:27), Aplin and Archer (1987:xxi), and Wroe (1999:512). Gardiner (1982:229) recognized Marsupialia at infraordinal rank, and McKenna and Bell (1997:51) created the new rank of cohort. Subclass rank recognized by Iredale and Troughton (1934:4), Strahan (1983:11, 1995:6, 45), and Van Dyck and Strahan (2008:9).

Order Pollicata Illiger, 1811a [part]:66.

Comments. Also described by Illiger (1811b:64). Synonymized within the subclass Marsupialia by McKenna and Bell (1997:51).

Family Salienta Illiger, 1811a:79.

Comments. Synonymized within the subclass Marsupialia by McKenna and Bell (1997:51).

Homonyms. Salientia Laurenti, 1768:24, amphibians of the class Amphibia (order Anura). Invalid synonym and/or a part of order Anura Fischer de Waldheim (1813:58).

Subclass Didelphes de Blainville, 1816:117.

Comments. Included the monotremes as "Didelphes Anomaux." Synonymized within the subclass Marsupialia by McKenna and Bell (1997:51).

Order Ferae Gray, 1821:308.

Comments. Junior homonym of Ferae Linnaeus (1758:37). Synonymized within the subclass Marsupialia by McKenna and Bell (1997:51).

Homonym. Ferae Linnaeus, 1758:37, of the class Mammalia and order Carnivora.

Order Marsupiata Gray, 1827:53, 185.

Comments. Recognized at ordinal rank by Bell (1829:121), Richardson (1837:138, 149), Waterhouse (1841:45), who referred to both Marsupiata and Marsupialia, and Waterhouse (1846:1). Term does not appear to have been used by subsequent authors except Turnbull (1971:176), who elevated it to cohort rank. Synonymized within the subclass Marsupialia by McKenna and Bell (1997:51). The author of the name was given as Richardson (1937:149) by McKenna and Bell (1997:51).

Didelphina Bonaparte, 1838:113.

Comments. Synonymized within the subclass Marsupialia by McKenna and Bell (1997:51).

Series Ovovivipara Bonaparte, 1838:113.

Comments. Not subsequently recognized.

Subclass Eutheria Gill, 1872 [part]:v, vi.

Comments. Synonymized within Theria by McKenna and Bell (1997:49).

Metatheria Huxley, 1880:654.

Comments. Recognized as a subclass by Ogilby (1892:4), an infraclass by Simpson (1945:41) and Szalay (1994:40), and a supercohort or infraclass by Shoshani (1992:108). Synonymized within the subclass Marsupialia by McKenna and Bell (1997:51).

Subclass Theria Parker and Haswell, 1897 [part]:448.

Comments. Used at subclass rank by Simpson (1945:40). Recognized at subcohort rank by Gardiner (1982:229), whereas Aplin and Archer (1987:xxi) included Theria at subclass rank. Recognized at the new rank of supercohort by McKenna and Bell (1997:49).

Subclass Marsupionta Gregory, 1947 [part]:46.

Comments. Included marsupials and monotremes. Synonymized within the subclass Marsupialia by McKenna and Bell (1997:51).

Cohort Metadelphia Archer, 1984:786.

Comments. Synonymized within the subclass Marsupialia by McKenna and Bell (1997:51).

\section{Cohort Australidelphia Szalay, 1982}

Cohort Australidelphia Szalay, 1982:629.

Comments. Used by Szalay (1994:42), Marshall et al. (1990:459), and Wroe (1999:512). Recognized at new rank of magnorder by McKenna and Bell (1997:53).

Order Gondwanadelphia Szalay, 1993:237, 240.

Comments. Reiterated as new by Szalay (1994:348). Synonymized within Australidelphia by McKenna and Bell (1997:53). 


\section{Order Diprotodontia Owen, 1877}

Suborder Diprotodontia Owen, 1877:xii, 107.

Comments. The rank appears to be derived from Owen (1868:293), who suggests that marsupial dentition shows them to be divisible into "two classes: one 'polyprotodont,' or characterized by several pairs of mandibular incisors; the other 'diprotodont,' or by a single pair." Rank not recognized by Krefft (1871:3), Gill (1872), Flower (1883:178), Bensley (1903:207), or Simpson (1945:45). Recognized at suborder rank by Nicholson (1880:661), Lydekker (1887:xi, xxi, 146), Thomas (1888a:xi，3), Flower and Lydekker (1891:xi, 144), Ogilby (1892:24), Cope (1889:876), Weber (1904:348, 1928:xiii, 75), Gregory (1910:197, 215), Osborn (1910:517), and Iredale and Troughton (1934:vii, 21). Recognized at ordinal rank by Haeckel (1895:466), Kirsch (1968:420, 1977a:112, 1977b:45) (as Diprotodonta), Strahan (1983:xxi) (as Diprotodonta), Archer (1984:787) (as Diprotodonta), and Aplin and Archer (1987:xxi), who proposed a new classification that included two suborders, the Vombatiformes and Phalangerida. Infraorder rank recognized by Archer (1984:786) and as a semiorder by Szalay (1993:239, 240, 1994:42). Kirsch et al. (1997:245-246) recognized three suborders, the Vombatiformes, Macropodiformes, and Phalangeriformes. The author of this rank has historically been incorrectly given as Owen (1866), never with page number, by all authors that include the citation for the rank, including Gregory (1910:98, 199, 464, 492), Marshall (1981:17), McKenna and Bell (1997:58), and Long et al. (2002:77).

Suborder Syndactyli Gill, 1871 [part]:533.

Comments. Definition expanded by Gill (1872:vi, 25). Included bandicoots and diprotodontids. Recognized as superorder by McKenna (1993:743) and at grandorder rank by McKenna and Bell (1997:56).

Order Macropoda Ameghino, 1889:263, 266.

Comments. Included the families Macropodidae, Phalangistidae, and Phascolomyidae. Subsequently used by Ameghino (1916:452) but does not appear to have been used by subsequent others. Synonymized within Diprotodontia by McKenna and Bell (1997:58).

Suborder Diprotodonta Thomas, 1895a:876.

Comments. Incorrect emendation of Diprotodontia. Spelling used by a number of authors at the suborder rank by Deberer (1909:614); infraordinal rank by Archer (1984:786); and ordinal rank by Archer (1984:787),
Ride (1964:97, 99), Kirsch (1968:420, 1977a:112, 1977b:45), Turnbull (1971:176), Baverstock (1984:2), and Strahan (1983:xxi). The correct spelling was reviewed by Aplin and Archer (1987:xliii), who concluded that Diprotodonta is an invalid emendation of Diprotodontia.

Suborder Syndactyla Jones, 1923 [part]:133.

Comments. Rank included bandicoots and diprotodontids. Recognized at ordinal rank by Szalay (1982:631, 1994:42), who also included the superfamily Notoryctoidea. Synonymized within Diprotodontia by Aplin and Archer (1987:xliii) and other authors, including Groves (2005:43). Synonymized within Syndactyli Gill (1871:8) by McKenna and Bell (1997:56).

Section Syndactyla Diprotodontia Jones, 1923:171.

Comments. Included bandicoots and $\mathrm{di}-$ protodontids. Recognized at ordinal rank by Szalay (1982:631, 1994:42). Synonymized within Diprotodontia by Aplin and Archer (1987:xliii) and other authors, including Groves (2005:43). Synonymized within Syndactyli (Gill, 1871:8) by McKenna and Bell (1997:56).

Duplicicommissurala Abbie, 1937:432.

Comments. Rank not specified. Synonymized within Diprotodontia by Aplin and Archer (1987:xliii) and McKenna and Bell (1997:58).

Semisuborder Diprotodontiformes Szalay, 1993:240.

Comments. The semisuborder Vombatomorphia was separated. Synonymized within Diprotodontia by McKenna and Bell (1997:58).

Order Diprotodontiformes Kinman, 1994:37.

Comments. Synonymized within Diprotodontia by McKenna and Bell (1997:58).

\section{Suborder Phalangerida Aplin and Archer, 1987}

Suborder Phalangerida Aplin and Archer, 1987:xxii, xlix.

Comments. Rank synonymized within Diprotodontia by McKenna and Bell (1997:58), but recognized by Strahan (1995:7, 206), Roberts et al. (2007:2), and Van Dyck and Strahan (2008:9, 209).

Suborder Phalangeriformes Szalay, 1982:631.

Comments. Synonymized within Diprotodontia by Aplin and Archer (1987:xliii) and McKenna and Bell (1997:58). Subordinal rank recognized by Woodburne 
(1984:71), who introduced it as new, and by Kirsch et al. (1997:245) and Marshall et al. (1990:459), who both attributed the name to Woodburne (1984:71). Subsequently both Szalay (1994:42) and Groves (2005:44) recognized the suborder with Szalay (1982) as the author.

Tribe Carpophaga Owen, 1839[part]:322.

COMMENTs. Included the genera Phalangista (Pseudocheiridae), Petaurus (Petauridae) and Phascolarctus [sic] (Phascolarctidae). Recognized by Waterhouse (1841:57) and Owen (1859:52) but not typically by other authors.

\section{Superfamily Petauroidea Bonaparte, 1832}

Petaurina Bonaparte, 1832:69.

Type Genus. Petaurus Shaw, 1791: pl. 60.

Comments. Tribe rank recognized by Bonaparte (1838:113, 1841:257). Attributed to Gill (1872:25) by authors, including Aplin and Archer (1987:xxii), Szalay (1994:43), Kirsch et al. (1997:245), and Brammal (1998:32), whereas McKenna and Bell (1997:65) attributed the name to Szalay (1994:43). Recognized at the superfamily rank by Aplin and Archer (1987:xxii), Marshall et al. (1990:460), Szalay (1994:43), Kirsch et al. (1997:245), and Long et al. (2002:126). Synonymized within the family Petauridae by McKenna and Bell (1997:65).

\section{Family Petauridae Bonaparte, 1832}

Petaurina Bonaparte, 1832:69.

Type Genus. Petaurus Shaw, 1791: pl. 60.

Comments. Tribe rank recognized by Bonaparte (1838:113, 1841:257). Historically included species now recognized within the family Pseudocheiridae (e.g., Kirsch, 1968:420; Strahan, 1983:124; McKay, 1988a:87; McKenna and Bell, 1997:65). The family name is often attributed to Gill (1872:25), e.g., Kirsch (1968:420, 1977a:113), Marshall (1981:28), Aplin and Archer (1987:xxii), Szalay (1994:43), and Kirsch et al. (1997:245). More recently the family name has been attributed to Bonaparte (1838:113) by McKenna and Bell (1997:65) and Groves (2005:53). The family has historically included two subfamilies, the Petaurinae and Pseudocheirinae, recognized by authors, including Kirsch (1968:420, 1977a:113), Marshall (1981:28), and McKenna and Bell (1997:65). In contrast, Szalay (1994:43) recognized two subfamilies, the Petaurinae and Burramyinae, with the former subfamily including the tribes Petaurini, Dactylopsilini, and
Pseudocheirini and the latter subfamily including the tribes Burramyini and Acrobatini. Separate families, i.e., Petauridae and Pseudocheiridae, are recognized by Baverstock (1984:4-5) and followed by Archer (1984:711, 786), Aplin and Archer (1987:xxii), Marshall et al. (1990:460, 494), Groves (1993:58, 60), Flannery (1994:60, 102), Kirsch et al. (1997:245), and subsequent authors.

Family Petaurusideae Lesson, 1842 [part]:189.

Type Genus. Petaurus Shaw, 1791: pl. 60.

Comments. Also included Acrobates from the family Acrobatidae and Schoinobates (=Petauroides) of the family Pseudocheiridae. Synonymized within Petauridae by Marshall et al. (1990:495).

Subfamily Petaurinae Gill, 1872:25.

Type Genus. $\quad$ Petaurus Shaw, 1791: pl. 60.

Comments. Synonymized within Petaurinae Bonaparte (1838:113) by McKenna and Bell (1997:65).

\section{Subfamily Petaurinae Bonaparte, 1832}

Petaurina Bonaparte, 1832:69.

Type Genus. Petaurus Shaw, 1791: pl. 60.

Comments. Tribe rank recognized by Bonaparte (1838:113, 1841:257). Subfamily rank recognized by Gill (1872:25), Marshall (1981:28, 1984:102), Marshall et al. (1990:460), Strahan (1995:7, 224), Kirsch et al. (1997:245), McKenna and Bell (1997:66), and Van Dyck and Strahan (2008:10, 226).

Tribe Petaurini Szalay, 1994:43.

Type Genus. Petaurus Shaw, 1791: pl. 60.

Comments. Synonymized within the subfamily Petaurinae by McKenna and Bell (1997:66).

\section{Petaurus Shaw, 1791}

Petaurus Shaw, 1791: pl. 60.

Type Species. $\quad$ Petaurus australis Shaw, 1791: pl. 60 .

Comments. Genus recognized by Waterhouse (1841:xvi, 282) but not various other authors, as Belideus was used in preference until it was fixed by Thomas (1888a:xii, 150). Publication date established from Sherborn (1895:376).

Ptilotus Fischer de Waldheim, 1814:512.

Type Species. $\quad$ Petaurus australis Shaw, 1791: pl. 60. 
Comments. Synonymized within Petaurus by Thomas (1888a:150), Iredale and Troughton (1934:23), Marshall (1981:28), McKay (1988a:91), and Marshall et al. (1990:495).

Homonyms. Ptilotis Swainson, 1837:326, honeyeaters of the class Aves (order Passeriformes, family Meliphagidae). Genus is a junior synonym of Meliphaga (Lewin, 1808:4).

Belidea Waterhouse, 1838:880a

Type Species. Petaurista (Belidea) breviceps Waterhouse, 1838a:880.

Comments. Recognised at generic rank by Gould (1842a:11; 1842b:404). Placed within Belideus by Palmer (1904:135).

Belideus Waterhouse, 1839a:149.

Type Species. Didelphis sciurea Shaw, 1794:29.

Comments. Described as a subgenus of Petaurus. Generic rank recognized by various authors, including De Vis (1883:619). Recognized as a subgenus of Petaurus by Waterhouse (1846:325) and Gervais (1869:574), but synonymized within Petaurus by Gray (1843:xxii, 83), Thomas (1888a:150), Iredale and Troughton (1934:23), Marshall (1981:28), McKay (1988a:91), and Marshall et al. (1990:495).

Belidens Wiegmann, 1839:418

Type Species. Misspelling of Belideus Waterhouse, 1839.

Comments. Misspelling of Belideus Waterhouse, 1839a. Synonymized within Belideus by Palmer (1904:135).

Xenochirus Gloger, 1841:xxx, 85.

Type Species. Didelphis sciurea Shaw, 1794:29.

Comments. Publication date established from Thomas (1895b:189). Synonymized within Petaurus by Thomas (1888a:150, 1895b:190), Iredale and Troughton (1934:23), Marshall (1981:28), McKay (1988a:91), and Marshall et al. (1990:495).

Homonyms. Xenochirus Gilbert, 1890:90, poacher fish or poachers of the superclass Pisces (order Scorpaeniformes, family Agonidae). Preoccupied by Xenochirus Gloger, 1841. Junior synonym of Xeneretmus Gilbert (Jordan, 1903:360).

Petaurula Matschie, 1916:261.

Type Species. Petaurus breviceps Waterhouse, 1839a:152.
Comments. Proposed as a subgenus of Petaurus Shaw, 1791. Synonymized within Petaurus by Iredale and Troughton (1934:23), Marshall (1981:28), McKay (1988a:91), and Marshall et al. (1990:495).

Petaurella Matschie, 1916:261.

Type Species. Petaurus breviceps var. papuanus Thomas, 1888a:158.

Comments. Not considered by Iredale and Troughton (1934:23) and synonymized within Petaurus by Marshall (1981:28), McKay (1988a:91), and Marshall et al. (1990:495).

\section{Petaurus abidi Ziegler, 1981 (northern glider)}

Petaurus abidi Ziegler, 1981:81.

Type Locality. West Sepik Province, Mount Soporo, Torricelli Mountains, Papua New Guinea. $3^{\circ} 25^{\prime}$ S, $142^{\circ} 5^{\prime} \mathrm{E}$.

Comments. Species rank accepted since its description.

Distribution. Papua New Guinea North Coast Ranges, comprising a section of mountain range approximately $100 \mathrm{~km}$ (62 mi) long and a few tens of kilometers wide, from at least 2Fas Village (to the east of Mount Menawa) in the west to Mount Sapua in the east, at elevations above $300 \mathrm{~m}(984 \mathrm{ft})$, although they are thought to be rare below $800 \mathrm{~m}(2,624 \mathrm{ft})$, with most animals thought to occur between 800 and $1200 \mathrm{~m} \mathrm{(2,626}$ and 3,936 ft) (Flannery, 1994:70).

\section{Petaurus australis Shaw, 1791 (yellow-bellied glider)}

Petaurus australis Shaw, 1791: pl. 60.

Type Locality. Sydney, New South Wales, Australia.

Comments. Type based on "Hepoona Roo" of J. Hunter in White (1790:288). Publication date established from Sherborn (1895:376). Taxonomic history reviewed by Thomas (1888a:151). Iredale and Troughton (1934:24) refer to the author as Shaw and Nodder; however, Nodder was the publisher. The taxonomy of the isolated population in north Queensland needs to be resolved. Fossils most similar to Petaurus australis from the Pliocene Hamilton Local Fauna, western Victoria, Australia, was described by Turnbull et al. (1987a:629) and with others found in subfossil deposits within the Pyramid Caves in eastern Victoria, Australia (Wakefield, 1972:8). 
Distribution. North Queensland down the east coast through New South Wales to Victoria, Australia. There are also several isolated populations in north Queensland, western Victoria and near the Victorian border in the extreme southeast of South Australia (Van Dyck and Strahan, 2008:228).

[Sciurus] novaehollandie Meyer, 1793 [part]:11.

Type Locality. New South Wales, Australia.

Comments. Combined description incorporating "Hepoona Roo" of J. Hunter in White (1790:188) and "Norfolk Island flying squirrel" of Anonymous in Philip (1789:151). Included within P. norfolcensis by Iredale and Troughton (1934:24). Split between norfolcensis and australis by Thomas (1888a:151), McKay (1988a:9394), and Flannery (1994:74).

Didelphis petaurus Shaw, 1800:496, pl. 112.

Type Locality. Sydney, New South Wales, Australia.

Comments. Replacement name for Petaurus australis Shaw, 1791, but part of description refers to the "black flying opossum" of Anonymous in Phillip (1789:297) (=Didelphis volans Kerr, 1792). Synonymized within australis by Thomas (1888a:151), Iredale and Troughton (1934:24), McKay (1988a:92), and Flannery (1994:74).

Voluccella nigra Bechstein, 1800 [part]:351.

Type Locality. Botany Bay, New South Wales, Australia.

Comments. Combined description; see part B under Petauroides volans volans in Kerr (1792). Synonymized within australis by McKay (1988a:92) and Flannery (1994:74).

Petaurus hepuna ru Oken, 1816:1118.

Type Locality. New name for Didelphis petaurus Shaw, 1800.

Comments. Synonymized within australis by Iredale and Troughton (1934:24) and not included within McKay (1988a:92).

Petaurista flaviventer Desmarest, 1818a:403.

Type Locality. New South Wales, Australia.

Comments. Recognized as a valid species within Petaurus by Waterhouse (1841:286) and within Belideus by Gould (1845-1863 [1845]: text to pl. 23). Synonymized within australis by Waterhouse (1846:327), Thomas (1888a:151), Iredale and Troughton (1934:24), McKay (1988a:92), and Flannery (1994:74).
P.[etaurus] cunninghami Gray, 1843:83.

Type Locality. New South Wales, Australia. Comments. Synonymized within australis by Thomas (1888a:152), Iredale and Troughton (1934:24), McKay (1988a:92), and Flannery (1994:74).

Petaurus opossum Falcimagne, 1854:366.

Type Locality. New South Wales, Australia. COMments. Synonymized within australis by Iredale and Troughton (1934:24) and not included within McKay (1988a:92).

Petaurus australis reginae Thomas, 1923a:249.

Type Locality. Gin Gin, $45 \mathrm{~km}(28 \mathrm{mi})$ inland of Bundaberg, southeast Queensland, Australia.

Comments. Subspecies rank recognized by Iredale and Troughton (1934:24), Tate (1945:7), Troughton (1967:86), Strahan (1983:136; 1995:228), McKay (1988a:92), and Flannery (1994:60). Although the separate north Queensland population is usually allocated to this subspecies, the type locality at Gin Gin in southern Queensland lies within the continuous range of Petaurus australis australis. The north Queensland population was proposed to be treated as an undescribed subspecies by Maxwell et al. (1996:8). More recently, it was recognized as a subspecies of australis by Groves (2005:55) and Clayton et al. (2006:104); however, a detailed genetic analysis by Brown et al. (2006:305) found their results do not support the classification of reginae as a subspecies for the original type specimen from southern Queensland. The north Queensland population was proposed by Brown et al. (2006:311) to represent a distinct "evolutionary significant unit," and they used this term in preference to subspecies.

\section{Petaurus biacensis Ulmer, 1940 (Biak glider)}

Petaurus (Petaurella) papuanus biacensis Ulmer, 1940:1.

Common Name. Biak glider.

Type LocAlity. Biak Island, Indonesia.

Comments. Generally recognized as a subspecies of breviceps, such as by Smith (1973:1). Separated from breviceps as a distinct species by Flannery (1994:80; 1995a:116) and Groves (2005:55).

Distribution. Biak, Supiori, and Owi islands, Schouten Islands group, Indonesia (Flannery, 1994:78).

Petaurus koblsi Troughton, 1945:273.

TYPe Locality. Owi Island, Schouten Islands group, Indonesia. 
Comments. Synonymized within Petaurus breviceps by Groves (1993:61) and Flannery (1994:78), but within biacensis by Groves (2005:55).

\section{Petaurus breviceps (Waterhouse, 1838) (sugar glider)}

\section{Petaurus breviceps breviceps (Waterhouse, 1838)}

[Petaurista] [Belidea] Breviceps Waterhouse, 1838a:880.

Type Locality. Sydney, New South Wales, Australia.

Comments. The first publication of this taxon appears to have been overlooked, with authors recognizing Waterhouse (1839a:152) as the publication which used the name Petaurus [Belideus] breviceps. This publication arose from the paper being read before the Zoological Society of London on 13 November 1838 and subsequently published in May 1839. McAllan and Bruce (1989:447) argued that the original publication of the name was Waterhouse (1838a:880) which was published on 8 December 1838, and this has been followed here. Included within Petaurus by Waterhouse (1841:290; 1846:334), Gray (1843:83) and most subsequent authors except Gould (1845-1863 [1849]: text to pl. 5), who placed it within Belideus. Taxonomic history was reviewed by Thomas (1888a:156) and Smith (1973:1). A fossil assigned to Petaurus breviceps was described by Aplin et al. (1999:378) from Pleistocene deposits at Bird's Head Peninsula, Papua (western New Guinea), Indonesia. Other fossils assigned to this species have been collected from Pleistocene deposits in the Naracoorte Caves, South Australia, Australia (Reed and Bourne, 2000:67), and from subfossil deposits from Pyramid Caves in eastern Victoria, Australia (Wakefield, 1972:8).

Distribution. Eastern mainland Australia from southern Queensland through New South Wales and Victoria into southeastern South Australia, and Tasmania (Flannery, 1994:80).

Petaurus sciureus Gunn, 1851:253.

Type LocAlity. Tasmania.

Comments. Recognized as a species within Belideus by Gould (1845-1863 [1845]: text to pl. 24). Synonymized within Petaurus breviceps by Thomas (1888a:156).

Petaurus (Belideus) notatus Peters, 1859:14.

Type Locality. Port Philip, Victoria, Australia. Comments. Recognized within Belideus by Gould (1845-1863 [1860]: text to pl. 26). Synonymized within Petaurus breviceps by Thomas (1888a:156), Iredale and Troughton (1934:25), McKay (1988a:93), Groves (1993:61), Flannery (1990:146; 1994:80; 1995a:118; 1995b:207), and subsequent authors.

\section{Petaurus breviceps ariel (Gould, 1842)}

Belidea ariel Gould, 1842a:11.

Type Locality. Port Essington, Northern Territory, Australia.

Comments. Type designated by Thomas (1922a:128). Synonymized within breviceps by Waterhouse (1846:336), but recognized within Belideus by Gould (1845-1863 [1849]: text to pl. 27). Synonymized within papuanus by Thomas (1888a:156). Subspecies rank recognized by Iredale and Troughton (1934:25), Tate (1945:9), Johnson (1964:450), Troughton (1967:83), Smith (1973:1), Strahan (1983:138; 1995:230), McKay (1988a:93), and subsequent authors.

Distribution. Northeastern Western Australian and northern Northern Territory including Bathurst Island, Melville Island, and Groote Eylandt, Australia (Flannery, 1994:80).

Petaurus (Belideus) arul Gervais, 1869:574.

TyPe LOCALITY. Incorrect subsequent spelling.

Comments. Not considered by Iredale and Troughton (1934:25), but synonymized within ariel by Smith (1973:1), McKay (1988a:93), Flannery (1990:146; 1994:80; 1995a:118; 1995b:207), and subsequent authors. Note Flannery (1990:146) recognizes "alba (Gervais, 1869)" as a synonym of breviceps; however, an assessment of this reference showed a reference to arul and other Petaurus but does not appear to include alba.

\section{Petaurus breviceps longicaudatus Longman, 1924}

Petaurus breviceps longicaudatus Longman, 1924:ix.

Type Locality. Mapoon Mission, Gulf of Carpentaria, north Queensland.

Comments. Not considered by Iredale and Troughton (1934:25), but the subspecies rank was recognized by Tate (1945:8), Troughton (1967:83), Smith (1973:1), Strahan (1983:138; 1995:230), McKay (1988a:93), and Flannery (1990:146; 1994:60) and was confirmed by Colgan and Flannery (1992:247) and followed by subsequent authors.

Distribution. Northern Queensland, Australia (Flannery, 1994:80). 


\section{Petaurus breviceps papuanus Thomas, 1888}

Petaurus breviceps var. papuanus Thomas, 1888a:158.

Type Locality. Huon Gulf, northeastern New Guinea.

Comments. Elevated to species rank by Matschie (1916:261), who also erected the subgenus Petaurella. Tate and Archbold (1935:1) also recognized the specific status within Petaurus. Subspecies recognized by Tate (1945:9), Laurie and Hill (1954:19), and Smith (1973:1). Again synonymized within breviceps by Groves (1993:61), but elevated to a subspecies of breviceps by Strahan (1983:138), Flannery (1990:146; 1994:60; 1995a:118; 1995b:207), and Groves (2005:55).

Distribution. Indonesia including Papua and surrounding islands including Numfoor Island, Japen (or Yapen) Island, Salawati Island, Misool Island, Adi Island, Kai Besar Island, Batjan Island, Gebe Island, Halmahera Island, and Ternate Island. Also occurs throughout Papua New Guinea and various surrounding islands including Bagabag Island, Bam Island, Blup Blup Island, Duke of York Island, Fergusson Island, Goodenough Island, Japen Island, Kadovar Island, Karkar Island, Koil Island, Misima Island, New Britain Island, Normandy Island, Tagula Island (also called Sudest Island), Vokeo Island, Wei Island, and Woodlark Island (Flannery, 1994:80; 1995a:117; 1995b:207).

Petaurus (Petaurella) papuensis tafa Tate and Archbold, 1935:1.

Type Locality. Eastern ridge, Mount Tafa, Central Division, Papua New Guinea. 2,000 m (6,562 ft).

Comments. Subspecies recognized by Tate (1945:10), Laurie and Hill (1954:19), Smith (1973:1), and Flannery (1990:146). Synonymized within breviceps by Groves (1993:61) and Flannery (1994:80; 1995a:118; 1995b:207) and within papuanus by Groves (2005:55).

Petaurus (Petaurella) papuensis flavidus Tate and Archbold, 1935:2.

Type Locality. Dogwa, Oriomo River, Western Division, Papua New Guinea. 30 m (98 ft).

Comments. Recognized at the subspecies rank by Tate (1945:9), Laurie and Hill (1954:19), Smith (1973:1), Strahan (1983:138), and Flannery (1990:146). Synonymized within breviceps by Groves (1993:61) and Flannery (1994:80; 1995a:118; 1995b:207) and within papuanus by Groves (2005:55).

\section{Petaurus gracilis (De Vis, 1883) (mahogany glider)}

Belideus gracilis De Vis, 1883:619.

Type Locality. "North of Cardwell," north Queensland, Australia.

Comments. History of description given by Van Dyck (1990:329; 1993:77). Synonymized within Petaurus norfolcensis (as P. sciureus) by Thomas (1888a:154). Elevated to subspecies of norfolcensis by Iredale and Troughton (1934:24), which was accepted by subsequent authors, including Tate (1945:8), Fleay (1947:111, 1954:210), Marlow (1965:75), Troughton (1967:84), Alexander (1981:64), Strahan (1983:140), and Colgan and Flannery (1992:245, 255). Synonymized within norfolcensis by McKay (1988a:93) and Van Dyck (1990:329), who said it should remain a junior synonym of norfolcensis and that caution should be exercised in applying subspecies status to animals outside the type locality near Mount Echo. With the exception of Van Dyck's observations these classifications were not based on inspections of specimens, and the species had not been recorded between 1886 and its rediscovery in December 1989. Upon its rediscovery and the assessment of new samples it was resurrected from synonymy with $P$. norfolcensis to species rank by Van Dyck (1991:295), with a formal reappraisal by Van Dyck (1993:84), who found gracilis and norfolcensis to be distinctly morphologically different. It was subsequently recognized as a species by all authors, including Flannery (1994:60, 84), Strahan (1995:232), Van Dyck and Strahan (2008:233), and Jackson (2011:141). Species rank was retained by Malekian et al. (2009:122, 130), although it was recognized that mitochondrial divergence with norfolcensis was less than within $P$. australis. This species is clearly distinct from norfolcensis in body length and mass (Van Dyck and Strahan, 2008:234, 236).

Distribution. Only known to occur between Ollera Creek (40 km [24.85 mi] south of Ingham) and the Hull River near Tully, a north-south distance of $122 \mathrm{~km}$ (76 mi), in north Queensland, Australia (Van Dyck and Strahan, 2008:234).

\section{Petaurus norfolcensis (Kerr, 1792) (squirrel glider)}

Sciurus (Petaurus) norfolcensis Kerr, 1792:270.

Type Locality. Sydney, New South Wales, Australia. Norfolk Island in error.

Comments. Type based on "Norfolk Island flying-squirrel” of Anonymous in Phillip (1789:151, pl. 
xvii). Fossil presently assigned to Petaurus norfolcensis described by Turnbull et al. (1987a:629) from Pliocene Hamilton Local Fauna, western Victoria, Australia, and from subfossils deposits from Pyramid Caves in eastern Victoria, Australia (Wakefield, 1972:8).

Distribution. East coast of Australia from central Cape York Peninsula to western Victoria and near Bordertown in extreme southeastern South Australia (Van Dyck and Strahan, 2008:235).

Sciurus novaehollandie Meyer, 1793 [part]:11.

Type Locality. New South Wales, Australia.

COMments. Synonymized within norfolcensis by Thomas (1888a:153) and Iredale and Troughton (1934:24) and noted by McKay (1988a:93) as a combined description; see part A under Petaurus australis australis Shaw, 1791. Also synonymized within norfolcensis by Flannery (1994:86).

Didelphis sciurea Shaw, 1794:29, pl. 11.

Type Locality. Sydney, New South Wales, Australia.

Comments. Recognized as a valid species within Didelphis by Shaw (1800:498) and within Petaurus by Waterhouse $(1841: 289 ; 1846: 331)$ and Gray (1843:83). Recognized at the species rank within Petaurus by Thomas (1888a:154), but synonymized within norfolcensis by Iredale and Troughton (1934:24), McKay (1988a:93), Flannery (1994:86), and subsequent authors.

Petaurus leucogaster Mitchell, 1838:xvii.

Type Locality. Banks of the Murray River, New South Wales?, Australia.

Comments. Nomen nudum. It was placed as a synonym of Petauroides volans by Iredale and Troughton (1934:29); however, this species does not occur near the Murray River. Therefore, it is most likely that it should be placed within Petaurus norfolcensis. Considered incertae sedis by McKay (1988a:97).

\section{Family Pseudocheiridae Winge, 1893}

Tribe Pseudochirini Winge, 1893:89.

Type Genus. Pseudocheirus Ogilby, 1837:457.

Comments. Family name not recognized by

Kirsch and Calaby (1977:16). Separated from Petauridae by Archer (1984:710, 719, 786); however, both groups combined within Petauridae by McKay (1988a:87) and Szalay (1994:43). Separate families recognized by Aplin and Archer (1987:xxii), Marshall et al. (1990:460),
Groves (1993:58, 60), Flannery (1994:60, 102), Kirsch et al. (1997:245), and Osborne and Christidis (2001:211), although they did question the separation of the families. Subsequent authors accepted the family, except McKenna and Bell (1997:65), who reduced it to a subfamily of the family Petauridae (see further comments under family Petauridae).

Family Phalangistae Lesson, 1842 [part]:188.

Type Genus. Phalanger Storr, 1780:33.

Comments. Also included members of the currently recognized Phalangeridae.

Family Petaurusideae Lesson, 1842 [part]:189.

Type Genus. Petaurus Shaw, 1791: pl. 60.

Comments. Family also included Petaurus (Petauridae), Acrobates (Acrobatidae) and Schoinobates (=Petauroides) of the family Pseudocheiridae.

Tribe Pseudochirini Winge, 1893:89.

Type Genus. Pseudocheirus Ogilby, 1837:457.

Comments. Tribe rank recognized by Szalay (1994:43) but not subsequent authors.

\section{Subfamily Hemibelideinae Kirsch et al., 1997}

Subfamily Hemibelideinae Kirsch et al., 1997:245.

Type Genus. Hemibelideus Collett, 1884:385.

Comments. Subfamily recognized by Groves (2005:50) but not by Van Dyck and Strahan (2008:10, 238).

\section{Petauroides Thomas, 1888}

Petauroides Thomas, 1888a:163.

Type Species. Didelphis volans Kerr, 1792:199.

Comments. Schoinobates (Lesson, 1842) was used in preference to Petauroides by Iredale and Troughton (1934:28), Simpson (1945:46), Tate (1945:11), and Ride (1970:80). The names Volucella and Petaurista were both preoccupied. The taxonomic decision of McKay (1988a:90) to use Petauroides was followed by subsequent authors with the exception of McKenna and Bell (1997:66), who used Schoinobates.

Voluccella Bechstein, 1800:351.

Type Species. Didelphis volans Kerr, 1792:199. Comments. Synonymized within Petauroides by Thomas (1888a:163) and McKay (1988a:89), and 
within Schoinobates by Iredale and Troughton (1934:28) and McKenna and Bell (1997:66).

Homonyms. Volucella, É. L. Geoffroy, 1762: 540 , hover flies of the class Insecta (order Diptera, family Syrphidae).

Voluccella Fabricius, 1794:55, dipterans of the class Insecta (order Diptera, family Syrphidae). Emendation of Volucella (E. L. Geoffroy, 1762:540).

Phalanger Lacépède, 1801:491.

Type SPecies. Didelphis volans Kerr, 1792: 199.

COMments. Genus is a junior homonym of Phalanger Storr, 1780:33.

Homonym. Phalanger Storr, 1780:33, cuscuses of the class Mammalia (order Diprotodontia, family Phalangeridae).

Petaurista Desmarest, 1820:268.

Type Species. Petaurus taguanoides Desmarest, 1818a:400.

Comments. Publication date established from Sherborn and Woodward (1906:580). Name preoccupied by Petaurista (Link, 1795:52, 78). Recognized as a subgenus of Petaurus by Waterhouse (1846:322) for taguanoïdes. Designation of $P$. taguanoides Desmarest, 1818 a as type species antedates that of Petaurus australis Shaw, 1791 by Iredale and Troughton (1934:29). Included as a synonym of Petauroides by Thomas (1888a:163) and Petaurus and Schoinobates and by Iredale and Troughton (1934:23, 29) and McKay (1988a:89).

Homonyms. Petaurista Link, 1795:52, 78, flying squirrels of the class Mammalia (order Rodentia, family Sciuridae).

Petaurista Meigen, 1800:15, flies of the class Insecta (order Diptera, family Trichoceridae). Suppressed by International Commission on Zoological Nomenclature (1963:339). Genus is a synonym of Trichocera (Meigen, 1803:262).

Petaurista Rafinesque, 1815:55, greater gliders of the class Mammalia (order Diprotodontia, family Pseudocheiridae). Name is a nomen nudum. Synonymized within Petauroides by Palmer (1904:526).

Petaurista Latreille, 1827:400, leaf beetles of the class Insecta (order Coleoptera, family Chrysomelidae). Genus is a synonym of Lema (Fabricius, 1798:4).

Petaurista Reichenbach, 1862:105, guenon monkeys of the class Mammalia (order Primates, family Cercopithecidae). Genus is a junior synonym of Cercopithecus (Linnaeus, 1758:26).
Schoinobates Iredale and Troughton, 1934:vii, 28.

Type Species. Didelphis volans Kerr, 1792: 199.

Comments. Iredale and Troughton (1934:viii, $28)$ give the author as Lesson (1842:190); however, they, like Palmer (1904:886), were wrong in assuming that the name Schoinobates initially referred to a marsupial (though the name was mistakenly placed with other marsupials). Schoinobates was applied by Lesson (1842), as Petaurus (Schoinobates) leucogenys, which is now known as Japanese giant flying squirrel Petaurista leucogenys (Temminck, 1827:xxvii). Schoinobates is therefore a junior subjective synonym of Petaurista (Link, 1795) (McKay, 1982:38). Schoinobates has commonly been used in preference to Petauroides by authors, including Simpson (1945:46), Tate (1945:11), Troughton (1967:87), Ride (1970:80), Kirsch and Calaby (1977:16), Marshall (1981:28), Honacki et al. (1982:41), and McKenna and Bell (1997:66).

Homonyms. Schoinobates Lesson, 1842:190, flying squirrels of the class Mammalia (order Rodentia, family Sciuridae). Name is a synonym of Petaurista (Link, 1795:78).

Petaurides Ramsay, 1890a:77.

Type Species. Petaurides cinereus Ramsay, 1890a:77.

Comments. Incorrect subsequent spelling of Petauroides Thomas, 1888a.

\section{†Petauroides ayamaruensis Aplin, 1999}

†Petauroides ayamaruensis Aplin, 1999:365, fig. 13.

Type Locality. Kria Cave, Bird's Head Peninsula, Papua (western New Guinea), Indonesia.

Comments. Holocene. This is an extremely distinctive pseudocheirid, which was assigned to Petauroides with considerable reservation (Aplin, 1999:365). Species recognized within Petauroides by Long et al. (2002:130), but more recent specimens suggest this taxon is not a glider (K. P. Aplin [formerly of CSIRO, Canberra], personal communication).

\section{†Petauroides marshalli (Turnbull and Lundelius, 1970)}

†Pseudocheirus marshalli Turnbull and Lundelius, 1970:40.

Type Locality. Hamilton Local Fauna, Grange Burn, western Victoria, Australia. 
Comments. Early Pliocene. Doubt exists as to the correct generic placement of this species, as it was originally assigned to Pseudocheirus by Turnbull and Lundelius (1970:40), with the placement of this species in Petauroides further challenged by Turnbull et al. (1987b:699), who suggested it should not be placed in this genus because of the absence of any evidence of gliding. Despite these reservations this taxon was placed within Petauroides by Long et al. (2002:130) but returned to Pseudocheirus by Crosby et al. (2004:167), who noted that it possibly should be placed within Petauroides.

\section{†Petauroides stirtoni (Turnbull and Lundelius, 1970)}

†Psendocheirus stirtoni Turnbull and Lundelius, 1970:34.

Type Locality. Hamilton Local Fauna, Grange Burn, western Victoria, Australia.

Comments. Early Pliocene. Although previously assigned to Pseudocheirus, it appears to be more closely allied to Petauroides and was placed in Petauroides by Archer (1984:714). This assertion has, however, been challenged by Turnbull et al. (1987b:699), who suggested that it should not be placed in this genus because of the absence of any evidence that stirtoni was specialized for gliding. Species recognized within Petauroides by Long et al. (2002:130) but returned to Pseudocheirus by Crosby et al. (2004:167), who noted that it possibly should be placed within Petauroides.

\section{Petauroides volans (Kerr, 1792) (greater glider)}

\section{Petauroides volans volans (Kerr, 1792)}

Didelphis volans Kerr, 1792:199.

Type Locality. Sydney, New South Wales, Australia. Type species based on "black flying opossum" of Anonymous in Philip (1789:297). Confused in the early years with Petaurus australis (Shaw, 1791) (see McKay, 1982:38).

Comments. Between Desmarest (1818a:400) and Thomas (1879:397), the name Didelphis volans was either synonymized or ignored (McKay, 1982:38). Early taxonomic history reviewed by Thomas (1888a:164). Thomas (1879:397) revived this taxon along with other names first used by Kerr. Included within Schoinobates by Iredale and Troughton (1934:29) and Ride (1970:80). Transferred to Petauroides by Thomas (1888a:164), Strahan (1983:134), McKay (1988a:90), and subsequent authors. Fossils assigned to this species have been collected from Pleistocene deposits in the Naracoorte Caves, South Australia, Australia (Reed and Bourne, 2000:67) and from subfossils deposits from Pyramid Caves in eastern Victoria, Australia (Wakefield, 1972:8).

Distribution. Eastern Australia from central eastern Queensland south to central Victoria (Flannery, 1994:148).

[Didelphis] voluccella Meyer, 1793:26.

Type Locality. New South Wales, Australia. Comments. Synonymized within volans by Thomas (1888a:164), Iredale and Troughton (1934:29), McKay (1988a:90), Flannery (1994:148), and subsequent authors.

Didelphis macroura Shaw, 1794:33, pl. 12.

Type Locality. New South Wales, Australia.

Comments. Recognized by Shaw (1800:500). Considered to be the young of Petaurus australis by Waterhouse (1841:288; 1846:330). Synonymized within volans by Thomas (1888a:164), Iredale and Troughton (1934:29), McKay (1988a:90), Flannery (1994:148), and subsequent authors.

Voluccella nigra Bechstein, 1800 [part]:351.

Type Locality. Botany Bay, New South Wales, Australia. Type species based on "black flying opossum" of Anonymous in Philip (1789:297) and "Hepoona Roo" of Hunter in White (1790:188).

Comments. Synonymized within volans by Thomas (1888a:164), Iredale and Troughton (1934:29), McKay (1988a:90), Flannery (1994:148), and subsequent authors.

Phalanger petaurista É. Geoffroy Saint-Hilaire, 1803a:150. Type Locality. Australia.

Comments. Synonymized within volans by Thomas (1888a:164).

P.[etaurus] niger Oken, 1816:1119.

Type Locality. Australia.

Comments. Synonymized within volans by Iredale and Troughton (1934:29).

Petaurus taguanoïdes Desmarest, 1818a:400.

Type Locality. Sydney, New South Wales, Australia. Type designation by de Beaufort (1966:534).

Comments. Recognized as a valid species by Waterhouse (1841:283), Gray (1843:84), and Gould 
(1845-1863 [1853]: text to pl. 22). Synonymized within volans by Thomas (1879:397), Thomas (1888a:164), Iredale and Troughton (1934:29), McKay (1988a:90), Flannery (1994:148), and subsequent authors.

Petaurus Peronii Desmarest, 1818a:404.

Type Locality. Sydney, New South Wales, Australia. Type designation by de Beaufort (1966:534).

Comments. Recognized as a valid species by Waterhouse (1841:284). Synonymized within taguanoides by Waterhouse (1846:322) and within volans by Thomas (1888a:164), Iredale and Troughton (1934:29), McKay (1988a:90), Flannery (1994:148), and subsequent authors.

[Petaurus] didelphoides F. Cuvier, 1825b:129.

Type LocAlity. Australia.

Comments. Synonymized within volans by Thomas (1888a:164), Iredale and Troughton (1934:29), McKay (1988a:90), Flannery (1994:148), and subsequent authors. Note the author of this taxon has been confused with Thomas (1888:164) and Iredale and Troughton (1934:29), giving the author as F. Cuvier, whereas McKay (1988:90) and Groves (2005:51) attribute the author to G. Cuvier. The confusion appears to have arisen because the title page indicates that the publication of F. Cuvier is based on the cabinet of anatomy formed by G. Cuvier.

P.[etaurus] maximus Partington, 1837:424.

Type Locality. Australia.

Comments. Synonymized within volans by Iredale and Troughton (1934:29), McKay (1988a:90), Flannery (1994:148), and subsequent authors.

Petauroides volans armillatus Thomas, 1923a:248.

Type Locality. Coomooboolaroo Station, $128 \mathrm{~km}(80 \mathrm{mi})$ southwest of Rockhampton, central Queensland, Australia.

Comments. Subspecies rank recognized by Troughton (1967:90) but synonymized within minor by Iredale and Troughton (1934:30), McKay (1988a:91), Flannery (1994:148), and subsequent authors. Recently, K. P. Aplin (pers. comm.) recognized its distinctiveness, both morphologically and genetically, as being distinct from $P$. volans, so it is likely this taxon will be elevated in rank.

Petaurus volans incanus Thomas, 1923a:247.

Type Locality. Eidsvold, near Mundubbera,

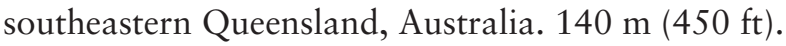

Comments. Subspecies status recognized by Iredale and Troughton (1934:29) and Troughton (1967:90) but synonymized within volans by McKay (1988a:90), Flannery (1994:148), and subsequent authors until Aplin (pers. comm.) recognized its distinctiveness, both morphologically and genetically, as being distinct from P. volans volans, so it is likely this taxon will be elevated in rank.

\section{Petauroides volans minor (Collett, 1887)}

Petaurista volans var. minor Collett, 1887:926.

TYPe LocAlity. Herbert Vale, Queensland, Australia.

Comments. Taxon not recognized as a subspecies by Maxwell et al. (1996:9). Subspecies status recognized by Thomas (1888a:166), Iredale and Troughton (1934:30), Troughton (1967:91), Strahan (1983:134; 1995:240), McKay (1988a:91), Groves (1993:53; 2005:51), Flannery (1994:103), Clayton et al. (2006:104), and Van Dyck and Strahan (2008:241). Recently, Aplin (pers. comm.) recognized its distinctiveness, both morphologically and genetically, as being distinct from P. volans, so it is likely to be elevated to species rank in the future.

Distribution. Central eastern Queensland to northern Queensland (Flannery, 1994:148).

Petaurides cinereus Ramsay, 1890a:77.

Type Locality. Bellenden-Ker Range, northeast Queensland, Australia.

Comments. In the same year this species was also exhibited by Ramsay (1890b:1030), who suggested that "the Belideus will be described under the name of B. cinereus." Synonymized within minor by Iredale and Troughton (1934:30), McKay (1988a:91), Flannery (1994:148), and subsequent authors.

\section{SUPERFAMILY TARSIPEDOIDEA Gervais and Verreaux, 1842}

Family Tarsipedidae Gervais and Verreaux, 1842:1.

Type Species. Tarsipes rostratus Gervais and Verreaux, 1842:1.

Comments. Superfamily rank recognized by Kirsch (1968:420), who included only the family Tarsipedidae. Synonymized within Tarsipedidae by McKenna and Bell (1997:59). Superfamily not recognized by Strahan (1983:xxi), who included Acrobates within the family Burramyidae in the superfamily Phalangeroidea; however, Aplin and Archer (1987:xxii) introduced the family Acrobatidae and included it within the superfamily Tarsipedoidea. This arrangement was followed by Kear and Cooke (2001:84), Long et al. (2002:143), and Crosby 
et al. (2004:171). Rank not recognized by either Groves (2005:vii, 55) or Van Dyck and Strahan (2008:10), who both placed the families Tarsipedidae and Acrobatidae within the superfamily Petauroidea.

\section{Family Acrobatidae Aplin, 1987}

Family Acrobatidae Aplin, 1987:xxii, lvii.

Type Genus. Acrobates Desmarest, 1818a:405.

Comments. Separated from Burramyidae by Aplin (in Aplin and Archer, 1987:xxii) and supported by Strahan (1987:113), Baverstock et al. (1990:273), Marshall et al. (1990:460), and subsequent authors.

Tribe Acrobatini Szalay, 1994:43.

Type Genus. Acrobates Desmarest, 1818a:405.

Comments. Szalay (1994:43) recognizes Aplin (in Aplin and Archer, 1987:xxii) as the author. Synonymized within Acrobatidae by McKenna and Bell (1997:67).

\section{Acrobates Desmarest, 1818}

Acrobates Desmarest, 1818a:405.

Type SPeCIEs. Didelphis pygmaea Shaw, 1794:5.

Comments. Recognized as the subgenus Acrobata within Petaurus by Waterhouse (1841:293; 1846:337). Genus rank recognized by Gray (1841:402; 1843:xxii, 83), Gould (1845-1863 [1849]: text to pl. 28), Krefft (1871:3), and Thomas (1888a:136).

Homonyms. Acrobates Bonaparte, 1850:284, scrub robins or bush chats of the class Aves (order Passériformes, family Muscicapidae). Appears to be an incorrect subsequent spelling of Agrobates (Swainson, 1837:63, 241) or Agrabates (Swainson, 1837:63, 64). These appear to be synonyms of Cercotrichas (F. Boie, 1831:542).

Opossum Perry, 1810 (1810-1811): text to pl. 32.

TYPE SPECIES. Opossum opossum Perry, 1810 (1810-1811).

COMMENTS. Plates unnumbered in original work but were numbered by Matthews and Iredale (1912:14) and Petit (2009:13). Genus not recognized by subsequent authors.

Homonym. Opossum opossum Perry, 1810 (1810-1811): text to pl. 21, wombat of class Mammalia, genus Vombatus É. Geoffroy Saint-Hilaire, 1803b:185.

Acrobata Desmarest, 1820:270.

Type Species. In error for Acrobates Desmarest, 1818a:405.
Comments. Does not appear to have been previously recognized. Included here as a synonym.

Ascobates Anonymous, 1839:454.

Type Species. In error for Acrobates Desmarest, 1818a:405.

COMments. Synonymized within Acrobates by Iredale and Troughton (1934:21) and McKay (1988b:98).

Cercoptenus Gloger, 1841:xxx, 85.

Type Species. Didelphis pygmaea Shaw, 1794:5.

Comments. Publication date established from Thomas (1895b:189). Synonymized within Acrobates by Thomas (1888a:136; 1895b:190), Iredale and Troughton (1934:22), Marshall (1981:28), and McKay (1988b:98).

\section{Acrobates pygmaeus (Shaw, 1794) (feathertail glider)}

Didelphis pygmaea Shaw, 1794:5, pl. 2.

Type Locality. Sydney, New South Wales, Australia. Type designated by Thomas (1922a:128).

Comments. Transferred to genus Acrobates by Desmarest (1818a:405), but placed within Petaurus (Acrobata) by Waterhouse (1841:293; 1846:339). Transferred to Acrobates by Desmarest (1818a:405), Gray (1841:402; 1843:83), Gould (1845-1863[1849]: text to pl. 28), Krefft (1871:3), and Thomas (1888a:136), who described the taxonomic history. Tate $(1938: 60)$ believed the single specimen (of A.pulchellus, which is considered a synonym of pygmaeus) obtained in NW New Guinea was probably an introduction as a pet. Included within Burramyidae by Kirsch and Calaby (1977:16) and McKay (1988b:99). Fossils tentatively identified as Acrobates pygmaeus have been collected from Pleistocene deposits in the Naracoorte Caves, South Australia, and subfossil deposits have been collected from Pyramid Caves in eastern Victoria, Australia (Wakefield, 1972:8; Reed and Bourne, 2000:67).

Distribution. Eastern mainland Australia, from Cape York Peninsula to southeastern South Australia (Flannery, 1994:40).

Opossum opossum Perry, 1810 (1810-1811): text to pl. 32.

Type Locality. New Holland.

COMMENTS. Plates unnumbered in original work but were numbered by Matthews and Iredale (1912:14) and Petit (2009:13). Species not recognized by subsequent authors. 
Dromicia frontalis De Vis, 1887:1134.

Type Locality. Herbert district, north Queensland, Australia.

Comments. Considered a subspecies of $p y g$ maeus by Iredale and Troughton (1934:22), but synonymized within pygmaeus by Thomas (1888a:137), McKay (1988b:99), Flannery (1994:40), and subsequent authors until it was recognized as being both morphologically and genetically distinct by Aplin (unpublished), so it is likely this taxon will be elevated in rank.

Acrobates pulchellus Rothschild, 1892:546.

TyPe LOCALITY. Unknown island north of Dutch New Guinea. This is almost certainly incorrect as this species has never been recorded outside eastern Australia.

Comments. Tate (1938:60) believed the single specimen obtained in NW New Guinea was probably an introduction as a pet from Australia. Taxon synonymized within pygmaeus by Thomas (1888a:137) and subsequent authors. The possibility of this species occurring in New Guinea was explored by Helgen (2003:107), who examined several specimens from Stockholm, of which one was collected in 1899-1900 and received from a dealer with the only information being "Nya Guinee." Helgen (2003:108) suggests that both specimens (from London and Stockholm) are left open to doubt because of the imprecise locality data but lent some credibility by their appearance.

\section{Subclass Placentalia Owen, 1837}

Placentalia Owen, 1837:903.

Comments. Rank not specified by Owen. Synonymized within Eutheria Gill, 1872 by Simpson (1945:47) and within Monodelphia by Gregory (1947:46). Recognized without rank by Bonaparte (1838:108), at subclass by Gill $(1872: v, 1)$ and Iredale and Troughton (1934:ix, 55), and at cohort rank by McKenna and Bell (1997:80) in preference to Eutheria. McKenna and Bell (1997:80) suggested there was confusion over the use of Eutheria because of its different use by Gill (1872:v) and Huxley (1880:657).

Unguiculata Linnaeus, 1766:21.

Comments. Synonymized within Placentalia by McKenna and Bell (1997:80).

Subclass Monodelphia de Blainville, 1816:117.

Comments. Synonymized within Eutheria by Simpson (1945:47) and within Placentalia by McKenna and Bell (1997:80), but recognized by Gregory (1947:46) at subclass rank.
Placentaria Fleming, 1822:169.

Comments. Rank not specified. Synonymized within Eutheria by Simpson (1945:47) and within Placentalia by McKenna and Bell (1997:80).

Monodelphia Gill, 1871:527.

Comments. Rank not specified. Synonymized within Placentalia by McKenna and Bell (1997:49, 80).

Subclass Eutheria Gill, 1872:v.

Comments. Written as "Sub-Class (Eutheria) Placentalia s. Monodelphia" in the contents page referring to p. 1 and as Placentalia on p. 1. Recognized as an infraclass by Simpson $(1931: 262 ; 1945: 47)$, infracohort by Gardiner (1982:229), supercohort by McKenna (1975:27), and supercohort or infraclass by Shoshani (1992:108). Synonymized within Placentalia by McKenna and Bell (1997:80). Subclass rank recognized by various authors, including Osborn (1910:515), who included the Marsupialia and Placentalia, Strahan (1983:xxi, 269; 2005:8, 412), and Van Dyck and Strahan (2008:10, 415).

Eutheria Huxley, 1880:657.

Comments. Not Eutheria of Gill, 1872. Synonymized within Placentalia by McKenna and Bell (1997:80).

Theria Parker and Haswell, 1897 [part]:448.

Comments. Used at subclass rank by Simpson (1945:40). Name is equivalent to Theria of Gill, 1872, but not Eutheria of Huxley and most other authors. Aplin and Archer (1987:xxi) included Theria at the rank of subclass. Recognized at the new rank of supercohort by McKenna and Bell (1997:49).

Cohort Ferungulata Simpson, 1945 [part]:105.

Comments. Synonymized within Placentalia by McKenna and Bell (1997:80).

Cohort Placentata Turnbull, 1971:176.

Comments. Synonymized within Placentalia by McKenna and Bell (1997:80).

\section{Order Dermoptera lluiger, 1811}

Family Dermoptera Illiger, 1811a:116.

Comments. Placed at subordinal rank within the order Insectivora by Dobson (1883:2) and within the order Primates by McKenna and Bell (1997:326), but recognized at ordinal rank by most authors, including Simpson (1945:53), Wilson (1993:135), Stafford and 
Szalay (2000:360), and Stafford (2005:110). A recent examination of paromomyid and micromomyid skeletons indicates that these mammals were incapable of mittengliding locomotion, were not specialized for quadrupedal suspensory behavior, and did not use sciurid-like gliding locomotion (Bloch et al., 2007; Boyer and Bloch, 2008:270). Therefore, the taxonomy followed here consists of that used by McKenna and Bell (1997:326) with the family Paromomyidae removed to reflect these recent studies. The ability of the different families and genera of extinct taxa to glide is poorly known, so it is likely that many species will be revealed as nongliders in the future as specimens with postcranial remains are discovered.

Order Pterophorae Gray, 1821:300.

Comments. Synonymized within Dermoptera by McKenna and Bell (1997:326).

Race Pleuronycterates Burnett, 1829:268.

Comments. Not subsequently recognized.

Order Ptenopleura Van der Hoeven, 1855:783.

Comments. Also recognized by Van der Hoeven (1858:742), which was recognized as the year of publication by McKenna and Bell (1997:326), who synonymized it within Dermoptera.

Galeopitheci Peters, 1864:20.

Comments. Synonymized within Dermoptera by McKenna and Bell (1997:326).

Galeopithecida Haeckel, 1895:593.

Comments. No rank. Synonymized within Dermoptera by McKenna and Bell (1997:326).

†Suborder Proglires Osborn, 1902:203.

Comments. Synonymized within Dermoptera by McKenna and Bell (1997:326).

Order Galeopithecia Cabrera, 1925:201.

Comments. Synonymized within Dermoptera by McKenna and Bell (1997:326).

Order Galeopithecoidea Wilder, 1926:12, 15.

Comments. Synonymized within Dermoptera by McKenna and Bell (1997:326).

Infraorder Eudermoptera Beard, 1993a:129, 145.

Comments. Synonymized within Dermoptera by McKenna and Bell (1997:326).
Order Dermopteriformes Kinman, 1994:37.

Comments. Synonymized within Dermoptera by McKenna and Bell (1997:326).

\section{†FAMILY INDETERMINATE}

\section{†Subfamily Thylacaelurinae Van Valen, 1967}

†Subfamily Thylacaelurinae Van Valen, 1967:271.

Type Genus. †Thylacaelurus Russell, 1954:96.

Comments. Late Paleocene?, middle to late Eocene, North America. The placement of this subfamily remains uncertain as it was originally placed in the ffamily Plagiomenidae by Van Valen (1967:277) and Bown and Rose (1979:102), with uncertainty, whereas McKenna and Bell (1997:326) did not include it within a specific family but placed it directly within the suborder Dermoptera, which is followed here.

\section{†Thylacaelurus Russell, 1954}

†Thylacaelurus Russell, 1954:96.

Type Species. †Thylacaelurus montanus Russell, 1954:96.

Comments. Middle to late Eocene, North America.

\section{†Thylacaelurus campester Storer, 1984}

†Thylacaelurus campester Storer, 1984:30.

Type Locality. Swift Current Creek, Saskatchewan, Canada.

Comments. Eocene.

\section{†Thylacaelurus montanus Russell, 1954}

†Thylacaelurus montanus Russell, 1954:96.

Type Locality. Kishenehn Formation, SE British Columbia, Canada.

Comments. Middle to late Eocene. This was originally described as a didelphid marsupial by Russell (1954:96).

\section{Family Cynocephalidae Simpson, 1945}

Family Cynocephalidae Simpson, 1945:54.

Type Genus. Cynocephalus Boddaert, 1768:8.

Comments. The author of the family is not Ameghino (1889:893), as his family group name Cynocephalidae was based on Cynocephalus É. Geoffroy and G. Cuvier (1795:462), which is a junior synonym of Papio 
(Erxleben, 1777:xxx, 15). As Cynocephalus É. Geoffroy and G. Cuvier (1795:462) is a junior homonym of Cynocephalus (Boddaert, 1768), the family name of Ameghino (1889:893) is invalid under Article 39 of the International Code of Zoological Nomenclature (International Commission on Zoological Nomenclature, 1999:46). Also, as the family Cynocephalidae Simpson, 1945, was in common usage before 1961, it should not be replaced according to Article 40.2 of the International Code of Zoological Nomenclature (International Commission on Zoological Nomenclature, 1999:46). Name synonymized within Galeopithecidae by McKenna and Bell (1997:328) but recognized by Stafford (2005:110) and most recent authors.

Homonyms. Family Cynocephalidae Ameghino, 1889:893, baboons of the class Mammalia (order Primates, family Cercopithecidae). Family name is a junior synonym of the family Cercopithecidae (Gray, 1821:297). See McKenna and Bell (1997:328) and Groves (2001:237) for discussion.

Family Galeopithecidae Gray, 1821:300.

Type Genus. Galeopithecus Pallas, 1780:208.

Comments. The type genus is a junior objective synonym of Cynocephalus Boddaert, 1768. The generic name Galeopithecus Pallas, 1780, is an available name but is not the valid name for Cynocephalus Boddaert, 1768 because of objective synonymy (see Melville, 1977:182, Opinion 1077). Family rank recognized by various authors, including Murray (1866:vii), Rose (1973:1), and Ducrocq et al. (1992:373). Rank recognized by Beard (1993a:145) and McKenna and Bell (1997:328) but synonymized within the family Cynocephalidae by Wilson (1993:135), Stafford and Szalay (2000:380), and Stafford (2005:110).

Kind Pleuropteridae Burnett, 1829:268.

Type Genus. Pleuropterus Burnett, 1829:268.

Comments. Synonymized within family Galeopithecidae by McKenna and Bell (1997:328).

Galeopithecina Bonaparte, 1838:111.

Type Genus. Galeopithecus Pallas, 1780:208.

Comments. Synonymized within the family Galeopithecidae by McKenna and Bell (1997:328).

Family Ptenopleura Haeckel, 1866:clix.

Type Genus. Galeopithecus Pallas, 1780:208.

Comments. Recognized at ordinal rank by Van der Hoeven (1852-1856:x, 783), but synonymized within the family Galeopithecidae by McKenna and Bell (1997:328).
Family Colugidae Miller, 1906a:41.

Type Genus. Colugo Gray, 1871:98.

Comments. Synonymized within the family Cynocephalidae by Wilson (1993:135) and Stafford (2005:110).

Family Galeopteridae Thomas, 1908a:254.

Type Genus. Galeopterus Thomas, 1908a:254.

Comments. Family rank recognized by Shufeldt (1911:185) and Harrison and Traub (1950:339). Synonymized within the family Cynocephalidae by Ellerman and Morrison-Scott (1955:5), Wilson (1993:135), and Stafford (2005:110).

Superfamily Galeopithecoidea Russell et al., 1973:42.

Type Genus. Galeopithecus Pallas, 1780:208.

Comments. Synonymized within the family

Galeopithecidae by McKenna and Bell (1997:328).

\section{Cynocephalus Boddaert, 1768}

Cynocephalus Boddaert, 1768:8.

Type Species. Lemur volans Linnaeus, 1758:30.

Comments. An application was made to the International Commission of Zoological Nomenclature to suppress Cynocephalus in favor of Galeopithecus in 1977; however, this was refused, and Galeopithecus was placed on the Official Index of Rejected and Invalid Generic Names in Zoology (Melville, 1977:182). All colugos were placed in Cynocephalus by Simpson (1945:54), Wilson (1993:135), and most authors until the genus Galeopterus Thomas, 1908, was resurrected for the species variegatus (Audebert, 1799) by Stafford and Szalay (2000:360).

Homonyms. Cynocephalus É. Geoffroy SaintHilaire and G. Cuvier, 1795:462, baboons of the class Mammalia (order Primates, family Cercopithecidae). Genus is a junior synonym of Papio (Erxleben, 1777:xxx, 15).

Galeopithecus Pallas, 1780:208, pls. vii, viii.

Type SPecies. Lemur volans Linnaeus, 1758:30.

Comments. Synonymized within Cynocephalus by Miller (1906a:41), Thomas (1908a:252), and subsequent authors, including Ellerman and Morrison-Scott (1951:89; 1955:5), Corbet and Hill (1992:53), Wilson (1993:135), and Stafford (2005:110). Opinion 1077 (Melville, 1977:182) identified Galeopithecus (Pallas, 1780) as a junior objective synonym of Cynocephalus (Boddaert, 1768). 
Galeopus Rafinesque, 1815:54.

Type Species. New name for Galeopithecus Pallas, 1780:208.

Comments. Synonymized within Cynocephalus by Corbet and Hill (1992:53), Wilson (1993:135), and Stafford (2005:110).

Dermopterus Burnett, 1829:268.

TyPe SPecies. Lemur volans Linnaeus, 1758:30.

Comments. Replacement name for Galeopithecus. Synonymized within Cynocephalus by Corbet and Hill (1992:53), Wilson (1993:135), and Stafford (2005:110).

Pleuropterus Burnett, 1829:268.

Type Species. Lemurvolans Linnaeus, 1758:30.

Comments. Replacement name for Galeopithecus. Synonymized within Cynocephalus by Corbet and Hill (1992:53), Wilson (1993:135), and Stafford (2005:110).

Galeolemur Lesson, 1840:261.

Type Species. Galeolemur macrourus Temminck, 1836:ix.

Comments. Synonymized within Cynocephalus by Ellerman and Morrison-Scott (1951:89), Wilson (1993:135), and Stafford (2005:110).

Colugo Gray, 1871:98.

Type Species. Described as a subgenus of $G a$ leopithecus Pallas, 1780:208.

Comments. Genus recognized by Miller (1906a:41). Synonymized within Cynocephalus by Corbet and Hill (1992:53), Wilson (1993:135), and Stafford (2005:110).

\section{Cynocephalus volans (Linnaeus, 1758) (Philippine colugo)}

[Lemur] volans Linnaeus, 1758:30.

Type Locality. Pampanga Province, Southern Luzon, Philippines.

Comments. Transferred to Cynocephalus by Thomas (1908a:253).

Distribution. Southern Philippines, including Basilan, Biliran, Bohol, Dinagat, Leyte, Maripipi, Mindanao, Samar, Siargao, and Tongquil islands (Heaney and Rabor, 1982:18; Corbet and Hill, 1992:54; Rickart et al., 1993:22; Heaney et al., 1998:132).
[Galeopithecus] philippinensis Waterhouse, 1839b:119.

Type Locality. Type locality not mentioned in description.

Comments. Synonymized within volans by Corbet and Hill (1992:54), Wilson (1993:135), and subsequent authors.

\section{Galeopterus Thomas, 1908}

Galeopterus Thomas, 1908a:254.

Type Species. Galeopithecus temminckii Waterhouse, 1839b:119.

Comments. Genus rank recognized by Chasen (1940:20) but synonymized within Cynocephalus by Simpson (1945:54), Ellerman and Morrison-Scott (1955:5), Corbet and Hill (1992:53), Wilson (1993:135), and McKenna and Bell (1997:328). Subgenus rank recognized by Ellerman and Morrison-Scott (1951:89; 1955:5). Recognized as a valid genus for variegatus by Stafford and Szalay (2000:360) and followed by Stafford (2005:110), Marivaux et al. (2006:395), and Janečka et al. (2007:793; 2008:R1001) but not by Lim (2007:15).

\section{Galeopterus variegatus (Audebert, 1799) (Malayan colugo)}

\section{Galeopterus variegatus variegatus (Audebert, 1799)}

\section{Galeopithecus variegatus Audebert, 1799:37, pl. 2. \\ Type Locality. Java.}

Comments. Placed in Galeopterus by Stafford and Szalay (2000:360) and followed by subsequent authors, including Stafford (2005:110), but not by Lim (2007:15), who placed variegatus within Cynocephalus. Stafford and Szalay (2000:360) recognize as subspecies variegatus, temminckii, borneanus, and peninsulae and suggest that it may be necessary to eventually designate separate subspecies for each of the dwarfed populations and other morphological variants from now-isolated islands, and they note the recent discovery of a dwarfed (unnamed) form from Laos. More recent research suggests that the diversity of the animals from mainland Southeast Asia, Java, and Borneo should be recognized as distinct species (Janečka et al., 2008:R1001).

Distribution. Java (Corbett and Hill, 1992:54).

Galeopithecus rufus Audebert, 1799:35, pl. 1.

Type Locality. Pelew (Palau) Island? 
Comments. The type location of this taxon is treated with considerable skepticism as it appears likely that colugos do not occur on the island. Instead, the apparent error may have resulted from islands throughout Indonesia generally being referred to as "pulau." Recognized as a synonym of Cynocephalus volans by Corbet and Hill (1992:54), and as a synonym of Cynocephalus volans by Wilson (1993:135), and as a synonym of variegatus by Stafford (2005:110). The author of this taxon has invariably been given as Desmarest (1820:108); however, the correct author appears to be Audebert (1799:35). Stafford (2005:110) suggests the description and plate of Desmarest $(1820: 108)$ is closer to variegatus than volans. The type locality of this taxon needs to be confirmed.

Galeopterus varius Desmarest, 1818b:376.

Type Locality. Java.

Comments. Dated 1817 but may not have been published until 1818. Derived from Galeopithecus variegatus of Audebert (1799:37). Synonymized within variegatus by Wilson (1993:135) and Stafford (2005:110).

Galeopithecus [sic] ternatensis Desmarest, 1820:108.

TYPE Locality. Ternate, probably in error.

Comments. Synonymized within volans by Corbet and Hill (1992:54) and within variegatus by Wilson (1993:135) and Stafford (2005:110). Stafford (2005:110) suggests the description and plate of Desmarest $(1820: 108)$ is closer to this species.

Galeopithecus macrourus Temminck, 1836:ix.

Type Locality. "Je présume, que l'espece vit à Ceylan" [translated as "I presume the species lives in Ceylon"]. Location of Ceylon is in error.

Comments. Name and type locality discussed by Mees (1957:215).

G.[aleopithecus] undatus Wagner, 1839:326.

TyPe Locality. Java?

COMMENTs. Incorrectly synonymized within volans by Wilson (1993:135). Synonymized within variegatus by Corbet and Hill (1992:53) and Stafford (2005:110).

\section{Galeopterus variegatus borneanus Lyon, 1911}

Galeopterus borneanus Lyon, 1911:124.

Type Locality. Tjantung, southeast Borneo.

Comments. Synonymized within natunae by Medway $(1965: 45 ; 1977: 28)$ and variegatus by Davis (1958:122), Corbet and Hill (1992:53), Wilson
(1993:135), and Stafford (2005:110). Recognized as a valid subspecies by Chasen and Kloss (1929a:18; 1932:46) and Stafford and Szalay (2000:360).

Distribution. Borneo and surrounding islands, including the Natuna Islands (Bunguran, Laut, $\mathrm{Na-}$ tuna, Serasan (Sirhassen), and Subi islands) off the west coast; Balambangan and Banggi off northern Borneo; Sebuku Island and Laut Island off southeastern Borneo; and Panebangan, Pelapis, and Karimata Islands off southwestern Borneo. On Borneo they are found from lowlands up

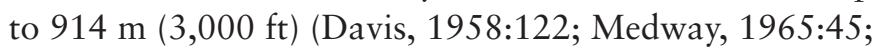
Stafford and Szalay, 2000:360; Meijaard, 2003:1256).

Galeopithecus gracilis Miller, 1903a:49.

Type Locality. Serasan Island (Sirhassen), Natuna Islands, Indonesia.

Comments. Recognized as a subspecies of variegatus by Chasen (1940:21). Synonymized within variegatus by Corbet and Hill (1992:53), Wilson (1993:135), and Stafford (2005:110).

Galeopithecus natunae Miller, 1903a:50.

Type Locality. Bunguran Island, Natuna Islands, Indonesia.

Comments. Subspecies rank recognized by Chasen and Kloss (1929a:17), Chasen (1940:21), and Medway (1965:45; 1977:28). Synonymized within variegatus by Corbet and Hill (1992:53), Wilson (1993:135), and Stafford (2005:110).

Galeopterus lautensis Lyon, 1911:125.

Type Locality. Laut Island, off southeastern Borneo, Indonesia.

Comments. Recognized as a subspecies of variegatus by Chasen (1940:21) and Medway (1965:45; 1977:29). Synonymized within variegatus by Corbet and Hill (1992:53), Wilson (1993:135), and Stafford (2005:110).

Galeopterus abbotti Lyon, 1911:126.

Type Locality. Panebangan Island, off southwestern Borneo, Indonesia.

Comments. Recognized as a subspecies of variegatus by Chasen $(1935: 7$; 1940:21) and Medway (1965:45; 1977:29). Synonymized within variegatus by Corbet and Hill (1992:53), Wilson (1993:135), and Stafford $(2005: 110)$.

Galeopterus lechei Gyldenstolpe, 1920:17.

Type Locality. Toembang, Maroewe, eastern Borneo, Indonesia. 
Comments. Synonymized within natunae by Medway $(1965: 45 ; 1977: 28)$ and variegatus by Corbet and Hill (1992:53), Wilson (1993:135), and Stafford (2005:110).

Galeopithecus hantu Cabrera, 1924:128.

Type Locality. North Sarawak, Borneo, Malaysia.

Comments. Synonymized within natunae by Medway $(1965: 45 ; 1977: 28)$ and variegatus by Corbet and Hill (1992:53), Wilson (1993:135), and Stafford (2005:110).

\section{Galeopterus variegatus peninsulae Thomas, 1908}

Galeopterus peninsulae Thomas, 1908c:303.

Type Locality. Semangko Pass, SelangorPahang Boundary, Malay Peninsula, Malaysia.

COMments. Synonymized within variegatus by Corbet and Hill (1992:53), Wilson (1993:135), and Stafford (2005:110). Recognized as a subspecies of variegatus by Chasen and Kloss (1929a:16), Chasen (1940:20), Ellerman and Morrison-Scott (1951:90), Yin (1967:1), Lekagul and McNeely (1988:40), and Stafford and Szalay (2000:360). Dwarf forms from central Laos by Ruggeri and Etterson (1998) and several islands may represent different taxa, although species rank for each dwarfed population should not be recognized (Stafford and Szalay, 2000:360).

Distribution. Southern Indochina, including southern Burma (now Myanmar), southern Thailand, southern Cambodia, southern Vietnam, Malay Peninsula, and various islands, including Anamba Islands (Siantan Island), Aur, Butang Islands (Adang and Terutau Islands), Langkawi, Pangkor, Penang (Pinang), Perhentian Island, Riau Islands (Batam, Bintan, Chombol, Durian, Galang, Great Karimon, Kundur, Sebang, and Sugi islands), Singapore, Tana Bala, Telo, Tinggi, and Tioman (Miller, 1906a:41; Medway, 1965:45; Lekagul and McNeely, 1988:40; Corbet and Hill, 1992:53; Ruggeri and Etterson, 1998:450; Stafford and Szalay, 2000:360; Meijaard, 2003:1256). Dwarfed forms have been found in central Laos and on many of the smaller islands of the Sunda Shelf (Ruggeri and Etterson, 1998:450; Stafford and Szalay, 2000:360).

Galeopithecus pumilus Miller, 1903a:46.

Type Locality. Adang Island, Butang Islands, Strait of Malacca, Thailand.
Comments. Subspecies status recognized by Chasen and Kloss (1929a:20) and Chasen (1940:20). Synonymized within variegatus by Corbet and Hill (1992:53), Wilson (1993:135), and Stafford (2005:110).

Galeopithecus aoris Miller, 1903a:47.

Type LocAlity. Aor (Aur) Island, eastern Malay Peninsula, Malaysia.

Comments. Subspecies status recognized by Chasen and Kloss (1929a:20) and Chasen (1940:21). Synonymized within variegatus by Corbet and Hill (1992:53), Wilson (1993:135) and Stafford (2005:110).

Galeopterus taylori Thomas, 1908d:49, 102.

Type Locality. Tioman Island, southern Malay Peninsula, Malaysia.

Comments. Subspecies recognized by Chasen and Kloss (1929a:17) and Chasen (1940:20). Synonymized within variegatus by Corbet and Hill (1992:53), Wilson (1993:135), and Stafford (2005:110).

Galeopterus chombolis Lyon, 1909:486.

Type Locality. Chombol Island, Riau Archipelago, south of Singapore, Indonesia.

Comments. Subspecies status recognized by Chasen and Kloss (1929a:19) and Chasen (1940:21). Synonymized within variegatus by Corbet and Hill (1992:53), Wilson (1993:135), and Stafford (2005:110).

Galeopithecus variegatus terutaus Chasen and Kloss, 1929b:11.

TYPe LOCALiTy. Terutau Island, northern Strait of Malacca, Thailand.

Comments. Recognized as a subspecies of variegatus by Chasen and Kloss (1929a:20), Chasen (1940:20), Lekagul and McNeely (1988:40), and Corbet and Hill (1992:54). Synonymized within variegatus by Wilson (1993:135) and Stafford (2005:110). Not recognized by Stafford and Szalay (2000:360).

Distribution. Tetutau Island off the Strait of Malacca, Thailand (Chasen and Kloss, 1929b:11; Corbet and Hill, 1992:54).

Galeopithecus variegatus perhentianus Chasen and Kloss, 1929b:11.

TYpe Locality. Eastern Perhentian Island, Trengganu Archipelago, Malaysia.

Comments. Valid subspecies according Chasen and Kloss (1929a:20), Chasen (1940:20), and Corbet and Hill (1992:54). Taxon not recognized by 
Wilson (1993:135) or Stafford and Szalay (2000:360). Synonymized within variegatus by Stafford (2005:110).

\section{Galeopterus variegatus temminckii (Waterhouse, 1839)}

[Galeopithecus] temminckii Waterhouse, 1839b:119.

Type Locality. Sumatra.

Comments. Tuangku Island (Banyak Islands) population erroneously named Galeopterus volans by Miller (1903b:471). Incorrectly synonymized within volans by Wilson (1993:135). Valid subspecies according to Chasen and Kloss (1929a:16), Chasen (1940:20), and Stafford and Szalay (2000:360). Synonymized within variegatus by Corbet and Hill (1992:53) and Stafford (2005:110).

Distribution. Sumatra, Lingga Islands (Bakung, Penuba, Sebangka, and Singkep islands) off eastern Sumatra, Bangka Island, and Rupat Island in the Strait of Malacca, Indonesia (Stafford and Szalay, 2000:360; Meijaard, 2003:1256). Also occurs on Tuangku Island and Bankaru Island (Banyak Islands), Musala Island, and Batu Islands (Tello, Pini, Tana Bala, and Tana Masa islands) off western Sumatra (Meijaard, 2003:1256).

\section{Galeopithecus marmoratus Temminck, 1836:ix.}

Type Locality. Sumatra, Indonesia.

Comments. Synonymized within volans by Wilson (1993:135). Stafford (2005:110) notes that Cabrera (1925:210) listed "G. marmoratus Temminck (1829)" as a synonym of G. variegatus, but Stafford was unable to locate that description, and the citation is unknown. Fischer (1829:79) lists this taxon as "G.[aleopithecus] marmorati nomen ab illo obtigit." Name and type locality are discussed by Mees (1957:215).

Galeopithecus saturatus Miller, 1903a:51.

Type Locality. Tana Bala Island, Batu Islands, western Sumatra, Indonesia.

Comments. Recognized as a subspecies of variegatus by Chasen (1940:20). Synonymized within variegatus by Corbet and Hill (1992:53), Wilson (1993:135), and Stafford (2005:110).

Galeopithecus tuancus Miller, 1903a:53.

Type Locality. Tuangku Island, Banyak (Banjak) Islands, western Sumatra, Indonesia.

Comments. Recognized as a subspecies of variegatus by Chasen (1940:20). Synonymized within variegatus by Corbet and Hill (1992:53), Wilson (1993:135), and Stafford (2005:110).
Cynocephalus tellonis Lyon, 1908:139.

Type Locality. Tello Island, Batu Islands, western Sumatra, Indonesia.

Comments. Recognized as a subspecies of variegatus by Chasen (1940:20). Synonymized within variegatus by Corbet and Hill (1992:53), Wilson (1993:135), and Stafford (2005:110).

\section{†Dermotherium Ducrocq et al., 1992}

†Dermotherium Ducrocq et al., 1992:373.

Type Species. †Dermotherium major Ducrocq et al., 1992:373.

Comments. Late Eocene, Asia. Placed within the family Galeopithecidae by McKenna and Bell (1997: 328).

\section{†Dermotherium major Ducrocq et al., 1992}

†Dermotherium major Ducrocq et al., 1992:373.

Type Locality. Wai Lek lignite pit, Changwat Krabi, southern Thailand.

Comments. Late Eocene. Stafford and Szalay (2000:378) suggest that if this species proves to be a dermopteran, then it may be appropriate to place this species within the family Cynocephalidae; however, they suggest the Dermopteran affinities are uncertain as the specimen is poorly preserved and only $\mathrm{m} 3$ has any diagnostic characters. These authors also suggest that some of the features listed as characteristic of Dermoptera are more widespread than is acknowledged by Ducrocq et al. (1992).

\section{†Dermotherium chimaera Marivaux et al., 2006}

†Dermotherium chimaera Marivaux et al., 2006:398.

Type Locality. Cha Prong pit, Nong Ya Plong coal mine, Phetchaburi Province, northern part of the Thailand peninsula.

Comments. Late Oligocene. Specimens close to this species have also been discovered from early Eocene deposits in Pakistan (Marivaux et al., 2006).

\section{†family Plagiomenidae Matthew, 1918}

†Family Plagiomenidae Matthew, 1918:598.

Type Genus. †Plagiomene Matthew, 1918: 601.

Comments. Early Paleocene to mid-Eocene, late? Eocene, late Oligocene, North America. Family placed within Dermoptera by McKenna and Bell (1997:327) and 
Silcox et al. (2005:134), with further support added by Bloch et al. (2007:1163).

\section{†Elpidophorus Simpson, 1927}

†Elpidophorus Simpson, 1927:5.

Type Species. †Elpidophorus elegans Simpson, 1927:5.

Comments. Early to late Paleocene, North America. Genus was tentatively placed within the $f$ family Oxyclaenidae by Simpson (1927:2), within Dermoptera by Gunnell (1989:28), and within †Plagiomenidae by Rose (1975:676), McKenna and Bell (1997:327), and Bloch et al. (2007:1163).

\section{†Elpidophorus elegans Simpson, 1927}

†Elpidophorus elegans Simpson, 1927:5.

Type Locality. Paskapoo Formation, Alberta, Canada.

Comments. Early to late Paleocene.

†Elpidophorus patratus Simpson, 1936:11.

Type Locality. Scarritt Quarry, Fort Union, Crazy Mountain Field, Montana, USA.

Comments. Upper Paleocene. Synonymized within telegans by Szalay $(1969: 218,219)$ and Rose (1975:676).

\section{†Elpidophorus minor Simpson, 1937}

†Elpidophorus minor Simpson, 1937:133.

Type Locality. Probably Silberling Quarry, Fort Union, Crazy Mountain Field, Montana, USA.

Comments. Middle Paleocene.

\section{†Eudaemonema Simpson, 1935}

†Eudaemonema Simpson, 1935:231.

Type Species. †Eudaemonema cuspidata Simpson, 1935:231.

Comments. Middle Paleocene. North America. Genus placed within the ffamily Mixodectidae by Gunnell (1989:56) and within the ffamily Plagiomenidae by McKenna and Bell (1997:327).

\section{†Eudaemonema cuspidata Simpson, 1935}

†Eudaemonema cuspidata Simpson, 1935:231.

Type Locality. Fort Union, Montana, USA. Comments. Middle Paleocene.

\section{†Subfamily Plagiomeninae Matthew, 1918}

†Family Plagiomenidae Matthew, 1918:598.

Type Genus. †Plagiomene Matthew, 1918:601.

Comments. Late Paleocene to early Eocene, North America. Subfamily rank recognized by Russell et al. (1973:50), McKenna (1990:212), and McKenna and Bell (1997:327). Included within Dermoptera by McKenna and Bell (1997:327) and Sundatheria by Bloch et al. (2007:1162).

\section{†Tribe Worlandini Bown and Rose, 1979}

†Tribe Worlandinae Bown and Rose, 1979:97.

Type Genus. †Worlandia Bown and Rose, 1979:97.

Comments. Late Paleocene to early Eocene, North America. Recognized at tribe rank by McKenna (1990:212, 231) and McKenna and Bell (1997:327).

\section{†Planetetherium Simpson, 1928}

†Planetetherium Simpson, 1928:11.

Type Species. †Planetetherium mirabile Simpson, 1928:11.

Comments. Late Paleocene, North America. Genus recognized by Rose and Simons (1977:221) and Bown and Rose (1979:89).

\section{†Planetetherium mirabile Simpson, 1928}

†Planetetherium mirabile Simpson, 1928:11.

Type Locality. Fort Union, southern Montana, USA.

Comments. Late Paleocene, Park County, Wyoming, USA.

\section{†Worlandia Bown and Rose, 1979}

†Worlandia Bown and Rose, 1979:97.

Type Species. †Worlandia inusitata Bown and Rose, 1979:99.

Comments. Late Paleocene to early Eocene, North America. Genus placed within Dermoptera by Gunnell (1989:147) and the tfamily Plagiomenidae by Bown and Rose (1979:97), Gingerich (1987:311), and McKenna and Bell (1997:327).

\section{†Worlandia inusitata Bown and Rose, 1979}

†Worlandia inusitata Bown and Rose, 1979:99.

Type Locality. Park County, Wyoming, USA. Comments. Early Eocene. 


\section{†Tribe Plagiomenini Matthew, 1918}

†Family Plagiomedidae Matthew, 1918:598.

Type Genus. †Plagiomene Matthew, 1918:601.

Comments. Late Paleocene to early Eocene, North America. Tribe rank created by McKenna and Bell (1997:327).

\section{†Plagiomene Matthew, 1918}

†Plagiomene Matthew, 1918:601.

Type Species. †Plagiomene multicuspis Matthew, 1918:601.

Comments. Early Paleocene to early Eocene, North America. Genus placed within Dermoptera by Gunnell (1989:147) and within †Plagiomenidae by Matthew (1918:601) and McKenna and Bell (1997:327).

\section{†Plagiomene accola Rose, 1981}

†Plagiomene accola Rose, 1981:46.

Type Locality. Clark's Fork Basin, Wyoming, USA.

Comments. Late Paleocene and early Eocene.

\section{†Plagiomene multicuspis Matthew, 1918}

†Plagiomene multicuspis Matthew, 1918:601.

Type Locality. Gray Bull beds of Bighorn Basin, Wyoming, USA.

COMments. Lower Eocene.

\section{†Ellesmene Dawson et al., 1993}

†Ellesmene Dawson et al., 1993:179, 180.

Type Species. †Ellesmene eureka Dawson et al., 1993:179, 180.

Comments. Early Eocene, North America. Genus assigned to the $†$ Family Plagiomenidae by Dawson et al. (1993:180) and McKenna and Bell (1997:327).

\section{†Ellesmene eureka Dawson et al., 1993}

†Ellesmene eureka Dawson et al., 1993:179, 180.

Type Locality. Ellesmene Island and Axel Heiberg Island, Eureka Sound Group, Canada.

Comments. Early Eocene, Canada.

\section{†Subfamily Ekgmowechashalinae Szalay, 1976}

†Subfamily Ekgmowechashalinae Szalay, 1976:349.
Type Genus. †Ekgmowechashala Macdonald, 1963:171.

Comments. Mid-Eocene, late? Eocene, late Oligocene, North America. Subfamily placed within the tfamily Omomyidae by Szalay (1976:349) and Szalay and Lucas (1996:32). Subfamily rank within the ffamily Plagiomenidae recognized by McKenna (1990:214) and McKenna and Bell (1997:327).

\section{†Tribe Tarkadectini Szalay and Lucas, 1996}

†Subfamily Tarkadectinae Szalay and Lucas, 1996:32.

Type Genus. Tarkadectes McKenna, 1990:224.

Comments. Mid-Eocene, late? Eocene, North America. Newly created rank by McKenna and Bell (1997:327). Placed in the ffamily Plagiomenidae by Szalay and Lucas (1996:32) and within the ffamily Omomyidae by $\mathrm{Ni}$ et al. (2010:1).

\section{†Tarkadectes McKenna, 1990}

†Tarkadectes McKenna, 1990:224.

Type Species. †Tarkadectes montanensis McKenna, 1990:224.

Comments. Middle and/or late Eocene, North America. Placed within the †subfamily Ekgmowechashalinae by McKenna (1990:224), †subfamily Tarkadectinae by Szalay and Lucas (1996:32), and the tribe Tarkadectini by McKenna and Bell (1997:327).

\section{†Tarkadectes montanensis McKenna, 1990}

†Tarkadectes montanensis McKenna, 1990:224.

Type Locality. Flathead County, Montana, USA.

Comments. Middle and/or late Eocene.

\section{†Tarka McKenna, 1990}

†Tarka McKenna, 1990:214.

Type Species. †Tarka stylifera McKenna, 1990:215.

Comments. Mid-Eocene, North America. Genus placed within the †subfamily Ekgmowechashalinae by McKenna (1990:214) and McKenna and Bell (1997:327) and the tsubfamily Tarkadectinae by Szalay and Lucas (1996:32) and Ni et al. (2010:247).

\section{†Tarka stylifera McKenna, 1990}

†Tarka stylifera McKenna, 1990:215. 
Type Locality. Fremont County, Wyoming, USA.

Comments. Mid-Eocene.

\section{†Tribe Ekgmowechashalini Szalay, 1976}

†Subfamily Ekgmowechashalinae Szalay, 1976:349.

Trpe Genus. †Ekgmowechashala Macdonald, 1963:171.

Comments. Late Oligocene, North America. Subfamily rank recognized by McKenna (1990:214). Taxon placed within the ffamily Plagiomenidae by McKenna (1990:214) and †Omomyidae by Szalay (1976:349) and Szalay and Lucas (1996:32). Tribe rank created by McKenna and Bell (1997:327).

\section{†Ekgmowechashala Macdonald, 1963}

†Ekgmowechashala Macdonald, 1963:171.

Type Species. †Ekgmowechashala philotau Macdonald, 1963:171.

Comments. Early Miocene, North America. Genus placed within the †subfamily Ekgmowechashalinae by Szalay (1976:349), †tribe Ekgmowechashalini by McKenna and Bell (1997:327), and the tfamily Omomyidae by Macdonald $(1963: 171 ; 1970: 24)$ and Gunnell and Rose (2002:72).

\section{†Ekgmowechashala philotau Macdonald, 1963}

†Ekgmowechashala philotau Macdonald, 1963:171.

Type LOCALITY. Wounded Knee, western South Dakota, USA.

Comments. Early Miocene.

\section{†Family Mixodectidae Cope, 1883}

†Family Mixodectidae Cope, 1883a:80.

Type Genus. †Mixodectes Cope, 1883b:559.

Comments. The family was placed within Quadrumana by Cope (1889:876), order Menotyphla by Gregory (1910:465), †superfamily Mixodectoidea by Gunnell (1989:147), and Dermoptera by McKenna and Bell (1997:327).

†Family Oldobotidae Schlosser, 1907:222.

Type Genus. †Olbodotes copei Osborn, 1902:205.

Comments. Synonymized within the ffamily Mixodectidae by McKenna and Bell (1997:327).
†Superfamily Mixodectoidea Simpson, 1945:53.

Type Genus. †Mixodectes Cope, 1883b:559.

Comments. Taxon placed within Insectivora by Simpson (1945:53) and Gunnell (1989:147) and within the tfamily Mixodectidae by McKenna and Bell (1997:327).

†Suborder Mixodectomorpha Saban, 1954:429.

Comments. Early Paleocene, North America. In part. Placed in the Insectivora for the families †Mixodectidae and †Apatemyidae (See McKenna and Bell, 1997:327).

\section{†Mixodectes Cope, 1883}

†Mixodectes Cope, 1883b:559.

Type SPeCIEs. Mixodectes pungens Cope, 1883b:559.

Comments. Early Paleocene, North America. Placed within the $†$ family Mixodectidae by Cope (1883b:559), Gunnell (1989:56), and McKenna and Bell (1997:328).

†Indrodon Cope, 1884:318.

Type Species. †Indrodon malaris Cope, 1884: 318.

Comments. Synonymized within $†$ Mixodectes by Gunnell (1989:57) and McKenna and Bell (1997:328).

†Olbodotes Osborn, 1902:205.

TYPe Species. †Olbodotes copei Osborn, 1902:205.

Comments. Synonymized within $†$ Mixodectes by Gunnell (1989:57) and McKenna and Bell (1997:328).

\section{†Mixodectes malaris (Cope, 1884)}

†Indrodon malaris Cope, 1884:318.

Type Locality. Nacimiento Formation, San Juan Basin, New Mexico, USA.

Comments. Eocene.

†Oxyacodon tecumsae Van Valen, 1978:65.

Type Locality. San Juan Basin Torrejonian, New Mexico, USA.

Comments. Early Paleocene. Synonymized within †malaris by Archibald et al. (1983:53) and Lucas (1986:39).

\section{†Mixodectes pungens Cope, 1883}

†Mixodectes pungens Cope, 1883b:559.

Type Locality. Torrejonian Formation, San Juan Basin, New Mexico, USA.

Comments. Early Paleocene. 
†Mixodectes crassiusculus Cope, 1883b:560.

Type Locality. San Juan Basin Torrejonian, New Mexico, USA.

Comments. Early Paleocene. Synonymized within †pungens by Gunnell (1989:57).

†Olbodotes copei Osborn, 1902:205.

Type Locality. San Juan Basin Torrejonian, New Mexico, USA.

Comments. Early Paleocene. Synonymized within †pungens by Gunnell (1989:57).

\section{†Dracontolestes Gazin, 1941}

†Dracontolestes Gazin, 1941:13.

Type SPecies. †Dracontolestes aphantus Gazin, 1941:13.

Comments. Early to middle Paleocene, North America. Recognized within the ffamily Mixodectidae by Gunnell (1989:56).

\section{†Dracontolestes aphantus Gazin, 1941}

†Dracontolestes aphantus Gazin, 1941:13.

Type Locality. Paleocene, Dragon Canyon, Emery County, Utah, USA.

Comments. Early to middle Paleocene. Recognized within the ffamily Mixodectidae by Gunnell (1989:56).

\section{Superorder Glires Linnaeus, 1758}

Glires Linnaeus, 1758:56.

COMments. Originally included lagomorphs, rodents, and Rhinoceros. The Rhinoceros were removed shortly after, with the notion of Glires linking rodents and lagomorphs persisting today. Significant support has been obtained for the recognition of Glires by recent research, giving increasing support for monophyly between the Rodentia and Lagomorpha. Some authors suggest limited or no support for Glires, including Wood (1957:424), Graur et al. (1996:333), Arnason et al. (2002:8154), Adkins et al. (2003:413), and Misawa and Janke (2003:320). In contrast, support for the acceptance of Glires includes Landry (1999:283), Liu et al. (2001:1786), Madsen et al. (2001:610), Meng and Wyss (2001:1), Murphy et al. (2001a:614), Huchon et al. (2002:1053), Lin et al. (2002:119), Meng et al. (2003:1), Douzery and Huchon (2004:922), Meng (2004:93), Asher et al. (2005:1091), and Kriegs et al. (2007:160). Reviewed by Meng (2004:93).
Order Rodentia Bowdich, 1821

Order Rodentia Bowdich, 1821:7, 51.

Comments. Reviewed by Wilson and Reeder (2005).

Rodentes Vicq-d'Azyr, 1792:xcvii.

Comments. Rank unknown. Synonymized within Rodentia by McKenna and Bell (1997:114).

Order Rosores Gray, 1821:302.

Comments. Included the lagomorphs. Later in the same paper Gray employed order Rosores a second time to include the family Cheiromydae (p. 309), which are primates that are now included in the family Daubentoniidae (Gray, 1863:151). Synonymized within Rodentia by McKenna and Bell (1997:114).

Order Rodentiformes Kinman, 1994:37.

Comments. Synonymized within the mirorder Simplicidentata (Weber, 1904:495) by McKenna and Bell (1997:113).

Clade Rodentiaformes Wyss and Meng, 1996:563.

Comments. Not currently recognized at a specific rank.

\section{Suborder ScIUROMORPHA Brandt, 1855}

Suborder Sciuromorphi Brandt, 1855:144, 292.

Comments. Subordinal rank recognized by McKenna and Bell (1997:115) and Thorington and Hoffmann (2005:754).

\section{Family Sciuridae Fischer de Waldheim, 1817}

Tribe? Sciurii Fischer de Waldheim, 1817:372.

Trpe Genus. $\quad$ Sciurus Linnaeus, 1758:63.

Comments. Author of the family given as Gray (1821:304) by Simpson (1945:78), Hemprich (1820:32) by Hoffmann et al. (1993:419), and Fischer de Waldheim (1817:372) by Thorington and Hoffmann (2005:754).

Family Sciuriorum Fischer de Waldheim, 1817:408.

Type Genus. $\quad$ Sciurus Linnaeus, 1758:63.

Comments. Synonymized within the family Sciuridae by McKenna and Bell (1997:121).

Family Arctomyidae Gray, 1821:303. 
Type Genus. Arctomys Schreber, 1780: pls. ccvii-ccxi (=Marmota Blumenbach, 1779:79).

Comments. Synonymized within the family Sciuridae by McKenna and Bell (1997:121). Date of type genus publication confirmed by Sherborn (1891:589).

Family Sciuridae Gray, 1821:304.

Type Genus. $\quad$ Sciurus Linnaeus, 1758:63.

Comments. Synonymized within the family Sciuridae by McKenna and Bell (1997:121).

Family Arctomysideae Lesson, 1842:115.

Type Genus. Arctomys Schreber, 1780: pls. ccvii-ccxi. (=Marmota Blumenbach, 1779:79).

Comments. Synonymized within the family Sciuridae by McKenna and Bell (1997:121). Date of type genus publication confirmed by Sherborn (1891:589).

Family Sciuroïdes Brandt, 1855:296.

Type Genus. $\quad$ Sciurus Linnaeus, 1758:63.

Comments. Not recognized by subsequent authors.

Homonym. † $\quad$ Sciuroides Major, 1873:79. See McKenna and Bell (1997:120).

Family Sciurina Haeckel, 1866:clx.

Type Genus. $\quad$ Sciurus Linnaeus, 1758:63.

Comments. Synonymized within the family Sciuridae by McKenna and Bell (1997:121).

Family Arctomyida Haeckel, 1866:clx.

Type Genus. Arctomys Schreber, 1780: pls. ccvii-ccxi (=Marmota Blumenbach, 1779:79).

Comments. Synonymized within the family Sciuridae by McKenna and Bell (1997:121). Date of type genus publication confirmed by Sherborn (1891:589).

Sciuroidea Gill, 1872:21.

Type Genus. $\quad$ Sciurus Linnaeus, 1758:63.

Comments. Rank unknown but at approximately superfamily rank. Synonymized within the family Sciuridae by McKenna and Bell (1997:121).

Superfamily Sciuroidae Miller and Gidley, 1918:432.

Type Genus. $\quad$ Sciurus Linnaeus, 1758:63.

Comments. Synonymized within the family Sciuridae by McKenna and Bell (1997:121).

Subfamily Marmotinae Pocock, 1923:240.

Type Genus. Marmota Blumenbach, 1779:79.
Comments. Synonymized within the family Sciuridae by McKenna and Bell (1997:121).

Family Marmotidae Weber, 1928:275.

Type Genus. Marmota Blumenbach, 1779:79. Comments. Synonymized within the family Sciuridae by McKenna and Bell (1997:121).

\section{Subfamily Sciurinae Fischer de Waldheim, 1817}

Tribe? Sciurii Fischer de Waldheim, 1817:372.

Type Genus. $\quad$ Sciurus Linnaeus, 1758:63

Comments. Subfamily recognized by McKenna and Bell (1997:122) and Thorington and Hoffmann $(2005: 754,757)$. The ability of the different genera of extinct taxa to glide is poorly known, so it is likely that many species will be revealed as nongliders in the future as specimens with postcranial remains are discovered.

Family Sciuriorum Fischer de Waldheim, 1817:408.

Type Genus. $\quad$ Sciurus Linnaeus, 1758:63.

Comments. Synonymized within the subfamily Sciurinae by McKenna and Bell (1997:122).

Family Sciuridae Gray, 1821:304.

Type Genus. $\quad$ Sciurus Linnaeus, 1758:63.

Comments. Synonymized within the subfamily Sciurinae by McKenna and Bell (1997:122).

Subfamily Sciurinae Baird, 1857:240.

Type Genus. $\quad$ Sciurus Linnaeus, 1758:63.

Comments. Synonymized within the subfamily Sciurinae by McKenna and Bell (1997:122).

Xeri Murray, 1866:256.

Type Genus. Xerus Hemprich and Ehrenberg, 1833: sig. Ee. pl. 9.

Comments. Rank unknown. Synonymized within the subfamily Sciurinae by McKenna and Bell (1997: 122).

Subfamily Xerinae Osborn, 1910:535.

Type Genus. Xerus Hemprich and Ehrenberg, 1833: sig. Ee. pl. 9.

Comments. Synonymized within the subfamily Sciurinae by McKenna and Bell (1997:122).

Subfamily Marmotinae Pocock, 1923:240.

Type Genus. Marmota Blumenbach, 1779:79. 
Comments. Synonymized within the subfamily Sciurinae by McKenna and Bell (1997:122).

Subfamily Spermophilinae Ognev, 1940:326, 432.

Type Genus. Spermophilus F. Cuvier, 1825b: 255.

Comments. Synonymized within the subfamily Sciurinae by McKenna and Bell (1997:122).

\section{TRIBE INDETERMINATE}

\section{†Sciurion Skwara, 1986}

†Sciurion Skwara, 1986:290.

Type Species. Sciurion campestre Skwara, 1986:290.

Comments. Early Miocene. This genus and species was described as a "flying squirrel" within the family Sciuridae by Skwara (1986:290, 292), who, because there was reasonable doubt about monophyly in modern flying squirrels and even doubt about the sciurid relationships of certain North American fossil teeth, refrained from placing Sciurion within Petauristinae (=Pteromyini) and appeared to be followed by McKenna and Bell (1997:122), who placed this taxon directly within the family Sciuridae, rather than at a more precise lower rank.

\section{† Sciurion campestre Skwara, 1986}

†Sciurion campestre Skwara, 1986:290.

Type Locality. Cypress Hills Formation, southwestern Saskatchewan, Canada.

Comments. Early Miocene.

\section{Tribe Pteromyini Brandt, 1855}

Pteromyini Brandt, 1855:151, 298.

Type Genus. Pteromys G. Cuvier, 1800: tab. 1.

Comments. Brandt (1855) refers to Pteromyini on p. 151 without rank and to the "Tribus Pteromyes seu melius Pterosciuri nob.” on p. 298. Some debate has occurred as to whether the flying squirrels are monophyletic (e.g., Hight et al., 1974:12); however, thorough examinations of sciurid taxa strongly suggested that they are (Thorington, 1984:1048; Thorington et al., 2002:99; Steppen et al., 2004:703). Recognized as the subfamily Pteromyinae by Trouessart (1904:297), Miller and Gidley (1918:433), McKenna and Bell (1997:127), and Wang (2003:155). Recognized as the family Pteromyidae by
Ognev (1966:248), but tribe rank synonymized within the family Pteromyidae by Corbet and Hill (1992:306) and within the subfamily Petauristinae by Hoffmann et al. (1993:459). The tribal rank Pteromyini within the subfamily Sciurinae was proposed by Steppan et al. (2004:715) and followed by Thorington and Hoffmann (2005:766).

Family Pteromidae Anderson, 1879:278.

Type Genus. Pteromys G. Cuvier, 1800: tab. 1. Comments. Incorrect subsequent spelling of the family Pteromyidae. Synonymized within the subfamily Pteromyinae by McKenna and Bell (1997:127).

Family Petauristidae Miller, 1912:940.

Type Genus. Petaurista Link, 1795:52, 78.

Comments. Family rank recognized by de Bruijn (1995:92; 1999:273), who suggested the family is polyphyletic on the basis of his study of fossil genera. Recognized at subfamily rank by Simpson (1945:80) and Hoffmann et al. (1993:459). Family rank synonymized within the family Pteromyidae by Corbet and Hill (1992:306). Tribe Petauristini recognized by de Bruijn et al. (1980:241, 244). Synonymized within the subfamily Pteromyinae by McKenna and Bell (1997:127).

Subfamily Pteromyinae Miller and Gidley, 1918:433.

Type Genus. Pteromys G. Cuvier, 1800: tab. 1. Comments. Synonymized within the subfamily Pteromyinae Brandt (1855:151) by McKenna and Bell (1997:127).

Subfamily Petauristinae Simpson, 1945:80.

Type Genus. Petaurista Link, 1795:52, 78.

Comments. Synonymized within the subfamily Pteromyinae by McKenna and Bell (1997:127).

Family Eupetauridae Schaub, 1953:395.

Type Genus. $\quad$ Eupetaurus Thomas, 1888b:256.

Comments. Recognized to include only Eupetaurus because of its distinctive hypsodont dentition. Family rank was followed by Grassé and Dekeyser (1955:1496) and Schaub (1958:714) but has not become widely accepted. Eupetaurus was subsequently returned to the subfamily Petauristinae by McKenna (1962:10).

†Tribe Blackiini de Bruijn et al., 1980:241, 253.

Type Genus. †Blackia Mein, 1970:44.

Comments. Tribe created for the extinct genera $\nmid$ Blackia and $\dagger$ Pliopetes. Synonymized within the subfamily Pteromyinae by McKenna and Bell (1997:127). 
†Tribe Petauristini de Bruijn et al., 1980:241, 244.

Type Genus. Petaurista Link, 1795:52, 78.

Comments. Tribe created to include the flying squirrels, including the extinct genera $\dagger$ Aliveria, $\dagger A l$ banensia, †Forsythia, and †Miopetaurista. Synonymized within the subfamily Pteromyinae by McKenna and Bell (1997:127).

\section{Aeretes G. Allen, 1940}

Aëretes G. Allen, 1940:745.

Type Species. Pteromys melanopterus MilneEdwards, 1867:375.

Comments. Early to middle Pleistocene to Recent, China. Fossil specimens allocated to this genus have been discovered in mid-Pleistocene mammalian fauna of Shanyangzhai cave in Qinhuangdao in China (Zhang et al., 2010:75).

\section{†Aeretes grandidens Zheng, 1993}

†A.[eretes] grandidens Zheng, 1993:239.

Type Locality. Sichuan-Guizhou, China.

Comments. Late Pliocene.

\section{Aeretes melanopterus (Milne-Edwards, 1867) (north Chinese flying squirrel)}

\section{Aeretes melanopterus melanopterus (Milne-Edwards, 1867)}

Pteromys melanopterus Milne-Edwards, 1867:375.

Type Locality. Tscheli (Chihli; old name for Hebei Province), China.

Comments. Further described by MilneEdwards (1872:138). Known only from two widely separated localities. Transferred to Petaurista by Allen (1925:15) and Aeretes by Allen (1940:745). Fossils from the late Pleistocene and Pliocene allocated to this species have been found in China (Zheng, 1993:239; Tong, 2007:219).

Distribution. Hebei Province, China (Corbet and Hill, 1992:314; Zhang et al., 1997:154; Smith and Xie, 2008:174).

Petaurista sulcatus Howell, 1927:82.

TYPe LOCALITY. Hsinlungshan, northeast of Peking (Beijing), China. $914 \mathrm{~m}$ (3,000 ft).

Comments. Species rank recognized within Petaurista by Howell (1929:47) and Ellerman (1940:289). Synonymized within melanopterus by Allen (1940:746),
Ellerman and Morrison-Scott (1951:465), Corbet and Hill (1992:314), and Thorington and Hoffmann (2005:766).

\section{Aeretes melanopterus szechuanensis Wang et al., 1966}

Aeretes melanopterus szechuanensis Wang et al., 1966:89.

Type Locality. Sichuan Province, China.

Comments. Subspecies recognized by Corbet and Hill (1992:314), Zhang et al. (1997:154), Thorington and Hoffmann (2005:766), and Smith and Xie (2008:174). Spelled sichuanensis and recognized as a subspecies of melanopterus by Wang (2003:159).

Distribution. Southern Gansu Province and central and northeastern Sichuan, China (Corbet and Hill, 1992:314; Zhang et al., 1997:154; Smith and Xie, 2008:174).

\section{†Aeretes premelanopterus Zheng, 1993}

†Aeretes premelanopterus Zheng, 1993:238.

Type Locality. Sichuan-Guizhou, China.

Comments. Late Pliocene.

\section{Aeromys Robinson and Kloss, 1915}

Aeromys Robinson and Kloss, 1915:23.

Type Species. Pteromys tephromelas Günther, 1873:413.

\section{Aeromys tephromelas (Günther, 1873) (black flying squirrel)}

\section{Aeromys tephromelas tephromelas (Günther, 1873)}

Pteromys tephromelas Günther, 1873:413.

Type Locality. Wellesley, Penang Island (Pinang Island), Malaysia.

Comments. Transferred to Hylopetes by Thomas (1908b:6) and to Aeromys by Robinson and Kloss (1915:23; 1918a:183), which was followed by Chasen (1940:120), Ellerman (1940:291), and subsequent authors.

Distribution. Southernmost Thailand?, Malay Peninsula, Penang Island (Pinang Island), Siberut Island, and northeastern Sumatra (Medway, 1969:65; Corbet and Hill, 1992:320; Meijaard, 2003:1256).

Petaurista bartelsi Sody, 1936:146.

Type Locality. Pagar, Djawa, Pematang Siantar, Deli District, northern Sumatra, Indonesia. 500 m (1,640ft). 
Comments. Species rank recognized within Aeromys by Ellerman (1940:291). Recognized as a subspecies of tephromelas by Chasen (1940:120). Synonymized within tephromelas by Corbet and Hill (1992:320) and Thorington and Hoffmann (2005:766).

\section{Aeromys tephromelas phaeomelas (Günther, 1873)}

Pteromys phaeomelas Günther, 1873:413, pl. 37.

Type Locality. Borneo.

Comments. Transferred to Hylopetes at species rank by Thomas (1908b:6) and to Aeromys by Robinson and Kloss (1915:23; 1918a:183) and Ellerman (1940:291). Recognized as a species within Petaurista (Aeromys) by Banks (1931:53). Synonymized within tephromelas by Corbet and Hill (1980:137; 1986:154; 1991:145). Subspecies recognized within tephromelas by Chasen (1940:120), Medway (1965:111; 1977:101), Corbet and Hill (1992:320), and Thorington and Hoffmann (2005:766).

Distribution. Known from several scattered localities in the northern part of Borneo, including the foothills of Gunung Kinabalu, Tenom, and Tawau in Sabah; northern Sarawak and Kuching; and Sombong near Samarinda in east Kalimantan (Medway, 1965:111; Payne et al., 1985:246; Corbet and Hill, 1992:320). Other specimens have been collected from G. Dulit and at Claudetown (Marudi), Baram (Hose, 1893:42), and various places in the lowlands of Sarawak (Banks, 1931:53), including the neighborhood of Kuching (Medway, 1965:111).

\section{Aeromys thomasi (Hose, 1900) (Thomas's flying squirrel)}

Petaurista thomasi Hose, 1900:215.

Type Locality. Silat River, south of Claudetown, eastern Sarawak, Borneo.

Comments. Transferred to Hylopetes by Thomas (1908b:6), which was followed by Chasen and Kloss (1932:19), Chasen (1940:118), and Davis (1962:84). Recognized as a subspecies of Petaurista nitida by Banks (1931:53). Placed in Aeromys by Robinson and Kloss (1918a:183) and Ellerman (1940:291) and followed by most subsequent authors.

Distribution. Confined to Borneo. Known from the lower slopes of Gunung Kinabalu (up to 1600 $\mathrm{m})$, Sandakan, and Tawau in Sabah; Sungai Baram in Sarawak; Gunung Liang Kubung in west Kalimantan; and Sungai Kayan in east Kalimantan (Medway, 1965:111; Payne et al., 1985:246).
Pteromys nitidus Jentink, 1897:55.

Type Locality. Mount Liang, Keoboeng, Borneo.

Comments. Synonymized within thomasi by Medway (1965:111; 1977:101), Hoffmann et al. (1993:459), and Thorington and Hoffmann (2005:766).

\section{†Albanensia Daxner-Höck and Mein, 1975}

†Albanensia Daxner-Höck and Mein, 1975:76.

Type Species. TSciuropterus albanensis Major, 1893:191.

Comments. Middle to late Miocene, Asia; middle to late Miocene, Europe. Genus recognized within the subfamily Pteromyinae by McKenna and Bell (1997:127) and family Petauristidae by de Bruijn (1999:275).

\section{†Albanensia albanensis (Major, 1893) \\ †Albanensia albanensis albanensis (Major, 1893)}

†Sciuropterus albanensis Major, 1893:191.

Type Locality. La Grive-Saint Alban (Isere), France.

Comments. Mid-Miocene. Included within †Albanensia by Daxner-Höck and Mein (1975:76), de Bruijn (1999:275), and Daxner-Höck (2004:390).

†Sciuropterus jourdani Gaillard, 1899:67.

Type Locality. La Grive-Saint Alban (Isere), France.

Comments. Miocene. Mein (1958:68), James (1963:87), and Black (1966:56) suggest that this species is a synonym for $\dagger$ Albanensia albanensis.

\section{†Albanensia albanensis quiricensis (Villalta, 1950)}

†Sc.[iuropterus] albanensis quiricensis Villalta, 1950:57.

Type Locality. San Quirze de Galliners, Spain.

Comments. Miocene. Recognized as a subspecies of albanensis within †Albanensia by Daxner-Höck and Mein (1975:76), de Bruijn (1999:275), and DaxnerHöck (2004:390).

\section{†Albanensia grimmi (Black, 1966)}

†Sciuropterus grimmi Black, 1966:56, pl. 6.

TyPe LocAlity. Marktl, Bavaria, Germany. 
Comments. Tertiary. Included within †Albanensia by Daxner-Höck and Mein (1975:76), de Bruijn (1999:275), and Daxner-Höck (2004:390).

\section{†Albanensia sansaniensis (Lartet, 1851 )}

†Sciurus sansaniensis Lartet, 1851:19.

Type Locality. Bassin Sous-Pyrénéen, France.

Comments. Miocene. Included within †Albanensia by Daxner-Höck and Mein (1975:76), de Bruijn (1999:275), and Daxner-Höck (2004:390).

\section{†Aliveria de Bruijn et al., 1980}

†Aliveria de Bruijn et al., 1980:241, 244.

Type Species. †Aliveria brinkerinki de Bruijn et al., 1980:244.

Comments. Early Miocene, Europe. Genus recognized within the tribe Petauristini by de Bruijn et al. (1980:241, 244), subfamily Pteromyinae by McKenna and Bell (1997:127), and family Petauristidae by de Bruijn (1999:275). Doubt was cast on this genus by Thorington et al. (2005:958).

\section{†Aliveria brinkerinki de Bruijn et al., 1980}

†Aliveria brinkerinki de Bruijn et al., 1980:241, 244.

Type Locality. Aliveri, island of Evia, Greece.

Comments. Early Miocene. Species recognized by de Bruijn (1999:275).

\section{†Aliveria luteyni de Bruijn et al., 1980}

†Aliveria luteyni de Bruijn et al., 1980:241, 248.

Type Locality. Aliveri, island of Evia, Greece.

Comments. Early Miocene. Species recognized by de Bruijn (1999:275).

\section{Belomys Thomas, 1908}

Belomys Thomas, 1908b:2.

Type Species. Sciuropterus pearsonii Gray, 1842:263.

Comments. Late Pliocene to Recent, Asia. Belomys recognized by most subsequent authors except Corbet and Hill (1992:306), who synonymized it within Trogopterus and suggested that they are very closely related.

\section{†Belomys parapearsoni Zheng, 1993}

†B.[elomys] parapearsoni Zheng, 1993:268.

Type Locality. Longgupo Cave, SichuanGuizhou, China.

Comments. Late Pliocene.

\section{Belomys pearsonii (Gray, 1842) (hairy-footed flying squirrel)}

\section{Belomys pearsonii pearsonii (Gray, 1842)}

S. [ciuropterus] pearsonii Gray, 1842:263.

TYPE LoCALITY. Darjeeling (Dargellan), Sikkim, India.

Comments. Recognized within Sciuropterus by Sclater (1891:37). Transferred to Pteromys at species rank by Anderson (1879:287) and Belomys by Thomas (1908b:2), Ellerman (1940:277), and Ellerman and Morrison-Scott (1951:459). This species was placed in Trogopterus by Corbet and Hill (1992:307) but transferred back to Belomys by Hoffmann et al. (1993:459) and recognized by subsequent authors. Found as fossil deposits from the mid-Pleistocene to Recent throughout Thailand (Chaimanee, 1998:153). Also found in China from the late Pleistocene (Zheng, 1993:264).

Distribution. Himalayas from eastern Nepal, Sikkim (Darjeeling [Darjilling]), to Bhutan and upper Assam (India) (Agrawal and Chakraborty, 1979a:335; Ghose and Chakraborty, 1983:411; Corbet and Hill, 1992:307). The limits of the distribution of the subspecies are not well understood.

Sc. [iuropterus] villosus Blyth, 1847:866.

Type Locality. Upper Assam (Singpho Country), India.

Comments. Recognized as a species within Belomys by Thomas (1908b:2). Subspecies rank recognized within pearsonii by Ellerman (1940:277). Synonymized within pearsonii by Ellerman and Morrison-Scott (1951:459), Ellerman (1961:18), Corbet and Hill (1992:307), Hoffmann et al. (1993:459), and Thorington and Hoffmann (2005:767).

\section{Belomys pearsonii blandus Osgood, 1932}

Belomys pearsoni blandus Osgood, 1932:269.

Type Locality. Muong Moun, south of Lai Chau, Tonkin, Vietnam.

Comments. Synonymized within trichotis by Ellerman and Morrison-Scott (1951:459). Subspecies 
rank recognized within pearsonii by Ellerman (1940:277), Corbet and Hill (1992:307), who placed it in Trogopterus, Wang (2003:155), and Thorington and Hoffmann (2005:767), who placed it in Belomys.

Distribution. Occurs in southeast and central China, including the provinces of Henan, Guizou, Guangxi, and Guangdong, and Hainan Island. The distribution extends into northern Burma, northern and central Thailand, and central Laos, with isolated populations throughout Vietnam (Lekagul and McNeely, 1988:387; Corbet and Hill, 1992:307; Zhang et al., 1997:150; Francis, 2008:152; Smith and Xie, 2008:174).

\section{Belomys pearsonii kaleensis Swinhoe, 1863}

Sciuropterus kaleënsis Swinhoe, 1863:359.

Type Locality. North Taiwan (formerly Formosa), China.

Comments. Recognized as a species within Belomys by Thomas (1908b:2). Synonymized within pearsonii by Ellerman and Morrison-Scott (1951:459), Corbet and Hill (1992:307), Hoffmann et al. (1993:459), and Thorington and Hoffmann (2005:767). Recognized as a subspecies of pearsonii by Ellerman (1940:279), Wang (2003:155), and Smith and Xie (2008:175).

\section{Belomys pearsonii trichotis Thomas, 1908}

Belomys trichotis Thomas, $1908 \mathrm{~b}: 7$.

Type Locality. Machi, Manipur, India.

COMments. Synonymized within pearsonii by Corbet and Hill (1992:307) and Thorington and Hoffmann (2005:767). Recognized as a subspecies of pearsonii by Ellerman (1940:279; 1961:22), Ellerman and Morrison-Scott (1951:459), Yin (1967:216), Agrawal and Chakraborty (1979a:335), Zhang et al. (1997:150), Wang (2003:155), and Smith and Xie (2008:175).

Distribution. Occurs in Yunnan, China, and in Manipur, India (Smith and Xie (2008:175).

\section{†Belomys thamkaewi Chaimanee and Jaeger, 2000}

†Belomys thamkaewi Chaimanee and Jaeger, 2000:307, 308.

Type Locality. Crystal Cave, Kanchanaburi Province, western Thailand.

Comments. Middle to late Pleistocene to late Pleistocene.

\section{Biswamoyopterus Saha, 1981}

Biswamoyopterus Saha, 1981:331.

Type Species. Biswamoyopterus biswasi Saha, 1981:333.

\section{Biswamoyopterus biswasi Saha, 1981 (Namdapha flying squirrel)}

Biswamoyopterus biswasi Saha, 1981:333, pls. 5, 6.

Type Locality. East of Miao, Namdapha, Tirap District, Arunachal Pradesh, Patkai Range, northeast India.

Comments. Known only from the holotype location.

Distribution. Only known from east of Miao, Namdapha, and Tirap districts in Arunachal Pradesh, India (Corbet and Hill, 1992:314).

\section{†Blackia Mein, 1970}

†Blackia Mein, 1970:44.

Type Species. †Blackia miocaenica Mein, 1970:44.

Comments. Early Miocene to Late Pliocene, Europe. Genus recognized within the family Sciuridae by Mein (1970:44), tribe Blackini by de Bruijn et al. (1980:241, 253), subfamily Pteromyinae by McKenna and Bell (1997:127), and the family Petauristidae by de Bruijn (1999:276).

\section{†Blackia miocaenica Mein, 1970}

†Blackia miocaenica Mein, 1970:44.

Type Locality. La Grive, France.

Comments. Mid-Miocene. Species recognized within †Blackia by Daxner-Höck (1975:64; 2004:402) and subsequent authors.

†Blackia parvula Baudelot, 1972: page unknown.

Type Locality. Sansan, France.

Comments. Mid-Miocene. Reference not seen, with information derived from the following sources. Synonymized with †Blackia miocaenica by several authors, including Engesser (1972:179), de Bruijn et al. (1980:253), and de Bruijn (1998:105; 1999:276), which was followed by Daxner-Höck (2004:404).

†Blackia ulmensis Werner, 1994:166.

Type Locality. Ulm-Westtangente, Germany. 
Comments. Early Miocene. Synonymized with †Blackia miocaenica by de Bruijn (1999:276).

\section{†Blackia woelfersheimensis Mein, 1970}

†Blackia woelfersheimensis Mein, 1970:47.

Type Locality. Wölfersheim, Germany.

Comments. Pliocene. The validity of this species has been questioned by several authors, who suggest that the type material is insufficiently known to define a separate species from Blackia miocaenica, including Daxner-Höck (1975:65), de Bruijn (1998:105), and Dahlmann (2001:56). Species recognized within †Blackia by de Bruijn (1999:276) and Daxner-Höck (2004:402).

†Blackia polonica Black and Kowalski, 1974:472.

Type Locality. Podlesice, Poland.

Comments. Pliocene. Synonymized within woelfersheimensis by de Bruijn (1999:276).

\section{Eoglaucomys Howell, 1915}

Eoglaucomys Howell, 1915:109.

Type Species. Sciuropterus fimbriatus Gray, 1837a:584.

Comments. Recognized by Ellerman (1940: 297), but Ellerman (1947:256; 1961:55, 71) and Ellerman and Morrison-Scott (1951:468; 1955:31) reduced Eoglaucomys to a subgenus of Hylopetes. Recognized at genus rank again by McKenna (1962:9) and Thorington et al. (1996:96) and subsequently used by McKenna and Bell (1997:128), Oshida et al. (2004a:1336), and Thorington and Hoffmann (2005:767).

\section{Eoglaucomys fimbriatus (Gray, 1837) (Kashmir flying squirrel)}

\section{Eoglaucomys fimbriatus fimbriatus (Gray, 1837)}

Sciuroptera fimbriata Gray, 1837a:584.

Type Locality. Shimla, Punjab State, India.

Comments. This taxon was also described in Gray (1837b:67). Transferred to Pteromys by Anderson (1879:296), but returned to Sciuropterus by Sclater (1891:37). Synonymized within baberi by Corbet and Hill (1991:145). Included within Eoglaucomys by Ellerman (1940:297) and Hylopetes by Agrawal and Chakraborty (1979a:346) and Corbet and Hill (1992:317); however, it was transferred to Eoglaucomys by Thorington et al. (1996) and adopted by McKenna and Bell (1997:128) and Thorington and Hoffmann (2005:767).

Distribution. Northern Punjab Province (Pakistan) and Kashmir east to Shimla, Himachal Pradesh, in northern India (Corbet and Hill, 1992:317).

\section{Eoglaucomys fimbriatus baberi (Blyth, 1847)}

Sc. [iuropterus] baberi Blyth, 1847:866.

Type Locality. Mountain district of Nijrow, Kohistan, Pakistan.

Comments. Recognized as the same or closely allied to fimbriatus by Jerdon (1874:179) but as a distinct species within Pteromys by Anderson (1879:297). Treated as a subspecies of fimbriatus by Ellerman (1940:298; 1961:76), Ellerman and Morrison-Scott (1951:468), and most subsequent authors. Transferred to Hylopetes as a full species by Chakraborty (1981:58) and Corbet and Hill (1986:154; 1991:145; 1992:317). However, the purported baculum differences with fimbriatus were not great on reexamination by Thorington et al. (1996:71), and it was subsequently lowered to subspecies status by Thorington and Hoffmann (2005:767).

Distribution. Northeastern Afghanistan in the Khost and Nangarhar provinces east to the North West Frontier and Federal Control regions of northern Pakistan (Corbet and Hill, 1992:317; Roberts, 1997:323).

\section{Eupetaurus Thomas, 1888}

Eupetaurus Thomas, 1888b:256.

Type Species. Eupetaurus cinereus Thomas, 1888b:256.

Comments. The divergent nature of the teeth of this genus compared with all other flying squirrels led Schaub (1953:395; 1958:714) and Grassé and Dekeyser $(1955: 1496)$ to place this genus in its own family, the Eupetauridae.

\section{Eupetaurus cinereus Thomas, 1888 (woolly flying squirrel)}

Eupetaurus cinereus Thomas, 1888b:258, pls. 22, 23.

Type Locality. Gilgit Valley, Kashmir, Pakistan. $1,828 \mathrm{~m}(\sim 6,000 \mathrm{ft})$.

Distribution. Restricted to only a few localities on the Himalayas, and appears to consist of two distinct populations. In the western Himalayan region, 
this species appears to be restricted to only a few localities between 2400 and $3600 \mathrm{~m}$ (8,000-12,000 ft) near Gilgit in the Northern Areas, where its range appears to fall within a small area where the Himalayan, Karakoram, and Hindu Kush mountain ranges meet (Zahler and Woods, 1997:503). A second population in the eastern Himalayas was first reported by Anderson (1879:284), who collected a specimen for the Leiden Museum. Specimens from this subpopulation are also known from Sikkim (northern India), Tibet, and Yunnan (southwestern China) (Agrawal and Chakraborty, 1970:615; Prater, 1980:195; Zhang et al., 1997:156; Wang, 2003:160; Wangchuk et al., 2004:149). This subpopulation has recently been proposed to be a separate species (Yu et al., 2004:735).

\section{†Forsythia Mein, 1970}

†Forsythia Mein, 1970:33.

Type Species. †Sciuropterus gaudryi Gaillard, 1899:67.

Comments. Mid-Miocene, Europe. Genus recognized within the family Petauristidae by de Bruijn (1999:275) and subfamily Pteromyinae by McKenna and Bell (1997:127).

\section{†Forsythia gaudryi (Gaillard, 1899)}

†Sciuropterus gaudryi Gaillard, 1899:66.

Type Locality. La Grive-Saint Alban (Isere), France.

Comments. Miocene. Species recognized within †Forsythia by de Bruijn (1999:275).

\section{Glaucomys Thomas, 1908}

Glaucomys Thomas, 1908b:5.

Type Species. Mus volans Linnaeus, 1758:59.

Comments. Revised by Howell (1918:11). Described as a subgenus of Sciuropterus. Elevated to generic rank by Ellerman (1940:261, 294) and recognized by subsequent authors. Mid-Pleistocene to Recent, North America. Various fossils, unassigned to species, have been found, including those by Ruez (2001:155) from the late Pliocene from Citrus County, Florida, USA.

Mus Linnaeus, 1758 [part]:59.

Type Species. Mus volans Linnaeus, 1758:63.

Comments. Synonymized within Glaucomys

by Howell (1918:11).
Sciurus Pallas, 1778 [part]:351.

Type Species. $\quad$ Sciurus volucella Pallas, 1778: 351.

Comments. Synonymized within Glaucomys by Howell (1918:11).

Homonym. Sciurus Linnaeus, 1758:63, tree squirrels of the class Mammalia (order Rodentia, family Sciuridae).

Pteromys Tiedemann, 1808 [part]:451.

Type Species. Pteromys russicus Tiedemann, 1808:451.

Comments. Synonymized within Glaucomys by Howell (1918:11).

Homonym. Pteromys G. Cuvier, 1800: tab. 1, Eurasian flying squirrels of the class Mammalia (order Rodentia, family Sciuridae).

Sciuropterus Lesson, 1827 [part]:241.

Type Species. Sciuropterus sagitta Linnaeus, 1766:88.

Comments. Synonymized within Glaucomys by Howell (1918:11). Not Sciuropterus F. Cuvier (1825a:126).

\section{Glaucomys sabrinus (Shaw, 1801) (northern flying squirrel)}

\section{Glaucomys sabrinus sabrinus (Shaw, 1801)}

Sciurus sabrinus Shaw, 1801:157.

Type Locality. A renaming of Sciurus hudsoni Gmelin. Not specified. Restricted by Howell (1918:33) to the mouth of Severn River, Ontario, Canada.

Comments. Included within Sciuropterus by most early authors, including Elliot (1901:107) and Thomas (1908b:6), who placed it in the subgenus Glaucomys. Included in Glaucomys at generic rank by Howell (1915:110; 1918:11, 16), Ellerman (1940:261, 294), and subsequent authors. Revised by Howell (1918:29) and Wells-Gosling and Heaney (1984:1). Subspecies follow Howell (1918:29), Hall (1981:407), Wells-Gosling and Heaney (1984:1), and Thorington and Hoffmann (2005:768). Fossils presently assigned to Glaucomys sabrinus are known from various Pleistocene and Holocene deposits in North America (Wells-Gosling and Heaney, 1984:3; Kurtén and Anderson, 1980:222). These include late Pleistocene deposits from Eagle Cave, West Virginia (Guilday and Hamilton, 1973:51), Baker Bluff, Tennessee (Guilday et al., 1978:38), Robinson Cave, Tennessee 
(Guilday et al., 1969:51), Bedford County, Pennsylvania (Guilday et al., 1964:153), and Augusta County, Virginia (Guilday, 1962a:93).

Distribution. Western Newfoundland through Quebec and northern Ontario to northwest portion of Northwest Territories, Canada (Wilson and Ruff, 1999: 463).

Pteromys canadensis É. Geoffroy Saint-Hilaire, 1803a:170. Type Locality. North America, probably Quebec, Canada.

Comments. Synonymized within sabrinus by Howell (1918:31), Hall and Kelson (1959:411), Hall (1981:453), Wells-Gosling and Heaney (1984:1), and Thorington and Hoffmann (2005:768).

[Sciurus] hudsonius Gmelin, 1788:153.

Type Locality. Mouth of the Severn River, Ontario, Canada.

Comments. Synonymized within sabrinus by Howell (1918:31), Hall and Kelson (1959:411), Hall (1981:453), Wells-Gosling and Heaney (1984:1), and Thorington and Hoffmann (2005:768).

\section{Glaucomys sabrinus alpinus (Richardson, 1828)}

Pteromys alpinus Richardson, 1828:519.

Type Locality. Jasper House, Alberta, Canada.

Comments. Transferred to Glaucomys by Howell (1918:56). Subspecies rank recognized within $s a-$ brinus by Howell (1918:40), Ellerman (1940:296), Hall and Kelson (1959:408), Hall (1981:450), Wells-Gosling and Heaney (1984:1), and Thorington and Hoffmann (2005:768).

Distribution. Northern and eastern British Columbia, Canada (Wilson and Ruff, 1999:463).

\section{Glaucomys sabrinus bangsi (Rhoads, 1897)}

Sciuropterus alpinus bangsi Rhoads, 1897:321.

Type Locality. Idaho County, Idaho, USA.

Comments. Transferred to Glaucomys by Howell (1918:38). Subspecies rank recognized within sabrinus by Howell (1918:38), Ellerman (1940:296), Hall and Kelson (1959:408), Hall (1981:450), Wells-Gosling and Heaney (1984:1), and Thorington and Hoffmann (2005:768).

Distribution. Central Idaho, western Montana, and the Black Hills in western South Dakota and northeastern Wyoming, USA (Wilson and Ruff, 1999:463).
Glaucomys bullatus Howell, 1915:113.

Type Locality. Sawtooth Lake, Idaho, USA.

Comments. Recognized as a subspecies of $s a b$ rinus by Howell (1918:51) and Ellerman (1940:297). Synonymized within sabrinus by Hall and Kelson (1959:408), Hall (1981:450), and Wells-Gosling and Heaney (1984:1) and within bangsi by Thorington and Hoffmann (2005:768).

\section{Glaucomys sabrinus californicus (Rhoads, 1897)}

Sciuropterus alpinus californicus Rhoads, 1897:323.

Type Locality. Near Squirrel Inn, San Bernardino Mountains, San Bernardino County, California, USA. $1,585 \mathrm{~m}(5,200 \mathrm{ft})$.

Comments. Transferred to Glaucomys by Howell (1918:56). Subspecies rank recognized within $s a$ brinus by Howell (1918:56), Ellerman (1940:297), Hall and Kelson (1959:408, 409), Hall (1981:450), WellsGosling and Heaney (1984:1), and Thorington and Hoffmann (2005:768).

Distribution. High peaks in southern California, USA (Wilson and Ruff, 1999:463).

\section{Glaucomys sabrinus canescens Howell, 1915}

Glaucomys sabrinus canescens Howell, 1915:111.

Type Locality. Portage la Prairie, Manitoba, Canada.

Comments. Subspecies rank recognized within sabrinus by Howell (1918:37), Ellerman (1940:296), Hall and Kelson (1959:408, 409), Hall (1981:450), WellsGosling and Heaney (1984:1), and Thorington and Hoffmann (2005:768).

Distribution. Northwestern Minnesota and eastern North Dakota, USA, and south central Manitoba, Canada (Wilson and Ruff, 1999:463).

\section{Glaucomys sabrinus coloratus Handley, 1953}

Glaucomys sabrinus coloratus Handley, 1953:191.

Type Locality. Bald Knob, Mount Mitchell, Yancey County, North Carolina, USA. 1,524 m (5,000 ft).

Comments. Subspecies rank recognized by Hall and Kelson (1959:408, 409), Hall (1981:450), WellsGosling and Heaney (1984:1), and Thorington and Hoffmann (2005:768).

Distribution. Mountains of western North Carolina and eastern Tennessee, USA (Wilson and Ruff, 1999:463). 


\section{Glaucomys sabrinus columbiensis Howell, 1915}

Glaucomys sabrinus columbiensis Howell, 1915:111.

TyPe Locality. Okanogan, British Columbia, Canada.

Comments. Subspecies rank recognized within sabrinus by Howell (1918:45), Ellerman (1940:296), Hall and Kelson (1959:408, 409), Hall (1981:451), WellsGosling and Heaney (1984:1), and Thorington and Hoffmann (2005:768).

Distribution. South central British Columbia, Canada, and adjacent Washington, USA (Wilson and Ruff, 1999:463).

\section{Glaucomys sabrinus flaviventris Howell, 1915}

Glaucomys sabrinus flaviventris Howell, 1915:112.

Type LocAlity. Head of Bear Creek, Trinity County, California, USA.

Comments. Subspecies rank recognized within sabrinus by Howell (1918:54), Ellerman (1940:297), Hall and Kelson (1959:408, 409), Hall (1981:451), WellsGosling and Heaney (1984:1), and Thorington and Hoffmann (2005:768).

Distribution. North central California, USA (Wilson and Ruff, 1999:463).

\section{Glaucomys sabrinus fuliginosus (Rhoads, 1897)}

Sciuropterus alpinus fuliginosus Rhoads, 1897:321.

Type Locality. Cascade Mountains, near Martin Station, Kittitas County, Washington, USA.

Comments. Subspecies rank recognized within sabrinus by Howell (1918:47), Ellerman (1940:296), Hall and Kelson (1959:408, 409), Hall (1981:451), WellsGosling and Heaney (1984:1), and Thorington and Hoffmann (2005:768).

Distribution. Southwestern Oregon, USA, to southwestern British Columbia, Canada (Wilson and Ruff, 1999:463).

\section{Glaucomys sabrinus fuscus Miller, 1936}

Glaucomys sabrinus fuscus Miller, 1936:143.

Type Locality. Cranberry Glades, Pocahontas County, West Virginia, USA. 1,000 m (3,300 ft).

Comments. Subspecies rank recognized within sabrinus by Ellerman (1940:297), Hall and Kelson (1959:408, 409), Hall (1981:451), Wells-Gosling and
Heaney (1984:1), and Thorington and Hoffmann (2005: 768).

Distribution. High mountains in east central West Virginia, USA (Wilson and Ruff, 1999:463).

\section{Glaucomys sabrinus goodwini Anderson, 1943}

Glaucomys sabrinus goodwini Anderson, 1943:55.

Type Locality. Junction Berry Mountain Brook and Grand Cascapedia River, Mantane County, Quebec, Canada. $457 \mathrm{~m}$ (1,500 ft).

Comments. Subspecies rank recognized by Hall and Kelson (1959:408, 409), Hall (1981:451), WellsGosling and Heaney (1984:1), and Thorington and Hoffmann (2005:768).

Distribution. Northern New Brunswick and adjacent Quebec, Canada (Wilson and Ruff, 1999:463).

\section{Glaucomys sabrinus gouldi Anderson, 1943}

Glaucomys sabrinus gouldi Anderson, 1943:56.

Type Locality. Frizzleton, Inverness County, Cape Breton Island, Nova Scotia, Canada.

Comments. Subspecies rank recognized by Hall and Kelson (1959:408, 410), Hall (1981:451), WellsGosling and Heaney (1984:1), and Thorington and Hoffmann (2005:768).

Distribution. Nova Scotia, Canada (Wilson and Ruff, 1999:463).

\section{Glaucomys sabrinus griseifrons Howell, 1934}

Glaucomys sabrinus griseifrons Howell, 1934:64.

Type Locality. Lake Bay, Prince of Wales Island, Alaska.

Comments. Subspecies rank recognized within sabrinus by Ellerman (1940:297), Hall and Kelson (1959:408, 410), Hall (1981:451), Wells-Gosling and Heaney (1984:1), and Thorington and Hoffmann (2005:768).

Distribution. Prince of Wales Island, Alaska, USA (Wilson and Ruff, 1999:463).

\section{Glaucomys sabrinus klamathensis (Merriam, 1897)}

Sciuropterus alpinus klamathensis Merriam, 1897:225.

TYPe LOcAlity. Fort Klamath, Klamath County, Oregon, USA.

Comments. Transferred to Glaucomys by Howell (1918:52). Subspecies rank recognized within 
sabrinus by Howell (1918:52), Ellerman (1940:297), Hall and Kelson (1959:408, 410), Hall (1981:451), WellsGosling and Heaney (1984:1), and Thorington and Hoffmann $(2005: 768)$.

Distribution. South central Oregon, USA (Wilson and Ruff, 1999:463).

\section{Glaucomys sabrinus lascivus (Bangs, 1899)}

Sciuropterus alpinus lascivus Bangs, 1899:69.

Type Locality. Tallac, El Dorado County, California, USA.

Comments. Subspecies rank recognized within sabrinus by Howell (1918:55), Ellerman (1940:297), Hall and Kelson (1959:408, 410), Hall (1981:451), WellsGosling and Heaney (1984:1), and Thorington and Hoffmann (2005:768).

Distribution. Sierra Nevada of California, USA (Wilson and Ruff, 1999:463).

\section{Glaucomys sabrinus latipes Howell, 1915}

Glaucomys sabrinus latipes Howell, 1915:112.

Type Locality. Glacier, British Columbia, Canada.

Comments. Subspecies rank recognized within sabrinus by Howell (1918:48), Ellerman (1940:296), Hall and Kelson (1959:408, 410), Hall (1981:451), and WellsGosling and Heaney (1984:1).

Distribution. British Columbia and Alberta, Canada, to Montana, northern Idaho, and adjacent parts of Washington, USA (Wilson and Ruff, 1999:463).

\section{Glaucomys sabrinus lucifugus Hall, 1934}

Glaucomys sabrinus lucifugus Hall, 1934:1.

Type Locality. $19 \mathrm{~km}$ (12 mi) east of Kamas, Summit County, Utah, USA.

Comments. Subspecies rank recognized within sabrinus by Ellerman (1940:297), Hall and Kelson (1959:408, 410), Hall (1981:451), Wells-Gosling and Heaney (1984:1), and Thorington and Hoffmann (2005:768).

Distribution. Mountains of central and northern Utah, USA (Wilson and Ruff, 1999:463).

\section{Glaucomys sabrinus macrotis (Mearns, 1898)}

Sciuropterus sabrinus macrotis Mearns, 1898:353.

Type Locality. Hunter Mountain (Catskills), Green County, New York, USA. 914 m (3,000ft).
Comments. Transferred to Glaucomys by Howell (1915:111). Subspecies rank recognized within sabrinus by Howell (1918:35), Ellerman (1940:296), Hall and Kelson (1959:408, 410), Hall (1981:452), WellsGosling and Heaney (1984:1), and Thorington and Hoffmann (2005:768).

Distribution. Southern Ontario, Canada, and New England, northern Michigan, and northern Wisconsin, USA (Wilson and Ruff, 1999:463).

\section{Glaucomys sabrinus makkovikensis (Sornborger, 1900)}

Sciuropterus sabrinus makkovikensis Sornborger, 1900:48.

TYpe Locality. Makkovik, Labrador, Newfoundland, Canada.

Comments. Transferred to Glaucomys by Howell (1918:34). Subspecies rank recognized within sabrinus by Howell (1918:34), Ellerman (1940:296), Hall and Kelson (1959:408, 410), Hall (1981:453), WellsGosling and Heaney (1984:1), and Thorington and Hoffmann (2005:768).

Distribution. Northeastern Newfoundland and adjacent Quebec, Canada (Wilson and Ruff, 1999:463).

\section{Glaucomys sabrinus murinauralis Musser, 1961}

Glaucomys sabrinus murinauralis Musser, 1961:120.

TYPe LOCALITY. $\quad 1.6 \mathrm{~km} \mathrm{(1} \mathrm{mi)} \mathrm{north} \mathrm{of}$ Big Flat Guard Station, Timid Springs, Tushar Mountains, Beaver County, Utah, USA. 3,139 m (10,300 ft).

Comments. Subspecies rank recognized by Hall (1981:453), Wells-Gosling and Heaney (1984:1), and Thorington and Hoffmann (2005:768).

Distribution. Mountains of southwestern Utah, USA (Wilson and Ruff, 1999:463).

\section{Glaucomys sabrinus oregonensis (Bachman, 1839)}

Pteromys oregonensis Bachman, 1839:101.

TYPe Locality. Columbia County, Oregon, USA.

Comments. Transferred to Glaucomys by Howell (1918:44). Subspecies rank recognized within sabrinus by Howell (1918:44), Ellerman (1940:296), Hall and Kelson (1959:408, 410), Hall (1981:453), Wells-Gosling 
and Heaney (1984:1), and Thorington and Hoffmann (2005:768).

Distribution. Southwestern British Columbia, Canada, and coastal Oregon and Washington, USA (Wilson and Ruff, 1999:463).

Sciuropterus alpinus olympicus Elliot, 1899:225.

TYpe Locality. Happy Lake, Challam County, Olympic Mountains, Washington, USA. 1,524 m (5,000 ft).

Comments. Recognized as a subspecies of sabrinus by Howell (1918:34) and Ellerman (1940:297). Synonymized within sabrinus by Wells-Gosling and Heaney (1984:1) and within oregonensis by Hall and Kelson (1959:410), Hall (1981:453), and Thorington and Hoffmann (2005:768).

\section{Glaucomys sabrinus reductus Cowan, 1937}

Glaucomys sabrinus reductus Cowan, 1937:79.

Type Locality. Lonesome Lake, on the Atnarko River, British Columbia, Canada. Approximately $52^{\circ} 10^{\prime} \mathrm{N}, 125^{\circ} 45^{\prime} \mathrm{W}$.

Comments. Subspecies rank recognized by Hall and Kelson (1959:408, 410), Hall (1981:453), WellsGosling and Heaney (1984:1), and Thorington and Hoffmann (2005:768).

Distribution. West central British Columbia, Canada (Wilson and Ruff, 1999:463).

\section{Glaucomys sabrinus stephensi (Merriam, 1900)}

Sciuropterus oregonensis stephensi Merriam, 1900:151.

TYPe LOCALITY. Sherwood, Mendocino County, California, USA. $762 \mathrm{~m}(2,500 \mathrm{ft})$.

Comments. Transferred to Glaucomys by Howell (1918:57). Subspecies rank recognized within sabrinus by Howell (1918:57), Ellerman (1940:297), Hall and Kelson (1959:408, 411), Hall (1981:453), Wells-Gosling and Heaney (1984:1), and Thorington and Hoffmann (2005:768).

Distribution. Northwestern California, USA (Wilson and Ruff, 1999:463).

\section{Glaucomys sabrinus yukonensis (Osgood, 1900)}

Sciuropterus yukonensis Osgood, 1900:25.

Type Locality. Cape Davidson, Yukon River, near Alaska-Canada boundary, Yukon, Canada.

Comments. Transferred to Glaucomys by Howell (1918:41). Subspecies rank recognized within $s a-$ brinus by Howell (1918:41), Ellerman (1940:296), Hall and Kelson (1959:408, 411), Hall (1981:453), WellsGosling and Heaney (1984:1), and Thorington and Hoffmann (2005:768).

Distribution. Central and southern Yukon, Canada, and southern and central Alaska, USA (Wilson and Ruff, 1999:463).

\section{Glaucomys sabrinus zaphaeus (Osgood, 1905)}

Sciuropterus alpinus zaphaeus Osgood, 1905:133.

Type Locality. Helm Bay, Cleveland Peninsula, southeast Alaska, USA.

COMments. Subspecies rank recognized within sabrinus by Howell (1918:43), Ellerman (1940:296), Hall and Kelson (1959:408, 411), Hall (1981:453), WellsGosling and Heaney (1984:1), and Thorington and Hoffmann (2005:768).

Distribution. Central and northern British Colombia, Canada (Wilson and Ruff, 1999:463).

\section{Glaucomys volans (Linnaeus, 1758) (southern flying squirrel)}

\section{Glaucomys volans volans (Linnaeus, 1758)}

[Mus] volans Linnaeus, 1758:63.

Type Locality. Virginia, USA, and Mexico; restricted by Elliot (1901:109) to Virginia, USA.

COMments. Included within Sciuropterus by most early authors, including Elliot (1901:107) and Thomas (1908b:6), who placed it in the subgenus Glaucomys. Included in Glaucomys at generic rank by Howell (1915:110; 1918:11, 16), Ellerman (1940:261, 294), and subsequent authors. Subspecies derived from Howell (1918:18), Hall (1981:449), Dolan and Carter (1977:1), and Thorington and Hoffmann (2005:768). Fossils presently assigned to Glaucomys sabrinus are known from various Pleistocene and Holocene deposits in North America (Dolan and Carter, 1977:2; Kurtén and Anderson, 1980:222). These include Baker Bluff, Tennessee (Guilday et al., 1978:38), Overton County, Tennessee (Guilday et al., 1969:52), Bedford County, Pennsylvania (Guilday et al., 1964:154), Augusta County, Virginia (Guilday, 1962a:93), and Wythe County, Virginia (Guilday, 1962b:79).

Distribution. Eastern North America from southern Ontario, southern Quebec, and Nova Scotia, Canada, and Maine, New Hampshire, and Vermont to Massachusetts, Connecticut, New York, Pennsylvania, New Jersey, Maryland, West Virginia, Ohio, Michigan, Indiana, Wisconsin, western Minnesota, Iowa, eastern 
Nebraska, eastern Kansas, Missouri, Kentucky, West Virginia, Virginia, Tennessee, and North Carolina, USA (Wilson and Ruff, 1999:465).

Sciurus petaurista Erxleben, 1777:435.

Type Locality. A renaming of Mus volans Linnaeus, 1758.

Comments. Synonymized within volans by Dolan and Carter (1977:1).

Sciurus volucella Pallas, 1778:353.

TYPe Locality. A renaming of Mus volans Linnaeus, 1758.

Comments. Recognized within Sciuropterus by Sclater (1891:40). Synonymized within volans by Howell (1918:19), Hall and Kelson (1959:407), Dolan and Carter (1977:1), Hall (1981:449), and Thorington and Hoffmann (2005:768).

Sciurus aërobates Schreber, 1792: pl. 222B.

Type Locality. Unknown.

Comments. Date of publication confirmed from Sherborn (1891:590). Synonymized within voluccella by Fischer (1829:365) and Wagner (1843:216).

P.[teromys] virginianus Tiedemann, 1808:451.

Type Locality. Virginia, USA.

Comments. Synonymized within volans by Howell (1918:19), Hall and Kelson (1959:407), Dolan and Carter (1977:1), Hall (1981:449), and Thorington and Hoffmann (2005:768).

Pt. [eromys] americana Oken, 1816:865.

TYPe Locality. Unknown.

COMments. Synonymized within volans by Howell (1918:19), Hall and Kelson (1959:407), Dolan and Carter (1977:1), Hall (1981:449), and Thorington and Hoffmann (2005:768).

Pt.[eromys] cucullatus Fischer, 1829:365.

Type Locality. Virginia?, USA.

COMments. Synonymized within volans by Howell (1918:19), Hall and Kelson (1959:407), Dolan and Carter (1977:1), Hall (1981:449), and Thorington and Hoffmann (2005:768).

Sciuropterus silus Bangs, 1896:163.

Type Locality. Katis Mountains, White Sulphur Springs, West Virginia, USA. 975 m (3,200 ft).

Comments. Synonymized within volans by Howell (1918:20), Hall and Kelson (1959:407), Dolan and Carter (1977:1), Hall (1981:449), and Thorington and Hoffmann (2005:768).

Pteromys volans nebrascensis Swenk, 1915:151.

Type Locality. Nebraska City, Otoe County, Nebraska, Canada.

COMments. Synonymized within volans by Howell (1918:20), Hall and Kelson (1959:407), Hall (1981:449), and Thorington and Hoffmann (2005:768).

\section{Glaucomys volans chontali Goodwin, 1961}

Glaucomys volans chontali Goodwin, 1961:3.

Type Locality. Santo Domingo, Chontecomatlén, District of Yautepec, Oaxaca, Mexico.

Comments. Subspecies rank recognized within volans by Dolan and Carter (1977:1), Hall (1981:448), and Thorington and Hoffmann (2005:768).

Distribution. District of Yautepec, Oaxaca, Mexico (Wilson and Ruff, 1999:465).

\section{Glaucomys volans goldmani (Nelson, 1904)}

Sciuropterus volans goldmani Nelson, 1904:148.

Type Locality. Southeast of Teopisca, Chiapas, Mexico.

Comments. Transferred to Glaucomys by Howell (1918:28). Subspecies rank recognized within volans by Howell (1918:28), Ellerman (1940:295), Goodwin (1961:5), Hall and Kelson (1959:406), Dolan and Carter (1977:1), Hall (1981:448), and Thorington and Hoffmann (2005:768).

Distribution. Highlands of Chiapas, Mexico (Wilson and Ruff, 1999:465).

\section{Glaucomys volans guerreroensis Diersing, 1980}

Glaucomys volans guerreroensis Diersing, 1980:162.

Type Locality. Omilteme, Guerrero, Mexico.

Comments. Subspecies rank not recognized by Wilson and Ruff (1999:465) but recognized by Thorington and Hoffmann (2005:768).

Distribution. Guerrero, Mexico (Diersing, 1980:162).

\section{Glaucomys volans herreranus Goldman, 1936}

Glaucomys volans herreranus Goldman, 1936:463.

Type Locality. Mountains of Vera Cruz, Mexico. 
Comments. Subspecies rank recognized within volans by Ellerman (1940:295), Hall and Kelson (1959:406), Goodwin (1961:7), Hall (1981:448), Dolan and Carter (1977:1), and Thorington and Hoffmann (2005:768).

Distribution. Higher elevations in parts of Tamaulipas, San Luis Potosi, Veracruz, Oaxaca, Queretaro, and Michoacan, Mexico (Wilson and Ruff, 1999:465).

\section{Glaucomys volans madrensis Goldman, 1936}

Glaucomys volans madrensis Goldman, 1936:463.

Type Locality. Sierra Madre, Chihuahua, Mexico.

Comments. Subspecies rank recognized within volans by Ellerman (1940:296), Hall and Kelson (1959:406, 407), Goodwin (1961:9), Hall (1981:448), Dolan and Carter (1977:1), and Thorington and Hoffmann (2005:768).

Distribution. Sierra Madre Occidentale, Chihuahua, Mexico (Wilson and Ruff, 1999:465).

\section{Glaucomys volans oaxacensis Goodwin, 1961}

Glaucomys volans oaxacensis Goodwin, 1961:11.

Type Locality. San Pedro Jilotepec, District of Tehuantepec, Oaxaca, Mexico.

Comments. Subspecies rank recognized within volans by Dolan and Carter (1977:1), Hall (1981:448), and Thorington and Hoffmann (2005:768).

Distribution. Higher elevations in parts of Guerrero and Oaxaca, Mexico (Wilson and Ruff, 1999:465).

\section{Glaucomys volans querceti (Bangs, 1896)}

Sciuropterus volans querceti Bangs, 1896:166.

Type Locality. Cintronelle, Citrus County, Florida, USA.

Comments. Transferred to Glaucomys by Howell (1918:26). Subspecies rank recognized within volans by Ellerman (1940:295), Hall and Kelson (1959:406, 407), Dolan and Carter (1977:1), Hall (1981:449), and Thorington and Hoffmann (2005:768).

Distribution. Southeastern Georgia and peninsular Florida, USA (Wilson and Ruff, 1999:465).

\section{Glaucomys volans saturatus Howell, 1915}

Glaucomys volans saturatus Howell, 1915:110.
Type Locality. Dothan, Houston County, Alabama, USA.

Comments. Subspecies rank recognized within volans by Howell (1918:24), Ellerman (1940:295), Hall and Kelson (1959:406, 407), Hall (1981:449), Dolan and Carter (1977:1), and Thorington and Hoffmann (2005:768).

Distribution. Eastern Oklahoma, Arkansas, Tennessee, western North Carolina, Louisiana, Mississippi, Alabama, Georgia, South Carolina, and northwestern Florida, USA (Wilson and Ruff, 1999:465).

\section{Glaucomys volans texensis Howell, 1915}

Glaucomys volans texensis Howell, 1915:110.

Type Locality. Sour Lake, Hardin County, Texas, USA.

Comments. Subspecies rank recognized within volans by Howell (1918:27), Ellerman (1940:295), Hall and Kelson (1959:406, 407), Hall (1981:449), Dolan and Carter (1977:1), and Thorington and Hoffmann (2005:768).

Distribution. Western Louisiana and eastern Texas, USA (Wilson and Ruff, 1999:465).

\section{Glaucomys volans underwoodi Goodwin, 1936}

Glaucomys volans underwoodi Goodwin, 1936:1.

Type Locality. Zambrano, Tegucigalpa, Honduras. 1,372 m (4,500 ft).

Comments. Subspecies rank recognized within volans by Ellerman (1940:296), Hall and Kelson (1959:406, 407), Goodwin (1961:12), Dolan and Carter (1977:1), Hall (1981:449), and Thorington and Hoffmann (2005:768).

Distribution. Highlands of central Guatemala and Honduras (Wilson and Ruff, 1999:465).

\section{Hylopetes Thomas, 1908}

Hylopetes Thomas, 1908b:6.

Type Species. Sciuropterus everetti Thomas, $1895 \mathrm{c}: 27$.

Comments. Described as a subgenus of $\mathrm{Sci}$ uropterus. Recognized as a subgenus of Pteromys by Allen (1940:722), but separated as a distinct genus by Pocock (1923:246) and subsequent authors. Ellerman (1947:256) included Eoglaucomys as a subgenus within Hylopetes, but it was separated as a distinct genus by McKenna (1962:9), Thorington et al. (1996:69), and 
subsequent authors. Late Miocene to Recent, Asia; early Pliocene, Europe; Recent, SE Asia. Two teeth assigned by Werner (1994:161) to Heteroxerus lavocati were considered to be reminiscent of Hylopetes by de Bruijn (1998:107).

\section{Hylopetes alboniger (Hodgson, 1836) (particolored flying squirrel)}

\section{Hylopetes alboniger alboniger (Hodgson, 1836)}

[Sciuropterus] alboniger Hodgson, 1836:231.

Type Locality. Nepal.

Comments. Recognized within Sciuropterus by Sclater (1891:37). Transferred to Pteromys by Anderson (1879:298) and Hylopetes by Thomas (1908b:6) and followed by most subsequent authors, except Allen (1925:15; 1940:723), who included it within Pteromys (Hylopetes).

Distribution. Eastern Himalayas from Nepal through Sikkim (India), southeastern Tibet, Bhutan, southern Assam (India), northern Burma, northern Thailand, Laos, and Vietnam. At altitudes of 1500-2800 $m$ in Nepal (Ghose and Chakraborty, 1983:411).

P.[teromys] leachii Gray, 1836:88.

Type Locality. India.

Comments. This taxon was also described by Gray (1837a:584). Synonymized within alboniger by Ellerman and Morrison-Scott (1951:469), Ellerman (1961:65), Corbet and Hill (1992:316), and Thorington and Hoffmann (2005:768).

Sciuróptera turnbúllii Gray, 1837a:584.

TYPe LOCALity. India.

Comments. This taxon was also described in Gray (1837b:68). Synonymized within alboniger by Ellerman and Morrison-Scott (1951:469), Ellerman (1961:65), Corbet and Hill (1992:316), and Thorington and Hoffmann (2005:768).

Pteromys (Hylopetes) leonardi Thomas, 1921:501.

Type LOcality. Kachin Province, north Burma. 2,438 m ( 8,000 ft). $28^{\circ} 5^{\prime} \mathrm{N}, 97^{\circ} 23^{\prime} \mathrm{E}$.

Comments. Species rank recognized within Hylopetes by Ellerman (1940:300). Recognized as a subspecies of alboniger by Ellerman and MorrisonScott (1951:470), Ellerman (1961:69, 70), and Yin (1967:227). Synonymized within alboniger by Corbet and Hill (1992:316). Recognized as a subspecies of alboniger by Wang (2003:160) and Smith and Xie (2008:176).

\section{Hylopetes alboniger chianfengensis Wang and Lu, 1966}

Hylopetes alboniger chianfengensis Wang and Lu, 1966:270, 276.

TYPe LocAlity. Chianfeng Mountain, Hainan Island, China.

Comments. Description of this species was identified as being only by the second and third authors. Subspecies rank recognized by Corbet and Hill (1992:316), Zhang et al. (1997:156), Wang (2003:161), and Thorington and Hoffmann (2005:768).

Distribution. Chianfeng Mountain, Hainan Island, China (Corbet and Hill, 1992:316).

\section{Hylopetes alboniger orinus (G. Allen, 1940)}

Pteromys (Hylopetes) alboniger orinus G. Allen, 1940:723.

Type Locality. Likiang Range, Yunnan, China. 2,377 $\mathrm{m}(\sim 7,800 \mathrm{ft})$.

Comments. Synonymized within alboniger by Ellerman and Morrison-Scott (1951:469) and Ellerman (1961:65). Subspecies rank recognized within alboniger by Allen (1940:723), Yin (1967:227), Corbet and Hill (1992:316), Zhang et al. (1997:156), Wang (2003:160), and Thorington and Hoffmann (2005:768).

Distribution. Yunnan, Sichuan, Guizhou, and Zhejiang provinces in China (Corbet and Hill, 1992:316; Zhang et al., 1997:156; Smith and Xie, 2008: 176).

\section{Hylopetes bartelsi (Chasen, 1939) (Bartel's flying squirrel)}

Petinomys bartelsi Chasen, 1939:185.

Type Locality. Tjilondong, Mount Pangrango, west Java, Indonesia. $900 \mathrm{~m}(2,953 \mathrm{ft})$.

Comments. Taxon not recognized by Corbet and Hill (1980:137; 1986:154; 1991:145). Included in Petinomys by Chasen (1940:119) and Corbet and Hill (1986:154; 1991:146), but transferred into Hylopetes by Corbet and Hill (1992:317), Hoffmann et al. (1993:460), and Thorington and Hoffmann (2005:769).

Distribution. Known only from the type locality in western Java (Chasen, 1939:185; Corbet and Hill, 1992:317). 


\section{Hylopetes nigripes (Thomas, 1893) (Palawan flying squirrel)}

\section{Hylopetes nigripes nigripes (Thomas, 1893)}

Sciuropterus nigripes Thomas, 1893:30.

Type Locality. Puerta Princesa, Palawan Island, Philippines.

Comments. Transferred to Hylopetes by Thomas (1908b:6). Corbet and Hill (1992:317) noted that despite its very isolated geographical position this species seems very similar to $H$. alboniger, and it is doubtful if its separation can be justified.

Distribution. Palawan Island, Philippines (Corbet and Hill, 1992:317; Heaney et al., 1998:32).

\section{Hylopetes nigripes elassodontus (Osgood, 1918)}

Sciuropterus nigripes elassodontus Osgood, 1918:1.

Type Locality. Bancalan Island, North Balabac Strait, Philippines.

Comments. Subspecies rank recognized within nigripes by Ellerman (1940:300), Corbet and Hill (1992:317), and Thorington and Hoffmann (2005:769).

Distribution. Bancalan Island (south of Palawan), Philippines (Corbet and Hill, 1992:317; Heaney et al., 1998:32).

\section{Hylopetes phayrei (Blyth, 1859) (Indochinese flying squirrel)}

\section{Hylopetes phayrei phayrei (Blyth, 1859)}

Sc.[iuropterus] phayrei Blyth, 1859:278.

Type Locality. Rangoon, Merqui, Burma.

Comments. Transferred to Hylopetes by Thomas (1908b:6) and followed by subsequent authors. Wang (2003:161) also included a southern China form from Guizhou, Guangxi, and Fujian provinces. Has been recorded as a fossil from several localities throughout Thailand from the late Pliocene to Recent (Chaimanee, 1998:168). Fossils recorded from Wazhuwan and Tianmem in Thailand from 0.5-0.1 MYA to Recent (Zheng, 1993:265).

Distribution. Burma, northwestern Thailand south to Phetburi Province, Laos, Vietnam, and Guizhou, Guangxi, and Fujian provinces in southern China (Lekagul and McNeely, 1988:382; Dao and Cao, 1990:1; Corbet and Hill, 1992:317; Francis, 2008:154; Smith and Xie, 2008:176).
Sciuropterus phayrei probus Thomas, 1914a:27.

Type Locality. Mount Popa, Burma. $910 \mathrm{~m}$ $(3,000 \mathrm{ft})$.

Comments. Subspecies rank recognized within phayrei by Ellerman (1940:300) and Yin (1967:226) . Synonymized within phayrei by Ellerman and MorrisonScott (1951:469), Ellerman (1961:60), Corbet and Hill (1992:317), and Thorington and Hoffmann (2005:769).

Sciuropterus phayrei laotum Thomas, 1914a:28.

Type Locality. Laos Mountains, northern Thailand.

Comments. Subspecies rank recognized within phayrei by Allen and Coolidge (1940:153) and Ellerman (1940:300). Synonymized within phayrei by Ellerman and Morrison-Scott (1951:469), Ellerman (1961:60), Corbet and Hill (1992:317), and Thorington and Hoffmann (2005:769).

Pteromys phayrei anchises G. Allen and Coolidge, 1940:153.

Type Locality. Mount Angka, northern Thailand. 1,310 m (4,300 ft).

Comments. Subspecies rank recognized within phayrei by Ellerman and Morrison-Scott (1951:469). Synonymized within phayrei by Corbet and Hill (1992:317) and Thorington and Hoffmann (2005:769).

\section{Hylopetes phayrei electilis (G. Allen, 1925)}

Pteromys (Petinomys) electilis G. Allen, 1925:16.

Type Locality. Nam Fong, Hainan Island, China.

Comments. Ellerman (1940:301) and Ellerman and Morrison-Scott (1951:470) recognized this taxon as a species within Petinomys. Species rank within Pteromys recognized by Allen (1940:725) and within Hylopetes by Zhang et al. (1997:156). Subspecies recognized within phayrei by Corbet and Hill (1992:317), Wang (2003:161), Thorington and Hoffmann (2005:769), and Smith and Xie (2008:176).

Distribution. Hainan Island, China (Corbet and Hill, 1992:317).

\section{Hylopetes platyurus (Jentink, 1890) (grey-cheeked flying squirrel)}

Sciuropterus platyurus Jentink, 1890a:147.

Type Locality. Deli, northeast Sumatra.

Comments. Transferred to Hylopetes by Thomas (1908b:6) and followed by Chasen (1940:118) and Ellerman (1940:299). Included in lepidus by Corbet 
and Hill (1992:316) and Hoffmann et al. (1993:461), but recognized as a subspecies of lepidus by Hill (1962:730) and Medway (1965:114; 1969:64; 1977:104). Species rank recognized by Thorington et al. (1996:72) and Thorington and Hoffmann (2005:769).

Distribution. Southernmost provinces of Thailand (and Terutau Island), Malay Peninsula, Borneo (within Sabah and Sarawak), and Indonesia, including Bunguran Island (Natuna Islands) and Sumatra (Payne et al., 1985:248; Lekagul and McNeely, 1988; Corbet and Hill, 1992:316; Thorington and Hoffmann, 2005:769; Francis, 2008:345; Rasmussen and Thorington, 2008:1303).

\section{Hylopetes sagitta (Linnaeus, 1766) (arrow-tailed flying squirrel)}

\section{Hylopetes sagitta sagitta (Linnaeus, 1766)}

[Sciurus] sagitta Linnaeus, 1766:88.

TYPe LocAlity. Java, Indonesia.

Comments. There are two original specimens, one now in the Naturhistoriska Riksmuseet in Stockholm and the other in the Evolutionsmuseet, University of Uppsala (A. Gentry, personal communication). Taxon was transferred to Sciuropterus by Sclater (1891:37) and Petinomys by Ellerman and Morrison-Scott (1955:31), Corbet and Hill (1986:155), and Thorington and Hoffmann (2005:773). Placed in Hylopetes by Chasen (1940:116), Ellerman (1940:299), Hubbs et al. (1953:518), and Medway (1965:113). Medway (1965:112) considered it inadvisable to synonymize sagitta and genibarbis until the relationship has been certainly established. Corbet and Hill (1992:318) considered sagitta as incertae sedis and placed it within Petinomys genibarbis. It was synonymized within lepidus by Lekagul and McNeely (1988:384) and Hoffmann et al. (1993:461). Synonymized within lepidus by Rasmussen and Thorington (2008, 1303). Recent observations of the type specimen of sagitta by A. Gentry (pers. comm.) and by the second author (RWT) show that it is the same species as lepidus.

Distribution. Java, Indonesia (Corbet and Hill, 1992:316). This species potentially occurs on Borneo; Rasmussen and Thorington (2008:1303), however, suggest that these records probably refer to Hylopetes platyurus.

Pteromys lepidus Horsfield, 1824:173, unnumbered plate.

Type Locality. Java, Indonesia.

Comments. Not lepidus of Lyon (1911:78). Species rank recognized within Hylopetes by Ellerman (1940:299; 1961:57) but synonymized within sagitta by Chasen (1940:116). Species revived by Ellerman and Morrison-Scott (1955:31) and reviewed by Hill (1962:730), who recognized lepidus as a species that included aurantiacus and platyurus as subspecies. Separated from sagitta as a distinct species by Medway (1965:113; 1969:63; 1977:104) and subsequent authors. Species rank recognized by Rasmussen and Thorington (2008:1296) with aurantiacus as a subspecies.

\section{Hylopetes sagitta aurantiacus Wagner, 1841}

Pteromys aurantiacus Wagner, 1841a:438.

Type Locality. Bangka Island, east of Sumatra, Indonesia.

Comments. $\quad$ Also described in Wagner (1841b: 135). Transferred to Hylopetes at species rank by Thomas (1908b:6) and followed by Sody (1937:238) and Ellerman (1940:299). Recognized as a subspecies of sagitta by Chasen (1940:117) and lepidus by Hill (1962:730), but synonymized within lepidus by Corbet and Hill (1992:316) and Hoffmann et al. (1993:461). Placed as a synonym of spadiceus by Thorington and Hoffmann (2005:769) and as a subspecies of lepidus by Rasmussen and Thorington (2008:1303).

Distribution. Bangka Island, east of Sumatra, Indonesia.

\section{Hylopetes sipora Chasen, 1940 (Sipora flying squirrel)}

Hylopetes sagitta sipora Chasen, 1940:117.

Type Locality. Sipora Island, Mentawai Islands, west Sumatra, Indonesia.

Comments. Has been the subject of considerable debate as reviewed by Hill (1962:731). Formerly included in spadiceus by authors, including Hill (1960:43), but not recognized by Corbet and Hill (1980:137; 1986:154). Given species rank by Hill (1962:731), who noted that an adult specimen is needed to clarify the status of this taxon. Recognized by Corbet and Hill (1991:145; 1992:316) and subsequent authors.

Distribution. Sipora Island, Mentawai Islands, west of Sumatra (Corbet and Hill, 1992:316).

\section{Hylopetes spadiceus (Blyth, 1847) (red-cheeked flying squirrel)}

\section{Hylopetes spadiceus spadiceus (Blyth, 1847)}

Sc.[iuropterus] spadiceus Blyth, 1847:867, pl. 36. TYPe Locality. Arakan, Burma. 
Comments. Recognized within Sciuropterus by Sclater (1891:37). Transferred to Pteromys by Anderson (1879:300) and Hylopetes by Thomas (1908b:6) and most subsequent authors. Recognized as a subspecies of sagitta by Chasen (1940:118). Formerly included sipora, but this was separated by Hill (1962:731). Corbet and Hill (1980:137; 1986:154) listed spadiceus in lepidus, without comment, which appeared to be followed by Lekagul and McNeely (1988:384). Recognized as a species within Hylopetes by Ellerman (1940:299), Medway (1969:63), Agrawal and Chakraborty (1979a:345), Corbet and Hill (1992:315), and subsequent authors. Has been recorded as a fossil from several localities throughout Thailand from the late Pliocene to Recent (Chaimanee, 1998:165).

Distribution. Southeastern Burma, western and southern Thailand, western Cambodia to southernmost Malay Peninsula, Singapore, southeastern Vietnam, and small islands, including Con Son Island (Vietnam), Terutau Island (Strait of Malacca, Thailand), and Kundur Island (Riau Islands), Bangka Island, and Bunguran Island (Natuna Islands) in Indonesia (Corbet and Hill, 1992:315; Meijaard, 2003:1256; Francis, 2008:154).

Sciuropterus amoenus Miller, 1906b:264.

Type Locality. Kundur Island, Riau Islands, Indonesia.

Comments. Recognized at species rank within Hylopetes by Ellerman (1940:299). Recognized as a subspecies of sagitta by Chasen (1940:118) and of spadiceus by Hill (1962:729). Synonymized within spadiceus by Corbet and Hill (1992:315), Thorington and Hoffmann (2005:769), and Rasmussen and Thorington (2008:1303).

Sciuropterus (Hylopetes) belone Thomas, 1908c:305.

Type Locality. Terutau Island, northern Strait of Malacca, Thailand.

Comments. Species rank recognized within Hylopetes by Ellerman (1940:299). Recognized as a subspecies of sagitta by Chasen (1940:118) and Ellerman and Morrison-Scott (1951:469), lepidus by Ellerman (1961:58) and Agrawal and Chakraborty (1979a:345; 1979b:163), and spadiceus by Hill (1962:729). Synonymized within spadiceus by Corbet and Hill (1992:315), Thorington and Hoffmann (2005:769), and Rasmussen and Thorington (2008:1303).

\section{Hylopetes spadiceus everetti Thomas, 1895}

Sciuropterus everetti Thomas, 1895c:27.
Type LocAlity. Bunguran Island, Natuna Islands, Indonesia.

Comments. Species rank recognized within Pteromys by Allen and Coolidge (1940:152) and Ellerman (1940:300). Recognized as a subspecies of sagitta by Chasen (1940:117) and spadiceus by Hill (1962:728) and Medway (1965:115; 1977:105). Synonymized within spadiceus by Corbet and Hill (1992:315), Hoffmann et al. (1993:461), and Thorington and Hoffmann (2005:769). Subspecies rank recognized by Rasmussen and Thorington (2008:1303).

Distribution. Sabah, Brunei, and Sarawak in northwest Borneo. Also occurs on Bunguran Island, Natuna Islands (Payne et al., 1985:248; Corbet and Hill, 1992:315).

Hylopetes harrisoni caroli Gyldenstolpe, 1920:29.

Type Locality. Boeloengan district, northeast Borneo.

Comments. Recognized as described by Ellerman (1940:299). Synonymized within Hylopetes sagitta harrisoni by Chasen (1940:116). Subspecies rank recognized by Corbet and Hill (1992:315) and Thorington and Hoffmann (2005:769) but reduced to a synonym of everetti by Rasmussen and Thorington (2008:1303).

Sciuropterus harrisoni Stone, 1900:462.

Type Locality. Menbuang River, Sarawak, Borneo.

Comments. Recognized as a species within Hylopetes by Ellerman (1940:299) and subspecies of $s a$ gitta by Chasen (1940:116). Synonymized within spadiceus by Corbet and Hill (1992:315) and Thorington and Hoffmann (2005:769), and within everetti by Medway (1965:115; 1977:105) and Rasmussen and Thorington (2008:1303).

\section{Hylopetes spadiceus sumatrae Sody, 1949}

Hylopetes sagitta sumatrae Sody, 1949:71.

Type Locality. Redelong, east Atjeh, northern Sumatra. 1,300 m (4,265 ft).

Comments. Synonymized within spadiceus by Corbet and Hill (1992:315) and Thorington and Hoffmann (2005:769), but recognized as a subspecies of spadiceus by Hill (1962:729) and Rasmussen and Thorington (2008:1303).

Distribution. Sumatra (Corbet and Hill, 1992:315). 


\section{Hylopetes winstoni (Sody, 1949) \\ (Sumatran flying squirrel)}

Iomys winstoni Sody, 1949:75.

Type Locality. Baleq, eastern Atjeh, northern Sumatra, Indonesia. 1,200 m (3,936 ft).

Comments. Not recognized by Corbet and Hill (1980:138; 1986:155). Recognized within Iomys by Corbet and Hill (1991:146), but transferred to Hylopetes by Corbet and Hill (1992:317).

Distribution. Known only from the type locality in Aceh, northern Sumatra, at 1,200 m (3,936 ft) (Corbet and Hill, 1992:317).

\section{Iomys Thomas, 1908}

Iomys Thomas, 1908b:1.

TYPe Species. Pteromys horsfieldi Waterhouse, $1838 \mathrm{~b}: 87$.

COMments. Formerly included winstoni but this was placed in Hylopetes by Corbet and Hill (1992:317). Pleistocene to Recent, SE Asia.

\section{lomys horsfieldi (Waterhouse, 1838) (Javanese flying squirrel)}

\section{lomys horsfieldi horsfieldi (Waterhouse, 1838)}

Pteromys (Sciuropterus) horsfieldi Waterhouse, 1838b:87. Type Locality. Either from Java or Sumatra. Restricted by Chasen (1940:114) to Sumatra.

Comments. Transferred to Iomys by Thomas (1908b:2) and followed by most subsequent authors, including Ellerman (1940:303), Corbet and Hill (1992:314), and (Thorington and Hoffmann (2005:770). Formerly included sipora and winstoni (Corbet and Hill, 1980:138). Found as a fossil in peninsular Thailand from midPleistocene to Recent (Chaimanee, 1998:157).

Distribution. Java and Sumatra, Indonesia (Corbet and Hill, 1992:314).

\section{lomys horsfieldi davisoni (Thomas, 1886)}

Sciuropterus davisoni Thomas, 1886a:74, pl. 6.

Type Locality. Malacca, Malay Peninsula.

Comments. Also described in Thomas (1886b:84). Recognized as a species within Iomys by Thomas (1908b:2) and as a subspecies of horsfieldi by Chasen (1940:114), Ellerman (1940:303), Medway
(1969:65), Corbet and Hill (1992:315), and Thorington and Hoffmann (2005:770).

Distribution. Malay Peninsula and Tioman Island, Malaysia, and Singapore (extinct?) (Medway, 1969:65; Corbet and Hill, 1992:314; Meijaard, 2003:1256).

\section{Iomys horsfieldi penangensis Chasen, 1940}

Iomys horsfieldii penangensis Chasen, 1940:115.

Type Locality. Penang Island (Pinang), Malaysia.

Comments. Recognized as a subspecies of horsfieldi by Medway (1969:65), Corbet and Hill (1992: 315), and Thorington and Hoffmann (2005:770).

\section{Distribution. Penang Island, Malaysia.}

\section{Iomys horsfieldi thomsoni (Thomas, 1900)}

Sciuropterus thomsoni Thomas, 1900a:275.

Type Locality. Bakong River, Baram District, eastern Sarawak, Borneo.

Comments. Recognized as a species within Iomys by Thomas (1908b:2) and as a subspecies of horsfieldi by Chasen (1940:115), Ellerman (1940:303), Medway (1965:110; 1977:101), Corbet and Hill (1992:315), and Thorington and Hoffmann (2005:770).

Distribution. Borneo, known from scattered localities throughout the west, up to $1,676 \mathrm{~m}(5,500 \mathrm{ft})$ on Gunung Kinabalu in Sabah south to Brunei in Sarawak and Batu Jurong in west Kalamantan. Also, one recorded from Sandakan, but none from east, south, or central Kalamantan. Most records are from lowlands and hills. Also recorded from the Kelabit uplands in Sarawak and up to 1800 m on Gunung Kinabalu (Allen and Coolidge, 1940:152; Medway, 1965:111; Payne et al., 1985:245).

Iomys lepidus Lyon, 1911:78.

Type Locality. Batu Jurog, southwestern Borneo.

Comments. Not lepidus of Horsfield (1824:173). Recognized as a subspecies of horsfieldi by Chasen (1940:115) and Ellerman (1940:303). Synonymized within horsfieldi by Corbet and Hill (1992:315) and Thorington and Hoffmann (2005:770).

\section{lomys sipora Chasen and Kloss, 1927 (Mentawai flying squirrel)}

Iomys horsfieldi sipora Chasen and Kloss, 1927:819. 
Type Locality. Sipora Island, off west Sumatra, Indonesia.

Comments. Recognized as a subspecies of Iomys horsfieldi by Chasen (1940:115) and Ellerman (1940:303), but separated as a distinct species by Corbet and Hill $(1991: 146 ; 1992: 315)$ and subsequent authors.

Distribution. Sipora Island and northern Pagai Island in Mentawai Islands west of Sumatra, Indonesia (Corbet and Hill, 1992:315).

\section{†Meinia Qiu, 1981}

†Meinia Qiu, 1981:229.

Type Species. Meinia asiatica Qiu, 1981:229.

Comments. Mid-Miocene, east Asia. Genus recognized within the subfamily Pteromyinae by McKenna and Bell (1997:128).

\section{†Meinia asiatica Qiu, 1981}

†Meinia asiatica Qiu, 1981:229.

Type Locality. Shanwang, Linqu, Shandon, China.

Comments. Mid-Miocene.

\section{†Miopetaurista Kretzoi, 1962}

†Miopetaurista Kretzoi, 1962:355.

Type Species. Sciurus gibberosus Hofmann, 1893:42.

Comments. Early Miocene to early Pliocene, Europe; mid-Miocene, west Asia; late Pliocene, North America. Genus recognized within the subfamily Pteromyinae by McKenna and Bell (1997:127) and the family Petauristidae by de Bruijn (1999:276).

†Cryptopterus Mein, 1970:22.

Type Species. Cryptopterus crusafonti Mein, 1970:22, 28.

Comments. Synonymized within Miopetaurista by Daxner-Höck and Mein (1975:76), McKenna and Bell (1997:127), and Daxner-Höck (2004:392).

\section{†Miopetaurista crusafonti (Mein, 1970)}

†Cryptopterus crusafonti Mein, 1970:22, 28.

Type Locality. Can Ponsich, Spain.

Comments. Upper Miocene. Species recognized within †Miopetaurista by Daxner-Höck and Mein (1975:76), de Bruijn (1995:96), and Daxner-Höck (2004:392).

\section{†Miopetaurista dehmi de Bruijn et al., 1980}

†Miopetaurista dehmi de Bruijn et al., 1980:241, 251.

Type Locality. Wintershof West, Germany.

Comments. Early Miocene. Species recognized within $†$ Miopetaurista by de Bruijn (1995:96) and Daxner-Höck (2004:392).

†Miopetaurista diescalidus Daams, 1977

†Miopetaurista diescalidus Daams, 1977:356.

Type Locality. Bunol, Spain.

Comments. Mid-Miocene. The type material of this proposed species is so poorly preserved that it has been considered insufficiently characteristic to define the species (de Bruijn et al., 1980:251). It was subsequently considered a nomen dubium by de Bruijn (1999:276).

\section{†Miopetaurista gaillardi (Mein, 1970)}

†Cryptopterus gaillardi Mein, 1970:25.

Type Locality. La Grive, France.

Comments. Mid-Miocene. Species recognized within $†$ Miopetaurista by Daxner-Höck and Mein (1975:76), de Bruijn (1995:96; 1999:276) and DaxnerHöck (2004:392).

\section{†Miopetaurista goeriachensis (Hofmann, 1893)}

†Sciurus göriachensis Hofmann, 1893:41.

Type Locality. Göriach, Austria.

Comments. Mid-Miocene. Not recognized within †Miopetaurista until Daxner-Höck (2004:392) gave it page priority over gibberosus.

†Sciurus gibberosus Hofmann, 1893:42.

Type Locality. Göriach, Austria.

Comments. Mein (1958:68), James (1963:87), and Black (1966:56) suggest this species is a synonym for †Albanensia albanensis. Placed within †Miopetaurista and recognized at species rank by Kretzoi (1962:355) and followed by Daxner-Höck (1975:57), Daxner-Höck and Mein (1975:76), and de Bruijn (1995:96; 1999:276).

\section{†Miopetaurista lappi (Mein, 1958)}

†Sciuropterus lappi Mein, 1958:69.

Type Locality. Vieux Collonges, France.

Comments. Early to middle Miocene. Species recognized within $†$ Miopetaurista by Daxner-Höck 
and Mein (1975:76), de Bruijn (1995:96; 1999:276), and Daxner-Höck (2004:392).

†Miopetaurista neogrivensis (Mein, 1970)

†Cryptopterus neogrivensis Mein, 1970:27.

Type Locality. La Grive, France.

Comments. Mid-Miocene. Species recognized within †Miopetaurista by Daxner-Höck and Mein (1975:76), de Bruijn (1995:96; 1999:276), and DaxnerHöck (2004:392).

\section{†Miopetaurista thaleri (Mein, 1970)}

†Cryptopterus thaleri Mein, 1970:29.

Type Locality. Marnes Celleneuve, Herault, France.

Comments. Pliocene. Species recognized within †Miopetaurista by Daxner-Höck and Mein (1975:76), de Bruijn (1995:96; 1999:276), and Dahlmann (2001:52).

†Cryptopterus tobieni Mein, 1970:30.

Type Locality. Wölfersheim-Wetterau, Germany.

Comments. Pliocene (Neogene). Species recognized within $†$ Miopetaurista by Daxner-Höck and Mein (1975:76) and Daxner-Höck (2004:393) but synonymized within thaleri by de Bruijn (1995:96; 1999:276) because of page priority and followed by Dahlmann (2001:52).

\section{†Miopetaurista webbi (Robertson, 1976)}

†Cryptopterus webbi Robertson, 1976:147.

TYPe LocAlity. Alachua County, Florida, USA. Comments. Late Pliocene.

\section{†Neopetes Daxner-Höck, 2004}

†Neopetes Daxner-Höck, 2004:387, 393.

Type Species. †Hylopetes hoeckarum de Bruijn, 1998:107.

Comments. Miocene. Placed in the subfamily Pteromyinae by Daxner-Höck (2004:389, 393).

\section{†Neopetes debruijni (Reumer and Hoek Ostende, 2003)}

†Hylopetes debruijni Reumer and Hoek Ostende, 2003: $455,457$.

Type Locality. Tegelen, province of Limburg, Netherlands.
Comments. Pleistocene. Species transferred to †Neopetes by Daxner-Höck (2004:396).

\section{†Neopetes hoeckarum (de Bruijn, 1998)}

†Hylopetes hoeckarum de Bruijn, 1998:107.

TYPe Locality. Oberdorf, Austria.

Comments. Lower Miocene. Species recognized within Hylopetes by de Bruijn (1999:276) but transferred to Neopetes by Daxner-Höck (2004:394).

\section{†Neopetes macedoniensis (Bouwens and de Bruijn, 1986)}

†Hylopetes macedoniensis Bouwens and de Bruijn, 1986:113, 119.

Type Locality. Maramena, Greece.

Comments. Upper Miocene. Species recognized within Hylopetes by de Bruijn (1995:92; 1999:276) but transferred to Neopetes by Daxner-Höck (2004:394).

\section{†Oligopetes Heissig, 1979}

†Oligopetes Heissig, 1979:154.

TYpe Species. †Oligopetes radialis Heissig, 1979:155.

Comments. Lower to middle Oligocene, Mediterranean. Early Oligocene, Europe. Genus recognized within the subfamily Pteromyinae by McKenna and Bell (1997:127) and the family Petauristidae by de Bruijn (1999:276).

\section{†Oligopetes lophulus Heissig, 1979}

†Oligopetes lophulus Heissig, 1979:157.

Type Locality. Schelklingen, Germany.

Comments. Lower to middle Oligocene. Has also been found in Olalla, Spain, and Kavakdere, Turkey, from the Oligocene (de Bruijn and Ünay, 1989:140, 142). Species rank recognized by de Bruijn and Ünay (1989:140).

\section{†Oligopetes obtusus Heissig, 1979}

†Oligopetes obtusus Heissig, 1979:158.

Type Locality. Möhren, Germany.

Comments. Lower to middle Oligocene. Has also been found in Kavakdere, Turkey, from the Oligocene (de Bruijn and Ünay, 1989:142). Species recognized within Oligopetes by de Bruijn (1999:276). 


\section{†Oligopetes radialis Heissig, 1979}

†Oligopetes radialis Heissig, 1979:155.

Type Locality. Möhren, Germany.

Comments. Lower to middle Oligocene. Has also been found in Hoogbutsel, Belgium, from the Oligocene (de Bruijn and Ünay, 1989:140). Species recognized within Oligopetes by de Bruijn (1999:276).

\section{†Parapetaurista Qiu and Liu, 1986}

†Parapetaurista Qiu and Liu, 1986:195.

Type Species. †Parapetaurista tenurugosa Qiu and Liu, 1986:195.

Comments. Mid-Miocene, Asia. Genus recognized within the subfamily Pteromyinae by McKenna and Bell (1997:128).

†Parapetaurista tenurugosa Qiu and Liu, 1986

†Parapetaurista tenurugosa Qiu and Liu, 1986:195, 196.

Type Locality. Songlinzhuang, Xiacaowan, Jiangsu, China.

Comments. Mid-Miocene.

\section{Petaurillus Thomas, 1908}

Petaurillus Thomas, 1908b:3.

Type Species. Sciuropterus hosei Thomas, 1900a:275.

\section{Petaurillus emiliae Thomas, 1908 (lesser pygmy flying squirrel)}

Petaurillus emiliae Thomas, 1908b:8.

Type Locality. Baram, eastern Sarawak, Borneo.

Comments. Known only from two specimens collected in 1901 (Corbet and Hill, 1992:320).

Distribution. Known only from the type locality where one adult male and female were collected in the Baram district, eastern Sarawak, Borneo in 1901 (Corbet and Hill, 1992:320).

\section{Petaurillus hosei (Thomas, 1900) (Hose's pygmy flying squirrel)}

Sciuropterus hosei Thomas, 1900a:275.

Type Locality. Toyut River, Baram District, eastern Sarawak, Borneo.
Comments. Transferred to Petaurillus by Thomas (1908b:3) and followed by subsequent authors.

Distribution. Known from western and northern Borneo at a few lowland sites, including the type locality at S. Toyut, Baram district; Sepilok in Sabah; Tasek Merimbun in Brunei; and the Baram district and Niah in Sarawak (Medway, 1965:110; Payne et al., 1985:245).

\section{Petaurillus kinlochii (Robinson and Kloss, 1911 ) (Selangor pygmy flying squirrel)}

Sciuropterus (Petaurillus) kinlochii Robinson and Kloss, 1911:171.

Type Locality. Kapar, Selangor, Malay Peninsula.

Comments. Recognized at species rank within Petaurillus by Chasen (1940:116), Ellerman (1940:303), Medway (1969:63), and Corbet and Hill (1980:138; 1986:155). Corbet and Hill (1991:146; 1992:320) included this form in hosei. Elevated to species rank by Hoffmann et al. (1993:462) and Thorington and Hoffmann (2005:770).

Distribution. Only known from Selangor, Malay Peninsula (Medway, 1969:63).

\section{Petaurista Link, 1795}

Petaurista Link, 1795:52, 78.

Type Species. Sciurus petaurista Pallas, 1766:54.

Comments. Genus resurrected by Thomas (1897:1015), who used this taxon for all large flying squirrels, except Eupetaurus, and Sciuropterus for all smaller species. Early Pleistocene to Recent, Asia; Recent, Southeast Asia. Significant uncertainty exists over the taxonomic placement and distribution of many taxa within this genus, and a revision of the entire genus is urgently needed.

Homonyms. Petaurista Meigen, 1800:15, flies of the class Insecta (order Diptera, family Trichoceridae). Suppressed by the International Commission on $\mathrm{Zo}-$ ological Nomenclature (1963:339). Genus is a synonym of Trichocera (Meigen, 1803:262).

Petaurista Desmarest, 1820:268, the greater glider of the class Mammalia (order Diprotodontia, family Pseudocheiridae). Genus is a junior synonym of Petauroides (Thomas, 1888a:163).

Petaurista Latreille, 1827:400, leaf beetles of the class Insecta (order Coleoptera, family Chrysomelidae). Genus is a synonym of Lema (Fabricius, 1798:4). 
Petaurista Reichenbach, 1862:105, guenon monkeys of the class Mammalia (order Primates, family Cercopithecidae). Genus is a junior synonym of Cercopithecus (Linnaeus, 1758:26).

Schoinobates Lesson, 1842:190.

TYPe Species. Pteromys leucogenys Temminck, 1827:xxvii.

Comments. This name was originally placed with the marsupial gliders as a subgenus of Petaurus. Schoinobates (Lesson, 1842) is therefore a junior subjective synonym of Petaurista (Link, 1795). See comments under Schoinobates (Iredale and Troughton, 1934:28).

Homonyms. Schoinobates Iredale and Troughton, 1934:28, greater gliders of the class Mammalia (order Diprotodontia, family Pseudocheiridae). Name is a synonym of Petauroides (Thomas, 1888a:163).

†Petauria Dehm, 1962:38.

Type Species. Petauria helleri Dehm, 1962:39.

Comments. Mid-Pleistocene, Europe. Doubt was cast on this genus by Thorington et al. (2005:958), who proposed that it should be considered a synonym of Petaurista.

\section{Petaurista albiventer (Gray, 1834) (white-bellied giant flying squirrel)}

\section{Petaurista albiventer albiventer (Gray, 1834)}

Pteromys albiventer Gray, 1834: pl. 18.

Type Locality. Nepal.

Comments. This taxon was also described by Gray (1836:88). Publication date confirmed by Sawyer (1953:52). Recognized as a species within Pteromys by Sclater (1891:32) and within Petaurista by Ellerman (1940:288). Recognized as a subspecies of petaurista by Ellerman and Morrison-Scott (1951:461), Agrawal and Chakraborty (1979a:341; 1979b:162), Mitchell (1979:22), and Day (1988:82), but synonymized within petaurista by Corbet and Hill (1992:309). Recognized as a subspecies of petaurista by Thorington and Hoffmann (2005:772) and as a distinct species by Wang (2003:157), Oshida et al. (2004b:15), and Yu et al. (2006:755).

Distribution. Northeastern Afghanistan (probably Konar, Badakhshan, and Laghman provinces); Kohistan and Punjab provinces, northern Pakistan; Punjab State, northern India; and Nepal. North of the Ganges in the western Himalayas in India. Also occurs in southeastern Tibet and western Yunnan Province, China (Ellerman,
1961:53; Corbet and Hill, 1992:310; Roberts, 1997:315; Wang, 2003:157; Smith and Xie, 2008:179).

Pteromys inornatus I. Geoffroy Saint-Hilaire, 1844:62, pl. 4.

TYpe Locality. Northern India.

Comments. Species rank recognized within Petaurista by Ellerman (1940:288). Synonymized within albiventer by Ellerman and Morrison-Scott (1951:461), Ellerman (1961:29, 53), Corbet and Hill (1992:309), and Thorington and Hoffmann (2005:772).

[Petaurista] birrelli Wroughton, 1911:1014, 1019.

Type Locality. Murree, Hazara, Punjab Province, Pakistan.

Comments. Species rank recognized within Petaurista by Ellerman (1940:288). Synonymized within albiventer by Ellerman and Morrison-Scott (1951:461), Ellerman (1961:29, 53), Corbet and Hill (1992:309), and Thorington and Hoffmann (2005:772).

[Petaurista] fulvinus Wroughton, 1911:1014, 1021.

Type Locality. Shimla, Punjab State, India.

Comments. Species rank recognized by Robinson and Kloss (1918a:176), Ellerman (1940:288), and Ghose and Bhattacharya (1995:254). Synonymized within albiventer by Ellerman and Morrison-Scott (1951:461), Ellerman (1961:29, 53), Corbet and Hill (1992:309), and Thorington and Hoffmann (2005:772).

Petaurista albiventer chayuensis Feng and Zheng, 2003: 157.

Type Locality. Chayu, southeastern Tibet.

Comments. Type locality and year of printing of publication confirmed as 2003 by Wang Yingxiang (Kunming Institute of Zoology, China; personal communication), although the book records the year of publication as 2002. Name not considered by subsequent authors. The status of the taxon needs to be confirmed.

\section{Petaurista albiventer barroni Kloss, 1916}

Petaurista annamensis barroni Kloss, 1916:33.

TYPe Locality. Hup Bon, near Sriracha, southeast Thailand.

Comments. Recognized as a subspecies of annamensis by Ellerman (1940:287) and alborufus by Ellerman and Morrison-Scott (1951:464) and Lekagul and McNeely (1988:380). Synonymized within Petaurista petaurista by Corbet and Hill (1992:309) and made a 
synonym of albiventer (which was placed within Petaurista petaurista) by Thorington and Hoffmann (2005:772). The taxonomic status of this taxon needs to be confirmed.

Distribution. North to at least Phitsanulok in the north to southeast Thailand. Exact distribution unknown (Lekagul and McNeely, 1988:380).

\section{Petaurista alborufus (Milne-Edwards, 1870) (red and white giant flying squirrel)}

\section{Petaurista alborufus alborufus (Milne-Edwards, 1870)}

Pteromys alborufus Milne-Edwards, 1870:342.

Type Locality. Moupin, Sichuan, China.

Comments. Further described by MilneEdwards (1872:298). Recognized within Pteromys by Sclater (1891:32). Transferred to Petaurista at species rank by Thomas (1911a:689) and subsequent authors. Included lena, which was subsequently treated as a separate species by Allen (1940:732), Kuntz and Ming (1970:34), and Zhang et al. (1997:152) but as a subspecies of alborufus by Jones (1975:192). Provisionally includes pectoralis (Corbet and Hill, 1992:312). Subspecies provisionally recognized by Corbet and Hill (1992:312) and Thorington and Hoffmann (2005:771). Chromosomes described by Oshida et al. (1992:59).

Distribution. Western Sichuan, Shaanxi, and Gansu provinces, China (Zhang et al., 1997:152; Smith and Xie, 2008:177). Fossil specimens allocated to this species have been discovered from various localities in China from the late Pleistocene to Recent (Zheng, 1993:264). These include mid-Pleistocene mammalian fauna of Shanyangzhai cave in Qinhuangdao, Hebei Province, China (Zhang et al., 2010:75).

\section{Petaurista alborufus candidula Wroughton, 1911}

[Petaurista] candidulus Wroughton, 1911:1014, 1021.

Type Locality. Kindat, Upper Chindwin, western Burma.

Comments. Species rank recognized by Ellerman (1940:287). Recognized as a subspecies of alborufus by Ellerman and Morrison-Scott (1951:463), Ellerman (1961:28, 36), Yin (1967:223), Agrawal and Chakraborty (1979a:337), Day (1988:81), and Lekagul and McNeely (1988:380). Subspecies rank recognized within petaurista by Corbet and Hill (1992:309) and Thorington and Hoffmann (2005:772). The color of this taxon, both dorsally and ventrally, is clearly different from other $P$. petaurista, so it has been included within $P$. alborufus.

Distribution. Burma and northern Thailand (Francis, 2008:150).

Petaurista taylori Thomas, 1914b:205.

TYPE LOCALITY. Bankasun, southern Tenasserim, Burma.

Comments. Species rank recognized by Ellerman (1940:288) and Yin (1967:224). Reduced to a synonym within Petaurista alborufus candidulus by Ellerman and Morrison-Scott (1951:463). Synonymized within Petaurista petaurista by Corbet and Hill (1992:309). Subspecies rank recognized within petaurista by Thorington and Hoffmann (2005:772). The color of this taxon, both dorsally and ventrally, is different from other petaurista so it has been returned to alborufus as a synonym of candidula, but further studies are needed to confirm this placement.

\section{Petaurista alborufus castaneus Thomas, 1923}

Petaurista alborufus castaneus Thomas, 1923b:172.

Type Locality. Ichang, Hubei, Middle Yangtsekiang, China.

Comments. Synonymized within alborufus by Ellerman and Morrison-Scott (1951:463). Recognized as a subspecies of alborufus by Allen (1925:13; 1940:735), Ellerman (1940:286), Day (1988:81), Corbet and Hill (1992:312), Zhang et al. (1997:152), and Thorington and Hoffmann (2005:771). Proposed to be a distinct species by Oshida et al. (2004b:21).

Distribution. Eastern Sichuan, Shaanxi, Chongqing, Hubei, Guizhou, Hunan, and Yunnan provinces, China (Corbet and Hill, 1992:312; Zhang et al., 1997:152; Smith and Xie, 2008:177).

\section{Petaurista alborufus leucocephalus (Hilzheimer, 1906)}

Pteromys alborusus [sic] leucocephalus Hilzheimer, 1906: 298.

Type Locality. Tibet?

COMMENTS. Incorrect subsequent spelling of alborufus. Synonymized within alborufus by Ellerman and Morrison-Scott (1951:463). Recognized as a subspecies of alborufus by Ellerman (1940:286), Day (1988:81), Corbet and Hill (1992:312), and Thorington and Hoffmann (2005:771).

Distribution. Tibet and Bhutan, south into Assam (India) and east to northern Burma (Corbet and Hill, 1992:312). 


\section{Petaurista alborufus ochraspis Thomas, 1923}

Petaurista alborufus ochraspis Thomas, 1923b:172.

Type Locality. Likiang Range, northwest Yunnan, China.

COMments. Synonymized within alborufus by Ellerman and Morrison-Scott (1951:463). Recognized as a subspecies of alborufus by Allen (1925:13; 1940:735), Ellerman (1940:286), Ellerman and Morrison-Scott (1951:463), Day (1988:81), Corbet and Hill (1992:312), Zhang et al. (1997:152), and Thorington and Hoffmann (2005:771).

Distribution. Likiang Range, Yunnan and Guangxi provinces, China (Corbet and Hill, 1992:312; Zhang et al., 1997:152; Smith and Xie, 2008:177).

\section{†Petaurista brachyodus (Young, 1934)}

†Pteromys brachyodus Young, 1934:44.

TYPe Locality. Koloshan Sichuan, northern China.

Comments. Mid-Pleistocene. Placed in Petaurista by Young and Liu (1950:44) and followed by Kawamura (1988:166). Found as fossil deposits in China from the late Pleistocene (Hsu et al., 1957:343, 350; Zheng, 1993:265).

\section{Petaurista caniceps (Gray, 1842) (gray-headed giant flying squirrel)}

\section{Petaurista caniceps caniceps (Gray, 1842)}

Sciuropterus caniceps Gray, 1842:262.

Type Locality. Nepal.

Comments. Transferred to Pteromys at species rank by Anderson (1879:287) and Petaurista by Ellerman (1940:288). Synonymized within elegans by Lekagul and McNeely (1988:377). Reduced to a subspecies of $\mathrm{el}$ egans by Ellerman and Morrison-Scott (1951:461) and most subsequent authors, including Mitchell (1979:22) and Thorington and Hoffmann (2005:771). Recognized as distinct species by Corbet and Hill (1992:312) and Smith and Xie (2008:177). Wang (2003:156) also recognize a Hubei form. Two undescribed forms have been recorded from Guangxi and Hunan and from Hubei, Shaanxi, and Gansu (Wang 2003:156).

Distribution. Nepal, Bhutan, southeastern Tibet, and Sikkim, northern West Bengal, and Arunachal Pradesh in north eastern India (Ellerman, 1961:33; Ghose and Chakraborty, 1983:411; Corbet and Hill, 1992:312).
[Sciuropterus] senex Hodgson, 1844:68, pl. [no. not given]. Type Locality. Nepal.

Comments. Synonymized within caniceps by Ellerman and Morrison-Scott (1951:461), Corbet and Hill (1992:312), and Thorington and Hoffmann (2005:771).

\section{Petaurista caniceps clarkei Thomas, 1922}

Petaurista clarkei Thomas, 1922b:396.

Type Locality. Mekong Valley, Yunnan Province, China. 2,743-3,048 m (9,000-10,000 ft).

Comments. Species rank recognized by Allen (1925:15; 1940:744), Howell (1929:47), and Ellerman (1940:288). Recognized as a subspecies of elegans by Ellerman and Morrison-Scott (1951:461), Ellerman (1961:28, 33), Yin (1967:218), and Zhang et al. (1997:154). Synonymized within caniceps by Corbet and Hill (1992:312) and Thorington and Hoffmann (2005:771). Recognized as a subspecies of caniceps by Wang (2003:156) and Smith and Xie (2008:178).

Distribution. Yunnan, Sichuan, and Guizhou provinces, China (Smith and Xie, 2008:178), and northern Burma (Zhang et al., 1997:154).

\section{Petaurista caniceps gorkhali (Lindsay, 1929)}

Sciuropterus gorkhali Lindsay, 1929:566.

Type Locality. Apoon Sottidanda, Gorkha, Nepal. 3,658 m (12,000 ft).

Comments. Species rank recognized within Petaurista by Ellerman (1940:288). Synonymized within caniceps by Corbet and Hill (1992:312) and Thorington and Hoffmann (2005:771). Recognized as a subspecies of elegans by Ellerman and Morrison-Scott (1951:461), Ellerman (1961:28, 34), Agrawal and Chakraborty (1979a:336), and Zhang et al. (1997:154). Recognized as a subspecies of caniceps by Wang (2003:156) and Smith and Xie (2008:178).

Distribution. Gorka region in central Nepal and adjacent southern Tibet (Corbet and Hill, 1992:312; Zhang et al., 1997:154; Smith and Xie, 2008:178).

\section{Petaurista caniceps sybilla Thomas and Wroughton, 1916}

Petaurista sybilla Thomas and Wroughton, 1916:423.

Type Locality. Near Kindat, Chin Hills, western Burma. 1,524 m (5,000 ft).

Comments. Recognized as a separate species by Corbet and Hill (1992:312), Wang (2003:156), and 
Francis $(2008: 150,341)$. Reduced to a subspecies of $\mathrm{el}$ egans by Ellerman and Morrison-Scott (1951:461), Ellerman (1961:28, 34), Yin (1967:218), and Thorington and Hoffmann (2005:771) and as a subspecies of caniceps by Smith and Xie (2008:178). Wang (2003:156) also recognized a Guizhou form.

Distribution. Northern Burma and adjacent western Yunnan and southern Sichuan and Guizhou provinces, China (Wang, 2003:156; Francis, 2008:150, 341; Smith and Xie, 2008:178).

\section{Petaurista elegans (Temminck, 1836) (spotted giant flying squirrel)}

\section{Petaurista elegans elegans (Temminck, 1836)}

Pteromys elegans Temminck, 1836:xii.

Type Locality. Nusa Kumbangan (Kambangan Island), south of Java, Indonesia.

Comments. Also described by Müller (1840: $35,56)$, who is recognized as the author by Thorington and Hoffmann (2005:771). Transferred to Pteromys at species rank by Anderson (1879:287) and Petaurista by Ellerman (1947:253) and subsequent authors. Includes clarkei and marica (see Ellerman and Morrison-Scott, 1951:460-461). Corbet and Hill (1992:312) considered caniceps from Nepal, Sikkim, northern Burma, and western China and sybilla from a few localities in Burma and western China as distinct species sympatric with elegans in western Yunnan, China. Taxon has been found as a late Pleistocene fossil from Sanjiacun, Yunnan, China (Qiu et al., 1984:287).

Distribution. Java (Corbet and Hill, 1992:312) and Kambangan Island (Meijaard, 2003: 256).

Petaurista elegans slamatensis Sody, 1949:70.

Type Locality. Kaligua, Mount Slamat, central Java. 1,400 m (4,593 ft).

Comments. Recognized as a subspecies by Corbet and Hill (1992:312). Synonymized within elegans by Thorington and Hoffmann (2005:771).

\section{Petaurista elegans banksi Chasen, 1933}

Petaurista punctatus banksi Chasen, 1933:194.

Type Locality. Lumu Lumu, Mount Kina Balu, northern Borneo. 1,676 m (5,500 ft).

Comments. Species rank recognized by Allen and Coolidge (1940:153) but as a subspecies within punctatus by Ellerman (1940:286). Recognized as a subspecies of elegans by Chasen (1940:114), Medway (1965:116; 1977:106), Corbet and Hill (1992:312), and Thorington and Hoffmann (2005:771).

Distribution. Borneo, known only from Gunung Kinabalu. 1,676 m (5500 ft) and the Crocker Range $(1140 \mathrm{~m})$ in Sabah and Gunung Dulit in Sarawak (Chasen, 1933:194; Allen and Coolidge, 1940:153; Payne et al., 1985:249). Also on Bunguran Island, Natuna Islands (Meijaard, 2003:1256).

\section{Petaurista elegans marica Thomas, 1912}

Petaurista marica Thomas, 1912:687.

Type Locality. Probably near Mongtze (Mengtsze), Yunnan, China.

Comments. Recognized as a subspecies of punctatus by Robinson and Kloss (1918a:178) and Ellerman (1940:286). Subspecies rank within elegans recognized by Ellerman and Morrison-Scott (1951:461), Ellerman (1961:28), Lekagul and McNeely (1988:377), Corbet and Hill (1992:312), Wang (2003:155), and Thorington and Hoffmann (2005:771). Recognized as a distinct species by Zhang et al. (1997:154).

Distribution. Southern Yunnan and Guangxi provinces, China. Extends into Bhutan, northern and eastern Burma, Laos, Vietnam, western and southern Thailand, and into central Malay Peninsula (Lekagul and McNeely, 1988:377; Francis, 2008:152; Smith and Xie, 2008:178).

Pteromys punctatus Gray, 1846:211.

Type Locality. Malacca, Malay Peninsula.

Comments. Recognized as a species within Petaurista by Ellerman (1940:286). Recognized as a subspecies within elegans by Chasen (1940:114), Medway (1969:67), Lekagul and McNeely (1988:377), Corbet and Hill (1992:312), and Thorington and Hoffmann (2005:771). Synonymized within marica by Smith and Xie (2008:178).

\section{Petaurista elegans sumatrana Kloss, 1921}

Petaurista punctata sumatrana Kloss, 1921:230.

Type Locality. Padang Highlands, western Sumatra, Indonesia.

Comments. Recognized as a subspecies of punctata by Ellerman (1940:289) and within elegans by Chasen (1940:114), Corbet and Hill (1992:312), and Thorington and Hoffmann (2005:771).

Distribution. Padang Highlands, western Sumatra, and Rupat Island (Corbet and Hill, 1992:312; Meijaard, 2003:1256). 


\section{Petaurista hainana G. Allen, 1925 (Hainan giant flying squirrel)}

Petaurista hainana G. Allen, 1925:14.

Type Locality. Nam Fong, Hainan Island, China.

COMments. Species rank recognized by Ellerman (1940:289) and Shaw et al. (1966:271). Reduced to a subspecies within petaurista by Ellerman and Morrison-Scott (1951:462) and Day (1988:82) and albiventer by Wang (2003:157). Synonymized within Petaurista philippensis by Corbet and Hill (1992:310) and Thorington and Hoffmann (2005:772). Recognized as a distinct species by Allen (1940:738), Zhang et al. (1997:151), and Yu et al. (2006:755).

Distribution. Hainan Island, China (Smith and Xie, 2008:179).

\section{†Petaurista helleri (Dehm, 1962)}

†Petauria helleri Dehm, 1962:39.

Type Locality. Bavaria, Germany.

Comments. Mid-Pleistocene. Placed within Petaurista by Thorington et al. (2005:958).

\section{Petaurista lena Thomas, 1907 (Taiwan giant flying squirrel)}

Petaurista lena Thomas, 1907a:522.

Type Locality. Tapposha, central Formosa (Taiwan), China.

Comments. Synonymized within alborufus by Corbet and Hill (1992:312), although they thought that lena was distinct enough to merit species rank. Recognized as subspecies of alborufus by Ellerman and Morrison-Scott (1951:463), Jones (1975:192), Day (1988:81), Zhang et al. (1997:152), Wang (2003:158), Thorington and Hoffmann (2005:771), Smith and Xie (2008:177), and Oshida et al. (2011:404). Recognized as a distinct species by Ellerman (1940:286), Kuroda (1940:92), Kuntz and Ming (1970:34), and Oshida et al. (2004b:20).

Distribution. Taiwan at elevations of 1100 $3600 \mathrm{~m}$ (Lee et al., 1986:113; Corbet and Hill, 1992:312; Zhang et al., 1997:152).

Pteromys pectoralis Swinhoe, 1871:634.

TYPe Locality. Takow, southwest Formosa (Taiwan), southwest China.

Comments. Species rank recognized within Petaurista by Ellerman (1940:289). Synonymized within alborufus by Corbet and Hill (1992:312), recognized as a distinct species by Zhang et al. (1997:153), but synonymized within lena by Thorington and Hoffmann (2005:771).

\section{Petaurista leucogenys (Temminck, 1827) (Japanese giant flying squirrel)}

\section{Petaurista leucogenys leucogenys (Temminck, 1827)}

Pteromys leucogenys Temminck, 1827:xxvii.

Type Locality. Kyushu, Japan.

Comments. Transferred to Pteromys at species rank by Anderson (1879:289) and Petaurista by Ellerman (1940:288). Formerly included xanthotis by Ellerman and Morrison-Scott (1951:464) and Corbet (1978:86). Subspecies follow Corbet (1978:86), with the exception of xanthotis. Chromosomal variation studied by Oshida and Obara (1991:26; 1993:61). Fossils have been found in various locations in Japan on the islands of Honshu, Shikoku, and Kyushu from the mid-Pleistocene to Recent (e.g., Shikama, 1949:114; Shikama and Okafuji, 1958:68; Hasegawa, 1966:34; Hasegawa et al., 1968:225; Kawamura, 1988:167). Specimens obtained in Korea and Manchuria were purchased in markets, and doubt of a Korean or Chinese provenance of these specimens was proposed by Jones and Johnson (1965:368). They suggest that the specimens could easily have been imported from the Japanese islands or elsewhere in Asia and that such a large rodent should have been reported elsewhere in the literature. Subspecies rank recognized within leucogenys by Ellerman (1940:289), Ellerman and Morrison-Scott (1951:465), Jones and Johnson (1965:368), and Corbet (1978:86) and followed by Thorington and Hoffmann (2005:771). Subspecies rank not recognized by Oshida (2006:69) or Ohdachi et al. (2009:192), who suggest that leucogenys is restricted to Japan.

Distribution. Kyushu and Shikoku islands, Japan (Dobson, 1994:97).

P.[etaurista] $l .[$ eucogenys] tosae Thomas, 1905a:488.

Type Locality. Tosa, Shikoku Island, Japan.

Comments. Recognized as a subspecies of leucogenys by Ellerman (1940:228), Kuroda (1940:89), and Ellerman and Morrison-Scott (1951:464). Synonymized within leucogenys by Thorington and Hoffmann (2005:771).

Petaurista leucogenys thomasi Kuroda and Mori, 1923:27.

Type Locality. Purchased at Seoul game market, central Korea. 
Comments. Synonymized within hintoni by Ellerman and Morrison-Scott (1951:465) and Thorington and Hoffmann (2005:771).

Petaurista leucogenys hintoni Mori, 1923:191.

Type Locality. Replacement name for Petaurista leucogenys thomasi Kuroda and Mori, 1923.

Comments. The designation of this subspecific name was due to the name thomasi (Kuroda and Mori, 1923:27) in combination with Petaurista being preoccupied.

Petaurista watasei Mori, 1927:107.

Type Locality. Mukden game market, southern Manchuria, China.

Comments. Species rank recognized by Ellerman (1940:289) and Wang (2003:159). Synonymized within hintoni by Thorington and Hoffmann (2005:771).

\section{Petaurista leucogenys nikkonis Thomas, 1905}

P.[etaurista] l.[eucogenys] nikkonis Thomas, 1905a:489.

Type Locality. Nikko, Central Honshu, Japan.

Comments. Subspecies rank recognized within leucogenys by Kuroda (1938:88; 1940:88), Ellerman (1940:228), Ellerman and Morrison-Scott (1951:464), Corbet (1978:86), and Thorington and Hoffmann (2005:771).

Distribution. Central and northern Honshu Island, Japan (Dobson, 1994:97).

Petaurista leucogenys osini Kuroda, 1938:88.

TYPe Locality. Osiu, northern Hondo, Japan.

Comments. Subspecies rank recognized within leucogenys by Kuroda (1940:88) and Ellerman and Morrison-Scott (1951:465). Synonymized within nikkonis by Thorington and Hoffmann (2005:771).

\section{Petaurista leucogenys oreas Thomas, 1905}

P.[etaurista] l.[eucogenys] oreas Thomas, 1905a:488.

TYPe Locality. Wakayama, southern peninsula of Honshu, Japan.

Comments. Subspecies recognized within leucogenys by Ellerman (1940:228), Ellerman and MorrisonScott (1951:464), Corbet (1978:86), and Thorington and Hoffmann (2005:771).

Distribution. Southern peninsula of Honshu, Japan (Dobson, 1994:97).

\section{Petaurista magnificus (Hodgson, 1836) (Hodgson's giant flying squirrel)}

[Sciuropterus] magnificus Hodgson, 1836:231.

Type Locality. Central and northern regions of Nepal.

Comments. Included within Pteromys by Anderson (1879:285) and Sclater (1891:32). Formerly included nobilis and chrysothrix by Blyth (1863:95) and Ellerman and Morrison-Scott (1951:464); however, these were excluded by Ghose and Saha (1981:95). Transferred to Petaurista by Ellerman $(1940: 288 ; 1947: 254)$ and subsequent authors.

Distribution. Nepal, Bhutan, extending into southern Tibet and to Sikkim and Darjeeling in northern West Bengal, India (Hudson, 1872:635; Ghose and Chakraborty, 1983:411; Corbet and Hill, 1992:312; Zhang et al., 1997:153; Wangchuk et al., 2004:149; Smith and Xie, 2008:178).

Petaurista magnificus hodgsoni Ghose and Saha, 1981:99.

Type Locality. Ghoombhanjang, Darjeeling District, northern West Bengal, India. 2,117 m (6,945 ft).

Comments. Recognized as a subspecies by Corbet and Hill (1992:313) but synonymized within magnificus by Thorington and Hoffmann (2005:771).

\section{Petaurista nobilis (Gray, 1842) (Bhutan giant flying squirrel)}

\section{Petaurista nobilis nobilis (Gray, 1842)}

Sciuropterus nobilis Gray, 1842:263.

Type Locality. Dargellan (Darjeeling), West Bengal, India.

Comments. Formerly synonymized in magnificus by authors, including Blyth (1863:95), Ellerman and Morrison-Scott (1951:464), Ellerman (1961:28, 39), and Corbet and Hill (1980:137; 1986:153). Elevated to specific rank by Ghose and Saha (1981:95), Corbet and Hill (1991:145; 1992:313), and subsequent authors.

Distribution. Eastern Nepal to Sikkim in India at approximately 1,670-3,000 m (5,479-9,842 ft) (Ghose and Chakraborty, 1983:411; Corbet and Hill, 1992:313).

S. [ciuropterus] chrysotrix Hodgson, 1844:67, pl. [no. not given].

Type Locality. Not known.

COMments. Synonymized within magnificus by Blyth (1863:95) and Ellerman and Morrison-Scott 
(1951:464). Included within nobilis by Ghose and Saha (1981:95), Corbet and Hill (1992:313), and Thorington and Hoffmann (2005:771).

\section{Petaurista nobilis singhei Saha, 1975}

Petaurista nobilis singhei Saha, 1975:27.

Type Locality. Gomchu, Gomchu Valley, Bhutan. 2,286 m ( 7,500 ft).

Comments. Subspecies recognized by Ghose and Saha (1981:95), Corbet and Hill (1992:313), and Thorington and Hoffmann (2005:771).

Distribution. Gomchu Valley, Bhutan (Corbet and Hill, 1992:313; Wangchuk et al., 2004:149).

\section{Petaurista petaurista (Pallas, 1766) (red giant flying squirrel)}

\section{Petaurista petaurista petaurista (Pallas, 1766)}

Sciurus petaurista Pallas, 1766:54.

TYPe Locality. Not stated. Restricted to western Java, Indonesia, by Robinson and Kloss (1918a:172).

Comments. Reviewed by Corbet and Hill (1992:309), who recognized philippensis as distinct and allocated many forms to it that were formerly assigned to petaurista; the two species are widely sympatric. Also reviewed from the literature by Day (1988:82) and karyotypic variation reported by Yong and Dhaliwal (1976:9). Wang (2003:157) recognized a Damingshan form. Has been recorded as a fossil from late Pliocene to Recent from several localities in peninsular and northeast Thailand (Chaimanee, 1998:161).

Distribution. Western Java (Corbet and Hill, 1992:309).

Petaurista taguan Link, 1795:52, 78.

Type Locality. Unknown, Java?

Comments. Synonymized within petaurista by Corbet and Hill (1992:309) and Thorington and Hoffmann (2005:772).

Pteromys nitidus Desmarest, 1818c:403.

Type Locality. Java.

Comments. Synonymized within petaurista by Corbet and Hill (1992:309) and Thorington and Hoffmann (2005:772).

\section{Petaurista petaurista batuana Miller, 1903}

Petaurista batuana Miller, 1903a:27.
Type Locality. Tana Bala, Batu Islands, west Sumatra, Indonesia.

Comments. Synonymized within Petaurista petaurista by Corbet and Hill (1992:309). Subspecies rank recognized within petaurista by Chasen (1940:113), Ellerman (1940:285), Day (1988:82), and Thorington and Hoffmann (2005:772).

Distribution. Batu Islands (Tana Bala Island, Tana Masa Island, and Pini Island), off west Sumatra (Robinson and Kloss, 1918a:173; Meijaard, 2003:1256).

\section{Petaurista petaurista cicur (Robinson and Kloss, 1914)}

Petaurista nitida cicur Robinson and Kloss, 1914:223.

Type Locality. Ban Kok Klap, Bandon, southern Thailand.

Comments. Recognized as a subspecies within Petaurista petaurista by Chasen (1940:112), Ellerman (1940:285), Day (1988:82), Lekagul and McNeely (1988:379), Corbet and Hill (1992:309), and Thorington and Hoffmann (2005:772).

Distribution. Southern Thailand peninsula south to Thung Song, Nakhon Si Thammarat (Lekagul and McNeely, 1988:379).

\section{Petaurista petaurista grandis (Swinhoe, 1863)}

Pteromys grandis Swinhoe, 1863:358, pl. 45.

Type Locality. Taiwan (Formosa), China.

Comments. Recognized as a distinct species in Petaurista by Ellerman (1940:286). Placed as a subspecies of petaurista by Ellerman and Morrison-Scott (1951:462), Day (1988:82), and Zhang et al. (1997:150). Recognized as a subspecies of albiventer by Wang (2003:157). Subspecies rank recognized within philippensis by Corbet and Hill (1992:310), Oshida et al. (2004a:15), Thorington and Hoffmann (2005:772), Smith and Xie (2008:179), and Oshida et al. (2011:404). Placed within P. petaurista by $\mathrm{Yu}$ et al. (2006:755), who found it was clearly not associated with philippensis, and most recently recognized as a distinct species by Oshida et al. (2010:89), although it grouped most closely with $P$. petaurista. Further research is warranted to confirm the species status of this taxon.

Distribution. Taiwan, China (Smith and Xie, 2008:179).

\section{Petaurista petaurista interceptio Sody, 1949}

Petaurista petaurista interceptio Sody, 1949:69. 
Type Locality. Mount Tjerimai, western

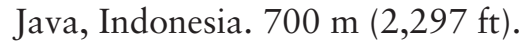

Comments. Recognized as a subspecies within Petaurista petaurista by Corbet and Hill (1992:309) and Thorington and Hoffmann (2005:772).

Distribution. Mount Tjerimai, western Java.

\section{Petaurista petaurista lumholtzi Gyldenstolpe, 1920}

Petaurista petaurista lumboltzi Gyldenstolpe, 1920:28.

Type Locality. Poeroek Tjahoe, Barito River, central Borneo.

Comments. Recognized as a subspecies within Petaurista petaurista by Chasen (1940:112), Ellerman (1940:286), Medway (1965:116; 1977:106), Day (1988:82), Corbet and Hill (1992:309), and Thorington and Hoffmann (2005:772).

Distribution. Recorded from central Kalimantan and from Talisajan in eastern Kalimantan, but probably widespread throughout the Kalimantan provinces, Borneo (Medway, 1965:116; Payne et al., 1985:249; Corbet and Hill, 1992:309).

\section{Petaurista petaurista marchio (Thomas, 1908)}

Petaurista nitida marchio Thomas, 1908e:251.

Type Locality. Si Rambi, Sumatra, Indonesia. Comments. Synonymized within Petaurista petaurista by Corbet and Hill (1992:309). Subspecies recognized within petaurista by Sody (1949:68) and Thorington and Hoffmann (2005:772).

Distribution. Si Rambi, Sumatra, and Rupat Island, off eastern Sumatra, Indonesia (Corbet and Hill, 1992:309).

Petaurista mimicus Miller, 1913:27.

Type Locality. Rupat Island, off eastern Sumatra, Indonesia.

Comments. Recognized as a subspecies of petaurista by Chasen (1940:114), Ellerman (1940:286), and Day (1988:82). Synonymized within Petaurista petaurista by Corbet and Hill (1992:309) and Thorington and Hoffmann (2005:772).

\section{Petaurista petaurista melanotus (Gray, 1836)}

Pteromys melanotus Gray, 1836:88.

Type Locality. Selangor; originally Nepal, in error. Ko-khau, Trang, Malay Peninsula substituted (see
Robinson and Kloss, 1918a:172; Hill, 1960:40; Corbet and Hill, 1992:309).

Comments. This taxon was also described by Gray (1837a:584). Synonymized within Petaurista petaurista by Corbet and Hill (1992:309). Proposed to be a distinct species by Oshida et al. (2004a:21). Subspecies rank within petaurista recognized by Chasen (1940:113), Ellerman (1940:285), Medway (1969:67), Agrawal and Chakraborty (1979a:343), Day (1988:82), Lekagul and McNeely (1988:379), and Thorington and Hoffmann (2005:772).

Distribution. Malay Peninsula to at least Pattani in southern Thailand. Also occurs on Tioman Island, Malaysia, and Singapore (extinct?) (Medway, 1969:65).

\section{Petaurista petaurista nigrescens Medway, 1965}

Petaurista petaurista nigrescens Medway, 1965:116.

Type Locality. Sandakan, Sabah, Borneo.

COMments. Recognized as a subspecies of petaurista by Sody (1949:69), Day (1988:82), Corbet and Hill (1992:309), and Thorington and Hoffmann (2005:772).

Distribution. Known only from the forests around Sandakan Bay north of southern Kinabatangan, Sabah, Borneo (Medway, 1965:116; Payne et al., 1985:249).

\section{Petaurista petaurista nigricaudatus Robinson and Kloss, 1918}

Petaurista petaurista nigricaudatus Robinson and Kloss, 1918b:223.

TYpe Locality. Idjen Massif, Ongop Ongop, near Banjoe-wangie, eastern Java, Indonesia. 1,737 m $(5,700 \mathrm{ft})$.

Comments. Recognized as a subspecies within Petaurista petaurista by Chasen (1940:112), Ellerman (1940:285), Agrawal and Chakraborty (1979a:343), Day (1988:82), Corbet and Hill (1992:309), and Thorington and Hoffmann (2005:772).

Distribution. Idjen Massif near Banjoewangi, eastern Java (Corbet and Hill, 1992:309).

\section{Petaurista petaurista nitidula Thomas, 1900}

Petaurista nitidula Thomas, 1900b:592.

Type Locality. Bunguran Island, Natuna Islands, Indonesia.

Comments. Synonymized within Petaurista petaurista by Corbet and Hill (1992:309). Subspecies rank recognized within petaurista by Chasen (1940:112), 
Ellerman (1940:285), Day (1988:82), and Thorington and Hoffmann (2005:772).

Distribution. Bunguran Island, Natuna Islands, Indonesia (Corbet and Hill, 1992:309).

\section{Petaurista petaurista penangensis Robinson and Kloss, 1918}

Petaurista petaurista penangensis Robinson and Kloss, 1918b:224.

Type Locality. Telok Bahang, Penang Island (Pinang), Malaysia.

Comments. Recognized as a subspecies of petaurista by Chasen (1940:113), Ellerman (1940:289), Medway (1969:67), Day (1988:82), Corbet and Hill (1992:309), and Thorington and Hoffmann (2005:772).

Distribution. Penang Island (Pinang), Malaysia (Medway, 1969:67; Corbet and Hill, 1992:309).

\section{Petaurista petaurista rajah Thomas, 1908}

Petaurista nitida rajab Thomas, 1908e:251.

Type Locality. Mount Dulit, Baram District, east Sarawak, Borneo. $609 \mathrm{~m} \mathrm{(2,000ft).}$

Comments. Recognized as a subspecies within Petaurista petaurista by Chasen (1940:112), Ellerman (1940:285), Medway (1965:115; 1977:105), Day (1988:83), Corbet and Hill (1992:309), and Thorington and Hoffmann (2005:772).

Distribution. Borneo, recorded from many localities throughout Sabah, Brunei, and Sarawak, up to 900 m (2,953 ft) on Gunnung Kinabalu, including Mount Dulit, Baram. Includes eastern Sabah, except the area occupied by P. p. nigrescens (Davis, 1962:84; Medway, 1965:115; Payne et al., 1985:249). Also occurs on Labuan Island, off the coast of Sabah, Borneo (Motley and Dillwyn, 1855:2; Meijaard, 2003:1256).

Pteromys melanopis Gray in Motley and Dillwyn, 1855:2.

Type Locality. Labuan Island, Malaysia.

Comments. Synonymized within rajah by Medway (1965:115), but not considered by other authors.

\section{Petaurista petaurista rufipes Sody, 1949}

Petaurista petaurista rufipes Sody, 1949:68.

Type Locality. Kluang, Palembang, southeast Sumatra.

Comments. Preoccupied by Petaurista rufipes G. Allen, 1925. Synonymized within Petaurista petaurista by Corbet and Hill (1992:309). Subspecies rank recognized within petaurista by Wang (2003:157) and Thorington and Hoffmann (2005:772). Synonymized within Petaurista petaurista but unmentioned subspecies by Smith and Xie (2008:179).

Distribution. Kluang, Palembang, southeast Sumatra (Corbet and Hill, 1992:309), and Sipura Island off western Sumatra (Meijaard, 2003:1256).

Petaurista petaurista sodyi Harris, 1951:234.

Type Locality. Southeast Sumatra, Indonesia.

Comments. The subspecies name was nominated because the name sodyi was preoccupied by $P$. $p$. rufipes G. Allen, 1925 from China (in P. philippensis). Synonymized within Petaurista petaurista by Corbet and Hill (1992:309) and within rufipes by Thorington and Hoffmann (2005:772).

\section{Petaurista petaurista stellaris Chasen, 1940}

Petaurista petaurista stellaris Chasen, 1940:113.

TYpe LocAlity. Bintang Island, Riau Islands, Indonesia.

Comments. Recognized as a subspecies within Petaurista petaurista by Chasen (1940:113) and Corbet and Hill (1992:309).

Distribution. Bintan Island, Riau Islands, Indonesia (Corbet and Hill, 1992:309).

\section{Petaurista petaurista terutaus Lyon, 1907}

Petaurista terutaus Lyon, 1907a:17.

TYPe Locality. Terutau Island, northern Strait of Malacca, Thailand.

Comments. Synonymized within Petaurista petaurista by Corbet and Hill (1992:309). Subspecies rank recognized within petaurista by Chasen (1940:113), Ellerman (1940:285), Day (1988:83), Lekagul and McNeely (1988:379), and Thorington and Hoffmann (2005:772).

Distribution. Terutau Island in the northern Strait of Malacca, Thailand (Lekagul and McNeely, 1988:379; Corbet and Hill, 1992:309).

\section{Petaurista philippensis (Elliot, 1839)} (Indian giant flying squirrel)

\section{Petaurista philippensis philippensis (Elliot, 1839)}

Pteromys philippensis Elliot, 1839:217. 
Type Locality. Near Madras, India. Comments. Species rank within Petaurista recognized by Allen (1925:15). Formerly included as a subspecies of petaurista by authors, including Ellerman and Morrison-Scott (1951:462), Ellerman (1961:28, 48), Agrawal and Chakraborty (1979a:338; 1979b:161), Day (1988:83), and Lekagul and McNeely (1988:377). Separated as a distinct species by Ellerman (1940:286) and Corbet and Hill (1991:145; 1992:310). Further work is needed on the geographic variation of this species. Wang (2003:158) recognizes a Hunan form.

Distribution. Western peninsular India, including Kerala, Karnataka, Maharashtra north to Mumbai (Bombay); Rajasthan; and southern Bihar, India, and Sri Lanka (Tehsin, 1981:498; Corbet and Hill, 1992:310).

Pteromys orál Tickell, 1842:401, pl. 11.

Type Locality. Singhbhum District, Orissa, southern Bihar, India.

Comments. Recognized as a species within Pteromys by Anderson (1879:279) and Sclater (1891:32) and as a subspecies within philippensis by Ellerman (1940:287). Synonymized within lanka by Phillips (1935:211; 1980:171) and philippensis by Ellerman and Morrison-Scott (1951:462), Ellerman (1961:28, 48), Corbet and Hill (1992:310), and Thorington and Hoffmann (2005:772).

Pteromys griseiventer Gray, 1843:133.

Type Locality. India.

COMments. Synonymized within philippensis by Ellerman and Morrison-Scott (1951:462), Corbet and Hill (1992:310), and Thorington and Hoffmann (2005:772).

[Petaurista] cinderella Wroughton, 1911:1013, 1018.

Type Locality. The Dangs, Surat District, Bombay, India.

Comments. Recognized as a subspecies within philippensis by Ellerman (1940:287). Synonymized within philippensis by Ellerman and Morrison-Scott (1951:462), Ellerman (1961:28, 48), Corbet and Hill (1992:310), and Thorington and Hoffmann (2005:772).

[Petaurista] lanka Wroughton, 1911:1013, 1017.

\section{Type Locality. Sri Lanka.}

Comments. Recognized as a subspecies within philippensis by Phillips (1935:211) and Ellerman (1940:287) but as a subspecies of petaurista by Ellerman and Morrison-Scott (1951:462), Ellerman (1961:28, 50),
Phillips (1980:171), and Day (1988:82). Synonymized within philippensis by Corbet and Hill (1992:310) and Thorington and Hoffmann (2005:772).

\section{Petaurista philippensis annamensis Thomas, 1914}

Petaurista annamensis Thomas, 1914b:204.

Type Locality. Bali, near Nha-Trang, southern Annam, Vietnam. 150 m (492 ft).

Comments. Species rank recognized by Allen and Coolidge (1940:153) and Ellerman (1940:287). Recognized as a subspecies within petaurista by Ellerman and Morrison-Scott (1951:462) and a subspecies of alborufus by Day (1988:81). Synonymized within philippensis by Corbet and Hill (1992:310). Subspecies rank recognized within philippensis by Thorington and Hoffmann (2005:772).

Distribution. Vietnam (Robinson and Kloss, 1918a:174; Francis, 2008:150).

Petaurista lylei badiatus Thomas, 1925:501.

Type Locality. Ngai-Tio, central Tonkin, Vietnam.

Comments. Recognized as a subspecies of lylei by Ellerman (1940:287) and philippensis by Corbet and Hill (1992:311). Synonymized within annamensis by Thorington and Hoffmann (2005:772).

Petaurista lylei miloni Bourret, 1942:28.

Type Locality. Milon at Diem-her, Lang-son Province, Tonkin, Vietnam.

Comments. Recognized as a subspecies within petaurista by Ellerman and Morrison-Scott (1951:463), Day (1988:82), and Zhang et al. (1997:150), but transferred as a subspecies within philippensis by Corbet and Hill (1992:311) and Wang (2003:158). Synonymized within annamensis by Thorington and Hoffmann (2005:772).

\section{Petaurista philippensis cineraceus (Blyth, 1847)}

Pt.[eromys] petaurista (?) var. cineraceus Blyth, 1847:865. Type Locality. Arakan, Burma.

Comments. Species rank recognized within Pteromys by Anderson (1879:279) and Sclater (1891:32) and within Petaurista by Ellerman (1940:287). Recognized as a subspecies within petaurista by Ellerman and Morrison-Scott (1951:462), Ellerman (1961:29, 50), Yin (1967:220), Agrawal and Chakraborty (1979a:339), and Day (1988:82). Synonymized within philippensis 
by Corbet and Hill (1992:310). Subspecies rank recognized within philippensis by Thorington and Hoffmann (2005:772).

Distribution. Arakan, Burma, to Arunchal Pradesh.

\section{Petaurista philippensis Iylei Bonhote, 1900}

Petaurista lylei Bonhote, 1900:192, pl. 18.

Type Locality. Doi Sritepe, Chiang Mai, northern Thailand.

Comments. Species rank recognized in Petaurista by Allen and Coolidge (1940:153) and Ellerman (1940:287). Recognized as a subspecies within petaurista by Ellerman and Morrison-Scott (1951:462), Ellerman (1961:29, 52), Yin (1967:220), Agrawal and Chakraborty (1979a:340; 1979b:162), Day (1988:82), and Lekagul and McNeely (1988:379). Synonymized within philippensis by Corbet and Hill (1992:310). Subspecies status recognized within philippensis by Zhang et al. (1997:153), Wang (2003:158), and Thorington and Hoffmann (2005:772).

Distribution. Yunnan and Guizhou provinces in southern China, eastern Burma, northern Thailand, Laos, and Cambodia (Lekagul and McNeely, 1988:379; Zhang et al., 1997:153; Francis, 2008:150).

Petaurista cineraceus stockleyi Carter, 1933:1.

Type Locality. Melamoong, northwest Thailand.

Comments. Recognized as a subspecies within cineraceus by Ellerman (1940:287), petaurista by Ellerman and Morrison-Scott (1951:463) and Lekagul and McNeely (1988:379), and philippensis by Corbet and Hill (1992:311). Synonymized within lylei by Thorington and Hoffmann (2005:772).

Petaurista lylei venningi Thomas, 1914a:26.

Type Locality. Kalaw, west of Tsunggyi, Burma. 1,430 m (4,700 ft).

Comments. Recognized as a subspecies within lylei by Ellerman (1940:287), petaurista by Yin (1967:220), and philippensis by Corbet and Hill (1992:311). Synonymized within lylei by Thorington and Hoffmann (2005:772).

\section{Petaurista philippensis mergulus Thomas, 1922}

Petaurista mergulus Thomas, 1922c:1067.

Type Locality. Ross Island, Mergui Archipelago, Burma.
Comments. Species rank recognized by Ellerman (1940:287). Recognized as a subspecies within petaurista by Ellerman and Morrison-Scott (1951:462), Ellerman (1961:29, 51), Yin (1967:220), and Day (1988:82). Synonymized within Petaurista philippensis by Corbet and Hill (1992:311). Elevated to subspecies by Thorington and Hoffmann (2005:772).

Distribution. Ross Island, Sullivan Island, and King Island, Mergui Archipelago, Burma (Thomas, 1922c:1067; Meijaard, 2003:1256).

Petaurista mergulus primrosei Thomas, 1926:22.

Type Locality. Sullivan Island, Mergui Archipelago, Burma.

Comments. Recognized as a subspecies within mergulus by Ellerman (1940:287) and within petaurista by Ellerman and Morrison-Scott (1951:463), Ellerman (1961:29, 51), Yin (1967:220), and Day (1988:83). Recognized as a subspecies within Petaurista philippensis by Corbet and Hill (1992:311). Synonymized within mergulus by Thorington and Hoffmann (2005:772).

Petaurista mergulus reguli Thomas, 1926:22.

Type Locality. King Island, Mergui Archipelago, Burma.

Comments. Recognized as a subspecies within mergulus by Ellerman $(1940: 287)$ and petaurista by Ellerman and Morrison-Scott (1951:463), Ellerman (1961:29, 51), Yin (1967:220), and Day (1988:83). Recognized as a subspecies within Petaurista philippensis by Corbet and Hill (1992:311). Synonymized within mergulus by Thorington and Hoffmann (2005:772).

\section{Petaurista xanthotis (Milne-Edwards, 1872) (Chinese giant flying squirrel)}

P.[teromys] xanthotis Milne-Edwards, 1872:301.

Type Locality. Moupin, Sichuan, China.

Comments. Transferred to Petaurista by Lyon (1907b:133) and followed by subsequent authors. Formerly included as a subspecies of leucogenys by Ellerman and Morrison-Scott (1951:464) and Corbet (1978:86), but separated as a distinct species by McKenna (1962:27), Corbet and Hill (1991:145; 1992:313), and subsequent authors. Found as fossil deposits in China from the late Pleistocene (Zheng, 1993:266).

Distribution. Eastern Tibet and western China from Gansu, Qinghai, Sichuan, and Yunnan provinces (Corbet and Hill, 1992:313; Zhang et al., 1997: 153). 
Pteromys filchnerinae Matschie, 1908:208.

Type Locality. Siningfu, upper Hwangho, Gansu, China.

Comments. Species rank recognized within Petaurista by Ellerman (1940:289). Recognized as a subspecies of xanthotis by Wang (2003:159) and Smith and Xie $(2008: 180)$. Synonymized within xanthotis by Allen (1940:741), Ellerman and Morrison-Scott (1951:464), Corbet (1978:86), Corbet and Hill (1992:313), and Thorington and Hoffmann (2005:772).

Pteromys büchneri Matschie, 1908:210.

Type Locality. Si-ning-Fu (upper HwangHo, Gansu), China.

Comments. Synonymized within xanthopus by Corbet and Hill (1992:313) and Thorington and Hoffmann (2005:772). Recognized as a subspecies of xanthotis by Smith and Xie (2008:180).

\section{Petaurista yunanensis (Anderson, 1875) (Yunnan giant flying squirrel)}

Pteromys yunanensis Anderson, 1875:282.

Type Locality. Teng-yue-chow, Yunnan, China.

Comments. Redescribed and spelled yunnanensis by Anderson (1879:282) and often spelled that way by subsequent authors. Recognized as a distinct species within Pteromys by Sclater (1891:32) and within Petaurista by Robinson and Kloss (1918a:173), Allen (1925:13; 1940:730, 737), Howell (1929:48), and Ellerman (1940:287), but reduced to a subspecies of petaurista by Ellerman and Morrison-Scott (1951:462; 1966:462), Ellerman (1961:29, 52), Yin (1967:220), Agrawal and Chakraborty (1979a:342), and Day (1988:83). Synonymized within petaurista by Lekagul and McNeely (1988:377) and within philippensis by Corbet and Hill (1992:310). Elevated to subspecies of albiventer by Wang (2003:157) and philippensis by Thorington and Hoffmann (2005:772) and Smith and Xie (2008:179). Species rank recognized by Zhang et al. (1997:151) and Yu et al. (2006:755), who found them to be distinct where they occur sympatrically with philippensis.

Distribution. Tibet, Sichuan, Yunnan, Guangxi, and Fujian provinces, China (Zhang et al., 1997:151; Smith and Xie, 2008:179). Also extends into northern Burma, Laos, and Vietnam (Yin, 1967:220; Francis, 2008:341).

Petaurista petaurista rufipes G. Allen, 1925:13.

Type Locality. Yungan (Yongan), Fukian (Fujian) Province, China.
Comments. Name has priority over rufipes Sody, 1949. Subspecies rank within petaurista recognized by Allen (1940:731), Ellerman (1940:286), Ellerman and Morrison-Scott (1951:462), and Day (1988:83). Synonymized within Petaurista philippensis by Corbet and Hill (1992:310) and within yunanensis by Thorington and Hoffmann (2005:772).

Petaurista petaurista nigra Wang, 1981:169.

Type Locality. Chiching, Gaoligong Mountains, Gongshan Xian, northwestern Yunnan, China. $1,900 \mathrm{~m}(6,234 \mathrm{ft})$.

Comments. Recognized as a subspecies within petaurista by Day (1988:82) and Zhang et al. (1997:150). Synonymized within Petaurista philippensis by Corbet and Hill (1992:310) and within yunanensis by Thorington and Hoffmann (2005:772). Recognized as a subspecies of albiventer by Wang (2003:157) and philippensis by Smith and Xie (2008:179).

Petaurista rubicundus Howell, 1927:82.

Type Locality. Mapientung, Szechwan (Sichuan), China.

Comments. Species rank recognized by Howell (1929:47) and Ellerman (1940:289). Recognized as a subspecies within petaurista by Allen (1940:731), Ellerman and Morrison-Scott (1951:463), Day (1988:83), and Zhang et al. (1997:150). Synonymized within Petaurista philippensis by Corbet and Hill (1992:310) and within yunanensis by Thorington and Hoffmann (2005:772). Recognized as a subspecies of sybilla by Wang (2003:156) and philippensis by Smith and Xie (2008:179).

\section{†Petauristodon Engesser, 1979}

†Petauristodon Engesser, 1979:23.

Type Species. †Sciuropterus mathewsi James, 1963:93.

Comments. Early to late Miocene, North America. Genus recognized within the family Sciuridae by Engesser (1979:23) and the subfamily Pteromyinae by McKenna and Bell (1997:127), although they suggested the placement within that subfamily was questionable. The identification of this genus was discussed by Pratt and Morgan (1989:94) and was agreed to by Thorington et al. (2005:958).

\section{†Petauristodon jamesi (Lindsay, 1972)}

†Sciuropterus jamesi Lindsay, 1972:31.

Type Locality. Barstow Formation, southern California, USA. 
Comments. Early Miocene. This species was proposed to be a member of $†$ Miopetaurista by de Bruijn et al. (1980:251), but it was tentatively excluded by de Bruijn (1998:104) and was not placed in another genus. Species recognized within †Petauristodon by Engesser (1979:23) and Pratt and Morgan (1989:90) but within Sciuropterus by Albright (1996:460). The potential of tjamesi being a synonym of mathewsi was raised by Engesser (1979:23).

\section{†Petauristodon mathewsi (James, 1963)}

†Sciuropterus mathewsi James, 1963:93.

Type Locality. Cuyama Valley, Badlands, California, USA.

Comments. Mid-Miocene to late Pleistocene. Taxon placed in †Petauristodon by Engesser (1979:23).

\section{†Petauristodon minimus (Lindsay, 1972)}

†Sciuropterus minimus Lindsay, 1972:33.

TYPe LocAlity. Barstow Formation, southern California, USA.

Comments. Miocene. Taxon placed in †Petauristodon by Engesser (1979:23).

\section{†Petauristodon pattersoni Pratt and Morgan, 1989}

†Petauristodon pattersoni Pratt and Morgan, 1989:89, 90.

Type Locality. Thomas Farm Local Fauna, Gilchrist County, Florida.

Comments. Early Miocene.

\section{†Petauristodon uphami (James, 1963)}

†Sciuropterus uphami James, 1963:91.

Type Locality. Cuyama Valley, Badlands, California, USA.

Comments. Mid-Miocene to late Pleistocene. Taxon placed in †Petauristodon by Engesser (1979:23).

\section{Petinomys Thomas, 1908}

Petinomys Thomas, 1908b:6.

Type Species. Sciuropterus lugens Thomas, 1908d:666.

Comments. Described as a subgenus of Sciuropterus. Transferred to Pteromys at subgenus rank by Allen (1940:725). Elevated to generic rank by Pocock (1923:246), Ellerman (1940:300), and subsequent authors.
Formerly included bartelsi and electilis, which are here included in Hylopetes; see McKenna (1962:35) and Corbet and Hill (1992:317). Late Miocene, mid-Pleistocene, and Recent, Asia; late Miocene to early Pliocene, Europe; Recent, SE Asia.

Olisthomys Carter, 1942:2.

Type Species. Pteromys (Olisthomys) morrisi Carter, 1942:2.

Comments. Synonymized within Petinomys by Ellerman and Morrison-Scott (1951:470), Corbet and Hill (1992:317), and Thorington and Hoffmann (2005:772).

\section{†Petinomys auctor Qiu, 1991}

†Petinomys auctor Qiu, 1991:238.

Type Locality. Ertemte 2, Huade County, Inner Mongolia, China.

Comments. Uppermost Miocene. Species placed within Hylopetes by de Bruijn (1995:92).

\section{Petinomys crinitus (Hollister, 1911 ) (Basilan flying squirrel)}

Sciuropterus crinitus Hollister, 1911:185.

Type Locality. Basilan Island, Philippines.

Comments. Appears to be known only from the type specimen. Species recognized within Sciuropterus by Taylor (1934:389). Transferred to Hylopetes by Rabor (1977:246) and Petinomys by Ellerman (1940:302), Hoffmann et al. (1993:463), and subsequent authors. Observations of the skulls of these species clearly show they are distinct, as crinitus is much smaller than mindanensis and has a more flattened tail.

Distribution. Basilan Island, Philippines (Heaney and Rabor, 1982:18; Corbet and Hill, 1992:318; Heaney et al., 1998:32; Thorington and Hoffmann, 2005:773).

\section{Petinomys fuscocapillus (Jerdon, 1847) (Travancore flying squirrel)}

Sciuropterus fuscocapillus Jerdon, 1847:867.

TYPe LocAlity. Travancore, southern India.

Comments. Recognized within Sciuropterus by Sclater (1891:37). Transferred to Pteromys by Anderson (1879:294) and Petinomys by Thomas (1908b:6) and followed by subsequent authors.

Distribution. Southern India and Sri Lanka (Ellerman, 1961:79; Corbet and Hill, 1992:318). 
Sciuropterus layardii Kelaart, 1850:215.

Type Locality. Dimbula, Sri Lanka. 1,372 m $(4,500 \mathrm{ft})$.

Comments. Recognized as a species within Pteromys by Phillips (1935:215) and Petinomys by Ellerman (1940:302) and as a subspecies of fuscocapillus by Ellerman and Morrison-Scott (1951:471) and Ellerman (1961:81). Synonymized within fuscocapillus by Corbet and Hill (1992:318) and Thorington and Hoffmann (2005:773).

\section{Petinomys genibarbis (Horsfield, 1824) (whiskered flying squirrel)}

Pteromys genibarbis Horsfield, 1824:167, unnumbered plate.

Type Locality. Eastern Java, Indonesia.

Comments. Transferred to Petinomys by Thomas (1908b:6) and followed by subsequent authors.

Distribution. Malay Peninsula including Penang Island, Sumatra including Bangka Island, Java and Sarawak, Brunei, Sabah, and Kalimantan Timur in Borneo (Payne et al., 1985:247; Corbet and Hill, 1992:318; Meijaard, 2003:1256).

Sciuropterus genibarbis borneoensis Thomas, 1908c:304.

TYPe LocAlity. Bakong River, Baram, east Sarawak, Borneo.

Comments. Recognized as a subspecies of genibarbis by Chasen (1940:120), Ellerman (1940:301), and Corbet and Hill (1992:318) but not by Thorington and Hoffmann (2005:773).

Sciuropterus genibarbis malaccanus Thomas, 1908c:304.

Type Locality. Malacca, Malay Peninsula.

Comments. Recognized as a subspecies of genibarbis by Chasen (1940:119), Ellerman (1940:301), Medway (1965:112; 1969:64; 1977:102), and Corbet and Hill (1992:318) but not by Thorington and Hoffmann (2005:773).

\section{Petinomys hageni (Jentink, 1888) (Hagen's flying squirrel)}

Sciuropterus hageni Jentink, 1888:26.

Type Locality. Tandjong-Morawa, Serdang, Deli, northeast Sumatra, Indonesia.

Comments. Transferred to Petinomys by Thomas (1908b:6) and followed by subsequent authors. Formerly included lugens (Chasen, 1940:119; Corbet and Hill, 1991:146).
Distribution. Sumatra, western Borneo (known only from a single specimen from Pontianak) (Corbet and Hill, 1992:317; Meijaard, 2003:1256).

Petinomys hageni ouwensi Sody, 1949:74.

TyPe Locality. Kubu region, Pontianak, western Borneo.

Comments. Recognized as a subspecies of hageni by Medway (1965:112), Payne et al. (1985:246), and Corbet and Hill (1992:317). Medway (1977:102) considered the status of ouwensi doubtful and placed it within hageni, which was also done by Thorington and Hoffmann (2005:773).

\section{Petinomys lugens (Thomas, 1895) (Siberut flying squirrel)}

Sciuropterus lugens Thomas, 1895d:666.

Type Locality. Si Oban, Sipora (Sipura) Island, Mentawai Islands, near western Sumatra, Indonesia.

Comments. Transferred to Petinomys by Thomas (1908b:6) and followed by subsequent authors. Formerly included as a subspecies of hageni by Chasen (1940:119), Jenkins and Hill (1982:220), and Chasen and Kloss (1927:819).

Distribution. Sipura Island and North Pagai Island, Mentawai Islands (west of Sumatra), Indonesia (Jenkins and Hill, 1982:220; Corbet and Hill 1992:317).

Sciuropterus maerens Miller, 1903a:26.

Type Locality. North Pagai Island, Mentawai Islands, west of Sumatra, Indonesia.

Comments. Recognized as a species in Petinomys by Thomas (1908b:6) and Ellerman (1940:302). Recognized as a subspecies within Petinomys hageni by Chasen (1940:119) and within Petinomys lugens by Corbet and Hill (1992:317). Synonymized within Petinomys lugens by Hoffmann et al. (1993:464) and Thorington and Hoffmann (2005:773).

\section{Petinomys mindanensis Rabor, 1939 (Mindanao flying squirrel)}

Sciuropterus mindanensis Rabor, 1939:390.

Type Locality. Badiangon, Gingoog, Oriental Misamis Province, northern coast of Mindanao, Philippines.

Comments. Synonymized within Petinomys crinitus by Corbet and Hill (1992:318), Hoffmann et al. (1993:463), and Heaney et al. (1998:32). Elevated to species rank by Thorington and Hoffmann (2005:773). 
Distribution. Dinagat, Siargao, and Mindanao islands, Philippines (Corbet and Hill, 1992:318; Heaney et al., 1998:32; Thorington and Hoffmann, 2005:773).

Petinomys crinitus nigricaudus Sanborn, 1953:285.

Type Locality. Tuod, near Mantikaw, Misamis Oriental, Mindanao Island, Philippines.

Comments. Subspecies status recognized by Corbet and Hill (1992:318) and synonymized with crinitus by Hoffmann et al. (1993:463) and Thorington and Hoffmann (2005:773).

\section{Petinomys setosus (Temminck, 1844) (Temminck's flying squirrel)}

Pteromys (Sciuropterus) setosus Temminck, 1844 (18431844): 49.

Type Locality. Padang, western Sumatra, Indonesia.

Comments. Transferred to Petinomys by Thomas (1908b:6) and followed by subsequent authors. Includes morrisi as outlined by Muul and Thonglongya (1971:362) and Corbet and Hill (1980:137). Oshida and Yoshida (1998:119) described the chromosomes.

Distribution. Northern Burma and northern Thailand, with a disjunct population in extreme southern Thailand and the adjacent Malayan Peninsula. Also occurs on Sumatra and Borneo in Sabah, Brunei, and Sarawak (Payne et al., 1985:247; Corbet and Hill, 1992:318). Found in fossil deposits from the mid-Pleistocene to Recent throughout Thailand (Chaimanee, 1998:174).

Pteromys (Olisthomys) morrisi Carter, 1942:2.

TYPe Locality. Dalu (Taro), northern Burma.

Comments. McKenna (1962:34) considered morrisi to belong to Pteromys within subgenus Olisthomys. Species rank recognized within Petinonys by Ellerman and Morrison-Scott (1951:470). Recognized as a subspecies of setosus by Yin (1967:229), Muul and Thonglongya (1971:262, 366), and Corbet and Hill (1992:318). Synonymized within setosus by Corbet and Hill (1991:146) and Thorington and Hoffmann (2005:774).

\section{Petinomys vordermanni (Jentink, 1890) (Vordermann's flying squirrel)}

Sciuropterus vordermanni Jentink, 1890b:150.

Type Locality. Billiton (Belitung Island), near eastern Sumatra, Indonesia.

Comments. Transferred to Petinomys by Thomas (1908b:6) and followed by subsequent authors.
McKenna (1962:6) considered vordermanni representative of an undescribed genus, but subsequent authors, including Hill (1962:733), retained it in Petinomys.

Distribution. Southern Burma, southern Thailand, Malay Peninsula, and Borneo (southern Sabah, Brunei and northern Sarawak, and central Kalimantan), and Belitung and Galang islands (Riau Islands) off the east coast of Sumatra, Indonesia (Muul, 1980:135; Payne et al., 1985:247; Corbet and Hill, 1992:319; Meijaard, 2003:1256).

Pteromys (Petinomys) phipsoni Thomas, 1916a:422.

TYPe Locality. Tenasserim Village, Tenasserim, southern Burma.

Comments. Species rank recognized within Petinomys by Ellerman (1940:301). Included as a subspecies of vordermanni by Chasen (1940:119), Hill (1962:734), and Medway (1969:65) and setosus by Ellerman and MorrisonScott (1951:470), Ellerman (1961:77), and Yin (1967:229). Synonymized within vordermanni by Corbet and Hill (1992:319) and Thorington and Hoffmann (2005:774).

\section{†Pliopetaurista Kretzoi, 1962}

†Pliopetaurista Kretzoi, 1962:367.

Type Species. †Sciuropterus pliocenicus Deperet, 1897:179.

Comments. Late Miocene, Asia; late Miocene to early Pleistocene, Europe. Genus recognized within the subfamily Pteromyinae by McKenna and Bell (1997:128) and family Petauristidae by de Bruijn (1999:275).

†Pliosciuropterus Sulimski, 1964:169.

TYPe SPecies. tPliosciuropterus dehneli Sulimski, 1964:172.

Comments. Late Miocene to early Pliocene, Europe. Recognized as a genus by McKenna and Bell (1997:128). Doubt was cast on this genus by Thorington et al. (2005:958).

\section{†Pliopetaurista bressana Mein, 1970<}

†Pliopetaurista bressana Mein, 1970:37.

TYPe Locality. Soblay, France.

Comments. Upper Miocene. Species recognized within $†$ Pliopetaurista by Daxner-Höck (1975:61; 2004:397) and de Bruijn (1995:92; 1999:275).

\section{†Pliopetaurista dehneli (Sulimski, 1964)}

†Pliosciuropterus dehneli Sulimski, 1964:172.

Type Locality. Weze, Poland. 
Comments. Pliocene. Species recognized within †Pliopetaurista by Mein (1970:39), de Bruijn (1995:92; 1999:275), and Daxner-Höck (2004:397).

†Pliosciuropterus schaubi Sulimski, 1964:179.

Type Locality. Weze, Poland.

Comments. Pliocene. The specific distinction of this taxon was questioned by Mein (1970:40) and Terzea (1980:198). Considered to be the same as tdehneli and is a junior synonym of that name because dehneli has page priority by de Bruijn (1995:92).

†Pliopetaurista moldaviensis Baranova and Konkova, 1974: 92, 93.

Type Locality. Moldavia.

Comments. Proposed to be a synonym of †dehneli by Terzea (1980:199).

\section{†Pliopetaurista kollmanni Daxner-Höck, 2004}

†Pliopetaurista kollmanni Daxner-Höck, 2004:387, 397.

Type Locality. Götzendorf an der Leitha, Vienna Basin, Austria.

Comments. Upper Miocene.

\section{†Pliopetaurista meini Black and Kowalski, 1974}

†Pliopetaurista meini Black and Kowalski, 1974:470.

Type Locality. Zalesiaki, Poland.

Comments. Pliocene. Species recognized within †Pliopetaurista by de Bruijn (1995:92; 1999:275) and Daxner-Höck (2004:397). Doubt was cast on this genus by Thorington et al. (2005:958), who suggest drawing of the teeth appears closer to Callosciurus than any flying squirrel.

\section{†Pliopetaurista pliocenica (Deperet, 1897)}

†Sciuropterus pliocenicus Deperet, 1897:179.

Type Locality. Perpignan, France.

Comments. Pliocene. Species recognized within †Pliopetaurista by de Bruijn (1995:92; 1999:275), Dahlmann (2001:54), and Daxner-Höck (2004:397).

†[Sciuropterus $]$ depereti Trouessart, 1898:400.

Type Locality. Gallia?

Comments. Pliocene. Synonymized within $\dagger$ Pliopetaurista pliocenica by Hugueney and Mein (1966: 244).

\section{†Pliopetaurista raui Dahlmann, 2001}

†Pliopetaurista raui Dahlmann, 2001:1, 54.

TYPe LocAlity. Wolfersheim, NNE Frankfurt am Main, Germany.

Comments. Pliocene. Recognized as a species within †Pliopetaurista by Daxner-Höck (2004:397).

\section{†Pliopetaurista rugosa Qiu, 1991}

†Pliopetaurista rugosa Qiu, 1991:223, 236.

Type Locality. Harr Obo 2, Huade County, Inner Mongolia, China.

Comments. Uppermost Miocene or lower Pliocene. Species recognized within + Pliopetaurista by de Bruijn (1995:92).

\section{†Pliopetes Kretzoi, 1959}

†Pliopetes Kretzoi, 1959:239.

Type Species. Pliopetes hungaricus Kretzoi, 1959:239.

Comments. Considered a synonym of $\mathrm{Hy}$ lopetes by van de Weerd (1979:132), Bouwens and de Bruijn (1986:118), and McKenna and Bell (1997:128). Recognized as a valid genus by Daxner-Höck (1975:63; 2004:404) and Dahlmann (2001:58).

\section{†Pliopetes hungaricus Kretzoi, 1959}

†Pliopetes hungaricus Kretzoi, 1959:239.

Type Locality. Csarnota, Hungary.

Comments. Upper Miocene to Pliocene. Species recognized within †Pliopetes by Daxner-Höck (1975:63), Dahlmann (2001:58), and Daxner-Höck (2004:404) but within Hylopetes by Bouwens and de Bruijn (1986:118) and de Bruijn (1999:276).

\section{Pteromys G. Cuvier, 1800}

Pteromys G. Cuvier, 1800: tab. 1.

Type Species. Sciurus volans Linnaeus, 1758:64.

COMMENTs. Sciuropterus was previously used by Simpson (1945:80), who believed Pteromys to be a synonym of Petaurista, but Ellerman and Morrison-Scott (1951:466) presented evidence for the validity of Pteromys. However, Pteromys may be the sister group to Petaurista (Oshida et al., 2000a:485). Late Pliocene to Recent, Asia; Recent, Europe.

Homonyms. Pteromys Tiedemann, 1808:451, flying squirrels of the class Mammalia (order Rodentia, 
family Sciuridae). Taxon is a synonym of Glaucomys (Thomas, 1908b).

Sciuropterus F. Cuvier, 1825a:126.

Type Species. Sciurus volans Linnaeus, 1758:64.

Comments. Also described by Cuvier (1825b:255). Genus recognized by Thomas (1897:1015) for all smaller flying squirrels. Synonymized within Pteromys by Miller (1914:216), Ellerman and MorrisonScott (1951:466), and Thorington and Hoffmann (2005: 774).

\section{†Pteromys lopingensis Young, 1947}

†Pteromys lopingensis Young, 1947:165.

Type Locality. Loping, Jiangxi, China.

Comments. Lower Pleistocene. Corbet and Hill (1992:306) proposed that it is probably referable to Petaurista or perhaps Trogopterus.

\section{Pteromys momonga Temminck, 1844 (Japanese flying squirrel)}

Pteromys momonga Temminck, 1844 (1843-1844):47, pl. 14.

Type Locality. Kyushu, Japan.

Comments. Transferred to Sciuropterus by Thomas (1908b:5) and Pteromys by Ellerman (1940:294). Proposed to be ancestral to $P$. volans by Oshida et al. (2000b:133). Fossils assigned to this species from the middle and late Pleistocene have been found in Japan by Kawamura (1981:69; 1982:60; 1988:194) and Kawamura et al. (1986:71; 1989:321).

Distribution. Honshu, Shikoku, and Kyushu islands, Japan (Dobson, 1994:97).

Sciuropterus momonga amygdali Thomas, $1905 \mathrm{~b}: 344$.

Type Locality. Washikaguchi, Nara Ken, southern central Honshu, Japan.

Comments. Subspecies rank recognized within momonga by Ellerman (1940:294). Synonymized within momonga by Ellerman and Morrison-Scott (1951:467) and Thorington and Hoffmann (2005:774).

Sciuropterus momonga interventus Kuroda, 1941:113.

TYPe Locality. Senjosen or Funanouesan, Isai-Mura, Tohaku-gun, Tottori Prefecture, southwestern Honshu, Japan. 610 m (2,000 ft).

Comments. Subspecies rank recognized within momonga by Ellerman and Morrison-Scott (1951:
467) but synonymized within momonga by Thorington and Hoffmann (2005:774).

\section{Płeromys volans (Linnaeus, 1758) (Siberian flying squirrel)}

\section{Pteromys volans volans (Linnaeus, 1758)}

[Sciurus] volans Linnaeus, 1758:64.

Type Locality. "In borealibus Europae, Asiae, et Americae.” Restricted by Thomas (1911b:149) to "Finland." Ognev (1966:268) proposed restriction to "central Sweden," but the species does not occur there (Sulkava 1978:76).

Comments. Transferred to Pteromys by Anderson (1879:302) and followed by most subsequent authors. Chromosomes described by Rausch and Rausch (1982:58) and Oshida et al. (2000b:133). Subspecies follow Corbet (1978:86). Fossils assigned to this species from the mid-Pleistocene have been found in Japan by Kowalski and Hasegawa (1976:36).

Distribution. Northern Palaearctic from Finland, Estonia, Latvia, Belarus, Russia, Siberia, and Mongolia, southward nearly to the boundary of northeastern Germany, and eastward into Scandinavia and to northwest to northeast China, extending into central China, including Xinjiang, Nei Mongol, Heilongjiang, Jilin, Liaoning, Hebei, Beijing, Shanxi, Henan, and Hunan provinces. Distribution extends into Korea (Vinogradov and Argiropulo, 1968:86-87; Zhang et al., 1997:155; Smith and Xie, 2008:180).

P.[teromys] russicus Tiedemann, 1808:451.

Type Locality. Russia.

Comments. Transferred to Sciuropterus by Thomas (1908b:5). Recognized as a synonym of volans by Ellerman and Morrison-Scott (1951:466) and Thorington and Hoffmann (2005:774).

Pteromys sibiricus Desmarest, 1822:342.

Type Locality. Russia.

Comments. Recognized as a synonym of $v o$ lans by Ellerman and Morrison-Scott (1951:466) and Thorington and Hoffmann (2005:774).

Pt.[eromys] vulgaris Wagner, 1843:228, pl. 223.

Type Locality. Europe.

COMments. Recognized as a synonym of $v o$ lans by Ellerman and Morrison-Scott (1951:466) and Thorington and Hoffmann (2005:774). 
Sciuropterus aluco Thomas, 1907b:464.

Type Locality. Kaloguai, $89 \mathrm{~km}(55 \mathrm{mi})$ northeast of Seoul, Korea. 150 m (500 ft).

Comments. Recognized as a subspecies of volans by Ellerman (1940:294), Ellerman and MorrisonScott (1951:466), and Jones and Johnson (1965:369). Synonymized within volans by Thorington and Hoffmann (2005:774). Koh et al. (2008:169) suggested that aluco might be a synonym of arsenjevi.

Pteromys volans incanus Miller, 1918:3.

Type Locality. Verkhne Kolymsk, east Siberia, Russia.

Comments. Recognized as a subspecies of $v$ olans by Ognev (1934:308, 314; 1966:278), Ellerman (1940: 294), and Ellerman and Morrison-Scott (1951:467). Synonymized within volans by Thorington and Hoffmann (2005:774).

Pteromys volans turovi Ognev, 1929:75.

Type Locality. Koty Peninsula, Baikal, Siberia, Russia.

Comments. Subspecies rank recognized within volans by Ognev (1934:306, 312). Recognized as a synonym of volans by Thorington and Hoffmann (2005:774). Recognized as a subspecies of volans by Ellerman (1940:294), Ellerman and Morrison-Scott (1951: 467), Ognev (1966:274), Zhang et al. (1997:155), Wang (2003:160), and Smith and Xie (2008:180).

Pteromys volans betulinus von Serebrennikov, 1930:142.

Type Locality. Pavlodar, Semipalatinsk, Siberia, Russia.

Comments. Recognized as a subspecies of volans by Ognev (1934:305, 312), Ellerman (1940:294), Ellerman and Morrison-Scott (1951:467), and Ognev (1966:272). Synonymized within volans by Thorington and Hoffmann (2005:774).

Pteromys volans gubari Ognev, 1934:304, 311.

Type Locality. District of Troitzk, formerly Bijsk, western Siberia, Russia.

Comments. Recognized as a subspecies of volans by Ellerman (1940:294), Ellerman and MorrisonScott (1951:467), and Ognev (1966:271). Synonymized within volans by Thorington and Hoffmann (2005:774).

Pteromys volans arsenjevi Ognev, 1934:309, 314.

Type Locality. Kulume River, Ussuri, Siberia, Russia.

Comments. Recognized as a subspecies of $v o-$ lans by Ellerman (1940:294), Ellerman and Morrison-Scott
(1951:467), Jones and Johnson (1965:369), Ognev (1966:282), and Zhang et al. (1997:155). Synonymized within volans by Thorington and Hoffmann (2005:774), but recognized as a subspecies by Wang (2003:160) and Smith and Xie (2008:180).

Pteromys volans ognevi Stroganov, 1936:539, 559.

Type Locality. Lake Peno, Kalininschen Region (the headwaters of the Volga River, a former district of the province of Tver Ostaschkowsche), Russia.

Comments. Recognized as a subspecies of volans by Ellerman (1940:294), Ellerman and MorrisonScott (1951:467), Ognev (1966:270), and Mitchell-Jones et al. (1999:196), who suggested it occurs in the southwestern parts of the species range, from southwest of Moscow and Novgorod. Synonymized within volans by Thorington and Hoffmann (2005:774).

Sciuropterus wulungshanensis Mori, 1939:59.

Type Locality. Mount Wu-ling (Wulung), Hsinglunghsien, southern Jehol Province, China. Note that Jehol is a defunct Chinese province that used to consist of part of today's Hebei Province, Shanxi Province, and Inner Mongolia.

Comments. Recognized as a synonym of $v o-$ lans by Thorington and Hoffmann (2005:774) and as a subspecies of volans by Allen (1940:720), Ellerman and Morrison-Scott (1951:467), Zhang et al. (1997:155), Wang (2003:16), and Smith and Xie (2008:180).

Pteromys volans anadyrensis Ognev, 1966:321.

TYPe Locality. Anadyr region, extreme northeast Siberia, Russia.

Comments. Recognized as a subspecies of volans by Ellerman and Morrison-Scott (1951:467) and Ognev (1966:281). Synonymized within volans by Thorington and Hoffmann (2005:774).

Pteromys russicus khinganensis Mori, 1942:25.

Type Locality. Dragotzenka, 97 km (60 mi) from Hailar, Manchuria.

Comments. Derived from secondary reference (Kaneko and Maeda, 2002:16). Synonymized within arsenjevi by Wang (2003:160).

\section{Pteromys volans athene (Thomas, 1907)}

Sciuropterus russicus athene Thomas, 1907c:409.

Type Locality. Korsakoff, Sakhalin Island, off eastern Siberia, Russia.

Comments. Recognized as a subspecies of volans by Ognev (1934:307, 313), Ellerman (1940:294), 
Ellerman and Morrison-Scott (1951:466), Ognev (1966:276), Corbet (1978:86), and Thorington and Hoffmann (2005:774).

Distribution. Korsakoff, Sakhalin Island, off eastern Siberia, Russia.

Pteromys volans buechneri (Satunin, 1902)

Sciuropterus buechneri Satunin, 1902:549.

Type Locality. Gansu Province, northeast China.

Comments. Transferred to Sciuropterus by Thomas (1908b:5) and used by Howell (1929:48), but moved to Pteromys by Ellerman (1940:294). Recognized as a synonym of volans by Allen (1940:720) but as a subspecies of volans by Ellerman and Morrison-Scott (1951:466), Corbet (1978:86), Zhang et al. (1997:155), and Wang (2003:160).

Distribution. Extends between southern Gansu, southeastern Qinghai, Ningxia, Henan, and northern Sichuan Province in China (Zhang et al., 1997:155; Smith and Xie, 2008:180).

\section{Płeromys volans orii (Kuroda, 1921)}

Sciuropterus russicus orii Kuroda, 1921:208.

Type Locality. Uyenai, Iburi Province, Hokkaido, Japan.

Comments. Species rank recognized within Pteromys by Ellerman (1940:294). Recognized as a subspecies of volans by Ellerman and Morrison-Scott (1951:467), Corbet (1978:86), and Thorington and Hoffmann (2005:774).

Distribution. Hokkaido Island, Japan (Dobson, 1994:96).

\section{Pteromyscus Thomas, 1908}

Pteromyscus Thomas, 1908b:3.

Type Species. Sciuropterus pulverulentus Günther, 1873:413.

Comments. Appears to have been recognized since its description.

Pteromyscus pulverulentus (Günther, 1873) (smoky flying squirrel)

\section{Pteromyscus pulverulentus pulverulentus} (Günther, 1873)

Sciuropterus pulverulentus Günther, 1873:413, pl. 38.

Type Locality. Penang Island (Pinang Island), Malay Peninsula.
Comments. Transferred to Pteromys by Anderson (1879:297) and Pteromyscus by Thomas (1908b:3) and followed by subsequent authors.

Distribution. Southern Thailand, Malay Peninsula, Penang Island (Pinang Island, Malaysia) and Sumatra (Hill, 1962:721; Medway, 1969:65; Corbet and Hill, 1992:308).

\section{Pteromyscus pulverulentus borneanus Thomas, 1908}

Pteromyscus borneanus Thomas, $1908 \mathrm{~b}: 7$.

TyPe Locality. Baram district, eastern Sarawak, Borneo.

Comments. Synonymized within pulverulentus by Corbet and Hill (1992:307), who noted that it was doubtfully distinct. Subspecies rank recognized within pulverulentus by Chasen (1940:116), Ellerman (1940:281), Medway (1965:115; 1977:105), and Thorington and Hoffmann (2005:775).

Distribution. Known from Poring (about $550 \mathrm{~m}$ ) in the eastern foothills of Gunnung Kinabalu in Sabah and Marudi, Panam District, Dulit, and west of Batang Lupar in Sarawak, Borneo (Medway, 1965:115; Payne et al., 1985:248).

\section{†Shuanggovia Qiu and Liu, 1986}

†Shuanggouia Qiu and Liu, 1986:197.

TYPe SPecies. Shuanggouia lui Qiu and Liu, 1986:198.

Comments. Mid-Miocene, Asia. Genus recognized within the subfamily Pteromyinae by McKenna and Bell (1997:127). Doubt was cast on this genus by Thorington et al. (2005:958).

\section{†Shuanggovia lui Qiu and Liu, 1986}

†Shuanggouia lui Qiu and Liu, 1986:198.

Type Locality. Shuanggou, Xiacaowan, Jiangsu, China.

Comments. Mid-Miocene.

\section{Trogopterus Heude, 1898}

Trogopterus Heude, 1898:46.

Type Species. Pteromys xanthipes MilneEdwards, 1867:376.

Comments. Belomys included in Trogopterus by Corbet and Hill (1992:306). 


\section{Trogopterus xanthipes (Milne-Edwards, 1867) (complex-toothed flying squirrel)}

Pteromys xanthipes Milne-Edwards, 1867:376.

Type Locality. Northeastern Hopei (Chihli), which is an old name for Hebei Province, China.

Comments. Further described by MilneEdwards (1872:171). Transferred to Trogopterus by Heude (1898:46). No subspecies recognized (Corbet and Hill, 1992:306).

Distribution. Southeastern Tibet and Liaoning, Beijing, Hebei, Shanxi, Henan, Shaanxi, Gansu, Qinghai, Sichuan, Chongqing, Hubei, Guizhou, and Yunnan provinces in China (Corbet and Hill, 1992:306; Zhang et al., 1997:150; Smith and Xie, 2008:181). Fossils allocated to this species have been described by Zheng (1993:264) from Pleistocene to Recent, China.

Trogopterus mordax Thomas, 1914c:230.

Type Locality. Ichang, Hupeh, Yangtzekiang, China.

Comments. Placed as a subspecies of xanthipes by Allen (1940:750), Ellerman (1940:279), and Zhang et al. (1997:150). Synonymized within xanthipes by Ellerman and Morrison-Scott (1951:460), Corbet and Hill (1992:306), and Thorington and Hoffmann (2005:775).

Trogopterus himalaicus Thomas, 1914c:231.

Type Locality. Gyantse, Chumbi Valley, southern Tibet.

Comments. Recognized as a subspecies within xanthipes by Ellerman (1940:279) and Zhang et al. (1997:150). Synonymized within xanthipes by Ellerman and Morrison-Scott (1951:460), Corbet and Hill (1992:306), and Thorington and Hoffmann (2005:775).

Trogopterus edithae Thomas, 1923c:658.

Type Locality. Northwest flank of Likiang Range, Yunnan, China. 3,350 m (11,000 ft).

Comments. Species rank recognized by Howell (1929:46). Recognized as a subspecies within xanthipes by Allen (1939:276; 1940:751), Ellerman (1940:280), and Zhang et al. (1997:150). Synonymized within xanthipes by Ellerman and Morrison-Scott (1951:460), Corbet and Hill (1992:306), and Thorington and Hoffmann (2005:775).

Trogopterus minax Thomas, 1923c:660.

Type Locality. Wonn Chuen (Wenchuan), Upper Min River, Sichuan, China.

Comments. Subspecies rank recognized within xanthipes by Ellerman (1940:280). Synonymized within mordax by Allen (1940:750) and xanthipes by Ellerman and Morrison-Scott (1951:460), Corbet (1978:87), Corbet and Hill (1992:306), and Thorington and Hoffmann (2005:775).

\section{Suborder Anomaluromorpha Bugge, 1974}

Suborder Anomaluromorpha Bugge, 1974:48.

Type Genus. Anomalurus Waterhouse, 1843a:124.

Comments. Suborder rank recognized by McKenna and Bell (1997:185).

\section{Superfamily Anomaluroidea Gervais, 1849}

Tribe Anomalurina Gervais, 1849:203.

Type Genus. Anomalurus Waterhouse, 1843a: 124.

Comments. Publication date established from Evenhuis (1990:224). Initially included within the family Muridae. Superfamily rank recognized by Gill (1872:21) and McKenna and Bell (1997:185). Late Eocene to early Oligocene, early to middle Miocene, early Pliocene, Recent, Africa.

\section{†FAmiLY INDETERMinATE}

\section{†Downsimys Flynn et al., 1986}

†Downsimys Flynn et al., 1986:2, 40.

Type Species. †Downsimys margolisi Flynn et al., 1986:2, 40.

Comments. Miocene. Originally described as family indeterminate, but was allocated to the superfamily Anomaluroidea by Marivaux and Welcomme (2003:422).

\section{†Downsimys margolisi Flynn et al., 1986}

†Downsimys margolisi Flynn et al., 1986:2, 40.

Type Locality. Bugti Hills, Balochistan, Pakistan.

Comments. Originally described as "family indeterminate" but was allocated to the superfamily Anomaluroidea by Marivaux and Welcomme (2003:422).

\section{Family Anomaluridae Gervais, 1849}

Tribe Anomalurina Gervais, 1849:203.

Type Genus. Anomalurus Waterhouse, 1843a: 124.

Comments. Publication date established from Evenhuis (1990:224). Family rank recognized by Gill (1872: 
21) and subsequent authors. Late Eocene to early Oligocene, Early to middle Miocene, early Pliocene, Recent, Africa.

Tribe Anomaluri Brandt, 1855:298.

Type Genus. Anomalurus Waterhouse, 1843a: 124.

Comments. Synonymized within the family Anomaluridae by McKenna and Bell (1997:185).

\section{Subfamily Anomalurinae Gervais, 1849}

Tribe Anomalurina Gervais, 1849:203.

Type Genus. Anomalurus Waterhouse, 1843a: 124.

Comments. Publication date established from Evenhuis (1990:224). Subfamily recognized by Delany (1975:24).

Tribe Anomaluri Brandt, 1855:298.

Type Genus. Anomalurus Waterhouse, 1843a: 124.

Comments. Rank not recognized previously.

Tribe Anomalurini Winge, 1924:7.

Type Genus. Anomalurus Waterhouse, 1843a: 124.

Comments. Rank not recognized previously. Initially included within the family Anomaluridae with the tribes Pseudosciurini, Trechomyini, Theridomyini, and Pedetini.

\section{Anomalurops Matschie, 1914}

Anomalurops Matschie, 1914:351.

Type Species. Anomalurus beecrofti Fraser, 1853:17.

Comments. Synonymized within Anomalurus by Delany (1975:24) and Dieterlen (1993:757; 2005:1532). Commonly accepted genus in association with beecrofti. Recognized by various authors, including Allen (1922:41, 65), Ellerman (1940:541) and Schunke and Hutterer (2005a:169).

\section{Anomalurops beecrofti (Fraser, 1853) (Beecroft's scaly-tailed flying squirrel)}

Anomalurus beecrofti Fraser, 1853:17, pl. 32.

Type Locality. Bioko Island (formerly Fernando Po), Equatorial Guinea, West Africa.

Comments. Placed in the subgenus Anomalurops by Matschie (1914:351; see also Dieterlen,
2005:1532). Anomalurops was also recognized by Schunke (2005:164) and Schunke and Hutterer (2005a:169) and is followed here.

Distribution. High and dry forests from Casamance (Senegal), east Guinea Bissau, Guinea, Sierra Leone, Liberia, Ivory Coast (Côte d'Ivoire), Togo, Benin, Nigeria, Cameroon, Central African Republic, Equatorial Guinea (including Bioko Island, formerly Fernando Po), Gabon, Democratic Republic of the Congo (Zaire), and Angola in western and central Africa (Dorst and Dandelot, 1970:28, Kingdon, 1997:178).

Anomalurus laniger Temminck, 1853:149.

Type Locality. Medje-Congo, West Africa.

Comments. Synonymized within beecrofti by Huet (1884:281) as "lanigera" and Dieterlen (1993:757).

Anomalurus fulgens Gray, 1869:467.

Type Locality. Gaboon (Gabon).

Comments. Species rank recognized by Huet (1884:281). Synonymized within beecrofti by Misonne (1974:4) and Dieterlen (1993:757).

Anomalurus beecrofti argenteus Schwann, 1904:70.

Type Locality. Abutschi, Niger River, Nigeria.

Comments. Recognized as a subspecies of beecrofti by Sanderson (1940:696). Synonymized within beecrofti by Misonne (1974:4) and Dieterlen (1993:757).

Anomalurus citrinus Thomas, 1916b:236.

Type Locality. Benito River, Spanish Guinea (Equatorial Guinea).

Comments. Recognized as a subspecies of beecrofti by Verheyen (1968a:407). Synonymized within beecrofti by Misonne (1974:4) and Dieterlen (1993:757).

Anomalurus chapini J. Allen, 1922:65.

Type Locality. Medje, Belgian Congo (Democratic Republic of the Congo [Zaire]), Africa.

Comments. Recognized as a subspecies of beecrofti by Verheyen (1968a:404). Synonymized within beecrofti by Misonne (1974:4), Delany (1975:27), and Dieterlen (1993:757).

Anomalurus beecrofti hervoi Dekeyser and Villiers, 1951:57.

Type Locality. Bignona (Casamance), Senegal.

Comments. Synonymized within beecrofti by Misonne (1974:4) and Dieterlen (1993:757). 
Anomalurops beecrofti schoutedeni Verheyan, 1968b:157.

Type Locality. Luebo, Belgian Congo (Democratic Republic of the Congo [Zaire]), Africa.

Comments. Recognized as a subspecies of beecrofti by Verheyen (1968a:406) and considered a distinct species by Cabral (1971:56). Synonymized within beecrofti by Dieterlen (1993:757).

\section{Anomalurus Waterhouse, 1843}

Anomalurus Waterhouse, 1843a:124.

TYPE SPECIES. Anomalurus fraseri Waterhouse, 1843a:124.

Comments. Also described in Waterhouse (1843b:52). Mid-Miocene to Recent, Africa.

Aroaethrus Waterhouse, 1843a:124.

Type Species. Substitute name for Anomalurus Waterhouse, 1843a:124.

Comments. Also described in Waterhouse (1843b:52). Synonymized within Anomalurus by Delany (1975:24) and Dieterlen (1993:757).

Anomalurodon Matschie, 1914:350.

TyPe SPecies. Anomalurodon auzembergeri Matschie, 1914:350.

Comments. Synonymized within Anomalurus by Dieterlen (1993:757).

Anomalurella Matschie, 1914:351.

Type SPeCIEs. Anomalurus pusillus Thomas, 1887:440.

Comments. Used in conjunction with pusilla by Allen (1922:41, 63). Synonymized within Anomalurus by Delany (1975:24) and Dieterlen (1993:757).

\section{Anomalurus derbianus (Gray, 1842) (Lord Derby's scaly-tailed flying squirrel)}

Pteromys derbianus Gray, 1842:262.

Type Locality. Sierra Leone, West Africa.

Comments. Synonymized within Anomalurus fraseri by Huet (1884:280).

Distribution. Rainforest region from Sierra Leone, Liberia, Ivory Coast (Côte d'Ivoire), Ghana, Nigeria, Cameroon, Central African Republic, Equatorial Guinea (including Bioko Island, formerly Fernando Po), Gabon, Congo (formerly French Congo and later People's Republic of the Congo), and northern Angola and eastward to eastern Democratic Republic of the Congo (Zaire) border, Rwanda, Burundi, and southern Uganda and southwest Kenya. Also in eastern Tanzania with northern Mozambique and northern Zambia and Malawi. Ranges from sea level up to 2,400 m (6,234 ft) (Dorst and Dandelot, 1970:28; Diller, 1977:148; Kingdon, 1997:176).

Anomalurus fraseri Waterhouse, 1843a:124.

Type Locality. Bioko Island (formerly Fernando Po), Equatorial Guinea.

Comments. Also described in Waterhouse (1843b:52). Taxon recognized by Huet (1884:280). Synonymized within derbianus by Misonne (1974:5), Delany (1975:25), and Dieterlen (1993:757).

Pt. [eromys] squamicaudatus Schinz, 1845:58.

Type Locality. Bioko Island (formerly Fernando Po), Equatorial Guinea.

Comments. Renaming of A. fraseri Waterhouse, 1843a. Synonymized within derbianus by Huet (1884:280) and Dieterlen (1993:757).

Anomalurus beldeni Du Chaillu, 1860:303.

Type Locality. Gabon, western Africa.

Comments. Synonymized within fraseri as "Belleni" by Huet (1884:280). Recognized as a subspecies of derbianus by Verheyen (1968a:403). Synonymized within derbianus by Misonne (1974:5) and Dieterlen (1993:757).

Anomalurus erythronotus Milne-Edwards, 1879:771.

TYPe Locality. Gaboon (Gabon).

Comments. Species rank recognized by Huet (1884:281). Synonymized within derbianus by Misonne (1974:5) and Dieterlen (1993:757).

Anomalurus orientalis Peters, 1880:164, pl.

Type Locality. Zanzibar according to the label, but Pakenham (1984:66) argued that it was more likely to have come from the mainland of Tanzania.

Comments. Species rank recognized by Huet (1884:281). Synonymized within derbianus by Dieterlen (1993:757).

Anomalurus chysophaenus Dubois, 1888:23.

Type Locality. Landana, Cabinda, Angola.

Comments. Synonymized within derbianus by Misonne (1974:5) and Dieterlen (1993:757).

Anomalurus cinereus Thomas, $1895 \mathrm{e}: 188$.

Type Locality. Upper Rovuma River, near Lake Nyasa, Mozambique.

Comments. Synonymized within derbianus by Misonne (1974:5) and Dieterlen (1993:757). 
Anomalurus jacksoni de Winton, 1898:251.

Type Locality. Ntebe (Entebbe), Uganda.

Comments. Recognized as a subspecies of derbianus by Verheyen (1968a:397). Synonymized within derbianus by Misonne (1974:5), Delany (1975:25), and Dieterlen (1993:757).

Anomalurus fraseri nigrensis Thomas, 1904:190.

Type Locality. Abutschi, Niger River, Nigeria.

Comments. Subspecies rank recognized within fraseri by Sanderson (1940:695). Synonymized within derbianus by Dieterlen (1993:757).

Anomalurus neavei Dollman, 1909:351.

Type Locality. Kambove, Katanga, south Congo (Democratic Republic of the Congo [Zaire]).

Comments. Recognized as a subspecies of derbianus by Verheyen (1968a:402). Synonymized within derbianus by Dieterlen (1993:757).

Anomalurus imperator Dollman, 1911:257.

Type Locality. Bibianaha, west of Kumasi, Gold Coast (Ghana).

Comments. Synonymized within derbianus by Misonne (1974:5) and Dieterlen (1993:757).

Anomalurus fraseri griselda Dollman, 1914:490.

Type Locality. Bitye, southern Cameroon. $610 \mathrm{~m}(2,000 \mathrm{ft})$.

Comments. Synonymized within derbianus by Misonne (1974:5) and Dieterlen (1993:757).

Anomalurus jacksoni perustus Thomas, 1916:235.

Type Locality. River Lubefu, $121 \mathrm{~km}(75$ mi) north of Lusambo, southern Congo (Democratic Republic of the Congo [Zaire]). $500 \mathrm{~m}$ (1640 ft).

Comments. Recognized as a subspecies of derbianus by Verheyen (1968a:400). Synonymized within derbianus by Dieterlen (1993:757).

Anomalurus jacksoni fortior Lönnberg, 1917:66.

Type Locality. Masisi, western Democratic Republic of the Congo (Zaire).

Comments. Synonymized within derbianus by Misonne (1974:5) and Dieterlen (1993:757).

Anomalurus fraseri laticeps d'Aguilar-Amat, 1922:52.

Type Locality. Pico de Santa Isabel, Bioko Island (formerly Fernando Po), Equatorial Guinea. 3,000 m $(9,842 \mathrm{ft})$.
Comments. Synonymized within derbianus by Dieterlen (1993:757).

Anomalurus jacksoni jordani St. Leger, 1935:251.

Type Locality. Fazenda Congulu, Amboin, Angola.

Comments. Synonymized within derbianus by Dieterlen (1993:757).

\section{†Anomalurus parvus Winkler, 1992}

†Anomalurus parvus Winkler, 1992:240.

Type Locality. Muruyur Beds, Baringo District, Kenya.

Comments. Middle Miocene.

\section{Anomalurus pelii (Schlegel and Müller, 1845) (Pel's scaly-tailed flying squirrel)}

\section{Anomalurus pelii pelii (Schlegel and Müller, 1845)}

Pteromys (Anomalurus) pelii Schlegel and Müller, 1845: 109.

Type Locality. Daboeram, Ghana, West Africa. Note the spelling of "Dabocrom" (Grubb et al., 1998:184).

Comments. Transferred to Anomalurus at the generic rank by Gervais (1853:246).

Distribution. High forest from Ghana to eastern Ivory Coast (Côte d'Ivoire) in West Africa (Schunke and Hutterer, 2005b:326).

\section{Anomalurus pelii auzembergeri (Matschie, 1914)}

A.[nomalurodon] auzembergeri Matschie, 1914:350.

Type Locality. "Bei Patokla am mittleren Cavally, Elfenbeinkuste, $150 \mathrm{~km}$ vom Mere”. Middle Cavalle River, Patokla, Ivory Coast (Côte d'Ivoire), near boundary with Liberia, West Africa. $05^{\circ} 28^{\prime} \mathrm{N}, 07^{\circ} 19^{\prime} \mathrm{W}$. Type locality confirmed by Schunke and Hutterer (2005b: 326).

Comments. Synonymized within pelii by Misonne (1974:4) and Dieterlen (1993:757), but elevated to subspecies rank by Kuhn (1965:330), confirmed by Schunke and Hutterer (2005b:326), and followed by Dieterlen (2005).

Distribution. Eastern Liberia and extreme western Ivory Coast (Côte d'Ivoire), west of the Sassandra River (Schunke and Hutterer, 2005b:326) 


\section{Anomalurus pelii peralbus Schunke and Hutterer, 2005}

Anomalurus pelii peralbus Schunke and Hutterer, 2005b:327.

Type Locality. Gueboua, Ivory Coast (Côte d'Ivoire), West Africa. $05^{\circ} 59^{\prime} \mathrm{N}, 05^{\circ} 41^{\prime} \mathrm{W}$.

Comments. Described as a subspecies.

Distribution. Ivory Coast (Côte d'Ivoire), between the Bandama and Sassandra rivers (Schunke and Hutterer, 2005b:327).

\section{Anomalurus pusillus Thomas, 1887 (dwarf scaly-tailed flying squirrel)}

Anomalurus pusillus Thomas, 1887:440.

Type Locality. Bellima, Monbuttu, northeast Congo (Democratic Republic of the Congo [Zaire]), West Africa.

Comments. Further described by Thomas (1888c:8) as the first description was considered preliminary.

Distribution. Occurs in central African rainforest from the high forests of Cameroon, southwestern Central African Republic, Equatorial Guinea, Gabon, Congo, and Democratic Republic of the Congo (Zaire) to western Uganda and northwest shore of Lake Tanganyika. There is also an isolated occurrence in west Liberia on the Du River (Diller, 1977:149; Kingdon, 1997:178).

Anomalurus batesi de Winton, 1897:524.

Type Locality. Como River, $75 \mathrm{mi}$ from Gaboon (Gabon).

Comments. Synonymized within pusillus by Misonne (1974:5) and Dieterlen (1993:757).

\section{†Paranomalurus Lavocat, 1973}

†Paranomalurus Lavocat, 1973:173.

Type Species. †Paranomalurus bishopi Lavocat, 1973:173.

Comments. Oligocene to mid-Miocene, Africa. Genus recognized within the subfamily Anomalurinae by McKenna and Bell (1997:186).

\section{†Paranomalurus bishopi Lavocat, 1973}

†Paranomalurus bishopi Lavocat, 1973:173.

Type Locality. Napak, Uganda, Africa.

Comments. Oligocene to mid-Miocene.

\section{†Paranomalurus soniae Lavocat, 1973}

†Paranomalurus soniae Lavocat, 1973:187.

Type Locality. Songhor, Kenya, Africa.

Comments. Oligocene to mid-Miocene.

†Paranomalurus walkeri Lavocat, 1973

†Paranomalurus walkeri Lavocat, 1973:191.

Type Locality. Songhor, Kenya, Africa.

Comments. Early Oligocene to mid-Miocene.

\section{Subfamily Zenkerellinae Matschie, 1898}

Subfamily Zenkerellinae Matschie, 1898:26.

Type Genus. Zenkerella Matschie, 1898:23.

Comments. Subfamily recognized by Delany

(1975:28).

Family Idiuridae Miller and Gidley, 1918:442.

Type Genus. Idiurus Matschie, 1894:194.

Comments. Synonymized within Zenkerellinae by McKenna and Bell (1997:186).

\section{Idiurus Matschie, 1894}

Idiurus Matschie, 1894:194.

Type Species. Idiurus zenkeri Matschie, 1894.

COMments. Reviewed by Verheyen (1963:157) and Schunke and Hutterer (2007:1), who considered the currently recognized species as valid and having no subspecies.

Idiurus macrotis Miller, 1898 (long-eared scaly-tailed flying squirrel)

Idiurus macrotis Miller, 1898:73.

Type Locality. Efulen, Cameroon, West Africa.

Comments. Reviewed by Verheyen (1963). Geographic variation assessed by Schunke and Hutterer (2007:1), who confirmed that no subspecies should be recognized.

Distribution. Equatorial Africa from Sierra Leone, Liberia, Ivory Coast (Côte d'Ivoire), Cameroon, Equatorial Guinea, Gabon, and farther east through Democratic Republic of the Congo (Zaire) to Ituri Forest and eastern Congo. The overall range is similar to I. zenkeri, but I. macrotis appears to be rarer than zenkeri in the eastern part of their ranges (Diller, 1977:151; Kingdon, 1997:179). 
Idiurus zenkeri kivuensis Lönnberg, 1917:67.

Type Locality. Masisi, about 64 km (40 mi) northwest of Lake Kivu, Belgian Congo (Democratic Republic of the Congo [Zaire]).

Comments. Recognized as a valid species by Hayman (1946:211). Synonymized within macrotis by Dieterlen (1993:758).

Idiurus langi J. Allen, 1922:69. pl. 5.

Type Locality. Medje, Belgian Congo (Democratic Republic of the Congo [Zaire]), West Africa.

Comments. Recognized as a subspecies of macrotis by Hayman (1946:212) and Verheyen (1963:169). Synonymized within macrotis by Dieterlen (1993:758).

Idiurus panga J. Allen, 1922:70.

Type Locality. Panga, Belgian Congo (Democratic Republic of the Congo [Zaire]), West Africa.

Comments. Recognized as a subspecies of kivuensis by Hayman (1946:212). Synonymized within macrotis by Dieterlen (1993:758).

Idiurus kivuensis cansdalei Hayman, 1946:211.

Type Locality. Oda, Oda Province, Gold Coast (Ghana), West Africa.

Comments. Recognized as a subspecies of $\mathrm{ki}$ vuensis by Hayman (1946:212) and Verheyen (1963:183). Synonymized within macrotis by Dieterlen (1993:758).

\section{Idiurus zenkeri Matschie, 1894 (pygmy scaly-tailed flying squirrel)}

Idiurus zenkeri Matschie, 1894:197, unnumbered fig.

Type Locality. Yaounde, southern Cameroon, West Africa.

Comments. Revised by Verheyen (1963:159). Geographic variation assessed by Schunke and Hutterer (2007:1), who confirmed that no subspecies should be recognized.

Distribution. Cameroon, southwestern Equatorial Guinea, Gabon, Congo, and Democratic Republic of the Congo (Zaire). Also occurs between the Aruwimi River and northeast and east Democratic Republic of the Congo to the foothills of Ruwenzori and Kivu to Lake Kivu and west Uganda (Diller, 1977:150; Kingdon, 1997:179).

Idiurus zenkeri haymani Verheyen, 1963:181.

Type Locality. Eshobi, Mamfe district, Nigérie (west Cameroon), West Africa. $168 \mathrm{~m}(550 \mathrm{ft})$.
Comments. Synonymized within zenkeri by Dieterlen (1993:758).

\section{SUPerfamily AnOMALUROIDEA INCERTAE SEDIS MARIVAUX ET AL., 2005}

Anomaluroidea incertae sedis Marivaux et al., 2005:220.

Comments. Late to middle Eocene. Myanmar and Algeria. These genera were suggested to lie within the Anomaluroidea by Marivaux et al. (2005:221); however, they suggested that these genera cannot be formally included within the Anomaluridae sensu stricto because of their peculiar dental complexity and the current lack of diagnostic postcranial remains.

\section{†Family Nementchamyidae Jackson and THORINGTON, NEW FAMILY}

†Family Nementchamyidae Jackson and Thorington, new family.

Type Genus. †Nementchamys Jaeger et al., 1985:580.

Diagnosis. The genera $†$ Nementchamys and $\dagger$ Pondaungimys that represent the family Nementchamyidae are distinguished by a dental pattern that is relatively more primitive in some respects than that of Miocene and modern anomalurids, and they show a derived dental complexity in some respects that indicates they are the closest outgroup of the Anomaluridae. Specific diagnosis includes a dental pattern that is characterized by an association of characters and the development of a neoloph, a large mesostyle, a well-marked anterostyle, and a complex third transverse crest on the upper molars, the lack of metalophulid I, the strong development of the anterocingulid, giving a complete anterolophid, the loss of the hypoconulid, and a well-marked mesolophid on the lower molars (Marivaux et al., 2005:218).

Comments. Late Eocene. Myanmar and Algeria. Family rank derived from Anomaluridae (part), Jaeger et al. (1985:580), McKenna and Bell (1997:185), and Dawson et al. (2003:205). The genera †Nementchamys and $\dagger$ Pondaungimys were suggested to lie within the Anomaluroidea by Marivaux et al. (2005:221); however, it was proposed that these genera cannot be formally included within the Anomaluridae sensu stricto because of their peculiar dental complexity and the current lack of diagnostic postcranial remains. Marivaux et al. (2005:220) suggest that $\dagger$ Nementchamys and $\dagger$ Pondaungimys will probably be included within a new family in the Anomaluroidea, which has been done here. 


\section{†Nementchamys Jaeger et al., 1985}

†Nementchamys Jaeger et al., 1985:580.

Type SPecies. †Nementchamys lavocati Jaeger et al., 1985:580.

Comments. Late to middle Eocene; Nementcha Mountains, Algeria. Genus recognized within the family Anomaluridae by McKenna and Bell (1997:185).

\section{†Nementchamys lavocati Jaeger et al., 1985}

$†$ Nementchamys lavocati Jaeger et al., 1985:580.

Type Locality. Nementcha Mountains, eastern Algeria.

Comments. Late to middle Eocene. Landry (1999:313) stated that this species description was not convincing and that it was better to leave it as Rodentia, incertae sedis, pending the discovery of more revealing details.

\section{†Pondaungimys Dawson et al., 2003}

†Pondaungimys Dawson et al., 2003:203, 205.

Type Species. †Pondaungimys anomaluropsis Dawson et al., 2003:203, 205.

Comments. Late to middle Eocene. Pondaung Formation, central Myanmar. Genus recognized within the family Anomaluridae by McKenna and Bell (1997:185) and Dawson et al. (2003:205).

\section{†Pondaungimys anomaluropsis Dawson et al., 2003}

†Pondaungimys anomaluropsis Dawson et al., 2003:203, 205.

Type Locality. Pondaung Formation, central Myanmar.

Comments. Late to middle Eocene.

\section{INFRAORDER GLIRIMORPHA ThaleR, 1966}

Suborder Glirimorpha Thaler, 1966:11, 101.

Comments. Recognized at infraordinal rank by McKenna and Bell (1997:174).

\section{Family Gliridae Muirhead, 1819}

Family Glirini Muirhead, 1819:433.

Type Genus. Glis Brisson, 1762:13, 113.

Comments. Synonymized within Myoxidae

by McKenna and Bell (1997:174). McKenna and Bell
(1997:174) note that "the currently fashionable return to Myoxidae and other family-group names based upon it, in preference to Gliridae and its coordinate names, may be in violation of the International Code of Zoological Nomenclature, Article 40, depending on the vague unwritten definition of 'general acceptance.' If Glis Brisson were to be validated by the International Commission on Zoological Nomenclature, then Muirhead's Glirini, not Gliridae Thomas, would be the basis for Gliridae." Family name was discussed by Wahlert et al. (1993:2) and the International Commission on Zoological Nomenclature (1995:78), with Glis and, in turn, the family name Gliridae being conserved by Opinion 1894 of the International Commission on Zoological Nomenclature (1998:64). It has been added to the Official Lists and Indexes of Names and Works in Zoology (Smith, 2001:34). Subsequently, Holden (2005:819, 840) reluctantly recognized Glis and the family Gliridae.

Family Myosidae Gray, 1821:303.

Type Genus. Myoxus von Zimmermann, 1780: 351 .

Comments. Recognized by McKenna and Bell (1997:174, 178), who place Glis Brisson, 1762, as a junior synonym of Myoxus von Zimmermann, 1780. McKenna and Bell refer to the International Code of Zoological Nomenclature Articles 11(c)(i) and 40 for confusing rules, and they suggest that Brisson, 1762, was not consistently binomial. Synonymized within the family Gliridae Muirhead, 1819, by Holden (2005:819).

Myoxina Gray, 1825:342.

Type Genus. Myoxus von Zimmermann, 1780:351.

Comments. Synonymized within Myoxidae by McKenna and Bell (1997:174) and within the family Gliridae Muirhead, 1819 by Holden (2005:819).

Family Myoxidae Waterhouse, 1839c:184.

Type Genus. Myoxus von Zimmermann, 1780:351.

Comments. Synonymized within Myoxidae by McKenna and Bell (1997:174) and within the family Gliridae Muirhead, 1819 by Holden (2005:819).

Family Myoxini Giebel, 1855:621.

Type Genus. Myoxus von Zimmermann, 1780:351.

Comments. Synonymized within Myoxidae by McKenna and Bell (1997:174) and within the family Gliridae Muirhead, 1819 by Holden (2005:819). 
Family Myoxida Haeckel, 1866:clx.

Type Genus. Myoxus von Zimmermann, 1780:351.

Comments. Synonymized within Myoxidae by McKenna and Bell (1997:174) and within the family Gliridae Muirhead, 1819 by Holden (2005:819).

Superfamily? Myoxoidea Gill, 1872:21.

Type Genus. Myoxus von Zimmermann, 1780:351.

Comments. Included the family Myoxidae. Synonymized within Myoxidae by McKenna and Bell (1997:174) and within the family Gliridae Muirhead, 1819 by Holden (2005:819).

Family Leithiidae Lydekker, 1895:862.

Type Genus. Leithia Lydekker, 1895:862.

Comments. Synonymized within the family Myoxidae by McKenna and Bell (1997:174), but recognized as a subfamily within Myoxidae on p. 175. Synonymized within the family Gliridae Muirhead, 1819 by Holden (2005:819, 829), but recognized as a subfamily.

Family Gliridae Thomas, 1897:1016.

Type Genus. Glis Brisson, 1762:13, 113.

Comments. Thomas rejected the family name Myoxidae because Myoxus, on which it is based, is a synonym of the earlier generic name Glis. Name recognized by many authors since its description. Synonymized within Myoxidae by McKenna and Bell (1997:174), but this may be incorrect. Synonymized within the family Gliridae Muirhead, 1819 by Holden (2005:819).

Family Muscardinidae Palmer, 1899:413.

Type Genus. Muscardinus Kaup, 1829:139.

Comments. Synonymized within Myoxidae by McKenna and Bell (1997:174), but recognized as a tribe within the subfamily Myoxinae (Gray, 1821:303). Synonymized within the family Gliridae Muirhead, 1819 by Holden (2005:819).

Family Seleviniidae Bashanov and Belosludov, 1939:3.

Type Genus. Selevinia Belosludov and Bashanov, 1939:81.

Comments. Name also described by Bashanov and Belosludov (1941:311). Synonymized within Myoxidae by McKenna and Bell (1997:174), but recognized as a tribe within the subfamily Leithiinae. Synonymized within the family Gliridae Muirhead, 1819 by Holden (2005:819).
Superfamily Gliroidea Simpson, 1945:91.

Type Genus. Glis Brisson, 1762:13, 113.

Comments. Synonymized within Myoxidae by McKenna and Bell (1997:174) and within the family Gliridae Muirhead, 1819 by Holden (2005:819).

\section{Subfamily Glirinae Muirhead, 1819}

Glirini Muirhead, 1819:433.

Type Genus. Glis Brisson, 1762:13, 113.

Comments. Subfamily rank recognized by Holden (2005:838).

Family Myosidae Gray, 1821:303.

Type Genus. Myoxus von Zimmermann, 1780:351.

Comments. Synonymized within the subfamily Gliridae Muirhead, 1819 by Holden (2005:838).

Myoxina Gray, 1825:342.

Type Genus. Myoxus von Zimmermann, 1780:351.

Comments. Synonymized within Myoxidae by McKenna and Bell (1997:174) and within the family Gliridae Muirhead, 1819 and subfamily Glirinae by Holden (2005:819, 838).

Subfamily Myoxinae Huxley, 1872:369.

Type Genus. Myoxus von Zimmermann, 1780:351.

Comments. Synonymized within the subfamily Gliridae Muirhead, 1819 by Holden (2005:838).

Subfamily Gliridae Thomas, 1897:1016.

Type Genus. Glis Brisson, 1762:13, 113.

Comments. Synonymized within the subfamily Gliridae Muirhead, 1819 by Holden (2005:838).

Subfamily Glirulinae de Bruijn, 1966:373.

Type Genus. Glis Brisson, 1762:13, 113.

Comments. Subfamily rank recognized by Suzuki et al. (1997:168, 173). Synonymized within the subfamily Gliridae Muirhead, 1819 by Holden (2005: 838).

\section{Glirulus Thomas, 1905}

Glirulus Thomas, $1905 \mathrm{~b}: 347$.

Type Species. Myoxus japonicus Schinz, 1845:530. 
Comments. The species was initially described in error as javanicus instead of japonicus, which must remain under the order of priority. This species is not found on Java but only in Japan. There is only one extant species within this genus.

\section{Glirulus japonicus (Schinz, 1845)}

Myoxus javanicus Schinz, 1845:530.

Type Locality. Japan.

Comments. Nongliding genus type species. Described from extant specimen. Originally described as javanicus. See Thomas (1905b:347) for an explanation of the emendation of javanicus to japonicus. This species and all species apart from that described by Mein and Romaggi (1991:45) appear to be nongliding.

\section{†Glirulus lissiensis Hugueney and Mein, 1965}

†Glirulus lissiensis Hugueney and Mein, 1965:117.

TyPe Locality. Lissieu (Rhone), France.

Comments. Neogene. Although there are various other fossil species within Glirulus, this is the only one that appears to have had the ability to glide (Mein and Romaggi, 1991:45).

\section{Infraorder Geomorpha Thaler, 1966}

†Suborder Geomorpha Thaler, 1966:11.

Comments. Recognized at infraordinal rank by McKenna and Bell (1997:174).

Family Sciurospalacoïdes Brandt, 1855:301.

Comments. Nomen oblitum. Synonymized within the infraorder Geomorpha by McKenna and Bell (1997:178).

\section{†SUPerfamily Eomyoidea Winge, 1887}

†Eomyini Winge, 1887:109, 122.

Type Genus. †Eomys Schlosser, 1884:328.

Comments. The paper gives the date as 1888 , but the author's separates were distributed in December 1887 (Palmer, 1904:740). Recognized at superfamily rank by McKenna and Bell (1997:178).

\section{tFamily Eomyidae Winge, 1887}

†Eomyini Winge, 1887:109, 122.
Type Genus. †Eomys Schlosser, 1884:328.

Comments. The paper gives the date as 1888; however, the author's separates were distributed in December 1887 (Palmer, 1904:740). Recognized at family rank by Deperet and Douxami (1902:69) and McKenna and Bell (1997:178).

†Family Adjidaumidae Miller and Gidley, 1918:434.

Type Genus. †Adjidaumo Hay, 1899:253.

Comments. Placed within the family Eomyidae by McKenna and Bell (1997:178).

\section{†Eomys Schlosser, 1884}

†Eomys Schlosser, 1884:328.

Type Species. †Eomys pomel Schlosser, 1884: 328.

Comments. Late Oligocene, Europe. Type species of the genus is not considered to glide.

\section{†Eomys quercyi \\ Compte and Vianey-Liaud, 1987}

†Eomys quercyi Compte and Vianey-Liaud, 1987:951.

Type Locality. Pech du Fraysse (Quercy).

Comments. Late Oligocene. There are various fossil species that have been allocated to this genus (e.g., Schlosser, 1884:328; Compte and Vianey-Liaud, 1987:951). This species was not initially considered to be a gliding mammal until a subsequent well-preserved specimen was discovered at Enspel near Bad Marienberg in the Westerwald, state of Rheinland-Pfalz, Germany (Storch et al., 1996:349). Given that it appears to be a gliding mammal, it should warrant being placed in a new genus and potentially a new family.

\section{tOrder Volaticotheria Meng et al., 2006}

†Order Volaticotheria Meng et al., 2006:889.

\section{†Family Volaticotheriddae Meng et al., 2006}

†Family Volaticotheriidae Meng et al., 2006:889.

Type Genus. †Volaticotherium Meng et al., 2006:889.

\section{† Volaticotherium Meng et al., 2006}

†Volaticotherium Meng et al., 2006:889. 
Type Species. †Volaticotherium antiquus Meng et al., 2006:889.

† Volaticotherium antiquus Meng et al., 2006

†Volaticotherium antiquus Meng et al., 2006:889.
Type Locality. Daohugou, Ningcheng County, Inner Mongolia, China.

Comments. Middle to Late Cretaceous, approximately 125 MYA. 



\section{References}

Abbie, A. A. 1937. Some Observations on the Major Subdivisions of the Marsupialia, with Special Reference to the Position of the Peramelidae and Caenolestidae. Journal of Anatomy, 71:424-436.

Adkins, R. M., and R. L. Honeycutt. 1991. Molecular Phylogeny of the Superorder Archonta. Proceedings of the National Academy of Science of the United States of America, 88:10,317-10,321. http://dx.doi.org/10.1073/pnas.88.22.10317.

Adkins, R. M., A. H. Walton, and R. L. Honeycutt. 2003. Higher-Level Systematics of Rodents and Divergence Time Estimates Based on Two Congruent Nuclear Genes. Molecular Phylogenetics and Evolution, 26:409-420. http://dx.doi.org/10.1016/ S1055-7903(02)00304-4.

Agrawal, V. C., and S. Chakraborty. 1970. Occurrence of the Woolly Flying Squirrel, Eupetaurus cinereus Thomas (Mammalia: Rodentia: Sciuridae) in North Sikkim. Journal of the Bombay Natural History Society, 66:615-616.

-1979a. Catalogue of Mammals in the Zoological Survey of India. Part 1. Sciuridae. Records of the Zoological Survey of India, 74:333-481.

- 1979b. Taxonomic Notes on Some Oriental Squirrels. Mammalia, 43:161-172. http://dx.doi.org/10.1515/mamm.1979.43.2.161.

Albright, L. B. 1996. Insectivores, Rodents, and Carnivores of the Toledo Bend Local Fauna: An Arikareean (Earliest Miocene) Assemblage from the Texas Coastal Plain. Journal of Vertebrate Paleontology, 16(3):458-473. http://dx.doi.org/10.1080/027 24634.1996.10011334.

Alexander, J. S. A. 1981. The Status of the Squirrel Glider, Petaurus norfolcensis (Marsupialia: Petauridae) in Victoria. B.Sc. honours thesis, Latrobe University, Melbourne.

Allen, G. M. 1925. Squirrels Collected by the American Museum Asiatic Expeditions. American Museum Novitates, 163:1-16.

- 1939. Zoological Results of the Second Dolan Expedition to Western China and Eastern Tibet, 1934-1936. Part III. Mammals. Proceedings of the Academy of Natural Sciences of Philadelphia, 90:261-294.

- 1940. The Mammals of China and Mongolia, Part 2, ed. W. Granger. Central Asiatic Expeditions of the American Museum of Natural History. Natural History of Central Asia, No. 11. New York: American Museum of Natural History.

Allen, G. M., and H. J. Coolidge. 1940. Mammals. Bulletin of the Museum of Comparative Zoology, 87:131-166.

Allen, J. A. 1922. Sciuridae, Anomaluridae and Idiuridae Collected by the American Museum in the Congo Expedition. Bulletin of the American Museum of Natural History, 47:39-71.

Ameghino, F. 1889. Contribucion al conocimiento de los mamiferos fosiles de la Republica Argentina. Actas de la Academia Nacional de Ciencias de la República Argentina en Córdoba, 6:1-1027. 
1916. Obras completas y correspondencia cientifica. Volume 6: Los Mamíferos fósiles de la República Argentina. La Plata, Argentina: Taller de Impresiones Oficiales.

Anderson, J. 1875. Description of Some New Asiatic Mammals and Chelonia. Annals and Magazine of Natural History, 4th ser., 16:282-285.

1879. Anatomical and Zoological Researches: Comprising an Account of the Zoological Results of Two Expeditions to Western Yunan in 1868 and 1875; and a Monograph of the Two Cetacean Genera Platanista and Orcella. Volume 1. London: Bernard Quaritch.

Anderson, R. M. 1943. Nine Additions to the List of Quebec Mammals with Descriptions of Six New Forms. Annual Report of the Provancher Society of Natural History, Canada, Quebec, 1942:49-62.

Anonymous. 1839. The Penny Cyclopedia of the Society for the Diffusion of Useful Knowledge. Volume 14. London: Charles Knight.

Aplin, K. P. 1999. "Petauroides ayamaruensis." In Late Quaternary Vertebrates from the Bird's Head Peninsula, Irian Jaya, Indonesia, Including Descriptions of Two Previously Unknown Marsupial Species. K. P. Aplin, J. M. Pasveer, and W. E. Boles. pp. 365-371. Records of the Western Australian Museum Supplement, 57:351-397.

Aplin, K. P., and M. Archer. 1987. "Recent Advances in Marsupial Systematics with a New Syncretic Classification”. In Possums and Opossums: Studies in Evolution, ed. M. Archer, pp. xv-lxxii. Sydney: Surrey Beatty.

Aplin, K. P., J. M. Pasveer, and W. E. Boles. 1999. Late Quaternary Vertebrates from the Bird's Head Peninsula, Irian Jaya, Indonesia, Including Descriptions of Two Previously Unknown Marsupial Species. Records of the Western Australian Museum Supplement, 57:351-397.

Archer, M. 1984. "The Australian Marsupial Radiation." In Vertebrate Zoogeography and Evolution in Australasia, ed. M. Archer and G. Clayton, pp. 633-808. Perth: Hesperian Press.

Archibald, J. D., J. K. Rigby Jr., and S. F. Robinson. 1983. Systematic Revision of the Oxyacodon (Condylartha, Periptychidae). Journal of Paleontology, 57:53-72.

Arnason, U., J. A. Adegoke, K. Bodin, E. W. Born, Y. B. Esa, A. Gullberg, M. Nilsson, R.V. Short, X. F. Xu, and A. Janke. 2002. Mammalian Mitogenomic Relationships and the Root of the Eutherian Tree. Proceedings of the National Academy of Sciences of the United States of America, 99:8151-8156. http://dx.doi.org/10.1073/pnas.102164299.

Asher, R. J., J. Meng, J. R. Wible, M. C. McKenna, G. W. Rougier, D. Dashzeveg, and M. J. Novacek. 2005. Stem Lagomorpha and the Antiquity of Glires. Science, 307:1091-1094. http:// dx.doi.org/10.1126/science.1107808.

Audebert, J. B. 1799. Histoire Naturelle Des Singes Makis. Paris: Desray.

Bachman, J. 1839. The Following Species Must Be Added to the List of Mr. Townsend's Quadrupeds. Journal of the Academy of Natural Sciences of Philadelphia, 5:101-105.

Baird, S. F. 1857. Reports of Explorations and Surveys, to Ascertain the Most Practicable and Economical Route for a Railroad from the Mississippi River to the Pacific Ocean. Volume 8: Part 1-General Report Upon the Zoology of the Several Pacific Railroad Routes: Mammals. Washington, D. C.: A. O. P. Nicholson.

Bangs, O. 1896. A Review of the Squirrels of Eastern North America. Proceedings of the Biological Society of Washington, 10:145-167.

- 1899. Descriptions of Some New Mammals from Western North America. Proceedings of the New England Zoological Club, 1:65-72.

Banks, E. 1931. A Popular Account of the Mammals of Borneo. Journal of the Malay Branch of the Royal Asiatic Society, 9(2):1-139.

Baranova, G. I., and N. I. Konkova. 1974. "A New Species of Flying Squirrel of the Genus Pliopetaurista Kretzoi, 1962 (Rodentia, Pteromyidae) in the Middle Pliocene Fauna of Moldavia." In Mammals of the Late Cenozoic of the Southwest of the USSR, ed. B. A. Trofimov, pp. 91-98. Kishinev, USSR: Shtiintsa.

Bashanov, B. S., and B. A. Belosludov. 1939. Novoe semeistvo otryada gryzunov. [New Family of the Order Rodentia. In Russian.] Uchenye Zapiski Kazakhsogo Gosudarstvennogo Universiteta, Alma Ata, 3:3-8.

- 1941. A Remarkable Family of Rodents from Kasakhstan, U. S.S. R. Journal of Mammalogy, 22:311-315. http:// dx.doi.org/10.2307/1374957.

Baudelot, S. 1972. Étude des chiroptères, insectivores et rongeurs du Miocène de Sansan (Gers). Ph. D. thesis, No. 496, Université de Toulouse, Toulouse.

Baverstock, P. R. 1984. "The Molecular Relationships of Australasian Possums and Gliders." In Possums and Gliders, ed. A. Smith and I. Hume, pp. 1-8. Sydney: Surrey Beatty.

Baverstock, P. R., M. Krieg, and J. Birrell. 1990. Evolutionary Relationships of Australian Marsupials as Assessed by Albumin Immunology. Australian Journal of Zoology, 37:273-287. http://dx.doi.org/10.1071/ZO9890273.

Beard, K. C. 1989. Evidence for Gliding Behaviour in the Early Eocene Dermopterans Ignacius graybullianus. Journal of Vertebrate Paleontology, 9:13A.

- 1990. Gliding Behaviour and Palaeoecology of the Alleged Primate Family Paromomyidae (Mammalia, Dermoptera). Nature, 345:340-341. http://dx.doi.org/10.1038/ $345340 \mathrm{a} 0$.

-1991. "Vertical Postures and Climbing in the Morphotype of Primatomorpha: Implications for Locomotor Evolution in Primate History." In Origine(s) de la Bipedie chez les Hominides, ed. Y. Coppens and B. Senut, pp. 79-87. Cahiers de Paleoanthropologie. Paris: Editions du CNRS.

- 1993a. "Phylogenetic Systematics of the Primatomorphia, with Special Reference to Dermoptera.” In Mammal Phylogeny: Placentals, ed. F. S. Szalay, M. J. Novacek, and M. C. McKenna, pp. 129-150. New York: Springer-Verlag. - 1993b. "Origin and Evolution of Gliding in Early Cenozoic Dermoptera (Mammalia, Primatomorpha).” In Primates and Their Relatives in Phylogenetic Perspective, ed. R. D. E. MacPhee, pp. 63-90. New York: Plenum Press.

Bechstein, J. M. 1800. Thomas Pennant's Allgemeine Uebersicht der Vierfüssigen Thiere. Volume 2. Aus dem Englischen Übersetzt und mit Anmerkungen und Zasätzen versehen von J. M. Bechstein. Weimar, Germany: IndustrieComptoir's. 
Bell, T. 1829. Description of a New Species of Phalangista. Transactions of the Linnean Society of London, 16:121-127. http://dx.doi.org/10.1111/j.1095-8339.1829.tb00261.x.

Belosludov, B. A., and B. S. Bashanov. 1939. A New Genus and Species of Rodent from the Central Kazakhstan (USSR). [In Russian.] Uchenye Zapiski Kazakhskovo Gosudarstvennovo Universiteta, Alma-Ata, 1(1):81-86.

Bensley, B. A. 1903. On the Evolution of the Australian Marsupialia; with Remarks on the Relationships of the Marsupials in General. Transactions of the Linnean Society of London, 2nd ser., 9:83-217, pls. 5-7.

Bininda-Emonds, O. R. P., M. Cardillo, K. E. Jones, R. D. E. MacPhee, R. M. D. Beck, R. Grenyer, S. A. Price, R. A. Vos, J. L. Gittleman, and A. Purvis. 2007. The Delayed Rise of Present-Day Mammals. Nature, 446:507-512. http:// dx.doi.org/10.1038/nature05634.

Black, C. C. 1966. Tertiary Sciuridae (Mammalia: Rodentia) from Bavaria. Mitteilungen Bayerische Staatsammlung fur Palaeontologie und Historische Geologie, 6:51-63.

Black, C. C., and K. Kowalski. 1974. The Pliocene and Pleistocene Sciuridae (Mammalia, Rodentia) from Poland. Acta Zoologica Cracoviensia, 19:461-485.

Bloch, J. I., and M. T. Silcox. 2001. New Basicrania of PaleoceneEocene Ignacius: Re-evaluation of the PlesiadapiformDermopteran Link. American Journal of Physical Anthropology, 116:184-198. http://dx.doi.org/10.1002/ ajpa. 1114.

Bloch, J. I., M. T. Silcox, D. M. Boyer, and E. J. Sargis. 2007. New Paleocene Skeletons and the Relationship of Plesiadapiformes to Crown-Clade Primates. Proceedings of the National Academy of Sciences of the United States of America, 104:11591164. http://dx.doi.org/10.1073/pnas.0610579104.

Blumenbach, J. F. 1779. Handbüch der Naturgeschichte. Volume 1. Göttingen: Johann Christian Dieterich.

Blyth, E. 1847. Supplementary Report by the Curator, Zoological Department. Journal of the Asiatic Society of Bengal, 16:861-880.

- 1859. Report of the Curator. Journal of the Asiatic Society of Bengal, 28:271-298.

-1863. Catalogue of the Mammalia in the Museum Asiatic Society. Calcutta: Savielle \& Cranenburgh.

Boddaert, P. 1768. Dierkundig Mengelwerk in Het Welke de Nieuwe of nog Duistere Zoorten Van Dieren. Volume 2. Abraham van Paddenburg en J. Van Schoonhoven.

Boie, F. 1831. Bemerkungen über Species und Einige ornithologische Familien. Isis von Oken, 24: 538-547.

Bonaparte, C. L. 1832. Saggio d'una Distribuzione Metodica degli Animali Vertebrati a Sangue Freddo. Rome: Presso Antonio Boulzaler.

- 1838. Synopsis vertebratorum systematis. Nuovi Annali delle Scienze Naturali, Bologna, 2(1):105-133.

- 1841. A New Systematic Arrangement of Vertebrated Animals. Transactions of Linnean Society of London, 18:247-304.

- 1850. Conspectus generum avium. Volume 1. Leiden: E. J. Brill.

Bonhote, J. L. 1900. On a Collection of Mammals from Siam Made by Mr T. H. Lyle. Proceedings of the Zoological Society of London, 1900:191-195.
Bonnet, R. 1892. Über Hypotrichosis congenita universalis. Anatomische Hefte. Abteilung 1, Arbeiten aus Anatomischen Instituten, 1:233-270.

Bourret, R. 1942. Sur quelques petits mammifères du Tonkin et du Laos. Bulletin du Conseil des Recherches Scientifique de l'Indochine, Conseil des Recherches Scientifique, 27-30.

Bouwens, P., and H. de Bruijn. 1986. The Flying Squirrels Hylopetes and Petinomys and Their Fossil Record. Proceedings of the Koninklijke Nederlandse Akademie van Wetenschappen, Series B, Palaeontology, Geology, Physics, Chemistry, Anthropology, 89:113-123.

Bowdich, T. E. 1821. An Analysis of the Natural Classifications of Mammalia for the Use of Students and Travellers. Paris: J. Smith.

Bown, T. M., and K. D. Rose. 1979. Mimoperadectes, a New Marsupial, and Worlandia, a New Dermopteran from the Lower Part of the Willawood Formation (Early Eocene), Bighorn Basin, Wyoming. Contributions from the Museum of Paleontology, University of Michigan, 25:89-104.

Boyer, D. M., and J. I. Bloch. 2008. "Evaluating the MittenGliding Hypothesis for Paromomyidae and Micromomyidae (Mammalia, 'Plesiadapiformes') Using Comparative Functional Morphology of New Paleogene Skeletons.” In Mammalian Evolutionary Morphology: A Tribute to Frederick S. Szalay, ed. E. J. Sargis and M. Dagosto, pp. 233284. New York: Springer.

Boyer, D. M., J. I. Bloch, and P. D. Gingerich. 2001. New Skeletons of Paleocene Paromomyids (Mammalia, ?Primates): Were They Mitten Gliders? Journal of Vertebrate Paleontology, 21(3), Suppl.:35A.

Boyer, D. M., G. V. R. Prasad, D. W. Krause, M. Godinot, A. Goswami, O. Verma, and J. J. Flynn. 2010. New Postcrania of Deccanolestes from the Late Cretaceous of India and Their Bearing on the Evolutionary and Biogeographic History of Euarchontan Mammals. Naturwissenschaften, 97:365-377. http://dx.doi.org/10.1007/s00114-010-0648-0.

Brammal, J. R. 1998. A New Petauroid Possum from the OligoMiocene of Riversleigh, Northwestern Queensland. Alcheringa, 23:31-50. http://dx.doi.org/10.1080/031155199086 19337.

Brandt, J. F. 1855. Beiträge zur nähern Kenntniss der Säugethiere Russland's. Mémoires de l'Académie Impériale des Sciences de St. Pétersbourg, 6th ser., 7:1-365.

Brisson, M. J. 1762. Regnum Animale in Classes in Classes IX. Distributum, sive Synopsis Methodica. Sistens Generalem Animalium distributionem in Classes IX, \& Duarum Primarum Classium, Quadrupedum Scilicet \& Cetaceorum, Particularem Divisionem in Ordines, Sectiones, Genera \& Species. Cum Brevi Cujusque Speciei Two Descriptione, Cicationibus Auctorum de iis Tractantium, Nominibus eis ab Ipsis \& Nationibus Impositis, Nominibusque Vulgaribus. Leiden: Theodorum Haak.

Brown, M., H. Cooksley, S. M. Carthew, and S. J. B. Coopers. 2006. Conservation Units and Phylogenetic Structure of an Arboreal Marsupial, the Yellow-Bellied Glider (Petaurus australis). Australian Journal of Zoology, 54:305-317. http://dx.doi.org/10.1071/ZO06034.

Bugge, J. 1974. The Cephalic Arterial System in Insectivores, Primates, Rodents, and Lagomorphs with Special Reference 
to the Systematic Classification. Acta Anatomica, 87:1-160. http://dx.doi.org/10.1159/000144205.

Burnett, G. T. 1829. Illustrations of the Alipeda (Alipeds), or Bats and Their Allies; Being the Arrangement of the Cheiroptera, Volitantia, or Wing-Footed Beasts, Indicated in Outline. Quarterly Journal of Science, Literature, and Art, 1829:262-269.

Cabral, J. C. 1971. Existencia em Angola de Anomalurops beecrofti (Fraser). Boletim do Instituto de Investigacao Cientifica de Angola, 8:55-63.

Cabrera, A. 1924. Una nueva forma de caguan de la isla de Borneo. Boletin de la Real Sociedad Espanola de Historia Natural, 24:128-130.

-1925. Genera Mammalium: Insectivora, Galeopithecia. Madrid: Museo Nactional de Ciencias Naturales.

Carter, T. D. 1933. A New Flying Squirrel of the Genus Petaurista from Northwestern Siam. American Museum Novitates, 674:1-7.

- 1942. Three New Mammals of the Genera Crocidura, Callosciurus and Pteromys from Northern Burma. American Museum Novitates, 1208:1-2.

Cartmill, M., and R. D. E. MacPhee. 1980. “Tupaiid Affinities: The Evidence of the Carotid Arteries and Cranial Skeleton." In Comparative Biology and Evolutionary Relationships of Tree Shrews, ed. W. P. Luckett, pp. 95-132. New York: Plenum Press.

Chaimanee, Y. 1998. Plio-Pleistocene Rodents of Thailand. Bangkok: Biodiversity Research and Training Program, National Center for Genetic Engineering and Biotechnology.

Chaimanee, Y., and J.-J. Jaeger. 2000. A New Flying Squirrel Belomys thamkaewi n. sp. (Mammalia: Rodentia) from the Pleistocene of West Thailand and Its Biogeography. Mammalia, 64:307-318. http://dx.doi.org/10.1515/ mamm.2000.64.3.307.

Chakraborty, S. 1981. Studies on Sciuropterus baberi Blyth. Proceedings of the Zoological Society of Calcutta, 32:57-63.

Chasen, F. N. 1933. A New Flying Squirrel from Borneo. Bulletin of the Raffles Museum, 8:194.

- 1935. On Some Mammals from the Karimata Islands and Dutch Western Borneo. Treubia, 15:1-7.

- 1939. Four New Mammals from Java. Treubia, 17:185188.

-1940. A Handlist of Malaysian Mammals. Bulletin of the Raffles Museum, 15:1-209.

Chasen, F. N., and C. B. Kloss. 1927. Spolia Mentawiensia-Mammals. Proceedings of the Zoological Society of London, 97:797-840. http://dx.doi.org/10.1111/j.1469 -7998.1927.tb07434.x.

- 1929a. Notes on Flying Lemurs (Galeopterus). Bulletin of the Raffles Museum, 2:12-22.

- 1929b. Two New Races of Galeopterus. Bulletin of the Raffles Museum, 2:11-12.

- 1932. On a Collection of Mammals from the Lowlands and Islands of North Borneo. Bulletin of the Raffles Museum, 6:1-82.

Clayton, M., J. C. Wombey, I. J. Mason, R. T. Chesser, and A. Wells. 2006. CSIRO List of Australian Vertebrates: A Reference with Conservation Status. Melbourne: CSIRO Publishing.
Colgan, D. J., and T. F. Flannery. 1992. Biochemical Systematics Studies in the Genus Petaurus (Marsupialia: Petauridae). Australian Journal of Zoology, 40:245-256. http://dx.doi .org/10.1071/ZO9920245.

Collett, R. 1884. On Some Apparently New Marsupials from Queensland. Proceedings of the Zoological Society of London, 1884:381-389.

- 1887. On a Collection of Mammals from Central and Northern Queensland. Zoologische Jahrbücher, Zeitschrift für Systematik, Geographie und Biologie der Thiere, 2:829940.

Compte, B., and M. Vianey-Liaud. 1987. Nouveaux Eomyidae du Paleogene d'Europe occidentale. Compte Rendus Academie des Sciences Paris, 304:951-954.

Cope, E. D. 1883a. On the Mutual Relations of the Bunotherian Mammalia. Proceedings of the Academy of Natural Sciences of Philadelphia, 35:77-83.

- 1883b. First Addition to the Fauna of the Puerto Eocene. Proceedings of the American Philosophical Society, 20:545-563.

-1884. Second Addition to the Knowledge of the Fauna of the Puerto Epoch. Proceedings of the American Philosophical Society, 21:309-324.

- 1889. Synopsis of the Families of Vertebrata. The American Naturalist, 23:849-877. http://dx.doi.org/10.1086/ 275018.

Corbet, G. B. 1978. The Mammals of the Palaearctic Region. London: British Museum (Natural History).

Corbet, G. B., and J. E. Hill. 1980. A World List of Mammalian Species. London: British Museum (Natural History) Publications.

- 1986. A World List of Mammalian Species. 2nd ed. London: British Museum (Natural History) Publications.

- 1991. A World List of Mammalian Species. 3rd ed. London: British Museum (Natural History) Publications.

- 1992. The Mammals of the Indomalayan Region: A Systematic Review. Oxford: Oxford University Press.

Cowan, I. M. 1937. The Distribution of Flying Squirrels in Western British Columbia with the Description of a New Race. Proceedings of the Biological Society of Washington, 50:77-82.

Crosby, K., M. Bassarova, M. Archer, and K. Carbery. 2004. "Fossil Possums in Australasia: Discovery, Diversity and Evolution." In Biology of Possums and Gliders, ed. R. L. Goldingay and S. M. Jackson, pp. 161-176. Sydney: Surrey Beatty.

Cuvier, F. 1825a. Recherches sue les rapports qui existent entre les animaux de la famille des Écureuils; c'est-à-dire, les Tamanias, les Macroxus, les Ecureuils, les Sciuroptères et les Ptéromys. Mémoires du Museum d'Histoire Naturelle, Paris, 10:116-128.

- $1825 \mathrm{~b}$. Des dents des mammifères, considérées comme caractères zoologiques. Paris: F. G. Levrault.

Cuvier, G. 1800. Leçon's d'anatomie comparée. Volume 1. Paris: Baudouin.

- 1817. Le règne animal distribué d'après son organisation pour servir de base à l'histoire naturelle des animaux et d'introduction à l'anatomie comparée. Volume 1. Paris: Déterville. 
1829. Le règne animal distribué d'après son organisation, pour servir de base à l'histoire naturelle des animaux et d'introduction à l'anatomie comparée. 2nd ed. Volume 1. Paris: Déterville.

Daams, R. 1977. Aragonian Sciuroptera (Sciuridae, Rodentia, Mammalia) from Spain. Proceedings of the Koninklijke Nederlandse Akademie van Wetenschappen, Series B, Palaeontology, Geology, Physics, Chemistry, Anthropology, 80:356-359.

d'Aguilar-Amat, J. B. 1922. Una nova forma de Anomalurus de Fernando Poo. Butlleti de la Institucio Catalana d'Historia Natural, Barcelona, 2(2):52-53.

Dahlmann, T. 2001. Die Kleinsäuger der unter-pliozänen Fundstelle Wölfersheim in der Wetterau (Mammalia: Lipotyphla, Chiroptera, Rodentia). Courier Forschungsinstitut Senckenberg, 227:1-129.

Dao, V. T., and V. S. Cao. 1990. Six New Vietnamese Rodents. Mammalia, 54:233-238.

Davis, D. D. 1958. Mammals of the Kelabit Plateau, Northern Sarawak. Fieldiana Zoology, 39:119-147.

- 1962. Mammals of the Lowland Rain-Forest of North Borneo. Bulletin of the National Museum of Singapore, 31:1-130.

Dawson, M. R., M. C. McKenna, K. C. Beard, and J. H. Hutchison. 1993. An Early Eocene Plagiomenid Mammal from Ellesmere and Axel Heiberg Islands, Arctic Canada. Kaupia, 3:179-192.

Dawson, M. R., T. Tsubamoto, M. Takai, N. Egi, S. T. Tun, and C. Sein. 2003. Rodents of the Family Anomaluridae (Mammalia) from Southeast Asia (Middle Eocene, Pondaung Formation, Myanmar). Annals of Carnegie Museum, 72(3):203-213.

Daxner-Höck, G. 1975. Sciuridae aus dem Jungtertiar von Osterreich. Paleontologische Zeitschrift, 49:56-74.

— 2004. Flying Squirrels (Pteromyinae, Mammalia) from the Upper Miocene of Austria. Annalen des Naturhistorischen Museums in Wien, Serie A, 106:387-423.

Daxner-Höck, G., and P. Mein. 1975. Taxonomische Probleme um das Genus Miopetaurista Kretzoi, 1962 (Fam. Sciuridae). Palaeontologische Zeitschrift, 49(1-2):75-77.

Day, Y. T. 1988. Subspecies and geographic variation of Petaurista alborufus and P. petaurista (Rodentia: Sciuridae). Journal of the Taiwan Museum, 41(1):75-83.

de Beaufort, F. 1966. Catalogue des types de mammifères du Muséum National d'Histoire Naturelle. Paris. VI. Monotremata.-VII Marsupialia. Bulletin du Muséum National d'Histoire Naturelle. Section B. Botanique, Biologie et Écologie Végétales Phytochimie, Paris, 2nd ser., 38:509553.

Deberer, P. H. 1909. Comparison of Caenolestes with Polyprotodonta and Diprotodonta. The American Naturalist, 43:614-618. http://dx.doi.org/10.1086/279094.

de Blainville, H. M. D. 1816. Prodrome d'une nouvelle distribution systématique du règne animal. Bulletin des Sciences, par la Société Philomatique de Paris, 1816:113-124.

de Bruijn, H. 1966. On the Mammalian Fauna of the HipparionBeds in the Calatayud-Teruel Basin (Prov. Zaragoza, Spain). Part II. The Gliridae (Rodentia). Proceedings of the Koninklijke Nederlandse Akademie van Wetenschappen, Serie B,
Palaeontology, Geology, Physics, Chemistry, Anthropology, 69:367-387.

- 1995. "Sciuridae, Petauristidae and Eomyidae (Rodentia, Mammalia)." In The Vertebrate Locality Maramena (Macedonia, Greece) at the Turolian-Ruscinian Boundary (Neogene), ed. N. Schmidt-Kittler. Münchner Geowissenschaftliche Abhandlungen, Reihe A, Geologie und Paläontologie, 28:87-102.

— 1998. Vertebrates from the Early Miocene Lignite Deposits of the Opencast Mine Oberdorf (Western Styrian Basin, Austria): 6. Rodentia 1 (Mammalia). Annalen des Naturhistorischen Museums in Wien, Series A, Mineralogie, Petrologie, Geologie, Paläeontologie, Archäeozoologie, Anthropologie, Präehistorie, 99:99-137.

- 1999. "Superfamily Sciuroidea." In The Miocene Land Mammals of Europe, ed. G. E. Rossner and K. Heissig, pp. 271-280. Munich: Verlag Dr Friedrich Pfeil.

de Bruijn, H., and E. Ünay. 1989. Petauristinae (Mammalia, Rodentia) from the Oligocene of Spain, Belgium and Turkish Thrace. Science Series Natural History Museum of Los Angeles County, 33:139-45.

de Bruijn, H., A. J. van der Meulen, and G. Katsikatsos. 1980. The Mammals of the Lower Miocene of Alivera (Island of Evia, Greece). Part 1. The Sciuridae. Proceedings of the Koninklijke Nederlandse Akademie van Wetenschappen, Series B, Palaeontology, Geology, Physics, Chemistry, Anthropology, 83:241-261.

Dehm, R. 1950. Die Nagetiere aus dem Mittel-Miocän (Burdigalium) von Wintershof-West bei Eichstätt in Bayern. Neues Jabrbuch für Mineralogie, Geologie und Paläontologie, Part B, Geologie and Paläontologie, 91:321-428.

- 1962. Altpleistocäne Säuger von Schernfeld bei Eichstätt in Bayern. Mitteilungen der Bayerischen Staatssammlung für Paläontologie und Historische Geologie, 2:17-61.

Dekeyser, P. L., and A. Villiers. 1951. "Description d'un Anomalurops de la région de Bignona. Bissau." In Conferência Internacional dos Africanistas Ocidentais, 2a, 1947. Vol. 3, part 2, pp. 57-62. Lisbon: Junta de Investigações Coloniais.

Delany, M. J. 1975. The Rodents of Uganda. London: British Museum of Natural History.

Deperet, C. 1897. Les animaux Pliocènes du Roussillon. Mémoires de la Société Géologique de France, Paléontologie, 7(4):1-194.

Deperet, C., and H. Douxami. 1902. Les Vertébrés oligocènes de Pyrimont-Challonges. Mémoires de la Société Paléontologique Suisse, 29:1-90.

Desmarest, A. G. 1818a. "Petauriste." In Nouveau dictionnaire d'histoire naturelle, appliquée aux arts, a l'agriculture, a l'economie rurale et domestique, a la medecine, etc. Par une société de natualistes et d'agriculteurs. Volume 25: PASPHO, ed. C. S. Sonnini, pp. 398-406. Nouvelle édition presqu'entièrement refondue et considerablement augmentee. Paris: Deterville.

—. 1818b. "Galeopitheque." In Nouveau dictionnaire d'histoire naturelle, appliquée aux arts, à l'agriculture, à l'economie rurale et domestique, à la medecine, etc. Par une société de natualistes et d'agriculteurs. Volume 12: FORGEN, ed. C. S. Sonnini, pp. 375-377. Nouvelle édition 
presqu'entièrement refondue et considérablement augmentée. Paris: Deterville.

-. 1818c. "Polatouche." In Nouveau dictionnaire d'histoire naturelle, appliquée aux arts, à l'agriculture, à l'économie rurale et domestique, à la médecine etc. Par une société de naturalites et d'agriculteurs. Volume 27: PLA-POR, ed. C. S. Sonnini, pp. 401-407. Nouvelle édition presqu'entièrement refondue et considérablement augmentée. Paris: Deterville.

- 1820. Mammalogie ou description des espèces de mammifères. Premier Partie, contenant les orders des bimanes, des quadrumanes et des carnassiers. Paris: V. Agasse.

- 1822. Mammalogie ou description des espèces de mammifères. Table méthodique des mammifères. Volume 2: Contenant les orders des Rongeurs, des Edentes, des Pachydermes des Ruminans et des Cetaces. Paris: Agasse.

De Vis, C. W. 1883. Description of a New Belideus from Northern Queensland. Abstracts and Proceedings of the Linnean Society of New South Wales, 7:619-620.

- 1887. On New or Rare Vertebrates from the Herbert River, North Queensland. Proceedings of the Linnean Society of New South Wales, 2nd Ser., 11:1129-1137.

de Winton, W. E. 1897. Description of Two New Mammals from West Africa. Annals and Magazine of Natural History, 6th ser., 20:524.

de Winton, W. E. 1898. Descriptions of Three New Rodents from Africa. Annals and Magazine of Natural History, 7th ser., 1:251-254.

Diersing, V. E. 1980. Systematics of Flying Squirrel (Glaucomys volans) From Mexico, Guatemala and Honduras. Southwestern Naturalist, 25:157-172. http://dx.doi.org/ $10.2307 / 3671238$.

Dieterlen, F. 1993. "Family Anomaluridae." In Mammal Species of the World: A Taxonomic and Geographic Reference, 2nd ed., ed. D. E. Wilson and D. M. Reeder, pp. 757-758. Washington, D. C.: Smithsonian Institution Press.

- 2005. "Family Anomaluridae." In Mammal Species of the World: A Taxonomic and Geographic Reference, 3rd ed., ed. D. E. Wilson and D. M. Reeder, pp. 1532-1534. Washington, D. C.: Smithsonian Institution Press.

Diller, T. H. M. 1977. A Field Guide to the Mammals of Africa Including Madagascar. London: Collins.

Dobson, G. E. 1883. A Monograph of the Insectivora: Systematic and Anatomical-Including the Erinaceidae, Centetidae, Solenodontidae, Potamogalidae, Chrysochloridae, Talpidae and Soricidae. London: J. van Voorst.

Dobson, M. 1994. Patterns of Distribution in Japanese Land Mammals. Mammal Review, 24:91-111. http://dx.doi.org/ 10.1111/j.1365-2907.1994.tb00137.x.

Dolan, P. G., and D. C. Carter. 1977. Glaucomys volans. Mammalian Species, 78:1-6. http://dx.doi.org/10.2307/3504026.

Dollman, G. 1909. On Mammals Collected by Mr. S. A. Neave, M. A., B.Sc. (Oxon.), in Katanga, Congo Free State. Annals and Magazine of Natural History, 8th ser., 3:348-354.

- 1911. New West-African Rodents. Annals and Magazine of Natural History, 8th ser., 8:257-259.

-1914. On a New Anomalurus from the Cameroons. Annals and Magazine of Natural History, 8th ser., 14:490.

Dorst, J., and P. Dandelot. 1970. A Field Guide to the Larger Mammals of Africa. London: Collins.
Douzery, E. J. P., and D. Huchon. 2004. Rabbits, If Anything, Are Likely Glires. Molecular Phylogenetics and Evolution, 33:922-935. http://dx.doi.org/10.1016/j.ympev.2004 .07 .014 .

Dubois, A. 1888. Description d'un rongeur nouveau du genre Anomalurus. Bulletin de la Société de Zoologie de France, 13:23-24.

Du Chaillu, P. B. 1860. Five New Species of Mammals Discovered in Western Equatorial Africa. Proceedings of the Boston Society of Natural History, 7:296-304.

Ducrocq, S., E. Buffetaut, H. Buffetaut-Tong, J.-J. Jaeger, Y. Jortgkanjanasoontorn, and V. Suteethorn. 1992. First Fossil Flying Lemur: A Dermopteran from the Late Eocene of Thailand. Palaeontology, 35:373-380.

Ellerman, J. R. 1940. The Families and Genera of Living Rodents. Volume 1: Rodents Other Than Muridae. London: British Museum (Natural History).

- 1947. A Key to the Rodentia Inhabiting India, Ceylon and Burma, Based on Collections in the British Museum. Part 1. Journal of Mammalogy, 28:249-278. http://dx.doi .org/10.2307/1375176.

. 1961. The Fauna of India. Mammalia. 2nd ed. Volume 3: Rodentia. Calcutta: Manager of Publications, Zoological Survey of India.

Ellerman, J. R., and T. C. S. Morrison-Scott. 1951. Checklist of Palaearctic and Indian Mammals 1758 to 1946. London: British Museum of Natural History.

- 1955. Supplement to Chasen (1940): A Handlist of Malaysian Mammals, Containing a Generic Synonymy and a Complete Index. London: British Museum (Natural History).

- 1966. Checklist of Palaearctic and Indian Mammals 1758 to 1946. 2nd Edition. London: British Museum of Natural History.

Elliot, D. G. 1899. Preliminary Description of New Rodents from the Olympic Mountains. Field Columbian Museum Publication, Zoological Series, 1:225-228.

— 1901. A Synopsis of the Mammals of North America and the Adjacent Seas. Field Columbian Museum Publication, Zoölogical Series, 2:1-471.

Elliot, W. 1839. A Catalogue of the Species of Mammalia Found in the Southern Mahratta Country; with Their synonyms in the Native Languages in Use There. Madras Journal of Literature and Science, 10:207-219.

Engesser, B. 1972. Die obermiozane Saugetierefauna von Anwil (Baselland). Tatigkeitsbericht der Naturforschenden Gesellschaft Baselland, 28:37-363.

- 1979. Relationships of Some Insectivores and Rodents from the Miocene of North America and Europe. Bulletin of Carnegie Museum of Natural History, 14:1-68.

Erxleben, J. C. P. 1777. Systema Regni Animalis per Classes, Ordines, Genera, Species, Varietates cum Synonymia et Historia Animalium. Classis 1 Mammalia. Leipzig: Impensis Weygandianis.

Evenhuis, N. L. 1990. Dating of the Livraisons and Volumes of d'Ordigny's Dictionnaire Universel d'Histoire Naturelle. Bishop Museum Occasional Papers, 30:219-225.

Fabricius, J. C. 1794. Genera \& Ordines Insectorum Linnaei, quae, in Entomologia Systematica Dni. Fabricii, tum quoad 
Totum, tum quoad Partem, Mutata, Reformata, Atque Nova \& Adaucta Exponuntur. Volume 4. Copenhagen. [Publisher unknown.]

- 1798. Supplementum Entomologiae Systematicae. Copenhagen. [Publisher unknown.]

Falcimange, A. 1854. Memoires Historiques sur l'Australie Par Mgr Rudesindo Salvado. Paris: Alphonse Pringuet.

Feng, Z., and C. Zheng. 2003. "Petaurista albiventer chayuensis." In A Complete Checklist of Mammal Species and Subspecies in China: A Taxonomic and Geographic Reference. Y.-X. Wang. p. 157. Beijing: Chinese Forestry Publishing House.

Fischer, J. B. 1829. Synopsis Mammalium. Addenda, emendanda et index. Stuttgart: J. G. Cottae.

Fischer de Waldheim, G. 1813. Zoognosia Tabulis Synopticis Illustrata: In Usum Praelectionum Academiae Imperialis Medico-Chirugicae Mosquensis Edita. Volume 2. Moscow: Nicolai S. Vsevolozsky.

-1814. Zoognosia Tabulis Synopticis Illustrata: In Usum Praelectionum Academiae Imperialis Medico-Chirurgicae Mosquensis. Volume 3. Moscow: Nicolai Sergeidis Vsevolozsky.

-1817. Adversaria Zoologica. Mémoires de la Société Impériale des Naturalistes de Moscou, 5:357-428.

Fischer, J. B. 1829. Synopsis Mammalium. (Addenda, emendanda et index.). J.G. Cottae, Stuttgardtiae.

Flannery, T. F. 1990. Mammals of New Guinea. Carina, Australia: Robert Brown \& Associates.

-1994. Possums of the World-A Monograph of the Phalangeroidea. Sydney: Geo Productions.

-1995a. Mammals of the South-West Pacific and Moluccan Islands, Sydney: Reed Books.

- 1995b. Mammals of New Guinea. 2nd ed. Sydney: Reed Books.

Fleay, D. 1947. Gliders of the Gum Trees. Melbourne: Bread and Cheese Club.

- 1954. The Squirrel Glider. Victorian Naturalist, 70:208210.

Fleming, J. 1822. The Philosophy of Zoology; or A General View of the Structure, Functions, and Classification of Animals. 2 Volumes. Edinburgh: Archbold Constable and Co.

Flower, W. H. 1883. On the Arrangement of the Orders and Families of Existing Mammalia. Proceedings of the Zoological Society of London, 1883:178-186.

Flower, W. H., and R. Lydekker. 1891. An Introduction to the Study of Mammals Living and Extinct. London: Adam \& Charles Black.

Flynn, L. J., L. L. Jacobs, and I. U. Cheema. 1986. Baluchimyinae, a New Ctenodactyloid Rodent Subfamily from the Miocene of Baluchistan. American Museum Novitates, 2841:1-58.

Francis, C. M. 2008. A Guide to the Mammals of Southeast Asia. Princeton: Princeton University Press.

Fraser, L. 1853. Description of a New Species of Anomalurus from Fernando Po. Proceedings of the Zoological Society of London, 1852:16-17.

Gaillard, C. 1899. Mammifères Miocènes nouveau ou peu connus de la Grive-Saint-Alban (Isère). Archives du Muséum d'Histoire Naturelle de Lyon, 7:4-68.
Gardiner, B. G. 1982. Tetrapod Classification. Zoological Journal of the Linnean Society, 74:207-232. http://dx.doi.org/ 10.1111/j.1096-3642.1982.tb01148.x.

Gazin, C. L. 1941. The Mammalian Faunas of the Paleocene of Central Utah, with Notes on the Geology. Proceedings of the United States National Museum, 91:1-53.

Geoffroy, É. L. 1762. Histoire abregée des insectes qui se trouvent aux environs de Paris; dans laquelle ces animaux sont rangés suivant un ordre méthodique. Volume 2. Paris: Durand.

Geoffroy Saint-Hilaire, É. 1803a. Catalogue des mammifères du Muséum National d'Histoire Naturelle. Paris: Museum National d'Histoire Naturelle. [Printed draft, not published.]

Geoffroy Saint-Hilaire, É. 1803b. Note sur une nouveau mammifère découvert à la Nouvelle Hollande, par M. Bass, voyageur anglais. Bulletin des sciences par la Société Philomatique de Paris, 3(72):185.

Geoffroy Saint-Hilaire, É., and G. Cuvier. 1795. Histoire naturelle orang-outangs: Des caractères qui peuvent server à diviser les singes. Magazin Encycopédique ou Journal des Sciences, des Lettres et des Arts, 3:451-463.

Geoffroy Saint-Hilaire, I. 1844. In V. Jacquemont. Voyage dans l'Inde pendant les années 1828 à 1832. Volume 4: Mammifères. Atlas 2. Paris: Didot.

Gervais, F. L. P. 1849. "Rongeurs.” In Dictionnaire Universel d'Histoire Naturelle. Volume 11, ed. C. D’Orbigny, pp. 198-204. Paris: Renard, Martinet et Cie.

- 1853. Descriptions ostéologique d'Anomalurus et remarques sur la classification naturelle des rongeurs. Annales des Sciences Naturelles, Zoologie et Biologie Animale, 3rd ser., 20:238-246.

- 1869. "Phalanger." In Dictionaire Universel d'Histoire Naturelle. 2nd edition. Volume 10, ed. C. D’Orbigny, pp. 568-574. Paris: Abel Pilon.

Gervais, F. L. P., and J. Verreaux. 1842. On a New Genus of Marsupial Animals, Tarsipes rostratus. Proceedings of the Zoological Society of London, 1842:1-5.

Gheerbrant, E., and D. E. Russell. 1989. Presence of the genus Afrodon (Mammalia, Lipotyphla (ß), Adapisoriculidae) in Europe: New Data for the Problem of Trans-Tethyan Relations between Africa and Europe around the K/T Boundary. Palaeogeography, Palaeoclimatology, Palaeoecology, 76:115. http://dx.doi.org/10.1016/0031-0182(89)90099-0.

. 1991. Bustylus cernaysi nov. gen., nov. sp., nouvel Adapisoriculidé (Mammalia, Eutheria) Paléocène d'Europe. Geobios, 24:467-481. http://dx.doi.org/10.1016/S0016 $-6995(06) 80247-0$.

Ghose, R. K., and T. P. Bhattacharya. 1995. New Distributional Record of Petaurista fulvinus Wroughton, 1911 (Mammalia: Rodentia: Sciuridae), with Comments on its Taxonomic Status. Journal of the Bombay Natural History Society, 92:254-255.

Ghose, R. K., and T. K. Chakraborty. 1983. A Note on the Status of the Flying Squirrels of Darjeeling and Sikkim. Journal of the Bombay Natural History Society, 80:411.

Ghose, R. K., and S. S. Saha. 1981. Taxonomic Review of Hodgson's Giant Flying Squirrel, Petaurista magnificus (Sciuridae: Rodentia), with Description of a New Subspecies from Darjeeling District, West Bengal, India. Journal of the Bombay Natural History Society, 78:93-102. 
Giebel, C. G. 1855. Die Säugethiere in Zoologischer, anatomischer und palaeontologischer Beziehung. Leipzig: Verlag Von Ambrosius Abel.

Gilbert, C. H. 1890. Scientific Results of Explorations by the U. S. Fish Commission Steamer Albatross. No. XII. A Preliminary Report on the Fishes Collected by the Steamer Albatross on the Pacific Coast of North America during the Year 1889, with Descriptions of Twelve New Genera and Ninety-Two New Species. Proceedings of the United States National Museum, 13:49-126.

Gill, T. 1871. On the Characteristics of the Primary Groups of the Class of Mammals. The American Naturalist, 5:526533. http://dx.doi.org/10.1086/270816.

- 1872. The Arrangement of the Families of Mammals with Analytical Tables. Smithsonian Miscellaneous Collections, 11:1-98.

Gingerich, P. D. 1987. Early Eocene Bats (Mammalia, Chiroptera) and Other Vertebrates in Freshwater Limestones of the Willwood Formation, Clark's Fork Basin, Wyoming. Contributions from the Museum of Paleontology, University of Michigan, 27:275-320.

Gloger, C. W. L. 1841. Gemeinnütziges Hand-und Hilfsbuch der Naturgeschichte. Für gebildete Leser aller Stände, besonders für die reifere Jugend und ihre Lehrer. Volume 1, Books 1-2. Breslau: A. Schultz \& Co.

Gmelin, J. F. 1788. Caroli a Linne Systema Naturae. 13th ed. Volume 1. Leipzig: G. E. Beer.

Godinot, M. 2007. "Primate Origins: A Reappraisal of Historical Data Favouring Tupaiid Affinities." In Primate Origins: Adaptations and Evolution, ed. M. J. Ravosa and M. Dagosto, pp. 83-142. New York: Springer. http://dx.doi.org/ 10.1007/978-0-387-33507-0_4.

Goldman, G. C. 1936. Two New Flying Squirrels from Mexico. Journal of the Washington Academy of Science, 26:462464.

Goodwin, G. G. 1936. A New Flying Squirrel from Honduras. American Museum Novitates, 898:1-2.

- 1961. Flying Squirrels (Glaucomys volans) of Middle America. American Museum Novitates, 2059:1-22.

Gould, J. 1842a. On Some New Species of Australian Mammals. Proceedings of the Zoological Society of London, 1842:10-14.

-1842b. New Australian Mammals. Annals and Magazine of Natural History, (1)10:404-406.

-. 1845-1863. The Mammals of Australia. London: Author.

Grassé, P.-P., and P. L. Dekeyser. 1955. "Ordre des Rongeurs.” In Traité de Zoologie: Anatomie, Systematique, Biologie. Volume 17: Mammifères, les Ordres: Anatomie, Ethologie, Systématique, Fascicule 2, ed. P. P. Grassé, pp. 1321-1525. Paris: Masson et Cie.

Graur, D., L. Duret, and M. Gouy. 1996. Phylogenetic Position of the Order Lagomorpha (Rabbits, Hares and Allies). Nature, 379:333-335. http://dx.doi.org/10.1038/379333a0.

Gray, J. E. 1821. On the Natural Arrangement of Vertebrose Animals. London Medical Repository, 15:296-310. - 1825. An Outline of an Attempt at the Disposition of the Mammalia into Tribes and Families with a List of the Genera Apparently Appertaining to Each Tribe. Annals of Philosophy, 2nd ser., 10:337-344.
1827. "Synopsis of the Species of the Class Mammalia." In The Animal Kingdom Arranged in Conformity with its Organisation, by the Baron Cuvier, Member of the Institute of France etc, with Additional Descriptions of All the Species Hitherto Named, and of Many Not Before Noticed. Volume 5 of 16 (1827-1835), ed. E. Griffith, C. H. Smith, and E. Pidgeon, pp. 1-391. London: G. B. Whittaker.

- 1834. Illustrations of Indian Zoology Chiefly Selected from the Collection of Major-General Hardwicke. London: Adolphus Richter \& Co.

. 1836. October 11. Proceedings of the Zoological Society of London, 1836:87-88.

-1837a. Description of Some New or Little Known Mammalia. Magazine of Natural History, 1:577-587.

- $1837 \mathrm{~b}$. Meeting of June 27th 1837. Proceedings of the Zoological Society of London, 1837:67-69.

- 1841. "Contributions towards the Geographical Distribution of the Mammalia of Australia, with Notes on Some Recently Discovered Species, in a Letter Addressed to the Author. Appendix C." In Journals of Two Expeditions of Discovery in North-west and Western Australia During the Years 1837, 38, and 39. Volume 2, ed. G. Grey, pp. 387414. London: T. W. Boone.

1842. Description of Some New Genera and Fifty Unrecorded Species of Mammalia. Annals and Magazine of Natural History, 1st ser., 10:255-267.

-1843. List of the Specimens of Mammalia in the Collection of the British Museum. London: British Museum.

- 1846. New Species of Mammalia. Annals and Magazine of Natural History, 1st ser., 18:211-212.

. 1863. Revision of the Species of Lemuroid Animals, with the Description of Some New Species. Proceedings of the Zoological Society of London, 1863:129-152.

-1869. Anomalurus fulgens, a New Species from the Gaboon. Annals and Magazine of Natural History, 4th ser., 3:467, pl. XXI.

-. 1871 ["1870"]. Catalogue of Monkeys, Lemurs and Fruit-Eating Bats in the Collections of the British Museum. London: British Museum.

Gregory, W. K. 1910. The Orders of Mammals. Bulletin of the American Museum of Natural History, 27:1-524.

- 1947. The Monotremes and the Palimpsest Theory. Bulletin of the American Museum of Natural History, 88:1-52.

Groves, C. P. 1993. “Order Diprotodontia.” In Mammal Species of the World: A Taxonomic and Geographic Reference, ed. D. E. Wilson and D. M. Reeder, pp. 45-62. Washington, D.C.: Smithsonian Institution Press.

- 2001. Primate Taxonomy. Washington, D.C.: Smithsonian Institution Press.

- 2005. "Order Diprotodontia." In Mammal Species of the World: A Taxonomic and Geographic Reference, 2nd ed., ed. D. E. Wilson and D. A. Reeder, pp. 43-70. Washington, D.C.: Smithsonian Institution Press.

Grubb, P., T. S. Jones, A. G. Davies, E. Edberg, E. D. Starin, and J. E. Hill. 1998. Mammals of Ghana, Sierra Leone and the Gambia. Cornwall: The Trendline Press.

Guilday, J. E. 1962a. The Pleistocene Local Fauna of the Natural Chimneys, Augusta County, Virginia. Annals of the Carnegie Museum, 36:87-122. 
1962b. Notes on Pleistocene Vertebrates from Wythe County, Virginia. Annals of the Carnegie Museum, 36:77-86.

Guilday, J. E., and H. W. Hamilton. 1973. The Late Pleistocene Small Mammals of Eagle Cave, Pendleton County, West Virginia. Annals of the Carnegie Museum, 44:45-58.

Guilday, J. E., H. W. Hamilton, E. Anderson, and P. W. Parmalee. 1978. The Baker Bluff Cave Deposit, Tennessee, and the Late Pleistocene faunal gradient. Bulletin of the Carnegie Museum of Natural History, 11:1-67.

Guilday, J. E., H. W. Hamilton, and A. D. McCrady. 1969. The pleistocene vertebrate fauna of Robinson Cave, Overton County, Tennessee. Palaeovertebrata, 2:25-75.

Guilday, J. E., P. S. Martin, and A. D. McCrady. 1964. New Paris. No. 4. A Late Pleistocene Cave Deposit in Bedford County, Pennsylvania. Bulletin of the National Speleological Society, 26:121-94.

Gunn, R. C. 1851. On the Introduction and Naturalisation of Petaurus sciureus in Tasmania. Papers and Proceedings of the Royal Society of Van Diemen's Land, 1:253-255.

Gunnell, G. F. 1989. Evolutionary History of Microsyopoidea (Mammalia, ?Primates) and the Relationship between Plesiadapiformes and Primates. University of Michigan, Papers on Paleontology, 27:1-157.

Gunnell, G. F., and K. D. Rose. 2002. "Tarsiiformes: Evolutionary History and Adaptation." In The Primate Fossil Record, ed. W. C. Hartwig, pp. 45-81. Cambridge: Cambridge University Press.

Günther, A. 1873. Descriptions of Three New Species of Flying Squirrels in the Collection of the British Museum. Proceedings of the Zoological Society of London, 1873:413-414.

Gyldenstolpe, N. 1920. On a Collection of Mammals Made in Eastern and Central Borneo by Mr. Carl Lumholtz. Kungliga Svenska VetenskAkademiens Handlingar, 60(6):1-62.

Haeckel, E. H. P. A. 1866. Generelle Morphologie der Organismen: Allgemeine Grundzüge der organischen FormenWissenschaft, mechanisch Begründet durch die von C. Darwin reformirte Decendenz-Theorie. Volume 2. Berlin: George Reimer.

- 1895. Systematische Phylogenie der Wirbelthiere (Vertebrata). Berlin: Georg Reimer.

Hall, E. R. 1934. Two New Rodents of the Genera Glaucomys and Zapus from Utah. Occasional Papers of the Museum of Zoology, University of Michigan, 296:1-3.

- 1981. The Mammals of North America. 2nd ed. New York: Ronald Press.

Hall, E. R., and K. R. Kelson. 1959. The Mammals of North America. New York: Ronald Press.

Handley, C. O., Jr. 1953. A New Flying Squirrel from the Southern Appalachian Mountains. Proceedings of the Biological Society of Washington, 66:191-194.

Harris, W. P. 1951. A Substitute Name for Petaurista petaurista rufipes Sody. Journal of Mammalogy, 32:234.

Harrison, J. L., and R. Traub. 1950. Rodents and Insectivores from Selangor, Malaya. Journal of Mammalogy, 31:337346. http://dx.doi.org/10.2307/1375305.

Hasegawa, Y. 1966. Quaternary Smaller Mammalian Fauna from Japan. Fossils, 11:31-40.

Hasegawa, Y., H. Yamauti, and G. Okafuji. 1968. A Fossil Assemblage of Macaca and Homo from Ojikado-Cave of
Hiraodai Karst Plateau, Northern Kyushu, Japan. Transactions of the Palaeontological Society of Japan, 69:218-229.

Hay, O. P. 1899. Notes on the Nomenclature of Some North American Fossil Vertebrates. Science, 10:253-254. http:// dx.doi.org/10.1126/science.10.243.253.

Hayman, R. W. 1946. Systematic Notes on the Genus Idiurus (Anomaluridae). Annals and Magazine of Natural History, 11th ser., 13:208-212.

Heaney, L. R., and D. S. Rabor. 1982. Mammals of Dinagat and Siargao Islands, Philippines. Occasional Papers of the $\mathrm{Mu}$ seum of Zoology, Michigan, 699:1-30.

Heaney, L. R., D. S. Balete, M. L. Dolar, A. C, Alcala, A. T. L. Dans, P. C. Gongales, N. R. Ingle, M. V. Lepiten, W. L. R. Oliver, P. S. Ong, E. A. Richart, B. R. Tabaranza Jr., and R. C. B. Utzurrum. 1998. A Synopsis of the Mammalian Fauna of the Philippine Islands. Fieldiana Zoology, 88:1-61.

Heissig, K. 1979. The Earliest Flying Squirrels and Primitive Ailuravinae (Rodentia, Mammalia) from the South German Oligocene. Mitteilungen der Bayerischen Staatssammlung für Paläontologie und Historische Geologie, 19:139-170.

Helgen, K. M. 2003. The Feather-Tailed Glider (Acrobates pygmeus [sic]) in New Guinea. Treubia, 33:107-111.

Hemprich, F. G., and C. G. Ehrenberg. 1833. Symbolae Physicae, seu Icones et Descriptiones Corporum Naturalium Novorum aut Minus Cognitorum quae ex Itin Eribus per Libyam Aegyptum Nubiam Dongolam Syrian Arabiam et Habessianiam Publico Institutis Sumptu Friedrich Guilelmi Hemprich et Christiani Godofredi Ehrenberg Medicinae et Chirurgiae Doctorum. Volume 1. Mammalia. Berolini [Berlin]. [Publisher unknown.]

Hemprich, W. 1820. Grundriss der Naturgeschichte für hohere Lebranstalten. Entworfen von Dr. W. Hemprich. Berlin: August Rucker.

Heude, P. M. 1898. Capricornes de Moupin. Mémoires Concernant L'Histoire Naturelle de L'Empire Chinois, 4(1):1-111.

Hight, M. E., M. Goodman, and W. Prychodko. 1974. Immunological Studies of the Sciuridae. Systematic Zoology, 23:1225. http://dx.doi.org/10.2307/2412236.

Hill, J. E. 1960. The Robinson Collection of Malaysian Mammals. Bulletin of the Raffles Museum, 29:1-112.

- 1962. Notes on Flying Squirrels of the Genera Pteromyscus, Hylopetes and Petinomys. Annals and Magazine of Natural History, 13th ser., 4:721-738.

Hilzheimer, M. 1906. Wissenschaftliche Mitteilungen. Zoologischer Anzeiger, 29:297-299.

Hodgson, B. H. 1836. Synoptical Descriptions of Sundry New Mammals. Journal of the Asiatic Society of Bengal, 5:231238.

- 1844. Summary Description of Two New Species of Flying Squirrel. Journal of the Asiatic Society of Bengal, 13:67-68.

Hoffmann, R. S., C. G. Anderson, R. W. Thorington, and L. R. Heaney. 1993. "Family Sciuridae." In Mammal Species of the World: A Taxonomic and Geographic Reference, ed. D. E. Wilson and D. M. Reeder, pp. 419-465. Washington, D.C.: Smithsonian Institution Press.

Hofmann, A. 1893. Die Fauna von Göriach. Abhandlungen der Kaiserlich-Königlichen Geologischen Reichsanstalt, 15(6):1-87. 
Holden, M. E. 2005. "Family Gliridae." In Mammal Species of the World: A Taxonomic and Geographic Reference, 3rd ed., ed. D. E. Wilson and D. M. Reeder, pp. 819-841. Washington, D.C.: Smithsonian Institution Press.

Hollister, N. 1911. Description of a New Philippine Flying Squirrel. Proceedings of the Biological Society of Washington, 24:185-186.

Honacki, J. H., K. E. Kinman, and J. W. Koeppl. 1982. Mammal Species of the World: A Taxonomic and Geographic Reference. Lawrence, Kans.: Allen Press.

Horsfield, T. 1824. Zoological Researches in Java and the Neighbouring Islands. London: Kingsbury.

Hose, C. 1893. A Descriptive Account of the Mammals of Borneo. London: Edward Abbott.

-1900. A New Flying Squirrel from Borneo. Annals and Magazine of Natural History, 7th ser., 5:214-216.

Howell, A. B. 1927. Five New Chinese Squirrels. Journal of the Washington Academy of Science, 17:80-84.

- 1929. Mammals from China in the Collections of the United States National Museum. Proceedings of the United States National Museum, 75:1-82.

Howell, A. H. 1915. Description of a New Genus and Seven New Races of Flying Squirrels. Proceedings of the Biological Society of Washington, 28:109-113.

- 1918. Revision of the American Flying Squirrels. North American Fauna, 44:1-64. http://dx.doi.org/10.3996/nafa .44 .0001 .

. 1934. Description of a New Race of Flying Squirrel from Alaska. Journal of Mammalogy, 15:64. http://dx.doi .org/10.2307/1373899.

Hsu, Y.-H., Y.-C. Lee, and H.-H. Hsieh. 1957. Mammalian Fossils from the Pleistocene Cave Deposits of Chihchin, Northwestern Kweichow. Acta Palaeontol Sinica, 5:343-350.

Hubbs, C. L., W. G. Frum, W. T. Neill, J. R. Tester, J. F. Welch, G. K. Godfrey, W. B. Jackson, T. T. Liu, R. K. Enders, L. Kilham, R. B. Chiasson, W. A. Morris, E. R. Kalmbach, S. B. Benson, W. E. Howard, J. C. Quast, E. B. Caswell, W. H. McCarley, W. N. Bradshaw, J. R. Ellerman, and T. C. S. Morrison-Scott. 1953. General Notes. Journal of Mammalogy, 34:498-518. http://dx.doi.org/10.2307/1375864.

Huchon, D., O. Madsen, M. J. J. B. Sibbald, K. Ament, M. J. Stanhope, F. Catzeflis, W. W. de Long, and E. J. P. Douzery. 2002. Rodent Phylogeny and a Timescale for the Evolution of Glires: Evidence from an Extensive Taxon Sampling Using Three Nuclear Genes. Molecular Biology and Evolution, 19:1053-1065.

Hudson, R. 1872. Red-Bellied Flying Squirrel (Pteromys magnificus). Proceedings of the Zoological Society of London, 1872:635-636.

Huet, M. 1884. Observations sur le genre Anomalurus et sur les espèces de la collection du Muséum d'Histoire Naturelle. Nouvelles Archives du Muséum d'Histoire Naturelle, 6(2):277-290, pls. 19-25.

Hugueney, M., and P. Mein. 1965. Lagomorphes et rongeurs du Neogene de Lissieu (Rhone). Travaux des Laboratoires de Géologie de la Faculté des Sciences de Lyon, 12:109-123.

. 1966. Les rongeurs Pliocene's du Roussillon dans les collections Lyonnaises. Travaux des Laboratoires de Géologie de la Faculté des Sciences de Lyon, 13:243-66.
Huxley, T. H. 1872. A Manual of the Anatomy of Vertebrated Animals. New York: D. Appleton and Co.

- 1880. On the Application of the Laws of Evolution to the Arrangement of the Vertebrate and More Particularly of the Mammalia. Proceedings of the Zoological Society of London, 1880:649-662.

Illiger, J. K. W. 1811a. Prodromus Systematis Mammalian et Avium Additis Terminis Zoographicis Utriusque Classis, Eorumque Versione Germanica. Berlin: Sumptibus C. Salfeld.

- 1811b. Ueberblick der säugthiere nach ihrer vertheilung über die welttheile. Abhandlungen der KöniglichPreussischen Akademie der Wissenschaften zu Berlin, 1804-1811:39-159.

International Commission on Zoological Nomenclature. 1963. Opinion 678. The Suppression under the Plenary Powers of the Pamphlet Published by Meigen, 1800. Bulletin of Zoological Nomenclature, 20:339-342.

- 1995. Comments on the Proposed Conservation of Some Mammal Generic Names First Published in Brisson's (1762) Regnum Animale. Case 2928. Bulletin of Zoological Nomenclature, 52:78-93.

. 1998. Opinion 1894. Regnum Animals, Ed. 2 (M. J. Brisson, 1762): Rejected for Nomenclatural Purposes with the Conservation of the Mammalian Generic Names Philander (Marsupialia), Pteropus (Chiroptera), Glis, Cuniculus and Hydrochoerus (Rodentia), Meles, Lutra and Hyaena (Carnivora), Tapirus (Perrissodactyla), Tragulus and Giraffa (Artiodactyla). Bulletin of Zoological Nomenclature, 55:64-71.

-1999. International Code of Zoological Nomenclature. 4th ed. London: The Natural History Museum.

Iredale, T., and E. Le G. Troughton. 1934. A Check-list of the Mammals Recorded from Australia. Memoirs of Australian Museum, 6:1-122.

Jackson, S. M. 2011. Petaurus gracilis. Mammalian Species, 43(882): 141-148.

Jackson, S. M., and P. Schouten. 2012. Gliding Mammals of the World. Melbourne: CSIRO Publishing.

Jaeger, J. J., C. Denys, and B. Coiffait. 1985. "New Phiomorpha and Anomaluridae from the Late Eocene of North-west Africa: Phylogenetic Implications.” In Evolutionary Relationships among Rodents: A Multidisciplinary Analysis, ed. P. W. Luckett and J. L. Hartenberger, pp. 567-588. New York: Plenum Press.

James, G. T. 1963. Paleontology and Nonmarine Stratigraphy of the Cuyama Valley Badlands California. Part 1. Geology, Faunal Interpretations, and Systematic Descriptions of Chiroptera, Insectivora, and Rodentia. University of California Publications in Geological Science, 45:1-154.

Janečka, J. E., K. M. Helgen, N. T. Lim, M. Baba, M. Izawa, Boeadi, and W. J. Murphy. 2008. Evidence for Multiple Species of Sunda Colugo. Current Biology, 18(21):R1001R1002.

Janečka, J. E., W. Miller, T. H. Pringle, F. Wiens, A. Zitzmann, K. M. Helgen, M. S. Springer, and W. J. Murphy. 2007. Molecular and Genomic Data Identify the Closest Living Relative of Primates. Science, 318:792-794.

Jenkins, P., and J. E. Hill. 1982. Mammals from Siberut, Mentawei Islands. Mammalia, 46:219-224. 
Jentink, F. A. 1888. On a Collection of Mammals from East Sumatra. Notes of the Leydon Museum, 11:17-30.

- 1890a. On a New Flying Squirrel from Deli, Sumatra. Notes of the Leyden Museum, 12:145-148.

- 1890b. On a Collection of Mammals from Billiton. Notes of the Leyden Museum, 12:149-152.

- 1897. Zoological Results of the Dutch Scientific Expedition to Central Borneo. Notes of the Leyden Museum, 19:26-126.

Jerdon, T. C. 1847. “Sc. fuscocapillus.” In Supplementary Report by the Curator, Zoological Department. E. Blyth, pp. 867. Journal of the Asiatic Society of Bengal, 16:861-880.

- 1874. The Mammals of India. London: John Wheldon.

Johnson, D. J. 1964. "Mammals of the Arnhem Land Expedition." In Records of the American-Australian Scientific Expedition to Arnhem Land. Volume 4, ed. R. L. Specht, pp. 427-515. Melbourne: Melbourne University Press.

Jones, F. W. 1923. The Mammals of South Australia. Adelaide: Government Printer.

Jones, G. S. 1975. Catalogue of the Type Specimens of Mammals of Taiwan. Quarterly Journal of the Taiwan Museum, 28:183-217.

Jones, J. K., Jr., and D. H. Johnson. 1965. Synopsis of the Lagomorphs and Rodents of Korea. University of Kansas Publications, Museum of Natural History, 16:357-407.

Jordan, D. S. 1903. Correspondence. The American Naturalist, 37:360.

Kaneko, Y., and K. Maeda. 2002. A List of Scientific Names and the Types of Mammals Published by Japanese Researchers. Mammalian Science, 42:1-21.

Kaup, J. J. 1829. Skizzirte Entwickelungs-Geschichte und natürliches System der Europäischen Thierwelt: Erster Theil welcher die Vogelsängethiere und Vögel, nebst Andeutung der Entstehung der letzteren aus Amphibien enthält. Darmstadt: Carl Wilhelm Leske.

Kawamura, Y. 1981. Mammalian Remains of the Pre-Jomon Period from Taishaku-Kannondo Cave Site (Part 2). Mammalian Remains Obtained by the Excavation of 1976. [In Japanese.] Annual Bulletin of Hiroshima University Taishaku-kyo Sites Research Centre, 4:67-88.

- 1982. Mammalian Remains of the Pre-Jomon Period from Taishaku-Kannondo Cave Site (Part 3). Mammalian Remains Obtained by the Excavation of 1978. [In Japanese.] Annual Bulletin of Hiroshima University Taishakukyo Sites Research Centre, 5:57-70.

- 1988. Quaternary Rodents Faunas in the Japanese Islands (Part 1). Memoirs of the Faculty of Science, Kyoto University, Series of Geology and Mineralogy, 53:31-348.

Kawamura, Y., T. Kamei, and H. Taruno. 1989. Middle and Late Pleistocene Faunas in Japan. The Quaternary Research, 28:317-326.

Kawamura, Y., Y. Yamada, and Y. Ando. 1986. Late Pleistocene Micro-mammals from Taishaku-Kannondo Cave Site (First Preliminary Report). [In Japanese.] Annual Bulletin of Hiroshima University Taishaku-kyo Sites Research Centre, 9:67-85.

Kay, R. F., R. W. Thorington Jr., and P. Houde. 1990. Eocene Plesiadapiform Shows Affinities with Flying Lemurs Not Primates. Nature, 345:342-343.
Kear, B. P., and B. N. Cooke. 2001. A Review of Macropodoid (Marsupialia) Systematics with the Inclusion of a New Family. Memoirs of the Association of Australasian Palaeontologist, 25:83-101.

Kelaart, E. F. 1850. Description of New Species and Varieties of Mammals Found in Ceylon. Journal of the Ceylon Branch of the Royal Asiatic Society, 2:208-215. (Reprinted 1890, pp. 321-328.)

Kerr, R. 1792. The Animal Kingdom, or Zoological System, of the Celebrated Sir Charles Linnaeus; Class1. Mammalia, Containing a Complete Systematic Description, Arrangement, and Nomenclature, of All the Known Species and Varieties of the Mammalia, or Animals Which Give Suck to Their Young; Being a Translation of That Part of the Systema Naturae, as Lately Published, with Great Improvements, by Professor Gmelin of Goettingen. Together with Numerous Additions from More Recent Zoological Writers, and Illustrated with Copper Plates. Volume 1. London: J. Murray \& R. Faulder.

Kingdon, J. 1997. The Kingdon Field Guide to African Mammals. London: Academic Press.

Kinman, K. E. 1994. The Kinman System: Toward a Stable Cladistic-Eclectic Classification of Organisms (Living and Extinct; 48 Phyla, 269 Classes, 1,719 Orders). Hays, Kans.: Author.

Kirsch, J. A. W. 1968. Prodromus of the Comparative Serology of Marsupialia. Nature, 217:418-420.

- 1977a. The Comparative Serology of Marsupialia, and a Classification of Marsupials. Australian Journal of Zoology, Supplement Series, 52:1-152.

- 1977b. "The Classification of the Marsupials." In The Biology of the Marsupials, ed. D. Hunsaker II, pp. 1-50. New York: Academic Press.

Kirsch, J. W., and J. H. Calaby. 1977. "The Species of Living Marsupials: An Annotated List." In The Biology of Marsupials, ed. B. Stonehouse and D. Gilmore, pp. 9-26. London: Macmillan.

Kirsch, J. A. W., J.-F. Lapointe, and M. S. Springer. 1997. DNAHybridisation Studies of Marsupials and Their Implications for Metatherian Classification. Australian Journal of Zoology, 45:211-280.

Kloss, C. B. 1916. On a New Race of Flying Squirrel from Siam. Journal of the Natural History Society of Siam, 2:33-36.

- 1921. Seven New Malayan Mammals. Journal of the Federal Malayan States Museum, 10:229-234.

Koh, H. S., Y. Jin, B. G. Yang, B. K. Lee, S. W. Heo, and K. H. Jang. 2008. Taxonomic Status of Siberian Flying Squirrel from Korea (Pteromys volans aluco Thomas 1907). The Korean Journal of Systematic Zoology, 24(2):169-172.

Kowalski, K., and Y. Hasegawa. 1976. Quaternary Rodents from Japan. Bulletin of the National Science Museum, Series $C$, Geology, 2(1):31-66.

Krause, D. W. 1991. Were Paromomyids Gliders? Maybe, Maybe Not. Journal of Human Evolution, 21:177-188.

Krefft, G. 1871. The Mammals of Australia. Sydney: Thomas Richards.

Kretzoi, M. 1959. Insectivoren, Nagetiere und Lagomorphen der jungstpliozanen Fauna von Csarota im Villanye Gebirge (Sudungarn). Vertebrata Hungarica, 1(2):237-246. 
Kretzoi, M. 1962. Fauna und Faunenhorizont von Csarnota. Jahresbericht der Ungarischen Geologischn Anstalt, 1962:344-395.

Kriegs, J. O., G. Churakov, J. Jurka, J. Brosius, and J. Schmitz. 2007. Evolutionary History of 7SL RNA-Derived SINEs in Supraprimates. Trends in Genetics, 23:158-161. http:// dx.doi.org/10.1016/j.tig.2007.02.002.

Kuhn, H.-J. 1965. A Provisional Check-list of the Mammals of Liberia. Senckenbergiana Biologica, 46:321-340.

Kuntz, A., and D. E. Ming. 1970. Vertebrates in Taiwan Taken for Parasitological and Biomedical Studies by U. S. Naval Medical Research Unit No. 2, Taipei, Taiwan, Republic of China. Quarterly Journal of the Taiwan Museum, 23:1-37.

Kuroda, N. 1921. On Three New Mammals from Japan. Journal of Mammalogy, 2:208-211. http://dx.doi.org/10.2307/ 1373554.

1938. A List of Japanese Mammals. Tokyo: Author.

. 1940. A Monograph of the Japanese Mammals. Tokyo: Sanseido.

- 1941. Descriptions of Two Apparently New Forms of Mammals from Saghalien and S. W. Hondo, Japan. Bulletin of the Biogeographical Society of Japan, 11:113-115.

Kuroda, N., and T. Mori. 1923. Two New and Rare Mammals from Korea. Journal of Mammalogy, 4:27-28. http://dx.doi .org/10.2307/1373526.

Kurtén, B., and E. Anderson. 1980. Pleistocene Mammals of North America. New York: Columbia University Press.

Lacépède, B. G. É. 1801. Mémoire sur une nouvelle table méthodique des animaux a mammelles. Mémoires de l'Institut des Sciences et Arts, Paris, 3:469-502.

Landry, S. O., Jr. 1999. A Proposal for a New Classification and Nomenclature for the Glires (Lagomorpha and Rodentia). Mitteilungen aus dem Museum fur Naturkunde in Berlin, Zoologischen Reibe, 75:283-316.

Lartet, E. 1851. Notice sur la colline de Sansan, suivie d'une récapitulation des diverses espèces d'animaux vertébrés fossiles, trouvés soit à Sansan, soint dans d'autres gisements du terrain tertiare miocène dans le Bassin Sous-Pyrénéen. Auch, France: J.-A. Portes.

Latreille, P. A. 1827. Natürliche Familien des Thierreichs. Aus dem Französischen mit Anmerkungen und Zusätzen von A. A. Berthold. Weimar, Germany: Im Verlage des Gr. H. S. priv. Landes-Industrie-Comptoirs.

Laurenti, J. N. 1768. Specimen Medicum, Exhibens Synopsin Reptilium Emendatam cum Experimentis circa Venena et Antidota Reptilium Austracorum, quod Authoritate et Consensu. Vienna: Joan Thomae.

Laurie, E. M. O., and J. E. Hill. 1954. List of Land Mammals of New Guinea, Celebes and Adjacent Islands 1758-1952. London: British Museum.

Lavocat, R. 1973. Les rongeurs du Miocene d'Afrique orientale. 1. Miocene inferieur. Mémoires et Travaux de l'Institut de Montpellier de l'Ecole Pratique des Hautes Etudes, Montpellier, 1:1-284.

Lee, P.-F., D. R. Progulke, and Y. S. Lin. 1986. Ecological Studies on Two Sympatric Petaurista Species in Taiwan. Bulletin of the Institute of Zoology, Academia Sinica, 25:113-24.

Le Gros Clark, W. E. 1927. Exhibition of Photographs of the Tree Shrew (Tupaia minor): Remarks on the Tree Shrew, Tupaia minor, with Photographs. Proceedings of the Zoological Society of London, 1927:254-256.
Lekagul, B., and J. A. McNeely. 1988. Mammals of Thailand. Bangkok: Association for the Conservation of Wildlife.

Lesson, R. P. 1827. Manuel de mammalogie, ou histoire naturelle des mammifères. Paris: Roret.

. 1840. Species des mammifères bimanes et quadrimanes. Paris: Bailliere.

. 1842. Nouveau tableau du règne animal: mammifères. Paris: Arthus Bertrand.

Lewin, J. 1808. Birds of New Holland with Their Natural History. London: White \& Bagster.

Lim, N. 2007. Colugo: The Flying Lemur of South-east Asia. Singapore: Draco Publishing.

Lin, Y. H., P. J. Waddell, and D. Penny. 2002. Pika and Vole Mitochondrial Genomes Increase Support for Both Rodent Monophyly and Glires. Gene, 294:119-129. http://dx.doi .org/10.1016/S0378-1119(02)00695-9.

Lindsay, E. H. 1972. Small Mammal Fossils from the Barstow Formation, California. University of California Publications in Geological Sciences, 93:1-104.

Lindsay, H. M. 1929. A New Flying Squirrel from Nepal. Journal of the Bombay Natural History Society, 33:565-569.

Link, H. F. 1795. Beiträge zur Naturgeschichte. Volume 1, Part 2: Ueber die Lebenskräfte in Naturhistorisher Rücksicht und die Klassifikation der Säugethiere. Rostock, Germany. [Publisher unknown.]

Linnaeus, C. 1758. Systema Naturae per Regna tria Naturae. Secundum Classes, Ordines, Genera, Species cum Characteribus, Differentis, Synonymis, Locis, 10th ed., revised, Volume 1: Regnum Animale. Stockholm: Laurentii Salvii.

- 1766. Systema Naturae per Regna Tria Naturae, 12th ed., revised, Volume 1: Regnum Animale. Stockholm: Laurentii Salvii.

Liu, F.-G. R., and M. M. Miyamoto. 1999. Phylogenetic Assessment of Molecular and Morphological Data for Eutherian Mammals. Systematic Biology, 48:54-64. http://dx.doi.org/ 10.1080/106351599260436.

Liu, F.-G. R., M. M. Miyamoto, N. P. Freire, P. Q. Ong, M. R. Tennant, T. S. Young, and K. F. Gugel. 2001. Molecular and Morphological Supertrees for Eutherian (Placental) Mammals. Science, 291:1786-1789. http://dx.doi.org/10.1126/ science. 1056346.

Long, J., M. Archer, T. Flannery, and S. Hand. 2002. Prehistoric Mammals of Australia and New Guinea: One Hundred Million Years of Evolution. Sydney: University of New South Wales Press.

Longman, H. A. 1924. [Untitled abstract.] Proceedings of the Royal Society of Queensland, 36:ix.

Lönnberg, E. 1917. Mammals Collected in Central Africa by Captain E. Arrhenius. Kungliga Svenska VetenskapsAkademiens, Handlingar, Stockholm, 58(2):1-110.

Lucas, S. G. 1986. Taxonomic Status of Oxyacodon tecumsae, a Paleocene Mammal from the San Juan Basin, New Mexico. New Mexico Journal of Science, 26:39-40.

Lydekker, R. 1887. Catalogue of the Fossil Mammalia in the British Museum (Natural History). Part V. Containing the Group Tillodontia, the Orders Sirenia, Cetacea, Edentata, Marsupialia, Monotremata, and Supplement. London: British Museum (Natural History).

1895. On the Affinities of the So-Called Extinct Giant Dormouse of Malta. Proceedings of the Zoological Society of London, 1895:860-863. 
Lyon, M. W. 1907a. A New Flying Squirrel from the Island of Terutau, West Coast of Malay Peninsula. Proceedings of the Biological Society of Washington, 20:17-18.

- 1907b. Notes on a Small Collection of Mammals from the Province of Kan-Su, China. Smithsonian Miscellaneous Collections, 50:133-138.

- 1908. On a Collection of Mammals from the Batu Islands, West Sumatra. Annals and Magazine of Natural History, 8th ser., 1:137-140.

-1909. Additional Notes on Mammals of the Rhio-linga Archipelago, with Descriptions of New Species and a Revised List. Proceedings of the United States National Museum, 36:479-491.

- 1911. Mammals Collected by Dr W. L. Abbott on Borneo and Some Small Adjacent Islands. Proceedings of the United States National Museum, 40:53-146.

Macdonald, J. R. 1963. The Miocene Faunas from the Wounded Knee Area of Western South Dakota. Bulletin of the American Museum of Natural History, 125:139-238.

- 1970. Review of the Miocene Wounded Knee Faunas of Southwestern South Dakota. Bulletin of the Los Angeles County Museum of Natural History, Science, 8:1-82.

Madsen, O., M. Scally, C. J. Douady, D. J. Kao, R. W. de Bry, R. M. Adkins, H. M. Amrine, M. J. Stanhope, W. W. de Jong, and M. S. Springer. 2001. Parallel Adaptive Radiations in Two Major Clades of Placental Mammals. Nature, 409:610-614. http://dx.doi.org/10.1038/35054544.

Major, C. J. F. 1873. Nagerüberreste aus Bohnerzen Süddeutschlands und der Schweiz, Palaeontographica, 22:75-130.

- 1893. On Some Miocene Squirrels, with Remarks on the Dentition and Classification of the Sciurinae. Proceedings of the Zoological Society of London, 1893:179-215.

Malekian, M., S. J. B. Cooper, J. A. Norman, L. Christidis, and S. M. Carthew. 2009. Molecular Systematics and Evolutionary Origins of the Genus Petaurus (Marsupialia: Petauridae) in Australia and New Guinea. Molecular Phylogenetics and Evolution, 54:122-135. http://dx.doi.org/10.1016/j .ympev.2009.07.026.

Marivaux, L., L. Bocat, Y. Chaimanee, J.-J. Jaeger, B. Marandat, P. Srisuk, P. Tafforeau, C. Yamee, and J. L. Welcomme. 2006. Cynocephalid Dermopterans from the Paleogene of South Asia (Thailand, Myanmar and Pakistan): Systematic, Evolutionary and Palaeobiogeographic Implications. Zoologica Scripta, 35:395-420. http://dx.doi.org/10.1111/ j.1463-6409.2006.00235.x.

Marivaux, L., S. Ducrocq, J.-J. Jaeger, B. Marandat, J. Sudre, Y. Chaimanee, S. T. Tun, W. Htoon, and A. N. Soe. 2005. New Remains of Pondaungimys anomaluropsis (Rodentia, Anomaluridae) from the Latest Middle Eocene Pondaung Formation of Central Myanmar. Journal of Vertebrate Paleontology, 25:214-227. http://dx.doi.org/10.1671/0272 -4634(2005)025[0214:NROPAR]2.0.CO;2.

Marivaux, L., and J.-L. Welcomme. 2003. New Diatomyid and Baluchimyine Rodents from the Oligocene of Pakistan (Bugti, Balochistan): Systematic and Paleobiogeographic Implications. Journal of Vertebrate Paleontology, 23:420-434. http://dx.doi.org/10.1671/0272-4634(2003)023[0420:ND ABRF]2.0.CO;2.

Marlow, B. J. 1965. Marsupials of Australia. Brisbane: Jacaranda Press.
Marshall, L. G. 1981. The Families and Genera of Marsupialia. Fieldiana Geology, n.s., 8:1-65.

- 1984. "Monotremes and Marsupials." In Orders and Families of Recent Mammals of the World, ed. S. Anderson and J. Knox Jones, pp. 57-115. New York: John Wiley \& Sons.

Marshall, L. G., J. A. Case, and M. O. Woodburne. 1990. "Phylogenetic Relationships of the Families of Marsupials." In Current Mammalogy, ed. H. H. Genoways, pp. 433-505. New York: Plenum Press.

Martin, R. D. 1990. Primate Origins and Evolution. Princeton: Princeton University Press.

Matschie, P. 1894. Neue Säugethiere aus den sammlungen der herren Zenker, Neumann, Stuhlmann und Emin. SitzungsBerichte der Gesellschraft Naturforschender Freunde zu Berlin, 8:194-202.

- 1898. Eine neue mit Idiurus Mtsch. verwandte Gattung der Nagethiere. Sitzungs-Berichte der Gesellschraft Naturforschender Freunde zu Berlin, 4:23-30.

- 1908. "Mammalia. Über Chinesische Säugetiere, bosonders aus den Sammlungen des Herren Wilhelm Filchner." In Wissenschaftliche Ergebnisse der Expedition Filchner nach China und Tibet 1903-1905. Volume 10, Part 1, pp. 134-244. Berlin: Ernst Siegfried Mittler und Sohn.

- 1914. Ein neuer Anomalurus von der Elfenbeinkuste. Sitzungs-Berichte der Gesellschraft Naturforschender Freunde zu Berlin, 1914:349-351.

- 1916. Die Verbreitung der Beuteltiere auf Neuguinea mit Einigen Bemerkungen über Ihre Einteilung in Untergattungen. Mitteilungen aus dem Zoologischen Museum in Berlin, 8:257-308.

Matthew, W. D. 1918. A Revision of the Lower Eocene Wasatch and Wind River Faunas. Part 5. Insectivora (Continued), Glires, Edentata. Bulletin of the American Museum of Natural History, 38:565-657.

Maxwell, S., A. A. Burbidge, and K. Morris, eds. 1996. The 1996 Action Plan for Australian Marsupials and Monotremes. Endangered Species Program, Project Number 500. Canberra: Wildlife Australia.

McAllan, I. A. W., and M. D. Bruce. 1989. Some Problems in Vertebrate Nomenclature. I. Mammals. Bollettino del Museo Regionale di Scienze Naturali di Torino, 7:443460.

McKay, G. M. 1982. Nomenclature of the Gliding Possum Genera Petaurus and Petauroides (Marsupialia: Petauridae). Australian Mammalogy, 5:37-39.

-. 1988a. "Petauridae." In Zoological Catalogue of Australia. Volume 5: Mammalia, ed. D. W. Walton, pp. 87-97. Canberra: Australian Government Publishing Service.

—. 1988b. "Burramyidae." In Zoological Catalogue of Australia. Volume 5: Mammalia, ed. D. W. Walton, pp. 98-102. Canberra: Australian Government Publishing Service.

McKenna, M. C. 1962. Eupetaurus and the Living Petauristine Sciurids. American Museum Novitates, 2104:1-38.

— 1975. "Toward a Phylogenetic Classification of the Mammalia." In Phylogeny of the Primates: A Multidisciplenary Approach, ed. W. P. Luckett and F. S. Szalay, pp. 21-46. New York: Plenum Press.

- 1990. Plagiomenids (Mammalia: ?Dermoptera) from the Oligocene of Oregon, Montana, and South Dakota, and 
Middle Eocene of Northwestern Wyoming. Geological Society of America Special Paper, 243:211-234.

. 1993. In R. K. Stucky and M. C. McKenna. "Mammalia.” In The Fossil Record 2, ed. M. J. Benton, pp. 739-771. London: Chapman \& Hall.

McKenna, M. C., and S. K. Bell. 1997. Classification of Mammals above the Species Level. New York: Columbia University Press.

Mearns, E. A. 1898. Notes on the Mammals of the Catskill Mountains, New York, with General Remarks on the Fauna and Flora of the Region. Proceedings of the United States National Museum, 21:341-360.

Medway, L. 1965. Mammals of Borneo: Field Keys and an Annoted Checklist. Kuala Lumpur: Perchetakan.

- 1969. The Wild Mammals of Malaya. London: Oxford University Press.

- 1977. Mammals of Borneo. Field Keys and an Annoted Checklist. 2nd ed. Monographs of the Malaysian Branch of the Royal Asiatic Society, No. 7. Kuala Lumpur: Malaysian Branch of the Royal Asiatic Society.

Mees, G. F. 1957. Over het belang Van Temminck's "Discours Préliminaire" voor de zoölogische nomenclator. Zoölogische Mededelingen, 35:205-227.

Meigen, J. W. 1800. Nouvelle classification des mouches à deux ailes, (Diptera L.), d'après un plan tout nouveau, \&́c. Paris. [Publisher unknown.]

- 1803. Versuch einer neuen Gattungs Eintheilung der europäischen zweiflügligen Insekten. Magazin für Insektenkunde, 2:259-281.

Meijaard, E. 2003. Mammals of South-east Asian Islands and Their Late Pleistocene Environments. Journal of Biogeography, 30:1245-1257. http://dx.doi.org/10.1046/j.1365 2699.2003.00890.x.

Mein, P. 1958. Les mammifères de la faune sidérolithique de Vieux-Collonges. Nouvelles Archives du Museum d'Histoire Naturelle de Lyon, 5:1-122.

- 1970. Les Sciuropteres (Mammalia, Rodentia) Neogenes d'Europe occidentale. Geobios, 3:7-77. http://dx.doi .org/10.1016/S0016-6995(70)80001-8.

Mein, P., and J.-P. Romaggi. 1991. A Flying Glirid (Mammalia, Rodentia) in the Upper Miocene of Ardeche; an Unknown Adaptation in the Recent Fauna. Geobios, 24(Suppl. 1):4550. http://dx.doi.org/10.1016/S0016-6995(66)80008-6.

Melville, R. V. 1977. Opinion 1077 Refusal of Request to Use the Plenary Powers to Suppress the Generic Name Cynocephalus Boddaert, 1768 (Mammalia). Bulletin of Zoological Nomenclature, 33:182-184.

Meng, J. 2004. Phylogeny and Divergence of Basal Glires. Bulletin of the American Museum of Natural History, 285: 93-109. http://dx.doi.org/10.1206/0003-0090(2004)285 $<0093$ :C $>2.0 . \mathrm{CO} ; 2$.

Meng, J., Y. Hu, and C. Li. 2003. The Osteology of Rhombomylus (Mammalia, Glires): Implications for Phylogeny and Evolution of Glires. Bulletin of the American Museum of Natural History, 275:1-247. http://dx.doi.org/10.1206/0003 -0090(2003)275<0001:TOORMG>2.0.CO;2.

Meng, J., Y. Hu, Y. Wang, X. Wang, and C. Li. 2006. A Mesozoic Gliding Mammal from Northeastern China. Nature, 444:889-893. http://dx.doi.org/10.1038/nature05234.
Meng, J., and A. R. Wyss. 2001. The Morphology of Tribosphenomys (Rodentiaformes, Mammalia): Phylogenetic Implications for Basal Glires. Journal of Mammalian Evolution, 8:1-71. http://dx.doi.org/10.1023/A:1011328616715.

Merriam, C. H. 1897. Description of a New Flying Squirrel from Ft. Klamath, Oregon. Proceedings of the Biological Society of Washington, 11:225.

-1900. Description of Two New Mammals from California. Proceedings of the Biological Society of Washington, 13:151-152.

Meyer, F. A.A. 1793. Systematische-summarische Uebersicht der Neuesten Zoologischen Entdeckungen in Neuholland und Afrika. Nebst Zwey Andern Zoologischen Abhandlungen. Leipzip: Dykischen Buchhandlung.

Miller, G. S. 1898. Description of a New Rodent of the Genus Idiurus. Proceedings of the Biological Society of Washington, 12:73-76, figs. 15-18.

. 1903a. Seventy New Malayan Mammals. Smithsonian Miscellaneous Collections, 45:1-73.

- 1903b. Mammals Collected by Dr. W. L. Abbott on the Coast and Islands of Northwest Sumatra. Proceedings of the United States National Museum, 26:437-483.

- 1906a. The Nomenclature of the Flying Lemurs. Proceedings of the Biological Society of Washington, 19:41.

- 1906b. The Mammals Collected by Dr W. L. Abbott in the Rhio-Linga Archipelago. Proceedings of the United States National Museum, 31:247-266.

-1912. Catalogue of the Mammals of Western Europe (Europe Exclusive of Russia) in the British Museum. London: British Museum (Natural History).

- 1913. Fifty-One New Malayan Mammals. Smithsonian Miscellaneous Collections, 61(21):1-30.

- 1914. The Generic Name of the Common Flying Squirrels. Proceedings of the Biological Society of Washington, 27:216.

-1918. A New Flying-Squirrel from Eastern Asia. Proceedings of the Biological Society of Washington, 31:3-4.

- 1936. A New Flying Squirrel from West Virginia. Proceedings of the Biological Society of Washington, 49:143144.

Miller, G. S., and J. W. Gidley. 1918. Synopsis of the Supergeneric Groups of Rodents. Journal of the Washington Academy of Sciences, 8:431-448.

Milne-Edwards, A. 1867. Observations sur quelques mammifères du nord la Chine. Annales des Sciences Naturelles, Zoologie, 8(5):374-376.

- 1870. Note sur quelques mammifères du Tibet oriental. Compte Rendus Academie des Sciences Paris, 70:341-342.

- 1872. "Memoire sur la fauna mammalogique du Tibet oriental." In Recherches pour servir à l'histoire naturelle des mammifères, ed. H. Milne-Edwards and A. Milne-Edwards, pp. 231-304. Paris: Masson.

- 1879. Note sur une nouvelle espèce du genre Anomalurus. Compte Rendus Academie des Sciences Paris, 79:771772 .

Misawa, K., and A. Janke. 2003. Revisiting the Glires Concept-Phylogenetic Analysis of nuclear Sequences. Molecular Phylogenetics and Evolution, 28:320-327. http://dx.doi .org/10.1016/S1055-7903(03)00079-4. 
Misonne, X. 1974. "Order Rodentia. Part 6." In The Mammals of Africa: An Identification Manual, ed. J. Meester and H. W. Setzer, pp. 1-39. Washington, D.C.: Smithsonian Institution Press.

Mitchell, R. M. 1979. The Sciurid Rodents (Rodentia: Sciuridae) of Nepal. Journal of Asian Ecology, 1:21-28.

Mitchell, T. L. 1838. Three Expeditions into the Interior of Eastern Australia; with Descriptions of the Recently Explored Region of Australia Felix, and of the Present Colony of New South Wales. Volume 1. London: T. and W. Boone.

Mitchell-Jones, A. J., G. Amori, W. Bogdanowicz, B. Krystufek, P. J. H. Reijnders, F. Spitzenberger, M. Stubbe, J. B. M. Thissen, V. Vohralik, and J. Zima. 1999. The Atlas of European Mammals. London: T. \& A. D. Poyser.

Mori, T. 1923. New Name for a Korean Flying Squirrel. Journal of Mammalogy, 4:191.

- 1927. On Three New Mammals from Manchuria. Annotationes Zoologicae Japonenses, 11(2):107-109.

- 1939. "Mammalia of Jehol and District North of It." In Report of the First Scientific Expedition to Manchoukuo under the Leadership of Shigeyasu. June-October 1933, Section 5, Division 2, Part 4, pp. 1-84.

-1942. Land Mammals of Manchuria. Xinjiang: Mainland Academy of Sciences.

Motley, J., and L. L. Dillwyn. 1855. Contributions to the Natural History of Labuan and the Adjacent Coasts of Borneo. London: J. Van Voorst.

Muirhead, L. 1819. “Mazology.” In The Edinburgh Encyclopaedia. 4th ed. Volume 13, ed. D. Brewster, pp. 393-480. Edinburgh: William Blackwood.

Müller, S. 1840. "Over de zoogdieren van den Indischen Archipel." In Verhandelingen over de Natuurlijke Geschiedenis der Nederlandsche Overzeesche Bezittingen. Volume 1, Part 1, ed. C. J. Temminck, pp. 9-57. Leiden. [Publisher unknown.]

Murphy, W. J., E. Eizirik, W. E. Johnson, Y. P. Zhang, O. A. Ryder, and S. J. O'Brien. 2001a. Molecular Phylogenetics and the Origins of Placental Mammals. Nature, 409:614618. http://dx.doi.org/10.1038/35054550.

Murphy, W. J., E. Eizirik, S. J. O’Brien, O. Madsen, M. Scally, C. J. Douady, E. Teeling, O. A. Ryder, M. J. Stanhope, W. W. de Jong, and M. S. Springer. 2001b. Resolution of the Early Placental Mammal Radiation Using Bayesian Phylogenetics. Science, 294:2348-2351. http://dx.doi.org/10.1126/ science. 1067179 .

Murray, A. 1866. The Geographic Distribution of Mammals. London: Day \& Son.

Musser, G. G. 1961. A New Subspecies of Flying Squirrel Glaucomys sabrinus from Southwestern Utah. Proceedings of the Biological Society of Washington, 74:119-125.

Muul, I. 1980. An Additional Specimen of the Squirrel, Petinomys vordermanni, in Thailand. Natural History Bulletin of the Siam Society, 28:135-136.

Muul, I., and K. Thonglongya. 1971. Taxonomic Status of Petinomys morrisi (Carter) and Its Relationship to Petinomys setosus (Temminck and Schlegel). Journal of Mammalogy, 52:362-369. http://dx.doi.org/10.2307/1378678.

Nelson, E. W. 1904. Descriptions of New Squirrels from Mexico. Proceedings of the Biological Society of Washington, 17:147-150.
Newman, E. 1843. The System of Nature: An Essay. 2nd ed. London: J. Van Voorst.

Ni, X., J. Meng, K. C. Beard, D. L. Gebo, Y. Wang, and C. Li. 2010. A New Tarkadectine Primate from the Eocene of Inner Mongolia, China: Phylogenetic and Biogeographic Implications. Proceedings of the Royal Society B: Biological Sciences, 277(1679):247-256. http://dx.doi.org/10.1098/ rspb.2009.0173.

Nicholson, H. A. 1880. Manual of Zoology for the Use of Students: With a General Introduction on the Principles of Zoology. Edinburgh: William Blackwood and Sons.

Novacek, M. J., and A. R. Wyss. 1986. Higher-Level Relationships of Recent Eutherian Orders: Morphological Evidence. Cladistics, 2:257-287. http://dx.doi.org/10.1111/j.1096-0031 .1986.tb00463.x.

Ogilby, J. D. 1892. Catalogue of Australian Mammalia, with Introductory Notes on General Mammalogy. Sydney: Australian Museum.

Ogilby, W. 1837. Observations on the Opposable Power of the Thumb in Certain Mammals, Considered as a Zoological a Character; and on the Natural Affinities Which Subsist between the Bimana, Quadrumana, and Pedimana. The Magazine of Natural History, 1:449-459.

Ognev, S. I. 1934. Review of the Flying Squirrels (Pteromys) Living in USSR. Bulletin de la Société des Naturalistes de Moscou, 43:303-315.

- 1940. Zveri SSSR i prilezhashchikh stran: Gryzuny (Zveri vostochnoi Evropy i severnoi Azii). [Mammals of the USSR and Adjacent Countries: Rodents (Mammals of Eastern Europe and Northern Asia).] Akademiya Nauk SSSR, 4:1-615. - 1966. Mammals of the USSR and Adjacent Countries: Mammals of Eastern Europe and Northern Asia. Volume 4: Rodents. Translated from Russian. Jerusalem: Israel Program for Scientific Translation.

Ognev, S. J. 1929. Über einige Nagetiere Ostsibiriens. Zoologischer Anzeiger, 83:71-89.

Ohdachi, S. D., Y. Ishibashi, M. A. Iswasi, and T. Saitoh, eds. 2009. The Wild Mammals of Japan. Kyoto: Shoukadoh.

Oken, L. 1816. Lehrbuch der Naturgeschichte. Volume 3: Zoologie. Part 2. Jena: Schmid und Co.

- 1847. Elements of Physiophilosophy. Translated from German by Alfred Tulk. London: Ray Society.

Olson, L. E., E. J. Sargis, and R. D. Martin. 2005. Intraordinal Phylogenetics of Treeshrews (Mammalia: Scandentia) Based on Evidence from the Mitochondrial 12S rRNA Gene. Molecular Phylogenetics and Evolution, 35:656-673. http:// dx.doi.org/10.1016/j.ympev.2005.01.005.

Osborn, H. F. 1902. American Eocene Primates and the Supposed Rodent Family Myxodectidae. Bulletin of the American Museum of Natural History, 16:169-214.

- 1910. The Age of Mammals in Europe, Asia and North America. New York: Macmillan.

Osborne, M. J., and L. Christidis. 2001. Molecular Phylogenetics and Australo-Papuan Possums and Glider (Family Petauridae). Molecular Phylogenetics and Evolution, 20:211-224. http://dx.doi.org/10.1006/mpev.2001.0960.

Osgood, W. H. 1900. Results of a Biological Reconnaissance of the Yukon River Region. North American Fauna, 19:1-100. http://dx.doi.org/10.3996/nafa.19.0001. 
1905. A New Flying Squirrel from the Coast of Alaska. Proceedings of the Biological Society of Washington, 18:133-134.

- 1918. A New Flying Squirrel from the Philippine Islands. Proceedings of the Biological Society of Washington, 31:1-2.

- 1932. Mammals of Kelley-Roosevelts and Delacour Asiatic Expeditions. Field Museum of Natural History, Zoological Series, 18:193-339.

Oshida, T. 2006. Is There an Evolutionary Relict of the Japanese Giant Flying Squirrel Petaurista leucogenys on the Asian Continent? Mammal Study, 31:69-72. http://dx.doi .org/10.3106/1348-6160(2006)31[69:ITAERO]2.0.CO;2.

Oshida, T., C. N. Dang, S. T. Nguyen, N. X. Nguyen, H. Endo, J. Kimura, M. Sasaki, A. Hayashida, A. Takano, and Y. Hayashi. 2010. Phylogenetics of Petaurista in Light of Specimens Collected from Northern Vietnam. Mammal Study, 35:85-91. http://dx.doi.org/10.3106/041.035.0107.

Oshida, T., L.-K. Lin, S.-W. Chang, Y.-J. Chen, and J. K. Lin. 2011. Phylogeography of Two Sympatric Giant Flying Squirrel Subspecies, Petaurista alborufus lena and P. philippensis grandis (Rodentia: Sciuridae), in Taiwan. Biological Journal of the Linnean Society, 102:404-419. http://dx.doi .org/10.1111/j.1095-8312.2010.01576.x,

Oshida, T., L-K. Lin, H. Yanagawa, H. Endo, and R. Masuda. 2000a. Phylogenetic Relationships Among Six Flying Squirrel Genera, Inferred from Mitochondrial Cytochrome b Gene Sequences. Zoological Science, 17:485-89. http://dx .doi.org/10.2108/zsj.17.485.

Oshida, T., and Y. Obara. 1991. Karyotypes and Chromosomes Banding Patterns of a Male Japanese Giant Flying Squirrel, Petaurista leucogenys Temminck. Chromosome Information Service, 50:26-28.

-1993. C-Band Variation in the Chromosomes of the Japanese Giant Flying Squirrel, Petaurista leucogenys. Journal of the Mammalogical Society of Japan, 18:61-67.

Oshida, T., H. Satoh, and Y. Obara. 1992. A Preliminary Note on the Karyotypes of Giant Flying Squirrels Petaurista alborufus and P. petaurista. Journal of the Mammalogical Society of Japan, 16:59-69.

Oshida, T., C. M. Shafique, S. Barkati, M. Yasuda, N. A. Hussein, H. Endo, H. Yanagawa, and R. Masuda. 2004a. Phylogenetic Position of the Small Kashmir Flying Squirrel, Hylopetes fimbriatus (= Eoglaucomys fimbriatus), in the Subfamily Pteromyinae. Canadian Journal of Zoology, 82:1336-1342. http://dx.doi.org/10.1139/z04-108.

Oshida, T., C. M. Shafique, S. Barkati, Y. Fujita, L.-K. Lin, and R. Masuda. 2004b. A Preliminary Study on Molecular Phylogeny of Giant Flying Squirrels, Genus Petaurista (Rodentia, Sciuraidae) Based on Mitochondrial Cytochrome $b$ Sequences. Russian Journal Theriology, 3(1):15-24.

Oshida, T., H. Yanagawa, M. Tsuda, S. Inoue, and M. C. Yoshida. 2000b. Comparisons of the Banded Karyotypes between the Small Japanese Flying Squirrel, Pteromys momonga and the Russian Flying Squirrel, P. volans (Rodentia, Sciuridae). Caryologia, 53:133-140.

Oshida, T., and M. C. Yoshida. 1998. A Note on the Chromosomes of the White-Bellied Flying Squirrel Petinomys setosus (Rodentia, Sciuridae). Chromosome Science, 2:119-121.

Owen, R. 1837. "Teeth. Comparative Anatomy." In The Cyclopaedia of Anatomy and Physiology. Volume 4, Part 2:
SPI-WRI, ed. R. B. Todd, pp. 864-935. London: Sherwood, Gilbert and Piper.

- 1839. Outlines of a Classification of the Marsupialia. Transactions of the Zoological Society of London, 2:315-333. http://dx.doi.org/10.1111/j.1469-7998.1839.tb 00026.x.

- 1859. On the Classification and Geographical Distribution of the Mammalia Being the Lecture on Sir Robert Reads Foundation, Delivered before the University of Cambridge, in the Senate-House, May 10, 1859. To Which is Added an Appendix "On the Gorilla," and "On the Extinction and Transmutation of Species.” London: John W. Parker.

- 1866. On the Anatomy of Vertebrates. Volume 2: Birds and Mammals. London: Longmans, Green \& Co.

- 1868. On the Anatomy of Vertebrates. Volume 3: Mammals. Longmans, Green \& Co., London.

-1877. Researches on the Fossil Remains of the Extinct Mammals of Australia; with a Notice of the Extinct Marsupials of England. Volume 1. London: J. Erxleben.

Paclt, J. 1960. The "Classes" of Rafinesque and the Modern Biosystematics. Taxon, 9(2):47-49. http://dx.doi.org/10.2307/ 1217837.

Pakenham, R. H. W. 1984. The Mammals of Zanzibar and Pemba Islands. Harpenden, UK: Author.

Pallas, P. S. 1766. Miscellanea Zoologica, quibus Novce Imprimis Atque Obscurce Animalium Species Describuntur et Observationibus Iconibusque Illustrantur. The Hague. [Publisher unknown.]

- 1778. Novae Species Quadrupedum e Glirium Ordine. Erlangen: W. Walther.

- 1780. Galeopithecus volans, camellii Descriptus. Acta Academiae Scientiarum Imperialis Petropolitanae, 1:208222.

Palmer, T. S. 1899. The Family Name of the Dormice. Science, 10:412-413. http://dx.doi.org/10.1126/science.10.247.412.

- 1904. Index Generum Mammalium: A List of the Genera and Families of Mammals (Index Genera Mammalium). North American Fauna, No. 23. Washington, D.C.: U.S. Department of Agriculture.

Parker, T. J., and W. A. Haswell. 1897. A Text-Book of Zoology. London: Macmillan.

Partington, C. F. 1837. The British Cyclopaedia of Natural History: A Scientific Classification of Animals, Plants and Minerals. Volume 3. London: W. S. Orr and Co.

Payne, J., C. M. Francis, and K. Phillips. 1985. A Field Guide to the Mammals of Borneo. Kota Kinabalu, Sabah, Malaysia: The Sabah Society.

Perry, G. 1810-1811. Arcana; or the Museum of Natural History. Volume 1. London: British Museum.

Peters, W. 1859. Über ein neues Flugbeutelthier, Petaurus (Belideus), aus dem südlichen Theile von Neuholland. Monatsberichte der Königlichen Preussischen Akademie der Wissenschaften zu Berlin, 1859:14-15.

—. 1864. Über die Säugethiergattung Solenodon. Abhandlunden der Königlichen Akademie der Wissenshaften zu Berlin, 1863-1864:1-22.

-1880. Über eine neue Art der Nagergattung Anomalurus von Zanzibar. Monatsberichte der Königlich Preussischen Akademie der Wissenschaften zu Berlin, 45:164-166. 
Petit, R. E. 2009. Perry's Arcana: A Facsimile Edition with Collation and Systematic Review. Philadelphia: Temple University Press.

Phillip, A. 1789. The Voyage of Governor Phillip to Botany Bay, with an Account of the Establishment of the Colonies of Port Jackson \& Norfolk Island Compiled from Authentic Papers, Which Have Been Obtained from the Several Departments, to Which are Added the Journals of Lieuts. Shortland, Watts, Ball o Capt. Marshall; with an Account of Their Discoveries, Embellished with LV copper plates, the Maps and Charts Taken from Actual Surveys, \& the Plans and Views Drawn on the Spot, by Capt. Hunter, Lieuts. Shortland, Watts, Dawes, Bradley, Capt. Marshall, \&c. London: John Stockdale.

Phillips, W. W. A. 1935. Manual of the Mammals of Ceylon. London: Dulau \& Co.

-1980. Manual of the Mammals of Sri Lanka. Battaramulla, Sri Lanka: Wildlife and Nature Protection Society of Sri Lanka.

Pocock, R. I. 1923. The Classification of the Sciuridae. Proceedings of the Zoological Society of London, 1923:209-246.

Prater, S. H. 1980. The Book of Indian Mammals. Reprinted with corrections. Bombay: Bombay Natural History Society.

Pratt, A. E., and G. S. Morgan. 1989. New Sciuridae (Mammalia: Rodentia) from Early Miocene Thomas Farm Local Fauna, Florida. Journal of Vertebrate Paleontology, 9:89100. http://dx.doi.org/10.1080/02724634.1989.10011741.

Pumo, D. E., P. S. Finamore, W. R. Franek, C. J. Phillips, S. Tarsami, and D. Balzaroano. 1998. Complete Mitochondrial Genome of a Neotropical Fruit Bat, Articebus jamaicensis, and a New Hypothesis of the Relationships of Bats to Other Eutherian Mammals. Journal of Molecular Evolution, 47:709-717. http://dx.doi.org/10.1007/PL00006430.

Qiu, Z. 1981. A New Sciuroptere from the Middle Miocene of Linqu, Shandong. Vertebrata Palasiatica, 19:228-238.

- 1991. The Neogene Mammalian Faunas of Ertente and Harr Obo in Inner Mongolia (Nei Mongol), China. 8. Sciuridae (Rodentia). Senckenbergiana Lethaea, 71:223-255.

Qiu, Z., C. K. Li, and S. J. Hu. 1984. Late Pleistocene Micromammal Fauna of Sanjiacun, Kunming. [In Chinese with English abstract.] Vertebrata Palasiatica, 22:281-293.

Qiu, Z., and Y. Liu. 1986. The Aragonian Vertebrate Fauna of Xiacaowan, Jiangsu; 5, Sciuridae (Rodentia, Mammalia). Vertebrata Palasiatica, 24:195-209.

Rabor, D. S. 1939. Sciuropterus mindanensis sp. nov., a New Species of Flying Squirrel from Mindanao. Philippine Journal of Science, 69:389-393.

- 1977. Philippine Birds and Mammals. Quezon City, Philippines: University of the Philippines Press.

Rafinesque, C. S. 1814a. Principes fondamentaux de Somiologie ou les loix de la nomenclature et de la classification de l'empire organique ou des animaux et des végétaux contenant les règles essentielles de l'art de leur imposer des noms immuables et de les classer méthodiquement, ơc. Palermo. [Publisher unknown.]

- 1814b. Précis des découvertes et travaux somiologiques. Entré 1800 et 1814. Ou choix raisonné de ses principales découvertes en zoologie et en botanique, pour servir d'introduction à ses ouvrages futures. Palermo: Royale Typographie Militaire.
1815. Analyse de la Nature ou Tableau de l'Univers et des Corps Organisés. Palermo: Jean Barravecchia.

Ramsay, E. P. 1890a. On a New Species of Petaurides from the Bellenden-Ker Range, Queensland. Records of the Australian Museum, 1:77-78. http://dx.doi.org/10.3853/j.0067 $-1975.1 .1890 .1231$.

1890b. Notes and Exhibits. Proceedings of the Linnean Society of New South Wales, 2nd ser., 4:1030.

Rasmussen, M. L., and R. W. Thorington Jr. 2008. Morphological Differentiation among Three Species of Flying Squirrels (Genus Hylopetes) from Southeast Asia. Journal of Mammalogy, 89:1296-1305. http://dx.doi.org/10.1644/07 -MAMM-A-303.1.

Rausch, V. R., and R. L. Rausch. 1982. The Karyotype of the Eurasian Flying Squirrel. Pteromys volans (L.) with a Consideration of Karyotypic and Other Distinctions in Glaucomys spp. (Rodentia: Sciuridae). Proceedings of the Biological Society of Washington, 95:58-66.

Ray, J. 1693. Synopsis Methodica Animalium Quadrupedum et Serpentini Generis. Vulgarium Natas Characteristicas, Rariorum Descriptiones Integras Exhibens: Cum Historiis \& Observationibus Anatomicis Perquam Curiosis. Promittuntur Nonnulla de Animalium in Genere. London: S. Smith \& B. Walford.

Rayner, J. M. V. 1981. Flight Adaptations in Vertebrates. Symposium of the Zoological Society of London, 48:137-172.

Reed, E. H., and S. J. Bourne. 2000. Pleistocene Fossil Vertebrate Sites of the South East Region of South Australia. Transactions of the Royal Society of South Australia, 124:61-90.

Reichenbach, H. G. L. 1862. Die vollständigste Naturgeschichte der Affen. Dresden und Leipzig. [Publisher unknown.]

Reumer, J. W. F., and L. W. van den Hoek Ostende. 2003. Petauristidae and Sciuridae (Mammalia, Rodentia) from Tegelen, Zuurland and the Maasvlakte (the Netherlands). Deinsea, 10:455-467.

Rhoads, S. N. 1897. A Revision of the West American Flying Squirrels. Proceedings of the Academy of Natural Sciences of Philadelphia, 47:314-327.

Richardson, J. 1828. Short Characters of a Few Quadrupeds Procured on Capt. Franklin's Late Expedition. Zoological Journal of the Linnean Society, 3:516-520.

- 1837. Report on North American Zoology. Report of the British Association for the Advancement of Science for 1836, 5:121-224.

Rickart, E. A., L. R. Heaney, P. D. Heideman, and C. B. Utzurrum. 1993. The Distribution and Ecology of Mammals on Leyte, Biliran, and Maripipi Islands, Philippines. Fieldiana Zoology, 72:1-62.

Ride, W. D. L. 1964. A Review of Australian Fossil Marsupials. Journal and Proceedings of the Royal Society of Western Australia, 47:97-131.

-1970. A Guide to the Native Mammals of Australia. Melbourne: Oxford University Press.

Roberts, K. K., M. Archer, S. J. Hand, and H. Godthelp. 2007. New Genus and Species of Extinct Miocene Ringtail Possums (Marsupialia: Pseudocheiridae). American Museum Novitates, 3560:1-15. http://dx.doi.org/10.1206/0003-0082 (2007)3560[1:NGASOE]2.0.CO;2. 
Roberts, T. J. 1997. The Mammals of Pakistan. rev. ed. Oxford: Oxford University Press.

Robertson, J. S., Jr. 1976. Latest Pliocene Mammals from Haile XVA, Alacha County, Florida. Bulletin of the Florida State Museum of Biological Science, 20:111-186.

Robinson, H. C., and C. B. Kloss. 1911. On Six New Mammals from the Malay Peninsula. Journal of the Federated Malay States Museum, 4:169-174.

- 1914. On New Mammals, Mainly from Bandon and the Adjacent Islands, East Coast of the Malay Peninsula. Annals and Magazine of Natural History, 8th ser., 13:223-234.

-1915. Aeromys, a New Genus of Flying Squirrel. Journal of the Federated Malay States Museum, 6:23.

- 1918a. A Nominal List of Sciuridae of the Oriental Region with a List of Specimens in the Collections of the Zoological Survey of India. Records of the Indian Museum, 15:171-254.

- 1918b. Notes on the Genus Petaurista, Pall., with Descriptions of Two New Races. Journal of the Federated Malay States Museum, 7:223-226.

Rose, K. D. 1973. The Mandibular Dentition of Plagiomene (Dermoptera, Plagiomenidae). Breviora, 411:1-17.

- 1975. Elpidophorus, the Earliest Dermopteran (Dermoptera, Plagiomenidae). Journal of Mammalogy, 56:676679. http://dx.doi.org/10.2307/1379482.

— 1981. The Clarkforkian Land-Mammal Age and Mammalian Faunal Composition across the Paleocene-Eocene Boundary. University of Michigan Papers on Paleontology, 26:1-197.

Rose, K. D., and E. L. L. Simons. 1977. Dental Function in the Plagiomenidae: Origin and Relationships of the Mammalian Order Dermoptera. Contributions from the Museum of Paleontology, University of Michigan, 24:221-236.

Rothschild, W. 1892. Descriptions of Two New Mammals from New Guinea. Proceedings of the Zoological Society of London, 1892:545-546.

Rowe, T. 1988. Definition, Diagnosis and Origin of Mammalia. Journal of Vertebrate Paleontology, 8:241-264. http:// dx.doi.org/10.1080/02724634.1988.10011708.

Rowe, T., and J. Gauthier. 1992. Ancestry, Paleontology, and the Definition of the Name Mammalia. Systematic Biology, 41:372-378. http://dx.doi.org/10.2307/2992573.

Ruez, D. R., Jr. 2001. Early Irvingtonian (Latest Pliocene) Rodents from Inglis 1C, Citrus County, Florida. Journal of Vertebrate Paleontology, 21:153-171. http://dx.doi.org/10.1671/0272 -4634(2001)021[0153:EILPRF]2.0.CO;2.

Ruggeri, N., and M. Etterson. 1998. The First Records of Colugo (Cynocephalus variegatus) from the Lao P. D. R. Mammalia, 62:450-451.

Runestad, J. A., and C. B. Ruff. 1995. Structural Adaptations for Gliding in Mammals with Implications for Locomotor Behaviour in Paromomyids. American Journal of Physical Anthropology, 98:101-119. http://dx.doi.org/10.1002/ ajpa.1330980202.

Russell, D. E., P. Louis, and D. E. Savage. 1973. Chiroptera and Dermoptera of the French Early Eocene. Berkeley: University of California Press.

Russell, L. S. 1954. Mammalian Fauna of the Kishenehn Formation, Southeast British Columbia. Bulletin of the National Museum of Canada, 132:92-111.
Saban, R. 1954. Phylogénie des insectivores. Bulletin de le Muséum Nationale d'Histoire Naturelle, 2nd ser., 26:419-432.

Saha, S. S. 1975. A New Subspecies of the Flying Squirrel, Petaurista nobilis (Gray) from Bhutan. Proceedings of the Zoological Society of Calcutta, 28:27-29.

-1981. A New Genus and a New Species of Flying Squirrel (Mammalia: Rodentia: Sciuridae) from Northeastern India. Bulletin of the Zoological Survey of India, 4:331-336.

Sanborn, C. C. 1953. Mammals of Mindano, Philippine Islands Collected by the Danish Philippine Expedition 1951-1952. Videnskabelige Meddelelser fra Dansk Naturhistorisk Forening, 115:283-288.

Sanderson, I. T. 1940. The Mammals of the North Cameroon Forest Area. Being the Results of the Percy Sladen Expedition to the Mamfe Division of the British Cameroons. Transactions of the Zoological Society of London, 24:623-725. http://dx.doi.org/10.1111/j.1096-3642.1940.tb00342.x.

Sargis, E. J. 2002a. Primate Origins Nailed. Science, 298:15641565. http://dx.doi.org/10.1126/science.1079034.

. 2002b. The Post Cranial Morphology of Ptilocercus lowii (Scandentia, Tupaiidae): An Analysis of Primatomorphan and Volitantian Characters. Journal of Mammalian Evolution, 9:137-160. http://dx.doi.org/10.1023/A:1021387928854.

- 2004. New Views on Tree Shrews: The Role of Tupaiids in Primate Supraordinal Relationships. Evolutionary Anthropology, 13:56-66. http://dx.doi.org/10.1002/evan.10131.

Satunin, K. A. 1902. Neue nagetiere aus den Materialien der grossen russischen Expeditionen nach Centralasien. Annuaire du Musée Zoologique de l'Académie Impériale des Sciences de St. Pétersbourg, 7:549-589.

Sawyer, F. C. 1953. The Dates of Issue of J. E. Gray's “Illustrations of Indian Zoology" (London, 1830-1835). Journal of the Society for the Bibliography of Natural History, 3:4855. http://dx.doi.org/10.3366/jsbnh.1953.3.Part_1.48.

Schaub, S. 1953. Remarks on the Distribution and Classification of the "Hystricomorpha." Verhandlungen der Naturforschenden Gesellschaft in Basel, 64(2):389-400.

— 1958. "Simplicidentata (Rodentia)." In Traité de Paléontologie. Volume 6, Part 2, ed. J. Piveteau, pp. 659-818. Paris: Masson.

Schinz, H. R. 1845. Systematisches Verzeichniss aller bis jetzt bekannten Säugethiere, oder Synopsis Mammalium nach dem Cuvierschen System. Volume 2. Solothurn, Germany: Verlag von Jent und Gassmann.

Schlegel, H., and S. Müller. 1845. "Bijdragen tot de Natuurlijke Geschiedenis der Vliegende Eekhorens (Pteromys)." In Verhandelingen over de Natuurlijke Geschiedenis der Nederlandische Overzeeche Bezittingen. Volume 1, Part 2, ed. C. J. Temminck, pp. 103-114. Leiden. [Publisher unknown.]

Schlosser, M. 1884. Nachtrage und Berichtigungen zu: die nager des europaischen Tertiars. Palaeontographica, 31:323-328. - 1907. Beitrag zur Osteologie und systematischen Stellung der Gattung Necrolemur, sowie zur Stammesgeschichte der Primaten überhaupt. Neues Jahrbuch für Mineralogie, Geologie und Paläontologie, 1907:197-226.

Schmitz, J., M. Ohme, B. Suryobroto, and H. Zischler. 2002. The Colugo (Cynocephalus variegatus, Dermoptera): The Primates' Gliding Sister? Molecular Ecology and Evolution, 19:2308-2312. 
Schreber, J. C. D. 1780. Die Säugethiere in Abbildungen nach der Natur mit Beschreibungen. Part 4. Leipzig: Wolfgang Walther.

- 1792. Die Säugthiere in Abbildungen nach der Natur. Volume 4. Erlangen: Walfgang Walther.

Schunke, A. C. 2005. Systematics and Biogeography of the African Scaly-Tailed Squirrels (Mammalia: Rodentia: Anomaluridae). Ph.D. thesis, Rheinischen FriedrichWilhelms-Universität Bonn, Bonn.

Schunke, A. C., and R. Hutterer. 2005a. The Variance of Variation: Geographic Patterns of Coat Colouration in Anomalurops and Anomalurus (Anomaluridae, Rodentia, Mammalia). Bonner Zoologische Beiträge, 53:169-185. . 2005b. "Geographic Variation in the West African Scaly-Tailed Squirrel Anomalurus pellii (Schlegel and Müller, 1845) and Description of a New Subspecies (Rodentia: Anomaluridae)." In African Biodiversity: Molecules, Organisms, Ecosystems: Proceedings of the 5th International Symposium on Tropical Biology, Museum Koenig, Bonn, ed. B. A. Huber, B. J. Sinclair, and K. H. Lampe, pp. 321328. Berlin: Springer-Verlag.

- 2007. Geographic Variation of Idiurus (Rodentia: Anomaluridae) with Emphasis on Skull Morphology. American Museum Novitates, 3548:1-22. http://dx.doi.org/10 .1206/0003-0082(2007)3548[1:GVOIRA]2.0.CO;2.

Schwann, H. 1904. On New Forms of Anomalurus and Sciurus from Tropical Africa. Annals and Magazine of Natural History, 7th ser., 13:70-73.

Sclater, W. L. 1891. Catalogue of Mammalia in the Indian Museum Calcutta. Part II. Rodentia, Ungulata, Proboscidea, Hyracoidea, Carnivora, Cetacea, Sirenia, Marsupialia, Monotremata. Calcutta: Trustees of the Indian Museum.

Shaw, G. 1791. The Naturalists Miscellany; or Coloured Figures of Natural Objects; Drawn and Described Immediately from Nature. Volume 2. London: Nodder.

-1794. Zoology of New Holland. London: J. Sowerby. . 1800. General Zoology or Systematic Natural History. Volume 1, Part 2: Mammalia. London: G. Kearsley. - 1801. General Zoology or Systematic Natural History. Volume 2, Part 1: Mammalia. London: G. Kearsley.

Shaw, T.-H., S. Wang, C.-K. Lu, and L.-K. Chang. 1966. A Survey of the Mammals of Hainan Island, China. Acta Zootaxonomica Sinica, 3:260-276.

Sherborn, C. D. 1891. On the Dates of the Parts, Plates, and Text of Schreber's 'Saugthiere.' Proceedings of the Zoological Society of London, 1891:587-592.

- 1895. On the Dates of Shaw and Nodder's "Naturalist's Miscellany." Annals and Magazine of Natural History, 6th ser., 15:375-376.

Sherborn, C. D., and B. B. Woodward. 1906. On the Dates of Publication of the Natural History Portion of the "Encyclopedie Methodique." Annals and Magazine of Natural History, 7th ser., 17:577-582.

Shikama, T. 1949. The Kuzuu Ossuaries. Geological and Palaeontological Studies of the Limestone Fissure Deposits, in Kuzuu, Totigi Prefecture. Science Reports of the Tohoku University, 2nd ser., 23:1-209.

Shikama, T., and G. Okafuji. 1958. Quaternary Cave and Fissure Deposits and Their Fossils in Akiyoshi District, Yamaguchi
Prefecture. Science Reports of the Yokohama National University, 2nd ser., 7:43-103.

Shoshani, J. 1992. "Cuvier vis-à-vis Huxley on the Relationship of Hyracoidea and an Update on an Old Controversy." In Ongulés/Ungulates 91: Proceedings of the International Symposium "Ongulés/Ungulates 91," Toulouse, France, September 2-6, 1991, ed. F. Spitz, pp. 103-112. Paris: Societe Francaise pour d'Etude Protection deles Mammales.

Shufeldt, R. W. 1911. The Skeleton in the Flying Lemurs, Galeopteridae. The Philippine Journal of Science, 6:185-211.

Silcox, M. T., J. L. Bloch, E. J. Sargis, and D. M. Boyer. 2005. "Euarchonta (Dermoptera, Scandentia, Primates)." In The Rise of Placental Mammals: Origins and Relationships of the Major Extant Clades, ed. K. D. Rose and J. D. Archibald, pp. 127-144. Baltimore: The Johns Hopkins University Press.

Simmons, N. B. 1993. "The Importance of Methods, Archontan Phylogeny and Cladistic Analysis of Morphological Data." In Primates and Their Relatives in Phylogenetic Perspective, ed. R. D. E. MacPhee, pp. 1-61. New York: Plenum Press.

- 1995. Bat Relationships and the Origin of Flight. Symposia of the Zoological Society of London, 67:27-43.

Simpson, G. G. 1927. Mammalian Fauna and Correlation of the Paskapoo Formation of Alberta. American Museum Novitates, 268:1-10.

- 1928. A New Mammalian Fauna from the Fort Union of Southern Montana. American Museum Novitates, 297:1-15. - 1931. A New Classification of Mammals. Bulletin of the American Museum of Natural History, 59:259-293.

- 1935. New Paleocene Mammals from the Fort Union of Montana. Proceedings of the United States National Museum, 83:221-244. http://dx.doi.org/10.5479/si.00963801 .2981 .221 .

-1936. A New Fauna from the Port Union of Montana. American Museum Novitates, 873:1-27.

- 1937. The Fort Union of the Crazy Mountain Field, Montana, and Its Mammalian Faunas. Bulletin of the United States National Museum, 169:1-287.

- 1945. The Principles of Classification and a Classification of Mammals. Bulletin of the American Museum of Natural History, 85:1-350.

Skwara, T. 1986. A New "Flying Squirrel" (Rodentia: Sciuridae) from the Early Miocene of Southwestern Saskatchewan. Journal of Vertebrate Paleontology, 6:290-294. http:// dx.doi.org/10.1080/02724634.1986.10011625.

Smith, A. T., and Y. Xie, eds. 2008. A Guide to the Mammals of China. Princeton: Princeton University Press.

Smith, J. D. D. 2001. Official Lists and Indexes of Names and Works in Zoology. Supplement 1986-2000. London: The International Trust for Zoological Nomenclature.

Smith, M. J. 1973. Petaurus breviceps. Mammalian Species, 30:1-5. http://dx.doi.org/10.2307/3503785.

Smith, T., E. De Blast, and B. Sige. 2009. Adapisoriculid Mammals from the Paleocene of Hainin (Belgium) Shed Light on the Phylogenetic Affinities of the Enigmatic Arboreal Cretaceous Deccanolestes from the Deccan Traps of India. Journal of Vertebrate Paleontology, 29(3):183A.

Sody, H. J. 1936. A New Flying Squirrel from Sumatra. Natuurkundig Tijdschrift voor Nederlandsch-Indie, 96:146-147. 
1937. On the Mammals of Banka. Temminckia, 2:221250.

. 1949. On a Collection of Sciuridae from the IndoMalayan and Indo-Australian Regions. Treubia, 20:57-120.

Sornborger, J. D. 1900. The Labrador Flying Squirrel. Ottawa Naturalist, 14:48-51.

Springer, M. S., W. J., Murphy, E. Eizirik, and S. J. O’Brien. 2003. Placental Mammal Diversification and the K-T Boundary. Proceedings of the National Academy of Sciences of the United States of America, 100:1056-1061.

Stafford, B. J. 2005. "Order Dermoptera.” In Mammal Species of the World: A Taxonomic and Geographic Reference, 3rd ed., ed. D. E. Wilson and D. M. Reeder, pp. 110. Washington, D.C.: Smithsonian Institute Press.

Stafford, B. J., and F. S. Szalay. 2000. Craniodental Functional Morphology and Taxonomy of Dermopterans. Journal of Mammalogy, 81:360-385. http://dx.doi.org/10.1644/1545 -1542(2000)081<0360:CFMATO>2.0.CO;2.

Stafford, B. J., and R. W. Thorington. 1998. Carpal Development and Morphology in Archontan Mammals. Journal of Morphology, 235:135-155. http://dx.doi.org/10.1002/(SICI)1097 -4687(199802)235:2<135::AID-JMOR4>3.0.CO;2-8.

Steppan, S. J., B. L. Storz, and R. S. Hoffmann. 2004. Nuclear DNA Phylogeny of the Squirrels (Mammalia: Rodentia) and the Evolution of Arboreality Using c-myc and RAG1. Molecular Phylogenetics and Evolution, 30:703-719. http:// dx.doi.org/10.1016/S1055-7903(03)00204-5.

St. Leger, J. 1935. Two New Subspecies of Mammals from Angola. Novitates Zoologicae, 39:251-252.

Stone, W. 1900. Description of a New Rabbit from the Liu Kiu Islands and a New Flying Squirrel from Borneo. Proceedings of the Academy of Science of Philadelphia, 52:460-463.

Storch, G. 2008. Skeletal Remains of a Diminutive Primate from the Paleocene of Germany. Naturwissenschaften, 95:927930. http://dx.doi.org/10.1007/s00114-008-0401-0.

Storch, G., B. Engesser, and M. Wuttke. 1996. Oldest Fossil Record of Gliding in Rodents. Nature, 379:439-441. http:// dx.doi.org/10.1038/379439a0.

Storer, J. E. 1984. Mammals of the Swift Current Creek Local Fauna (Eocene: Uintan), Saskatchewan. Natural History Contributions, No. 7. Regina, Canada: Royal Saskatchewan Museum.

Storr, G. C. C. 1780. Prodromus Methodi Mammalium ... Inauguralem Disputationem Propositus. Tubingen: Royal Saskatchewan Museum.

Strahan, R., ed. 1983. The Complete Book of Australian Mammals. Sydney: Angus and Robertson.

, ed. 1987. What Mammal is That? Sydney: Angus and Robertson.

- ed. 1995. The Mammals of Australia. 2nd ed. Sydney: Reed Books.

Stroganov, S. U. 1936. Die Säugetierfauna des Walaihügellandes. Zoologitscheskij Journal, Vormals Revue Zoologique Russe (Moscow), 15:520-559.

Sulimski, A. 1964. Pliocene Lagomorpha and Rodentia from Weze. I. (Poland). Acta Palaeontologica Polonica, 9:149240.

Sulkava, S. 1978. "Pteromys volans (Linnaeus, 1758) Flughornchen." In Handbuch der Saugetiere Europas, Vol- ume 1. ed. J. Niethammer and F. Krap, pp. 71-84. Wiesbaden: Akademische Verlagsgesellschaft.

Suzuki, H., S. Minato, S. Sakurai, K. Tsuchiya, and I. M. Fokin. 1997. Phylogenetic Position and Geographic Differentiation of the Japanese Dormouse, Glirulus japonicus, Revealed by Variations among rDNA, mtDNA and the Sry Gene. Zoological Science, 14:167-173. http://dx.doi.org/10.2108/ zsj.14.167.

Swainson, W. 1837. On the Natural History and Classification of Birds. Volume 2. London: Longman, Rees, Orme, Brown, Green, and Longman.

Swenk, M. H. 1915. On a New Subspecies of Flying Squirrel from Nebraska. University of Nebraska Studies, 15:151154.

Swinhoe, R. 1863. On the Mammals of the Island of Formosa (China). Proceedings of the Zoological Society of London, 1862:347-365.

- 1871. Catalogue of the Mammals in China (South of the River Yangtsze). Proceedings of the Zoological Society of London, 1870:615-653.

Szalay, F. S. 1969. Mixodectidae, Microsyopidae, and the Insectivore-Primate Transition. Bulletin of the American Museum of Natural History, 140:193-330.

-1976. Systematics of the Omomyidae (Tarsiiformes, Primates): Taxonomy, Phylogeny, and Adaptations. Bulletin of the American Museum of Natural History, 156:157-450.

- 1982. "A New Appraisal of Marsupial Phylogeny and Classification.” In Carnivorous Marsupials. Volume 2, ed. M. Archer, pp. 621-640. Sydney: Royal Zoological Society of New South Wales.

- 1993. "Metatherian Taxon Phylogeny: Evidence and Interpretation from Cranioskeletal System." In Mammal Phylogeny: Mesozoic Differentiation, Multituberculates, Monotremes, Early Therians and Marsupials, ed. F. S. Szalay, M. J. Novacek, and M. C. McKenna, pp. 216-242. New York: Springer-Verlag.

-1994. Evolutionary History of the Marsupials and an Analysis of Osteological Characters. Cambridge: Cambridge University Press.

Szalay, F. S., and G. Drawhorn. 1980. "Evolution and Diversification of the Archonta in an Arboreal Milieu." In Comparative Biology and Evolutionary Relationships in Tree Shrews, ed. W. P. Luckett, pp. 133-169. New York: Plenum Press.

Szalay, F. S., and S. G. Lucas. 1993. "Cranioskeletal Morphology of Archontans and Diagnoses of Chiroptera, Volitantia and Archonta." In Primates and Their Relatives in Phylogenetic Perspective, ed. R. D.E MacPhee, pp. 187-226. New York: Plenum Press.

- 1996. The Postcranial Morphology of Paleocene Chriacus and Mixodectes and the Phylogenetic Relationships of Archontan Mammals. New Mexico Museum of Natural History and Science Bulletins, 7:1-47.

Szalay, F. S., and E. J. Sargis. 2001. Model-Based Analysis of Postcranial Osteology of Marsupials from the Paleocene of Itaboraí (Brazil) and the Phylogenetics and Biogeography of Metatheria. Geodiversitas, 23:139-302.

Tate, G. H. H. 1938. New or Little Known Marsupials: A New Species of Phascolgalinae, with Notes on Acrobates pulchellus Rothschild. Novitates Zoologicae, 41:58-60. 
1945. Results of the Archbold Expeditions. No. 55. Notes on the Squirrel-Like and Mouse-Like Possums (Marsupialia). American Museum Novitates, 1305:1-12.

Tate, G. H. H., and R. Archbold. 1935. Results of the Archbold Expeditions. No. 5. Seven Apparently New Forms of Phalangeridae from the New Guinea Region. American Museum Novitates, 810:1-8.

Taylor, E. H. 1934. Philippine Land Mammals. Manila: Bureau of Printing.

Tehsin, R. H. 1981. Occurrence of the Large Brown Flying Squirrel and Mouse Deer near Udaipur, Rajasthan. Journal of the Bombay Natural History Society, 77:498.

Temminck, C. J. 1827. Monographies de Mammalogie. Volume 1. Paris: Dufour.

- 1836. "Coup d'oeil sur la faune des Îles de la Sonde et de l'empire du Japon. Discours préliminaire destiné à servir d'introduction à la Faune du Japon." In Fauna Japonica sive Descriptie, quae in Itinere per Japoniam, Jusu et Auspiciis Speriorum, qui, Summum in India, Batavia, Imperium Tenent, Fuscepto, Annis 1823-1830, ed. P. F. Siebold, pp. ixxx. Leiden: Lugduni Batavorum.

- 1843-1844. "Aperçu général et spécifique sur les mammifères qui abitent le Japon et les îles qui en dependent." In Fauna Japonica sive Desciptie, quae in Itinere per Japoniam, Jusu et Auspiciis Speriorum, qui, Summum in India, Batavia, Imperium Tenent, Fuscepto, Annis 1823-1830, ed. P. F. von Siebold, pp. 1-24, pls. 1-10: 1843; pp. 25-59, pls. 11-20, and marine mammals pp. 1-26, pls. 21-30: 1844. Amsterdam: Müller.

— 1853. Esquisses zoologiques sur la côte de Guiné. 1, Mammiferes. Leiden: Brill.

Terzea, E. 1980. Deux micromammifères du Pliocène de Roumanie. Travaux de l'Institut de Spéléologie "Emile Racovitza.” 19:191-201.

Thaler, L. 1966. Les rongeurs fossils du Bas-Languedoc dans leurs rapports avec l'histoire des faunes et la stratigraphie du Tertiarie d'Europe. Mémoires du Muséum National d'Histoire Naturelle, Paris, Series C, 17:1-296.

Thewissen, J. G. M., and S. K. Babcock. 1991. Distinctive Cranial and Cervical Innervation of Wing Muscles: New Evidence for Bat Monophyly. Science, 251:934-936. http:// dx.doi.org/10.1126/science.2000493.

. 1993. "The Implications of the Propatiagial Muscles of Flying and Gliding Mammals in Archontan Systematics." In Primates and Their Relatives in Phylogenetic Perspective, ed. R. D. E. MacPhee, pp. 91-109. New York, Plenum Press.

Thomas, O. 1879. On Robert Kerr's Translation of the 'Systema Naturae' on Linnaeus. Annals and Magazine of Natural History, 5th ser., 4:396-397.

- 1886a. On the Mammals Presented by Allan O. Hume, Esq., C. B., to the Natural History Museum. Proceedings of the Zoological Society of London, 1886:54-78.

- 1886b. Diagnoses of Three New Oriental Mammals. Annals and Magazine of Natural History, 5th ser., 17:84.

- 1887. Diagnosis of Two New Central-African Mammalia. Annals and Magazine of Natural History, 5th ser., 20:440. - 1888a. Catalogue of the Marsupialia and Monotremata in the Collection of the British Museum (Natural History). London: British Museum of Natural History. 1888b. Eupetaurus, a New Form of Flying Squirrel from Kashmir. Journal of the Asiatic Society of Bengal, 57(2):256-260.

- 1888 c. On a Collection of Mammals Obtained by Emin Pasha in Equatorial Africa, and Presented by Him to the Natural History Museum. Proceedings of the Zoological Society of London, 1888:3-17.

- 1893. Description of a New Sciuropterus from the Philippines. Annals and Magazine of Natural History, 6th ser., 12:30-31.

- 1895a. On Caenolestes, a Still Existing Survivor of the Epanorthidae of Ameghino, and the Representative of a New Family of Recent Marsupials. Proceedings of the Zoological Society of London, 1895:870-878.

- 1895b. An Analysis of the Mammalian Generic Names Given in Dr. C. W. L. Gloger's "Naturgeschichte” (1841). Annals and Magazine of Natural History, 6th ser., 15:189193.

. 1895c. Revised Determinations of Three of the Natuna Rodents. Novitates Zoologicae, 2:26-28.

— 1895 d. On Some Mammals Collected by Dr E. Modigliani in Sipora, Mentawei Islands. Annali del Museo Civico di Storia Naturale di Geneva, 14:660-672.

- 1895 e. Diagnosis of Two New East-African Mammals. Annals and Magazine of Natural History, 6th ser., 15:187188.

- 1897. On the Genera of Rodents: An Attempt to Bring up to Date the Current Arrangement of the Order. Proceedings of the Zoological Society of London, 1896:1012-1028.

- 1900a. Descriptions of Two New Sciuropteri Discovered by Mr. Charles Hose in Borneo. Annals and Magazine of Natural History, 7th ser., 5:275-276.

. 1900b. The Red Flying Squirrel of the Natuna Islands. Novitates Zoologicae, 7:592.

- 1904. On Mammals from the Island of Fernando Po, Collected by Mr. E. Seimund. Proceedings of the Zoological Society of London, 1904:183-193.

_ 1905a. On Some New Japanese Mammals Presented to the British Museum by Mr. R. Gordon Smith. Annals and Magazine of Natural History, 7th ser., 15:487-495.

. 1905b. The Duke of Bedford's Zoological Explorations in Eastern Asia. 1. List of Mammals Obtained by Mr M. P. Anderson in Japan. Proceedings of the Zoological Society of London, 1905:331-363.

. 1907a. A New Flying Squirrel from Formosa. Annals and Magazine of Natural History, 7th ser., 20:522-523.

. 1907b. The Duke of Bedford's Zoological Exploration in Eastern Asia. V. Second List of Mammals from Korea. Proceedings of the Zoological Society of London, 1907:462-466.

- 1907c. The Duke of Bedford's Zoological Exploration in Eastern Asia. IV. List of Small Mammals from the Islands of Saghalien and Hokkaido. Proceedings of the Zoological Society of London, 1907:404-414.

- 1908a. The Nomenclature of the Flying Lemurs. Annals and Magazine of Natural History, 8th ser., 1:252-255. . 1908b. The Genera and Subgenera of the Sciuropterus Group, with Descriptions of Three New Species. Annals and Magazine of Natural History, 8th ser., 1:1-8. 
1908c. On Mammals from the Malay Peninsula and Islands. Annals and Magazine of Natural History, 8th ser., 2:301-306.

- 1908 d. On the Mammals Collected by Mr. H. C. Robinson on Tioman and Aor Islands, S. China Sea. Journal of the Federated Malay States Museum, 2:49-106.

-1908e. The Large Flying Squirrels Referred to Petaurista nitida Desmarest. Annals and Magazine of Natural History, 8th ser., 1:250-252.

-1911a. The Duke of Bedford's Zoological Exploration of Eastern Asia. XIV. On Mammals from Southern Shensi, Central China. Proceedings of the Zoological Society of London, 1911:687-695.

- 1911b. The Mammals of the Tenth Edition of Linnaeus; an Attempt to Fix the Types of the Genera and the Exact Bases and Localities of the Species. Proceedings of the Zoological Society of London, 1911:120-158.

- 1912. New Species of Crocidura and Petaurista from Yunnan. Annals and Magazine of Natural History, 8th ser., 9:686-688.

- 1914a. Scientific Results from the Mammal Survey. No. VII. Journal of the Bombay Natural History Society, 23:23-31.

- 1914b. Two New Flying Squirrels. Journal of the Bombay Natural History Society, 23:204-205.

- 1914c. On Small Mammals Collected in Tibet and the Mishmi Hills by Capt. F. M. Bailey. Journal of the Bombay Natural History Society, 23:230-233.

-1916a. A New Flying Squirrel from Tenasserim. Journal of the Bombay Natural History Society, 24:422-423.

-1916b. On Small Mammals Obtained in Sankuru, South Congo, by Mr. H. Wilson. Annals and Magazine of Natural History, 8th ser., 18:234-239.

- 1921. On Small Mammals from the Kachin Province, Northern Burma. Journal of the Bombay Natural History Society, 27:499-505.

-1922a. A Selection of Lectotypes of the Typical Australian Marsupials in the British Museum Collection. Annals and Magazine of Natural History, 9th ser., 10:127-128.

- 1922b. On Mammals from the Yunnan Highlands Collected by Mr. George Forrest and Presented to the British Museum by Col. Stephenson R. Clarke, D. S. O. Annals and Magazine of Natural History, 9th ser., 10:391-406.

-1922c. Two New Rodents from the Mergui Archipelago. Journal of the Bombay Natural History Society, 28:10671068.

-1923a. On Some Queensland Phalangeridae. Annals and Magazine of Natural History, 9th ser., 11:246-250.

- 1923b. Geographical Races of Petaurista alborufus. Annals and Magazine of Natural History, 9th ser., 12:171-172.

- 1923c. On Mammals from the Li-kiang Range, Yunnan, Being a Further Collection Obtained by Mr. George Forest. Annals and Magazine of Natural History, 9th ser., 11:655-663.

-1925. The Mammals Obtained on the Sladen-Godman Expedition to the Tonkin. Proceedings of the Zoological Society of London, 95:495-506. http://dx.doi.org/10.1111/j .1096-3642.1925.tb01524.x.
- 1926. Two New Flying Squirrels from the Mergui Archipelago. Journal of the Bombay Natural History Society, 31:22.

Thomas, O., and R. C. Wroughton. 1916. A New Flying Squirrel from the Chin Hills. Journal of the Bombay Natural History Society, 24:423-424.

Thorington, R. W., Jr. 1984. Flying Squirrels Are Monophyletic. Science, 225:1048-1049. http://dx.doi.org/10.1126/science .225 .4666 .1048 .

Thorington, R. W., and R. S. Hoffmann. 2005. "Family Sciuridae." In Mammal Species of the World: A Taxonomic and Geographic Reference, ed. D. E. Wilson and D. M. Reeder, pp. 754-818. Washington, D.C.: Smithsonian Institution Press.

Thorington, R. W., Jr., A. L. Musante, C. G. Anderson, and K. Darrow. 1996. Validity of Three Genera of Flying Squirrels: Eoglaucomys, Glaucomys and Hylopetes. Journal of Mammalogy, 77:69-83. http://dx.doi.org/10.2307/1382710.

Thorington, R. W., D. Pitassy, and S. A. Jansa. 2002. Phylogenies of Flying Squirrels (Pteromyinae). Journal of Mammalian Evolution, 9:99-133. http://dx.doi.org/10.1023/A :1021335912016.

Thorington, R. W., C. E. Schennum, L. A. Pappas, and D. Pitassy. 2005. The Difficulties of Identifying Flying Squirrels (Sciuridae: Pteromyini) in the Fossil Record. Journal of Vertebrate Paleontology, 25:950-961. http://dx.doi.org/10.1671/0272 -4634(2005)025[0950:TDOIFS]2.0.CO;2.

Tickell, S. R. 1842. On the Orál, or Singhoom Flying Squirrel, Pteromys Orál. Calcutta Journal of Natural History, 2:401-408.

Tiedemann, F. 1808. Fliegendes Eichorn Pteromys. Zoologie. Zu seinen Vorlesungen entworfen. Landshut, 1:449-451.

Tong, H. 2007. Aeretes melanopterus (Pteromyinae, Rodentia) from Tianyuan Cave near Zhoukoudian (Choukoutien) in China. Geobios, 40:219-230. http://dx.doi.org/10.1016/j .geobios.2006.04.006.

Trouessart, E. L. 1898. Catalogus Mammalium tam Viventium Quam Fossilium. Volume 1. Berlin: Friedlander und Sohn.

- 1904. Catalogus Mammalium tam Viventium quam Fossilium. Supplement. Berlin: R. Friedlander und Sohn.

Troughton, E. Le G. 1945. Diagnoses of New Mammals from the South-west Pacific. Records of the Australian Museum, 21:373-375. http://dx.doi.org/10.3853/j.0067-1975.21.1945 .551 .

- 1967. Furred Animals of Australia. 9th ed. Sydney: Angus and Robertson.

Turnbull, W. D. 1971. "The Trinity Therians: Their Bearing on Evolution in Marsupials and Other Therians." In Dental Morphology and Evolution, ed. A. A. Dahlberg, pp. 151179. Chicago: University of Chicago Press.

Turnbull, W. D., and E. L. Lundelius Jr. 1970. The Hamilton Fauna, a Late Pliocene Mammalian Fauna from the Grange Burn, Victoria, Australia. Fieldiana Geology, 19:1-123.

Turnbull, W. D., T. H. V. Rich, and E. L. Lundelius. 1987a. "The Petaurids (Marsupialia: Petauridae) of the Early Pliocene Hamilton Local Fauna, Southwestern Victoria." In Possums and Opossums: Studies in Evolution, ed. M. Archer, pp. 629-638. Sydney: Surrey Beatty. 
1987b. "Pseudocheirids (Marsupialia: Pseudocheiridae) from the Early Pliocene Hamilton Local Fauna, Southwestern Victoria." In Possums and Opossums: Studies in Evolution, ed. M. Archer, pp. 689-713. Sydney: Surrey Beatty.

Ulmer, F. A. 1940. Zoological Results of the Denison-Crockett South Pacific Expedition for the Academy of Natural Sciences of Philadelphia, 1937-38. Part VI. A New Race of the New Guinea Short-Headed Flying Phalanger from Biak Island. Notulae Naturae of the Academy of Natural Sciences of Philadelphia, 52:1-3.

Van Den Bussche, R. A., and S. R. Hoofer. 2004. Phylogenetic Relationships among Recent Chiropteran Families and the Importance of Choosing Appropriate Outgroup Taxa. Journal of Mammalogy, 85:321-330. http://dx.doi.org/10.1644/1545 -1542(2004)085<0321:PRARCF>2.0.CO;2.

Van der Hoeven, J. 1855. Handbuch der Zoologie. Volume 2. Leipzig: Leopold Voss.

- 1856. Handbuch der Zoologie. Volume 10. Leipzig: Leopold Voss.

1858. Handbook of Zoology. Volume 2. London: Longman, Brown, Green, Longmans, and Roberts.

van de Weerd, A. 1979. Early Ruscinian Rodents and Lagomorphs (Mammalia) from the Lignites near Ptolemais (Macedonia, Greece). Proceedings of the Koninklijke Nederlandse Akademie van Wetenschappen, Series B, Palaeontology, Geology, Physics, Chemistry, Anthropology, 82(2):127-170.

Van Dyck, S. 1990. Belideus gracilis-Soaring Problems for an old De Vis glider. Memoirs of the Queensland Museum, 28:329-336.

- 1991. "The Status of Mammals." In An Atlas of Queensland's Frogs, Reptiles Birds and Mammals, ed. G. J. Ingram and R. J. Raven, pp. 349-353. Brisbane: Queensland Museum.

- 1993. The Taxonomy and Distribution of Petaurus gracilis (Marsupialia: Petauridae), with Notes on Its Ecology and Conservation Status. Memoirs of the Queensland Museum, 33:77-122.

Van Dyck, S., and R. Strahan, eds. 2008. The Mammals of Australia. 3rd ed. Sydney: Reed New Holland.

Van Valen, L. 1967. New Paleocene Insectivores and Insectivore Classification. Bulletin of the American Museum of Natural History, 135:217-284.

- 1978. The Beginning of the Age of Mammals. Evolutionary Theory, 4:45-80.

Verheyen, W. N. 1963. Contribution a la systematique du genre Idiurus (Rodentia: Anomaluridae). Revue de Zoologie et de Botanique Africaines, 68:157-197.

- 1968a. The Anomalurinae of the Congo. Revue de Zoologie et de Botanique Africaines, 77:392-411.

—. 1968b. Description d'une nouvelle sous-espece d'Anomalurops beecroft de la region congolais. Revue de Zoologie et de Botanique Africaines, 77:157-161.

Vicq-d'Azyr, F. M. 1792. Encyclopédie Méthodique. Systême Anatomique. Quadrupèdes. Volume 2: Quadrupèdes. Paris: Panckoucke.

Villalta, J.-F. 1950. Sobre un esciuroptero del Vindoboniense del Valles-Penedes. Boletin de la Real Sociedad Espanola de Historia Natural, Madrid, 48:53-59.
Vinogradov, B. S., and A. I. Argiropulo. 1968. Fauna of the USSR: Mammals. Jerusalem: Israel Program for Scientific Translations.

von Serebrennikov, M. K. 1930. Ein flatterhornchen aus dem kirgisengebiet. Zeitschrift fur Saugetierk, 4:142-143.

von Zimmermann, E. A. W. 1780. Geographische Geschichte des Menschen, und der allgemein verbreiteten Vierfüssigen Thiere, nebst einer hieher gehörigen zoologischen Weltcharte. Volume 2. Leipzig: Weygandschen Buchhlandlung.

Waddell, P. J., N. Okada, and M. Hasegawa. 1999. Towards Resolving the Interordinal Relationships of Placental Mammals. Systematic Biology, 48:1-5. http://dx.doi.org/10 .1093/sysbio/48.1.1.

Wagner, J. A. 1839. Die Saugethiere in Abbildungen nach der Natur mit Beschreibungen. Supplement 1. Leipzig: Weigel.

- 1841a. Gruppirung der Gattungen der Nager. Gelehrte Anzeigen, Akademie der Wissenschaften, Munchen, $12: 433-440$

- 1841b. Gruppirung der Gattungen der Nager in natürlichen Familien, nebst Beschreibung einiger neuen Gattungen und Arten. Archiv für Naturgeschichte, Mecklenburg, 7th ser., 1:111-138.

—. 1843. In J. C. D. von Schreber. Die Sängethiere in Abbildungen nach der Natur mit Beschreibungen. Fortgesetzt von A. Goldfuss Supplementband von J. A. Wagner. Supplement Volume 3. Erlangen: Voss.

Wahlert, J. H., S. L. Sawitzke, and M. E. Holden. 1993. Cranial Anatomy and Relationships of Dormice (Rodentia, Myoxidae). American Museum Novitates, 3061:1-32.

Wakefield, N. A. 1972. Paleoecology of Fossil Mammal Assemblages from Some Australasian Caves. Proceedings of the Royal Society of Victoria, 85(1):1-26.

Wang, S., and C.-K. Lu. 1966. "Hylopetes alboniger chianfengensis." In A Survey of the Mammals of Hainan Island, China. T.-H. Shaw, S. Wang, C.-K. Lu, and L.-K.Chang. pp. 270, 276. Acta Zootaxonomica Sinica, 3:260-276.

Wang, T. C., Y. R. Tue, and S. Wang. 1966. Notes on Some Small Mammals from Szechuan Province with Description of a New Subspecies. [In English and Chinese.] Acta Zootaxonomica Sinica, 3:89-90.

Wang, Y. 1981. In H. Peng and Y. Wang. New Mammals from the Gaoligong Mountains. Acta Theriologica Sinica, 1:167-176.

Wang, Y.-X. 2003 [“2002”]. A Complete Checklist of Mammal Species and Subspecies in China: A Taxonomic and Geographic Reference. Beijing: Chinese Forestry Publishing House.

Wangchuk, T., P. Thinley, K. Tshering, C. Tshering, and D. Yonten. 2004. A Field Guide to the Mammals of Bhutan. Thimphu, Bhutan: Department of Forestry, Ministry of Agriculture, Royal Government of Bhutan.

Waterhouse, G. R. 1838a. [No title.] The Athenaeum, 580:880.

- 1838b. Report on a Meeting on September 26th 1837. Proceedings of the Zoological Society of London, 1837:87-90.

- 1839a. Observations on Certain Modifications Observed in the Dentition of the Flying Opossums (the Genus Petaurus of Authors). Proceedings of the Zoological Society of London, 1838:149-156. 
1839b. Some Specimens of Flying Lemurs (Galeopithecus). Proceedings of the Zoological Society of London, 1838:119-120.

- 1839c. Observations on the Rodentia, with a View to Point out the Groups, as Indicated by the Structure of the Crania, in This Order of Mammals. The Magazine of Natural History, 1st ser., 3:90-96, 184-188, 274-279, 593-600. - 1841. The Naturalist's Library. Mammalia. Volume 11: Marsupialia or Pouched Animals. Edinburgh: Lizards.

-1843a. Mr Fraser at Fernando Po. Proceedings of the Zoological Society of London, 1842:124-127.

- 1843b. Mr Fraser at Fernando Po. Annals and Magazine of Natural History, 1st ser., 12:52-55.

-1846. A Natural History of the Mammalia. Volume 1: Containing the Order Marsupiata, or Pouched Animals. London: Hippolyte Bailliere.

Weber, M. C. W. 1904. Die Säugetiere: Einführung in die Anatomie und Systematik der recenten und fossilen Mammalia. Volume 2: Systematischer Teil. Jena: Gustav Fischer.

- 1928. Die Sängetiere: Einführung in die Anatomie und Systematik der recenten und fossilen Mammalia. 2nd ed. Volume 2: Systematischer Teil. Jena: Gustav Fischer.

Wells-Gosling, N., and L. R. Heaney. 1984. Glaucomys sabrinus. Mammalian Species, 229:1-8. http://dx.doi.org/10 .2307/3503926.

Werner, J. 1994. Beiträge zur Biostratigraphie der Unteren Süßwasser-Molasse Süddeutschlands-Rodentia und Lagomorpha (Mammalia) aus den Fundstellen der Ulmer Gegend. Stuttgarter Beiträge zur Naturkunde, Serie B, Geologie und Paläontologie, 200:1-263.

White, J. 1790. Journal of a Voyage to New South Wales; with Sixty-Five Plates of Non Descript Animals, Birds, Lizards, Serpents, Curious Cones of Trees and Other Natural Productions. London: J. Debrett.

Wible, J. R., and J. R. Martin. 1993. "Ontogeny of the Tympanic Floor and Roof in Archontans." In Primates and Their Relatives in Phylogenetic Perspective, ed. R. D. E. MacPhee, pp. 111-148. New York: Plenum Press.

Wiegmann, A. F. A. 1839. Amphibia, Aves, Mammalia Bearbeitet com Herausgeber. Archiv für Naturgeschichte, 5(2):386-428.

Wilder, H. H. 1926. The Pedigree of the Human Race. New York: H. Holt and Co.

Wilson, D. E. 1993. “Order Dermoptera.” In Mammal Species of the World: A Taxonomic and Geographic Reference, ed. D. E. Wilson and D. M. Reeder, p. 136. Washington, D.C.: Smithsonian Institution Press.

Wilson, D. E., and D. M. Reeder, eds. 2005. Mammal Species of the World: A Taxonomic and Geographic Reference. 3rd ed. Washington, D.C.: Smithsonian Institution Press.

Wilson, D. E., and S. Ruff. 1999. North American Mammals. Washington, D.C.: Smithsonian Institution Press.

Winge, H. 1887. Jordfundne og nulevende Gnavere (Rodentia) fra Lagoa Santa, Minas Geraes, Brasilien. Med Udsigt over Gnavernes indbyrdes Slaegtskab. Volume 1, Part 3. Copenhagen: Museo Lundii.

- 1893. Jordfunde og nulevende Pungdyr (Marsupialia) fra Lagoa Santa, Minas Geraes, Brasilien: Med Udsight over
Pungdyrenes Slaegtskab. Samling af Afhandlinger E Museo Lundii, 2(2):1-149.

-1924. Pattedyr-Slaegter. Volume 2: Rodentia, Carnivora, Primates. Copenhagen: H. Hagerups Forlag.

Winkler, A. J. 1992. Systematics and Biogeography of Middle Miocene Rodents from the Muruyur Beds, Baringo District, Kenya. Journal of Vertebrate Paleontology, 12:236-249. http://dx.doi.org/10.1080/02724634.1992.10011453.

Wood, A. E. 1957. What, If Anything, Is a Rabbit? Evolution, 11:417-425. http://dx.doi.org/10.2307/2406062.

Woodburne, M. O. 1984. "Families of Marsupials: Relationships, Evolution and Biogeography." In Mammals: Notes for a Short Course, ed. T. W. Broadhead, pp. 48-71. Studies in Geology, No. 8. Knoxville: University of Tennessee Press.

Wroe, S. 1999. The Geologically Oldest Dasyurid, from the Miocene of Riversleigh, North-west Queensland. Palaeontology, 42:501-527. http://dx.doi.org/10.1111/1475-4983.00082.

Wroughton, R. C. 1911. Oriental Flying Squirrels of the "Pteromys" Group. Journal of the Bombay Natural History Society, 20:1012-1023.

Wyss, A. R., and J. Meng. 1996. Application of Phylogenetic Taxonomy to Poorly Resolved Crown Clades: A Stem-Modified Node-Based Definition of Rodentia. Systematic Biology, 45:559-568. http://dx.doi.org/10.1093/sysbio/45.4.559.

Yin, U. T. 1967. Wild Animals of Burma. Rangoon: Rangoon Gazette.

Yong, H.-S., and S. S. Dhaliwal. 1976. Variations in the Karyotype of the Red Giant Flying Squirrel Petaurista petaurista (Rodentia, Sciuridae). Malaysian Journal of Science, 4(A):9-12.

Young, C.-C. 1934. On the Insectivora, Chiroptera, Rodentia and Primates Other Than Sinanthropus from Locality 1 at Choukoutien. Paleontologica Sinica, Series C, 8:1-139.

- 1947. Notes on a Pleistocene Microfauna from Loping, Kiangsi. Bulletin of the Geological Society of China, 27:163-170.

Young, C.-C., and P. T. Liu. 1950. On the Mammalian Fauna at Koloshan near Chungking, Szechuan. Paleontologica Sinica, Bulletin of the Geological Society of China, 30:43-90. http:// dx.doi.org/10.1111/j.1755-6724.1950.mp30001006.x.

Yu, F., F. Fu, J. Pang, C. W. Kilpatric, P. M. McGuire, Y. Wang, S. Lu, and C. A. Woods. 2006. Phylogeography and Biogeography of the Petaurista philippensis Complex (Rodentia: Sciuridae), Inter- and Intraspecific Relationships Inferred from Molecular and Morphometric Analysis. Molecular Phylogenetics and Evolution, 38:755-766. http://dx.doi.org/ 10.1016/j.ympev.2005.12.002.

Yu, F., F. Yu, P. M. McGuire, C. W. Kilpatrick, J. Pang, Y. Wang, S. Lu, and C. A. Woods. 2004. Molecular Phylogeny and Biogeography of Woolly Flying Squirrel (Rodentia: Sciuridae), Inferred from Mitochondrial Cytochrome b Gene Sequences. Molecular Phylogenetics and Evolution, 33:735744. http://dx.doi.org/10.1016/j.ympev.2004.05.008.

Zahler, P., and C. A. Woods. 1997. "The Status of the Woolly Flying Squirrel (Eupetaurus cinereus) in Northern Pakistan." In Biodiversity of Pakistan, ed. S. A. Mufti, C. A. Woods, and S. A. Hasan, pp. 495-514. Islamabad: Pakistan Museum of Natural History. 
Zhang, Y., S. Jin, G. Quan, S. Li, Z. Ye, F. Wang, and M. Zhang. 1997. Distribution of Mammalian Species in China. Beijing: China Forestry Publishing House.

Zhang, Y. X., Y.-X. Li, W. Wang, and H.-J. Gong. 2010. Middle Pleistocene Mammalian Fauna of Shanyangzhai Cave in Qinhuangdao Area, China and Its Zoogeographical Significance. Chinese Science Bulletin, 55:72-76. http://dx.doi .org/10.1007/s11434-009-0360-7.
Zheng, S. 1993. Quaternary Rodents of Sichuan-Guizhou Area, China. Beijing: Science Press.

Ziegler, A. C. 1981. Petaurus abidi, a New Species of Glider (Marsupialia: Petauridae) from Papua New Guinea. Australian Mammalogy, 4:81-88. 



\section{Index of Common and Scientific Names}

Page numbers in bold are those on which currently recognised taxa are described.

abbotti, Galeopterus, 24

abidi, Petaurus, 11

accola, Plagiomene, 28

Acrobata, 2, 19,

Acrobates, 2, 6, 10, 15, 18, 19-20

pulchellus, 20

pygmaeus, 2, 19-20

Acrobatidae, 1, 10, 15, 18, 19

Acrobatini, 10, 19

Adjidaumidae, 80

Adjidaumo, 80,

aërobates, Sciurus, 43

Agrabates, 19

Agrobates, 19

Aeretes, 5, 33, grandidens, 33

melanopterus, 33

melanopterus szechuanensis, 33

premelanopterus, 33

Aeromys, 5, 33-34

tephromelas, 33-34

tephromelas phaeomelas, 34

thomasi, 34

Aistheseozoa, 7

Albanensia, 33, 34-35, 50

albanensis, 34, 50

albanensis quiricensis, 34

grimmi, 34

sansaniensis, 35

albanensis, Albanensia, 34, 50

albiventer, Petaurista, 53-54, 57, 59, 64

Pteromys, 53

alboniger, Hylopetes, 45, 46

Sciuropterus, 45

alborufus, Petaurista, 53, 54-55, 57, 62

Pteromys, 54 
Aliveria, 33, 35

brinkerinki, 35

luteyni, 35

alpinus, Glaucomys sabrinus, 39-42

Pteromys, 39

aluco, Sciuropterus, 70

americana, Pteromys, 43

amoenus, Sciuropterus, 48

amygdali, Sciuropterus momonga, 69

anadyrensis, Pteromys volans, 70

anchises, Pteromys phayrei, 46

annamensis, Petaurista, 53, 62

Petaurista philippensis, 57, 59, 61, 62-64

Anomalurella, 74

Anomaluri, 73

Anomaluridae, 1, 72-73, 77, 78

Anomalurina, 72, 73

Anomalurinae, 73, 76

Anomalurini, 73

Anomalurodon, 74

auzembergeri, 74, 75

Anomaluroidea, 2, 5, 72, 77

Anomaluromorpha, 72

Anomalurops, 5, 73-74

beecrofti, 5, 73-74

beecrofti schoutedeni, 74

anomaluropsis, Pondaungimys, 78

Anomalurus, 5, 72-73, 74-76

batesi, 76

beecrofti, 5, 73-74

beecrofti argenteus, 73

beecrofti hervoi, 73

beldeni, 74

chapini, 73

chysophaenus, 74

cinereus, 74

citrinus, 73

derbianus, 5, 74-75

erythronotus, 74

fraseri, 74, 75

fraseri griselda, 75

fraseri laticeps, 75

fraseri nigrensis, 75

fulgens, 73

imperator, 75

jacksoni, 75

jacksoni fortior, 75

jacksoni jordani, 75

jacksoni perustus, 75

laniger, 73

neavei, 75

orientalis, 74

parvus, 75

pelii, 5, 75-76,

pelii auzembergeri, 75

pelii peralbus, 76

pusillus, 5, 74, 76

antiquus, Volaticotherium, 5, 81 aoris, Galeopithecus, 25

aphantus, Dracontolestes, 30

Arctomyida, 31

Arctomyidae, 30

Arctomys, 31

Arctomysideae, 31

argenteus, Anomalurus beecrofti, 73

ariel, Petaurus breviceps, 13

armillatus, Petauroides volans, 18

Aroaethrus, 74

arrow-tailed flying squirrel, 47

arsenjevi, Pteromys volans, 70

arul, Petaurus (Belideus), 13

Ascobates, 19

asiatica, Meinia, 50

athene, Pteromys volans, 70

Sciuropterus russicus, 70

auctor, Petinomys, 65

aurantiacus, Hylopetes sagitta, 47

Pteromys, 47

Australidelphia, 8

australis, Petaurus, 2, 10, 11-12, 14-17

auzembergeri, Anomalurodon, 74, 75

Anomalurus pelii, 5, 75

ayamaruensis, Petauroides, 16

baberi, Eoglaucomys fimbriatus, 37

Sciuropterus, 37

badiatus, Petaurista lylei, 62

bangsi, Glaucomys sabrinus, 39

Sciuropterus alpinus, 39-42

banksi, Petaurista elegans, 56

Petaurista punctatus, 56

barroni, Petaurista annamensis, 53

Bartel's flying squirrel, 45

bartelsi, Hylopetes, 45, 65

Petaurista, 33

Petinomys, 45

Basilan flying squirrel, 65

batesi, Anomalurus, 76

batuana, Petaurista, 59

Petaurista petaurista, 59

beecrofti, Anomalurops, 5, 73-74

Beecroft's scaly-tailed flying squirrel, 5, 73

Beldeni, Anomalurus, 74

Belidea, 11,

ariel, 13

Belideus, 2, 10-14, 18

gracilis, 14

Belomys, 4, 35-36, 71

parapearsoni, 35

pearsonii, 35

pearsonii blandus, 35

pearsonii kaleensis, 36

pearsonii trichotis, 36

thamkaewi, 36

trichotis, 36

belone, Sciuropterus (Hylopetes), 48 betulinus, Pteromys volans, 70

Bhutan giant flying squirrel, 58

biacensis, Petaurus, 12-13

Petaurus (Petaurella) papuanus, 11-14

Biak glider, 12

birrelli, Petaurista, 53

bishopi, Paranomalurus, 76

Biswamoyopterus, 5, 36

biswasi, 36

biswasi, Biswamoyopterus, 36

black flying squirrel, 33

Blackia, 32, 36

miocaenica, 36-37

parvula, 36

polonica, 37

ulmensis, 36

woelfersheimensis, 37

Blackiini, 32

blandus, Belomys pearsonii, 35

borneanus, Galeopterus varigatus, 23, 24

Pteromyscus, 71

Pteromyscus pulverulentus, 71

borneoensis, Sciuropterus genibarbis, 66

brachyodus, Petaurista, 55

Pteromys, 55

bressana, Pliopetaurista, 67

breviceps, Petaurus, 2, 11, 12, 13-14

brinkerinki, Aliveria, 35

büchneri, Pteromys, 64

buechneri, Pteromys volans, 71

Sciuropterus, 71

bullatus, Glaucomys, 39

californicus, Glaucomys sabrinus, 39

Sciuropterus alpinus, 39

campester, Thylacaelurus, 21

campestre, Sciurion, 32

canadensis, Pteromys, 39

candidula, Petaurista alborufus, 54

candidulus, Petaurista, 54

canescens, Glaucomys sabrinus, 39

caniceps, Petaurista, 55-56

Sciuropterus, 55

cansdalei, Idiurus kivuensis, 77

caroli, Hylopetes harrisoni, 48

Carpophaga, 10

castaneus, Petaurista alborufus, 54

Cercoptenus, 19

chapini, Anomalurus, 73

chayuensis, Petaurista albiventer, 53

chianfengensis, Hylopetes alboniger, 45

chimaera, Dermotherium, 26

Chinese giant flying squirrel, 63

chombolis, Galeopterus, 25

chontali, Glaucomys volans, 43

chrysotrix, Sciuropterus, 58

chysophaenus, Anomalurus, 74 
cicur, Petaurista nitida, 59

Petaurista petaurista, 59

cinderella, Petaurista, 62

cineraceus, Petaurista philippensis, 62-63

Pteromys petaurista, 62

cinereus, Anomalurus, 4, 74

Eupetaurus, 37

Petaurides, 16, 18

citrinus, Anomalurus, 73

clarkei, Petaurista, 55

Petaurista caniceps, 55-56

coloratus, Glaucomys sabrinus, 39

Colugidae, 22

Colugo, 2, 22, 23

columbiensis, Glaucomys sabrinus, 40

complex-toothed flying squirrel, 4, 72

copei, Olbodotes, 29, 30

crassiusculus, Mixodectes, 30

crinitus, Petinomys, 65-67

Sciuropterus, 65

crusafonti, Cryptopterus, 50

Miopetaurista, 50

Cryptopterus, 50,

crusafonti, 50

gaillardi, 50

neogrivensis, 51

thaleri, 51

tobieni, 51

webbi, 51

cucullatus, Pteromys, 43

cunninghami, Petaurus, 12

cuspidata, Eudaemonema, 27

Cynocephalidae, 21-22, 26

Cynocephalus, 2, 21, 22-24, 26

tellonis, 26

volans, 23,24

davisoni, Iomys horsfieldi, 49

Sciuropterus, 49

debruijni, Hylopetes, 51

Neopetes, 51

dehmi, Miopetaurista, 50

dehneli, Pliopetaurista, 67-68

Pliosciuropterus, 67

depereti, Sciuropterus, 68

derbianus, Anomalurus, 5, 74-75

Pteromys, 5, 74

Dermoptera, 1, 3, 4, 6, 20-21, 26-29

Dermopteriformes, 21

Dermopterus, 2, 23

Dermotherium, 4, 26

chimaera, 26

major, 26

Didelphina, 8

Didelphis, 2, 15

macroura, 17

petaurus, 12

pygmaea, 19 sciurea, 11,15

volans, 12, 15-17

voluccella, 17

didelphoides, Petaurus, 18

diescalidus, Miopetaurista, 50

Diprotodonta, 9

Diprotodontia, 6, 9, 16, 52, 53

Diprotodontiformes, 9

Downsimys, 72

margolisi, 72

Dracontolestes, 30

aphantus, 30

Dromicia frontalis, 20

Duplicicommissurala, 9

dwarf scaly-tailed flying squirrel, 5, 76

edithae, Trogopterus, 72

Ekgmowechashala, 28, 29

philotau, 29

Ekgmowechashalinae, 28-29

Ekgmowechashalini, 29

elassodontus, Hylopetes nigripes, 46

Sciuropterus nigripes, 46

electilis, Hylopetes phayrei, 46, 65

Pteromys (Petinomys), 46

elegans, Elpidophorus, 27

Petaurista, 55, 56

Pteromys, 56

Ellesmene, 28

eureka, 28

Elpidophorus, 27

elegans, 27

minor, 27

patratus, 27

emiliae, Petaurillus, 52

Eoglaucomys, 4, 5, 37, 44

fimbriatus, 37

fimbriatus baberi, 37

Eomyidae, 5, 80

Eomyini, 80

Eomyoidea, 80

Eomys, 80

pomel, 80

quercyi, 5,80

erythronotus, Anomalurus, 74

Eudaemonema, 27

cuspidata, 27

Eudermoptera, 21

Eupetauridae, 32, 37

Eupetaurus, 4, 32, 37, 52

cinereus, 4, 37

eureka, Ellesmene, 28

Eutheria, 4, 8, 20

everetti, Sciuropterus, 44, 48

feathertail glider, 1, 2, 19

Ferae, 8

Ferungulata, 20

filchnerinae, Pteromys, 64 fimbriata, Sciuroptera, 37

fimbriatus, Eoglaucomys, 37

flavidus, Petaurus (Petaurella) papuensis, 14

flaviventer, Petaurista, 12

flaviventris, Glaucomys sabrinus, 40

Forsythia, 33, 38

gaudryi, 38

fortiori, Anomalurus jacksoni, 75

fraseri, Anomalurus, 74, 75

frontalis, Dromicia, 20

fulgens, Anomalurus, 73

fuliginosus, Glaucomys sabrinus, 40

Sciuropterus alpinus, 40

fulvinus, Petaurista, 53

fuscocapillus, Petinomys, 65-66

Sciuropterus, 65

fuscus, Glaucomys sabrinus, 40

gaillardi, Cryptopterus, 50

Miopetaurista, 50

Galeolemur, 23

Galeopitheci, 21

Galeopithecida, 21

Galeopithecidae, 22

Galeopithecina, 22

Galeopithecoidea, 21, 22

Galeopithecus, 2, 22, 23

aoris, 25

gracilis, 24

bantu, 25

macrourus, 24

marmoratus, 26

natunae, 24

philippinensis, 23

pumilus, 25

rufus, 23

saturatus, 26

temminckii, 23, 26

ternatensis, 24

tuancus, 26

undatus, 24

variegatus, 23, 24

variegatus perhentianus, 25

variegatus terutaus, 25

Galeopteridae, 22

Galeopterus, 2, 22, 23

abbotti, 25

borneanus, 24

chombolis, 25

lautensis, 24

lechei, 24

taylori, 25

variegatus, 23

variegatus borneanus,

variegatus peninsulae, 25

variegatus temminckii, 26

varius, 24

Galeopus, 2, 23 
gaudryi, Forsythia, 38

Sciuropterus, 38

genibarbis, Petinomys, 47, 66

Pteromys, 66

Geomorpha, 80

gibberosus, Sciurus, 50

Glaucomys, 4, 38, 39

bullatus, 39

sabrinus, 38,42

sabrinus alpinus, 39

sabrinus bangsi, 39

sabrinus californicus, 39

sabrinus canescens, 39

sabrinus coloratus, 39

sabrinus columbiensis, 40

sabrinus flaviventris, 40

sabrinus fuliginosus, 40

sabrinus fuscus, 40

sabrinus goodwini, 40

sabrinus gouldi, 40

sabrinus griseifrons, 40

sabrinus klamathensis, 40

sabrinus lascivus, 41

sabrinus latipes, 41

sabrinus lucifugus, 41

sabrinus macrotis, 41

sabrinus makkovikensis, 41

sabrinus murinauralis, 41

sabrinus oregonensis, 41-42

sabrinus reductus, 42

sabrinus stephensi, 42

sabrinus yukonensis, 42

sabrinus zaphaeus, 42

volans, 4, 42

volans chontali, 43

volans goldmani, 43

volans guerreroensis, 43

volans herreranus, 43

volans madrensis, 44

volans oaxacensis, 44

volans querceti, 44

volans saturatus, 44

volans texensis, 44

volans underwoodi, 44

Glires, 30

Gliridae, 78

Glirimorpha, 78

Glirinae, 79

Glirini, 78, 79

Gliroidea, 79

Glirulus, 79

japonicus, 80

lissiensis, 5, 80

Glis, 78, 79

goeriachensis, Miopetaurista, 50

goldmani, Sciuropterus volans, 43

goodwini, Glaucomys sabrinus, 40

göriachensis, Sciurus, 50

gorkhali, Petaurista caniceps, 55

Sciuropterus, 55 gouldi, Glaucomys sabrinus, 40

gracilis, Belideus, 14

Galeopithecus, 24

Petaurus, 14

grandidens, Aeretes, 33

grandis, Petaurista petaurista, 59

Pteromys, 59

gray-headed giant flying squirrel, 55

greater glider, 1, 2, 17, 52

grey-cheeked flying squirrel, 46

grimmi, Albanensia, 34

griseifrons, Glaucomys sabrinus, 40

griselda, Anomalurus fraseri, 75

griseiventer, Pteromys, 62

gubari, Pteromys volans, 70

guerreroensis, Glaucomys volans, 43

hageni, Petinomys, 66

Sciuropterus, 66

Hagen's flying squirrel, 66

Hainan giant flying squirrel, 57

hainana, Petaurista, 57

hairy-footed flying squirrel, 35

hantu, Galeopithecus, 25

harrisoni, Sciuropterus, 48

haymani, Idiurus zenkeri, 77

belleri, Petauria, 53

Petaurista, 57

Hemibelideinae, 15

Hemibelideus, 15

hepuna ru, Petaurus, 12

herreranus, Glaucomys volans, 43

hervoi, Anomalurus beecrofti, 73

himalaicus, Trogopterus, 72

hintoni, Petaurista leucogenys, 58

hodgsoni, Petaurista magnificus, 58

Hodgson's giant flying squirrel, 58

hoeckarum, Hylopetes, 51

Neopetes, 51

horsfieldi, Iomys, 49

Iomys horsfieldi, 49

Pteromys, 49

Pteromys (Sciuropterus), 49

hosei, Petaurillus, 52

hosei, Sciuropterus, 52

Hose's pygmy flying squirrel, 52

hudsonius, Sciurus, 39

hungaricus, Pliopetes, 68

Hylopetes, 4, 33, 34, 37, 44-49, 51, 65,68

alboniger, 45

alboniger chianfengensis, 45

alboniger orinus, 45

bartelsi, 45

debruijni, 51

harrisoni caroli, 48

boeckarum, 51

macedoniensis, 51

nigripes, 46

nigripes elassodontus, 46 phayrei, 46

phayrei electilis, 46

platyurus, 46

sagitta, 47

sagitta aurantiacus, 47

sagitta sipora, 47

sipora, 47

spadiceus, 47

spadiceus everetti, 48

spadiceus sumatrae, 48

winstoni, 49

Idiurus, 5, 76,

kivuensis cansdalei, 77

langi, 77

macrotis, 76

panga, 77

zenkeri, 76, 77

zenkeri haymani, 77

zenkeri kivuensis, 77

imperator, Anomalurus, 75

incanus, Pteromys volans, 70

Petaurus volans, 18

Indian giant flying squirrel, 61

Indochinese flying squirrel, 46

Indrodon, 29

malaris, 29

inornatus, Pteromys, 53

interceptio, Petaurista petaurista, 59

interventus, Sciuropterus momonga, 69

inusitata, Worlandia, 27

Iomys, 49,

horsfieldi, 49-50

horsfieldi davisoni, 49

horsfieldi horsfieldi, 49-50

borsfieldi penangensis, 49

horsfieldi thomsoni, 49

horsfieldi sipora, 49

lepidus, 49

sipora, 49

winstoni, 49

jacksoni, Anomalurus, 75

jamesi, Sciuropterus, 64, 65

Japanese flying squirrel, 69

Japanese giant flying squirrel, 16, 57

japonicus, Glirulus, 80

Myoxus, 79, 80

Javanese flying squirrel, 49

javanicus, Myoxus, 80

jordani, Anomalurus jacksoni, 75

jourdani, Sciuropterus, 34

kaleensis, Belomys pearsonii, 36

kaleënsis, Sciuropterus, 36

Kashmir flying squirrel, 37

khinganensis, Pteromys russicus, 70

kinlochii, Petaurillus, 52

Sciuropterus (Petaurillus), 52

kivuensis, Idiurus zenkeri, 77 
klamathensis, Glaucomys sabrinus, 40

Sciuropterus alpinus, 40

kohlsi, Petaurus, 12

kollmanni, Pliopetaurista, 68

langi, Idiurus, 77

laniger, Anomalurus, 73

lanka, Petaurista, 62

laotum, Sciuropterus phayrei, 46

lappi, Miopetaurista, 50

Sciuropterus, 50

lascivus, Glaucomys sabrinus, 41

Sciuropterus alpinus, 41

laticeps, Anomalurus fraseri, 75

latipes, Glaucomys sabrinus, 41

lautensis, Galeopterus, 24

lavocati, Nementchamys, 78

layardii, Sciuropterus, 66

leachii, Pteromys, 45

lechei, Galeopterus, 24

Leithiidae, 79

Lemur, 2, 22, 23

volans, 2, 22, 23

lena, Petaurista, 54, 57

leonardi, Pteromys (Hylopetes), 45

lepidus, Iomys, 49

Pteromys, 46-48

lesser pygmy flying squirrel, 52

leucocephalus, Petaurista alborufus, 54

Pteromys alborusus [sic], 54

lencogaster, Petaurus, 15

leucogenys, Petaurista, 57

Pteromys, 57

lissiensis, Glirulus, 5, 80

long-eared scaly-tailed flying squirrel, 5,76

longicaudatus, Petaurus breviceps, 13

lophulus, Oligopetes, 51

lopingensis, Pteromys, 69

Lord Derby's scaly-tailed flying squirrel, 74

lucifugus, Glaucomys sabrinus, 41

lugens, Petinomys, 66

Sciuropterus, 65, 66

lui, Shuanggouia, 71

lumboltzi, Petaurista petaurista, 60

luteyni, Aliveria, 35

lylei, Petaurista, 62, 63

Petaurista philippensis, 63

macedoniensis, Hylopetes, 51

Neopetes, 51

Macropoda, 9

macrotis, Glaucomys sabrinus, 41

Idiurus, 5, 76-77

Sciuropterus sabrinus, 41

macroura, Didelphis, 17

macrourus, Galeopithecus, 24

Galeolemur, 23

madrensis, Glaucomys volans, 44 maerens, Sciuropterus, 66

magnificus, Petaurista, 58

Sciuropterus, 58

mahogany glider, 14

major, Dermotherium, 26

makkovikensis, Glaucomys sabrinus, 41

Sciuropterus sabrinus, 41

malaccanus, Sciuropterus genibarbis, 66

malaris, Indrodon, 29

Mixodectes, 29

Malayan colugo, 2, 23

Mammalea, 7

Mammalia, 7

Mammaliaformes, 7

marchio, Petaurista nitida, 60

Petaurista petaurista, 60

margolisi, Downsimys, 72

marica, Petaurista, 56

Petaurista elegans, 56

marmoratus, Galeopithecus, 26

Marmota, 31

Marmotidae, 31

Marmotinae, 31

marshalli, Petauroides, 16

Pseudocheirus, 16

Marsupialia, 6, 8, 20

Marsupiata, 8

Marsupionta, 8

Mastodia, 7

mathewsi, Petauristodon, 65

Sciuropterus, 64

maximus, Petaurus, 18

meini, Pliopetaurista, 68

Meinia, 50

asiatica, 50

melanopis, Pteromys, 61

melanopterus, Aeretes, 33

Pteromys, 33

melanotus, Petaurista petaurista, 60

Pteromys, 60

Mentawai flying squirrel, 49

mergulus, Petaurista philippensis, 63

Metadelphia, 8

Metatheria, 8

miloni, Petaurista lylei, 62

mimicus, Petaurista, 60

minax Trogopterus, 72

Mindanao flying squirrel, 66

mindanensis, Petinomys, 66

Sciuropterus, 66

minimus, Petauristodon, 65

Sciuropterus, 65

minor, Elpidophorus, 27

Petaurista volans, 18

miocaenica, Blackia, 36, 37

Miopetaurista, 33, 50, 51, 65

crusafonti, 50

dehmi, 50

diescalidus, 50

gaillardi, 50 goeriachensis, 50

lappi, 50

neogrivensis, 51

thaleri, 51

webbi, 51

mirabile, Planetetherium, 27

Mixodectes, 29

crassiusculus, 30

malaris, 29

pungens, 29

Mixodectidae, 27, 29, 30

Mixodectoidea, 29

Mixodectomorpha, 29

moldaviensis, Pliopetaurista, 68

momonga, Pteromys, 69

Monodelphia, 20

montanensis, Tarkadectes, 28

mordax, Trogopterus, 72

morrisi, Pteromys (Olisthomys), 65, 67

multicuspis, Plagiomene, 28

murinauralis, Glaucomys sabrinus, 41

Mus, 4

volans, 4, 38, 42-43

Muscardinidae, 79

Myosidae, 79

Myoxida, 79

Myoxina, 79

Myoxinae, 79

Myoxini, 78

Myoxoidea, 79

Myoxus, 78, 79

Myoxus japonicus, 79-80

javanicus, 80

Namdapha flying squirrel, 36

natunae, Galeopithecus, 24, 25

neavei, Anomalurus, 75

nebrascensis, Pteromys volans, 43

Nementchamyidae, 5, 77

Nementchamys, 77, 78

lavocati, 78

neogrivensis, Cryptopterus, 51

Miopetaurista, 51

Neopetes, 51

debruijni, 51

boeckarum, 51

macedoniensis, 51

niger, Petaurus, 17

nigra, Petaurista petaurista, 64

Voluccella, 12, 17

nigrensis, Anomalurus fraseri, 75

nigrescens, Petaurista petaurista, 60

nigricaudatus, Petaurista petaurista, 60

nigricaudus, Petinomys crinitus, 67

nigripes, Hylopetes, 46

Sciuropterus, 46

nikkonis, Petaurista leucogenys, 58

nitidula, Petaurista, 60

Petaurista petaurista, 60

nitidus, Pteromys, 34 
nobilis, Petaurista, 58-59

Sciuropterus, 58

norfolcensis, Petaurus, 12, 14-15

Sciurus (Petaurus), 14

north Chinese flying squirrel, 33

northern flying squirrel, 38

northern glider, 11

notatus, Petaurus (Belideus), 13

novaehollandie, Sciurus, 12, 15

oaxacensis, Glaucomys volans, 44

obtusus, Oligopetes, 51

ochraspis, Petaurista alborufus, 55

ognevi, Pteromys volans, 70

Olbodotes, 29

copei, 29, 30

Oldobotidae, 29

Oligopetes, 51

lophulus, 51

obtusus, 51

radialis, 51, 52

Olisthomys, 65

olympicus, Sciuropterus alpinus, 42

opossum, Petaurus, 12

orál, Pteromys, 62

oreas, Petaurista leucogenys, 58

oregonensis, Glaucomys sabrinus,

$$
\text { 41-42 }
$$

Pteromys, 41

orientalis, Anomalurus, 74

orii, Pteromys volans, 71

Sciuropterus russicus, 71

orinus, Hylopetes alboniger, 45

Pteromys (Hylopetes) alboniger, 45

osiui, Petaurista leucogenys, 58

ouwensi, Petinomys hageni, 66

Oxyacodon tecumsae, 29

Palawan flying squirrel, 46

panga, Idiurus, 77

papuanus, Petaurus breviceps, 11-14

Paranomalurus, 5, 76

bishopi, 76

soniae, 76

walkeri, 76

parapearsoni, Belomys, 35

Parapetaurista, 52

tenurugosa, 52

particolored flying squirrel, 45

parvula, Blackia, 36

parvus, Anomalurus, 75

patratus, Elpidophorus, 27

pattersoni, Petauristodon, 65

pearsonii, Belomys, 35-36

Sciuropterus, 35

pelii, Anomalurus, 75

Pel's scaly-tailed flying squirrel, 75

penangensis, Iomys horsfieldi, 49

Petaurista petaurista, 61 peninsulae, Galeopterus variegatus, 23, 25

peralbus, Anomalurus pelii, 76

peronii, Petaurus, 18

perhentianus, Galeopithecus variegatus, 25

perustus, Anomalurus jacksoni, 75

Petaurella, 2, 11, 14

Petauria, 53

helleri, 53, 57

Petauridae, 1, 2, 10, 15

Petaurides, 16, 18

cinereus, 16, 18

Petaurillus, 4, 52

emiliae, 52

hosei, 52

kinlochii, 52

Petaurina, 10

Petaurinae, 10

Petaurini, 10

Petaurista, 2, 4-5, 11, 15, 16, 32-34, $52-59,62-64,68,69$

albiventer, 53

albiventer barroni, 53

albiventer chayuensis, 53

alborufus, 54

alborufus candidula, 54

alborufus castaneus, 54

alborufus leucocephalus, 54

alborufus ochraspis, 55

annamensis, 62

annamensis barroni, 53

bartelsi, 33

batuana, 59

(Belidea) breviceps, 11

birrelli, 53

brachyodus, 55

candidulus, 54

caniceps, 55

caniceps clarkei, 55

caniceps gorkhali, 55

caniceps sybilla, 55

cinderella, 62

cineraceus stockleyi, 63

clarkei, 55

elegans, 56

elegans banksi, 56

elegans marica, 56

elegans slamatensis, 56

elegans sumatrana, 56

flaviventer, 12

fulvinus, 53

hainana, 57

belleri, 57

lanka, 62

lena, 57

leucogenys, 57

leucogenys hintoni, 58

leucogenys nikkonis, 58 leucogenys oreas, 58

leucogenys osiui, 58

leucogenys tosae, 57

leucogenys thomasi, 57-58

lylei, 63

lylei badiatus, 62

lylei miloni, 62

lylei venningi, 63

magnificus, 58

magnificus hodgsoni, 58

marica, 56

mergulus, 63

mergulus primrosei, 63

mergulus reguli, 63

mimicus, 60

nitida, 34

nitida cicur, 59

nitida marchio, 60

nitida rajah, 61

nitidula, 60

nobilis, 58

nobilis singhei, 59

petaurista, 54, 59-61

petaurista batuana, 59

petaurista cicur, 59

petaurista grandis, 59

petaurista interceptio, 59

petaurista lumboltzi, 60

petaurista marchio, 60

petaurista melanotus, 60

petaurista nigra, 64

petaurista nigrescens, 60

petaurista nigricaudatus, 60

petaurista nitidula, 60

petaurista penangensis, 61

petaurista rajah, 61

petaurista rufipes, 61, 64

petaurista sodyi, 61

petaurista stellaris, 61

petaurista terutaus, 61

philippensis, 57, 61, 63, 64

philippensis annamensis, 62

philippensis cineraceus, 62

philippensis lylei, 63

philippensis mergulus, 63

punctatus banksi, 56

punctata sumatrana, 56

rubicundus, 64

rufipes, 61

sulcatus, 33

sybilla, 55-56, 64

taguan, 59

taylori, 54

terutaus, 61

thomasi, 34

volans minor, 18

watasei,

xanthotis, 63

yunanensis, 64 
petaurista, Petaurista, 54, 59-61

Phalanger, 17

Sciurus, 43, 52

Petauristidae, 5, 32, 34-36, 38, 50, 51, 67

Petauristinae, 32

Petauristini, 32, 33, 35

Petauristodon, 64-65

jamesi, 64

mathewsi, 65,

minimus, 65,

pattersoni, 65

uphami, 65

Petauroidea, 19

Petauroides, 1, 2, 6, 10, 15-17, 52, 53

ayamaruensis, 16

marshalli, 16

stirtoni, 17

volans, 2, 12, 15

volans armillatus, 18

volans minor, 18

volans volans, 17

Petaurula, 2, 11

Petaurus, 2, 10-11, 19, 53

abidi, 11

australis, 10, 11-12, 16, 17

australis reginae, 12

(Belideus) arul, 13

(Belideus) notatus, 13

biacensis, 12

breviceps, 11, 13

breviceps ariel, 13

breviceps longicaudatus, 13

breviceps papuanus, 11, 14

cunninghami, 12

didelphoides, 18

flaviventer, 12

gracilis, 14

hepuna ru, 12

kohlsi, 12

leucogaster, 15

maximus, 18

niger, 17

norfolcensis, 14, 15

opossum, 12

peronii, 18

(Petaurella) papuanus biacensis, 12

(Petaurella) papuensis flavidus, 14

(Petaurella) papuensis tafa, 14

sciureus, 11, 13

taguanoïdes, 16, 17

volans incanus, 18

petaurus, Didelphis, 12

Petaurusideae, 10, 15

Petinomys, 4, 47, 65-66

auctor, 65

bartelsi, 45

crinitus, 65

crinitus nigricaudus, 67

fuscocapillus, 65 genibarbis, 47, 66

hageni, 66

hageni ouwensi, 66

lugens, 66

mindanensis, 66

setosus, 67

vordermanni, 67

phaeomelas, Aeromys tephromelas, 34

Pteromys, 34

Phalanger, 15, 16

petaurista, 17

Phalangerida, 9

Phalangeriformes, 9

Phalangistae, 15

phayrei, Hylopetes, 46

Sciuropterus, 46

philippensis, Petaurista, 57, 59, 61-62

Pteromys, 61

Philippine colugo, 2, 23

philippinensis, Galeopithecus, 23

philotau, Ekgmowechashala, 29

phipsoni, Pteromys (Petinomys), 67

Pilifera, 7

Placentalia, 20

Placentata, 20

Plagiomene, 26, 27, 28

accola, 28

multicuspis, 28

Plagiomenidae, 21, 26-29

Plagiomeninae, 27

Plagiomenini, 28

Planetetherium, 27

mirabile, 27

platyurus, Hylopetes, 46-47

Sciuropterus, 46

Pleuronycterates, 21

Pleuropteridae, 22

Pleuropterus, 22

pliocenica, Pliopetaurista, 68

pliocenicus, Sciuropterus, 67, 68

Pliopetaurista, 67, 68

bressana, 67

debneli, 67

kollmanni, 68

meini, 68

moldaviensis, 68

pliocenica, 68

rani, 68

rugosa, 68

Pliopetes, 32, 68

hungaricus, 68

Pliosciuropterus, 67

dehneli, 67

schaubi, 68

Pollicata, 8

polonica, Blackia, 37

pomel, Eomys, 80

Pondaungimys, 5, 77, 78

anomaluropsis, 78 premelanopterus, Aeretes, 33

primrosei, Petaurista mergulus, 63

probus, Sciuropterus phayrei, 46

Proglires, 21

Pseudocheiridae, 1, 2, 10, 15-16, 52, 53

Pseudocheirus, 15, 17

marshalli, 16

stirtoni, 17

Pseudochirini, 15

Ptenopleura, 21, 22

Pteromidae, 32

Pteromyinae, 5, 32-36, 38, 50-52, 64, 67,71

Pteromyini, 5, 6, 32

Pteromys, 4, 5, 32-35, 37-39, 41, 43$49,53-62,64-67,68-72,74,75$

albiventer, 53

alborufus, 54

alborusus leucocephalus, 54

alpinus, 39

americana, 43

(Anomalurus) pelii, 75

aurantiacus, 47

brachyodus, 55

büchneri, 64

canadensis, 39

cucullatus, 43

derbianus, 5, 74

elegans, 56

filchnerinae, 64

genibarbis, 66

grandis, 59

griseiventer, 62

horsfieldi, 49

(Hylopetes) alboniger orinus, 45

(Hylopetes) leonardi, 45

inornatus, 53

leachii, 45

lepidus, 47

leucogenys, 53, 57

lopingensis, 69

melanopis, 61

melanopterus, 33

melanotus, 60

momonga, 69

nitidus, 34, 59

(Olisthomys) morrisi, 65, 67

orál, 62

oregonensis, 41

pectoralis, 54, 57

petaurista var. cineraceus, 62

(Petinomys) electilis, 46

(Petinomys) phipsoni, 67

phaeomelas, 34

phayrei anchises, 46

philippensis, 61

punctatus, 56

russicus, 38

russicus khinganensis, 70 
Pteromys (continued)

(Sciuropterus) horsfieldi, 49

(Sciuropterus) setosus, 67

sibiricus, 69

squamicaudatus, 74

tephromelas, 33

russicus, 38, 69

russicus khinganensis, 70

virginianus, 43

volans, 4, 69

volans anadyrensis, 70

volans arsenjevi, 70

volans athene, 70

volans betulinus, 70

volans buechneri, 71

volans gubari, 70

volans incanus, 70

volans nebrascensis, 43

volans ognevi, 70

volans orii, 71

volans turovi, 70

vulgaris, 69

xanthipes, 72

xanthotis, 71

yunanensis, 64

Pteromyscus, 71

borneanus, 71

pulverulentus, 71

Pterophorae, 21

Ptilotus, 2, 10

pulchellus, Acrobates, 19, 20

pulverulentus, Pteromyscus, 71

Sciuropterus, 71

pumilus, Galeopithecus, 25

punctatus, Pteromys, 56

pungens, Mixodectes, 29-30

pusillus, Anomalurus, 5, 74, 76

pygmaea, Didelphis, 19

pygmaeus, Acrobates, 2, 19-20

pygmy scaly-tailed flying squirrel, 77

querceti, Glaucomys volans, 44

Sciuropterus volans, 44

quercyi, Eomys, 5, 80

quiricensis, Albanensia albanensis, 34

radialis, Oligopetes, 51, 52

rajah, Petaurista nitida, 61

Petaurista petaurista, 61

raui, Pliopetaurista, 68

red and white giant flying squirrel, 54

red-cheeked flying squirrel, 47

red giant flying squirrel, 59

reductus, Glaucomys sabrinus, 42

reginae, Petaurus australis, 12

reguli, Petaurista mergulus, 63

Rodentes, 30

Rodentia, 30

Rodentiformes, 30

Rosores, 30 rubicundus, Petaurista, 64

rufipes, Petaurista petaurista, 61

rufus, Galeopithecus, 23

rugosa, Pliopetaurista, 68

russicus, Pteromys, 69

Sciuropterus, 70, 71

sabrinus, Glaucomys, 38

Sciurus, 38

sagitta, Hylopetes, 47-48

Sciuropterus, 38

Sciurus, 47

Salienta, 8

sansaniensis, Albanensia, 35

saturatus, Galeopithecus, 26

Glaucomys volans, 44

schaubi, Pliosciuropterus, 68

Schoinobates, 2, 10, 15-17, 53

schoutedeni, Anomalurops beecrofti, 74

sciurea, Didelphis, 11, 15

sciureus, Petaurus, 13

Sciuridae, 1, 5, 16, 30-32, 36, 38, 64, 69

Sciurii, 30, 31

Sciurina, 31

Sciurinae, 5, 31-32

Sciuriorum, 30

Sciuroidae, 31

Sciuroidea, 31

Sciuromorpha, 30

Sciuroptera fimbriata, 37

Sciuróptera turnbúllii, 45

Sciuropterus, 4-5, 34-50, 52, 55, 58, 64-71

albanensis, 34

alboniger, 45

alpinus bangsi, 39

alpinus californicus, 39

alpinus fuliginosus, 40

alpinus klamathensis, 40

alpinus lascivus, 41

alpinus olympicus, 42

alpinus zaphaeus, 42

aluco, 70

amoenus, 48

baberi, 37

buechneri, 71

caniceps, 55

chrysotrix, 58

crinitus, 65

davisoni, 49

depereti, 68

everetti, 44, 48

fimbriatus, 37

fuscocapillus, 65

gaudryi, 38

genibarbis borneoensis, 66

genibarbis malaccanus, 66

gorkhali, 55

grimmi, 34

hageni, 66 harrisoni, 48

hosei, 52

(Hylopetes) belone, 48

jamesi, 64

jourdani, 34

kaleënsis, 36

gorkhali,

jamesi, 64

lappi, 50

layardii, 66

lugens, 65, 66

maerens, 66

magnificus, 58

mathewsi, 64, 65

mindanensis, 66

minimus, 65

momonga amygdali, 69

momonga interventus, 69

nigripes, 46

nigripes elassodontus, 46

nobilis, 58

oregonensis stephensi, 42

pearsonii, 35

(Petaurillus) kinlochii, 52

phayrei, 46

phayrei laotum, 46

phayrei probus, 46

platyurus, 46

pliocenicus, 67, 68

pulverulentus, 71

russicus athene, 70

russicus orii, 71

sabrinus macrotis, 41

sabrinus makkovikensis, 41

sagitta, 38

senex, 55

silus, 43

spadiceus,

thomsoni, 49

uphami, 65

villosus, 35

volans goldmani, 43

volans querceti, 44

vordermanni, 67

wulungshanensis, 70

yukonensis, 42

Sciurospalacoïdes, 80

Sciurus, 2, 4, 30, 31, 38

aërobates, 43

gibberosus, 50

göriachensis, 50

budsonius, 39

novaehollandie, 12, 15

petaurista, 43, 52, 59

(Petaurus) norfolcensis, 14

sabrinus, 38

sagitta, 47

sansaniensis, 35

volans, 4, 68, 69

volucella, 38,43 
Sciurion, 32

campestre, 32

Selangor pygmy flying squirrel, 52

Seleviniidae, 79

senex, Sciuropterus, 55

setosus, Petinomys, 67

Pteromys (Sciuropterus), 67

Shuanggouia, 71

lui, 71

Siberian flying squirrel, 69

Siberut flying squirrel, 66

sibiricus, Pteromys, 69

silus, Sciuropterus, 43

singhei, Petaurista nobilis, 59

Sipora flying squirrel, 47

sipora, Hylopetes, 47-48

Hylopetes sagitta, 47

Iomys, 49

Iomys horsfieldi, 49

slamatensis, Petaurista elegans, 56

smoky flying squirrel, 71

sodyi, Petaurista petaurista, 61

soniae, Paranomalurus, 76

southern flying squirrel, 42

spadiceus, Hylopetes, 47-48

Sciuropterus, 47

Spermophilinae, 32

Spermophilus, 32

spotted giant flying squirrel, 56

squamicaudatus, Pteromys, 74

squirrel glider, 14

stellaris, Petaurista petaurista, 61

stephensi, Sciuropterus oregonensis, 42

stirtoni, Petauroides, 17

Pseudocheirus, 17

stockleyi, Petaurista cineraceus, 63

stylifera, Tarka, 28

sugar glider, 2, 13

sulcatus, Petaurista, 33

sumatrae, Hylopetes sagitta, 48

Hylopetes spadiceus, 48

Sumatran flying squirrel, 49

sumatrana, Petaurista elegans, 56

Petaurista punctata, 56

sybilla, Petaurista, 55

Petaurista caniceps, 55, 56, 64

Syndactyla, 9

Syndactyla Diprotodontia, 9

Syndactyli, 9

szechuanensis, Aeretes melanopterus, 33

tafa, Petaurus (Petaurella) papuensis, 14

taguan, Petaurista, 59

taguanoides, Petaurus, 16, 17

Taiwan giant flying squirrel, 57

Tarka, 28

stylifera, 28

Tarkadectes, 28

montanensis, 28
Tarkadectini, 28

Tarsipedidae, 18

Tarsipedoidea, 18

Tarsipes rostratus, 18

taylori, Galeopterus, 25

Petaurista, 54

tecumsae, Oxyacodon, 29

tellonis, Cynocephalus, 26

temminckii, Galeopithecus, 26

Galeopterus variegatus, 23, 26

Temminck's flying squirrel, 67

tephromelas, Aeromys, 33

ternatensis, Galeopithecus, 24

terutaus, Galeopithecus variegatus, 25

Petaurista, 61

Petaurista petaurista, 61

texensis, Glaucomys volans, 44

thaleri, Cryptopterus, 51

Miopetaurista, 51

thamkaewi, Belomys, 36

Theria, 8

thomasi, Aeromys, 34

Petaurista, 34

Petaurista leucogenys, 57-58

Thomas's flying squirrel, 34

thomsoni, Iomys horsfieldi, 49

Sciuropterus, 49

Thricozoa, 7

Thylacaelurinae, 21

Thylacaelurus, 21

campester, 21

montanus, 21

tobieni, Cryptopterus, 51

tosae, Petaurista leucogenys, 57

Travancore flying squirrel, 65

trichotis, Belomys, 35, 36

Trogopterus, 4, 35, 36, 69, 71

edithae, 72

himalaicus, 72

$\operatorname{minax}, 72$

mordax, 72

xanthipes, 72

tuancus, Galeopithecus, 26

turnbúllii, Sciuróptera, 45

turovi, Pteromys volans, 70

ulmensis, Blackia, 36

undatus, Galeopithecus, 24

underwoodi, Glaucomys volans, 44

Unguiculata, 20

uphami, Petauristodon, 65

Sciuropterus, 65

variegatus, Galeopithecus, 22, 23-25

varius, Galeopterus, 24

venningi, Petaurista lylei, 63

virginianus, Pteromys, 43

volans, Cynocephalus, 23, 24

Didelphis, 2, 12, 15-18
Galeopterus, 26

Glaucomys, 4, 42, 44

Lemur, 2, 22, 23

Mus, 4, 38, 42-43

Petauroides, 2, 12, 15, 17

Pteromys, 4, 43, 69-70

Sciuropterus, 4

Sciurus, 4, 68, 69

Volaticotheria, 5, 80

Volaticotheriidae, 80

Volaticotherium, 80

antiquus, 80

voluccella, Didelphis, 17, 43

Volucella, 2, 15, 16

nigra, 12

volucella, Sciurus, 38, 43

Sciuropterus, 4

vordermanni, Petinomys, 67

Sciuropterus, 67

Vordermann's flying squirrel, 67

walkeri, Paranomalurus, 76

watasei, Petaurista, 58

webbi, Cryptopterus, 51

Miopetaurista, 51

whiskered flying squirrel, 66

white-bellied giant flying squirrel, 53

winstoni, Hylopetes, 49

Iomys, 49

woelfersheimensis, Blackia, 37

woolly flying squirrel, 37

Worlandiini, 27

Worlandia, 27

inusitata, 27

wulungshanensis, Sciuropterus, 70

xanthipes, Pteromys, 71

Trogopterus, 4, 72

xanthotis, Petaurista, 57, 63

Pteromys, 63

Xenochirus, 2, 11

Xeri, 31

Xerinae, 31

Xerus, 31

yellow-bellied glider, 2, 11

yukonensis, Glaucomys sabrinus, 42

Sciuropterus, 42

yunanensis, Petaurista, 64

Pteromys, 64

yunnanensis, Pteromys, 64

Yunnan giant flying squirrel, 64

zaphaeus, Glaucomys sabrinus, 42

Sciuropterus alpinus, 42

Zenkerellinae, 76

zenkeri, Idiurus, 5, 76, 77 


\section{REQUIREMENTS FOR SMITHSONIAN SERIES PUBLICATION}

ALL MANUSCRIPTS ARE REVIEWED FOR ADHERENCE TO THE SISP MANUSCRIPT PREPARATION AND STYLE GUIDE FOR AUTHORS (available on the "Submissions" page at www.scholarlypress.si.edu). Manuscripts not in compliance will be returned to the author. Manuscripts intended for publication in the Contributions Series are evaluated by a content review board and undergo substantive peer review. Accepted manuscripts are submitted for funding approval and scheduling to the Publications Oversight Board.

MINIMUM MANUSCRIPT LENGTH is thirty manuscript pages. If a manuscript is longer than average, an appropriate length will be determined during peer review and evaluation by the Content Review Board. Authors may be asked to edit manuscripts that are determined to be too long.

TEXT must be prepared in a recent version of Microsoft Word; use a Times font in 12 point for regular text; be double spaced; and have 1" margins. Each chapter/section must be saved in a separate file.

REQUIRED ELEMENTS are title page, abstract page, table of contents, main text, and reference section. See the SISP Manuscript Preparation and Style Guide for Authors for the order of all elements.

HEADINGS should be styled so different levels of headings are distinct from each other and so the organization of the manuscript is clear. Insert one line space above and one line space below all headings.

FRONT MATTER should include title page, abstract page, and table of contents. All other sections are optional. Abstracts must not exceed 300 words. Table of contents should include A-, B-, and C-level headings.

TABLES (numbered, with captions, stubs, rules) should be submitted in separate MS Word files; should include footnotes, if appropriate; should have rules only at top, bottom, and beneath column heads. Print outs of each table should accompany the manuscript to ensure correct layout of data. Tabulations within running text should not be numbered or formatted like formal tables, and should be included in the text of the manuscript.

FIGURE CAPTIONS should be provided in a separate MS Word file.

FIGURES (e.g., photographs, line art, maps) should be numbered sequentially $(1,2,3$, etc.) in the order called out; be placed throughout text, not at end of manuscript; have all components of composites lettered with lowercase letters and described in the caption; include a scale bar or scale description, if appropriate; include any legends in or on the figure rather than in a caption.
ART must not be embedded in the main text.

Figures must be original and submitted as individual TIFF or EPS files. Resolution for art files must be at least $300 \mathrm{dpi}$ for grayscale and color images and at least $1200 \mathrm{dpi}$ for line art. Electronic images should measure no more than 100\% and no less than $75 \%$ of final size when published. JPG files will not be accepted. Color images significantly increase costs so should be included only if required. Funding for color art is subject to approval by SISP and the Publications Oversight Board.

TAXONOMIC KEYS in natural history papers should use the aligned-couplet form for zoology. If cross referencing is required between key and text, do not include page references within the key but number the keyed-out taxa, using the same numbers with their corresponding heads in the text.

SYNONOMY IN ZOOLOGY must use the short form (taxon, author, year:page), with full reference at the end of the paper under "References."

IN-TEXT REFERENCES should be used rather than bibliographic notes and should follow the author-date system in the following format: "(author last name, year)" or ". . . author (year)"; "(author, year:page used within the text)" or “.. . author (year:page)." A full citation should be included in a "References" section.

ENDNOTES are to be used in lieu of footnotes and should be keyed manually into a separate MS Word file, in a section titled "Notes". Notes should not contain bibliographic information. Manually type superscript numerals in text and use full-sized numerals at the beginning of each note in the "Notes" section. SISP will determine the best placement of the notes section, either at the end of each chapter or at the end of the main text.

REFERENCES should be in alphabetical order, and in chronological order for same-author entries. Each reference should be cited at least once in main text. Complete bibliographic information must be included in all citations (e.g., author/editor, title, subtitle, edition, volume, issue, pages, figures). For books, place of publication and publisher are required. For journals, use the parentheses system for volume(number):pagination [e.g., "10(2):5-9"]. Do not use "et al.”; all authors/ editors should be included in reference citations. In titles, capitalize first word, last word, first word after colon, and all other words except articles, conjunctions, and prepositions. Examples of the most common types of citations are provided in the SISP Manuscript Preparation and Author Style Guide.

For questions regarding the guidelines, please email SISP at schol.press@si.edu. 